\title{
A BATTERY ELECTRIC AIRCRAFT FEASIBILITY INVESTIGATION \\ INCLUDING A BATTERY-IN-WING CONCEPTUAL DESIGN
}

\author{
A Thesis \\ presented to \\ the Faculty of California Polytechnic State University, \\ San Luis Obispo \\ In Partial Fulfillment \\ of the Requirements for the Degree \\ Master of Science in Mechanical Engineering
}

by

Mark H. Shushnar

June 2014 
(C) 2014

Mark H. Shushnar

ALL RIGHTS RESERVED 
TITLE:

AUTHOR:

DATE SUBMITTED:

COMMITTEE CHAIR:

COMMITTEE MEMBER:

COMMITTEE MEMBER:
A Battery Electric Aircraft Feasibility Investigation Including a Battery-in-Wing Conceptual Design

Mark H. Shushnar

June 2014

Dr. Joseph Mello, PhD

Professor of Mechanical Engineering

Dr. Patrick Lemieux, $\mathrm{PhD}$

Associate Professor of Mechanical

Engineering

Dr. Kurt Colvin, PhD

Professor of Industrial and Manufacturing Engineering 


\begin{abstract}
A Battery Electric Aircraft Feasibility Investigation

Including a Battery-In-Wing Conceptual Design
\end{abstract}

Mark H. Shushnar

The feasibility of converting an existing internal combustion powered general aviation aircraft to battery electric propulsion was studied. The theoretical performance of various types of airframes with battery electric propulsion systems was compared to determine which type of airframe would be best suited for conversion. It was found that battery electric propulsion is best used in aircraft intended for slow speed, efficient flight and carrying limited payload which is a mission typically flown in motor gliders. A reference motor glider was selected and a conceptual power system packaging design study was performed. The study determined that a critical component of the power system packaging design was the technical feasibility of packaging the batteries inside of the wing structure. This was driven by center of gravity restrictions. Technical concerns related to a battery-in-wing design were investigated, included wing aeroelastic performance, wing stiffness and wing strength. The results showed that aeroelastic flutter was not a driving design criteria for the reference airframe used as the physical size of the battery did not allow for them to be packaged in wing locations that detrimentally affected flutter performance. The battery packaging layout was instead driven by access for battery maintenance, battery safety and the battery thermal management system. Overall weight change from packaging the batteries in the wing compared to the fuselage was found to be negligible. The resulting aircraft conceptual design indicated a powered flight range with reserves of over 200 miles and a powered flight endurance of greater than 3 hours with 2 persons onboard. 


\section{TABLE OF CONTENTS}

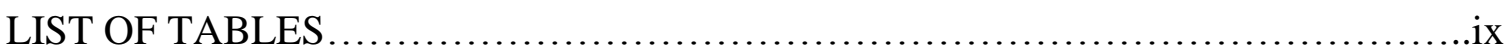

LIST OF FIGURES .....................................................................

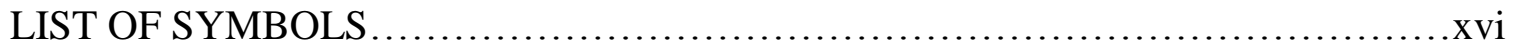

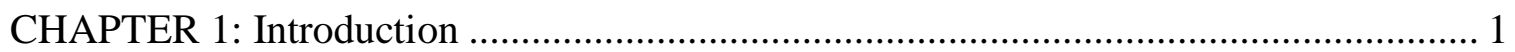

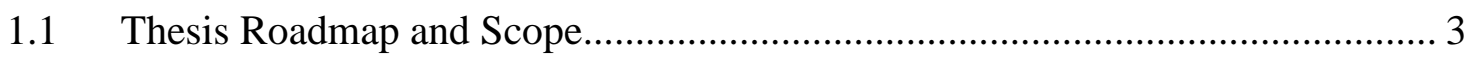

CHAPTER 2: Existing Electric Aircraft................................................................... 5

2.12011 NASA Green Flight Challenge …………….......................................... 5

2.2 Airbus Siemens E-Star 2 Hybrid Aircraft ......................................................... 10

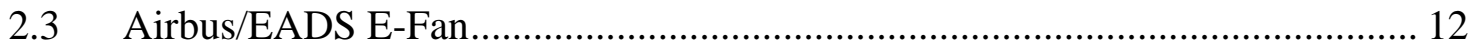

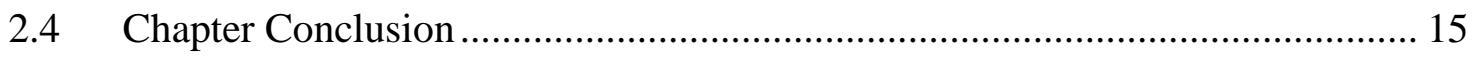

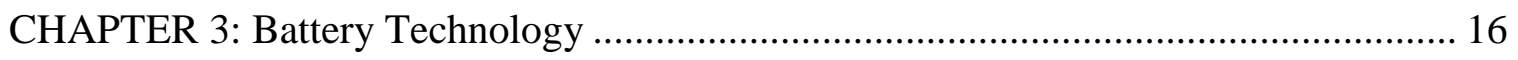

3.1 Battery Cells ……………………………….......................................... 16

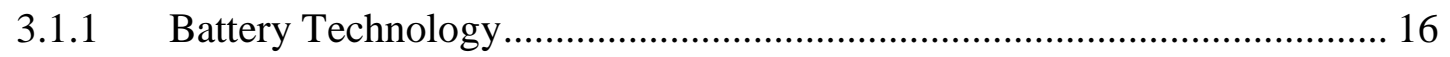

3.1.2 Battery Cell Safety Features .................................................................. 17

3.1.3 Battery Pack Assembly ........................................................................... 21

3.1.4 Battery Management System .................................................................. 22

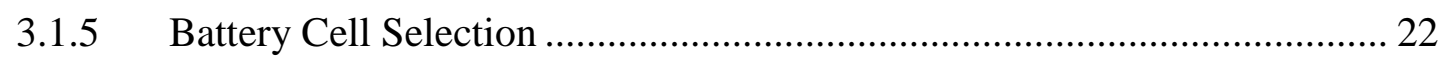

3.2 Existing Automotive Battery Pack Methods ..................................................... 24

3.2.1 Nissan Leaf Battery Pack ........................................................................... 24

3.2.2 Chevrolet Volt Battery Pack …………………........................................... 25

3.2.3 AC Propulsion and the BMW Mini E Battery Pack ……………............... 27

3.2.4 Tesla Motors Battery Pack ....................................................................... 29

3.2.5 Boeing 787 Battery Design and Safety ……………….............................. 31

3.3 Battery Energy Density for Design Study .................................................... 35

3.4 Battery Design Requirements and Best Practices ............................................ 36

CHAPTER 4: Electric Motor and Controller Technology ................................................ 38

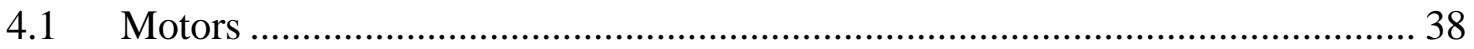

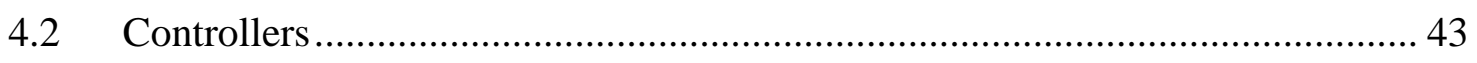

4.3 Motor and Controller Requirements .............................................................. 46 
4.4 Motor and Controller Metrics ................................................................ 46

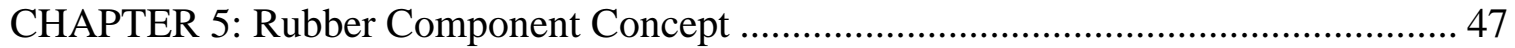

CHAPTER 6: Airframe Performance Analysis ........................................................... 49

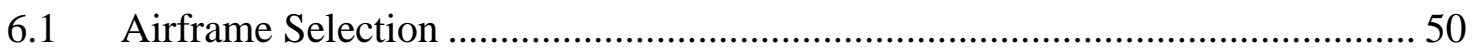

6.2 Airframe requirements and feasibility evaluation....................................... 50

6.3 Electric Propulsion System for various Airframes........................................ 51

6.4 Drag, Thrust Power and Traction Battery Drain ............................................. 52

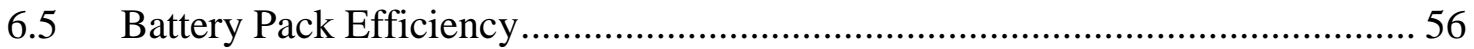

6.6 Estimation of Electric Propulsion System Component Weight ......................... 57

6.7 Aircraft Cruise Endurance and Range at Various Speeds ............................... 58

CHAPTER 7: Battery Electric Propulsion System Layout in a Motor Glider ................. 74

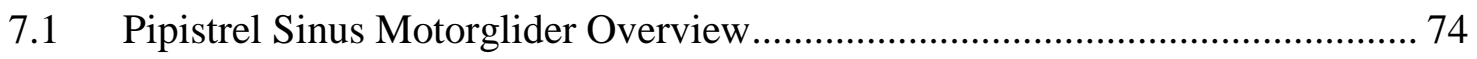

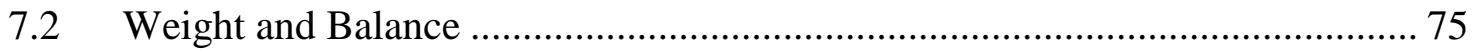

7.3 Pipistrel Sinus Battery Electric Propulsion System Layout .............................. 81

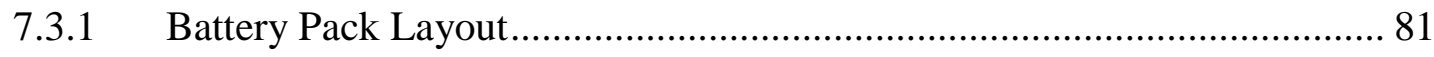

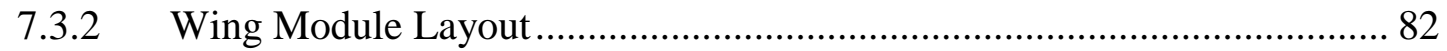

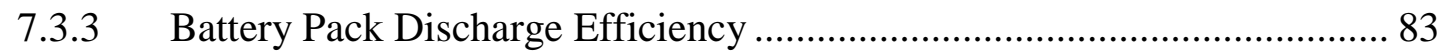

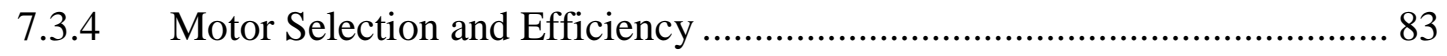

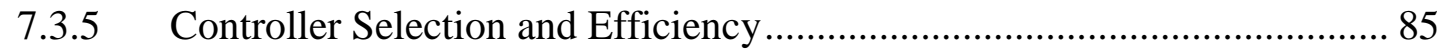

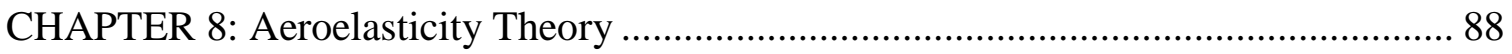

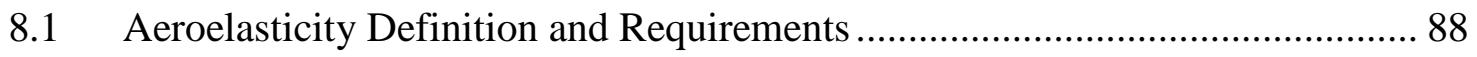

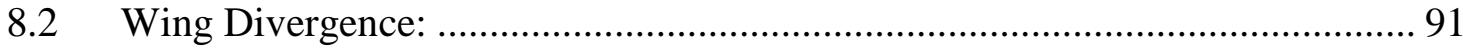

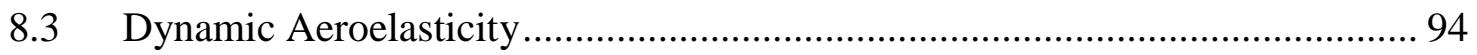

8.4 V-g Flutter Method Using Assumed Modes .................................................. 95

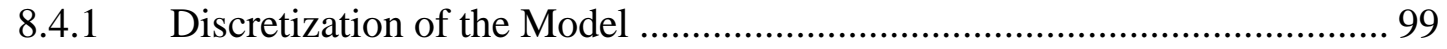

8.4.2 Flexibility Influence Coefficient Matrix Calculation .............................. 100

8.4.3 Mode Shape and Natural Frequency Development ................................ 100

8.4.4 Flutter Determinant Development ...................................................... 102

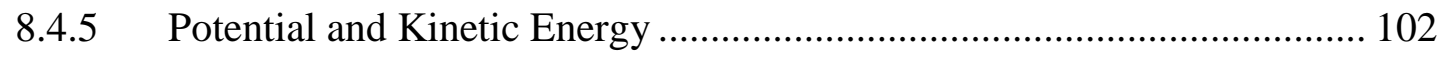

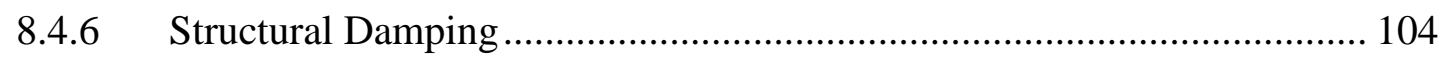

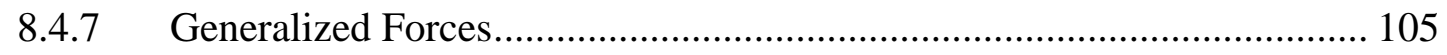


8.4.8 Equation of Motion Development ………………............................... 106

8.4.9 Assumption of Simple Harmonic Motion.................................................. 107

8.4.10 Summary of Flutter Methodology ............................................................. 109

8.5 Flutter Flight Testing............................................................................ 110

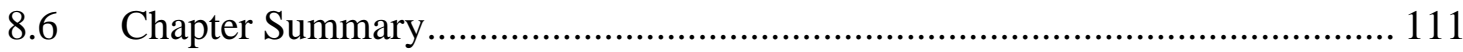

CHAPTER 9: Wing Structural Design Requirements ................................................. 112

9.1 Factor of Safety: FAR 23.303 …………………................................... 113

9.2 Strength and Deformation: FAR 23.305 …………………….................... 113

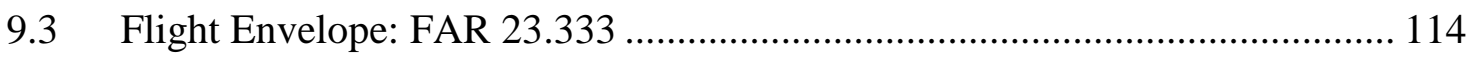

9.4 Maneuvering Envelope: .................................................................... 115

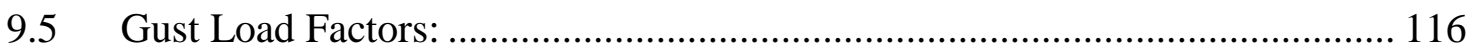

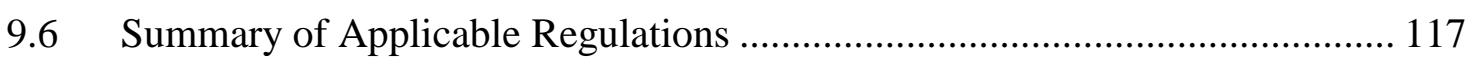

CHAPTER 10: Wing Structural Design............................................................... 119

10.1 Existing Structural Design Information ................................................... 119

10.1.1 Existing Material Database and Existing Aircraft Structural Sizing ........ 119

10.1.2 Laminate Data for Existing Composite Aircraft ........................................ 121

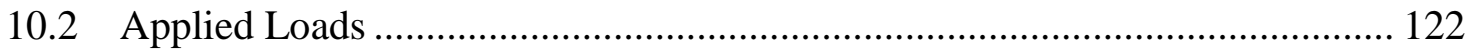

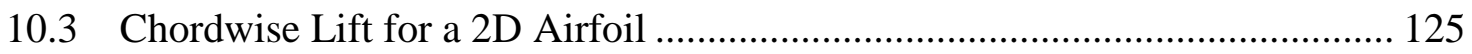

10.4 Wing Development Methodology ……………......................................... 126

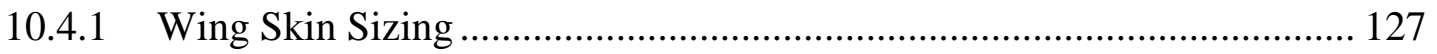

10.4.2 2.) Rib Spacing and Wing Skin Buckling, Rib Thickness ......................... 128

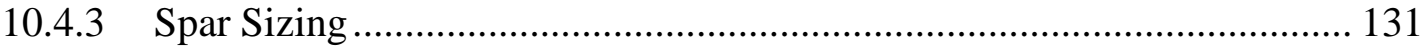

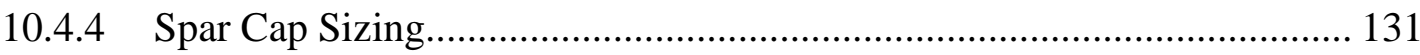

10.4.5 Shear Center and Torsion Constant Calculation ....................................... 132

10.4.6 Procedure for Determination of Shear Center ......................................... 133

10.4.7 Description of Table Operations ……………………….......................... 137

10.4.8 Torsion Constant (J) Calculation for a 3 Cell Beam.................................. 139

10.4.9 Distributed Torsion Load Determination................................................... 140

10.4.10 Effective EI and GJ Determination ....................................................... 141

10.4.11 Rib Laminate Determination ............................................................ 142

10.4.12 Wing Mass, Static Moment, Mass Moment of Inertias.......................... 142 


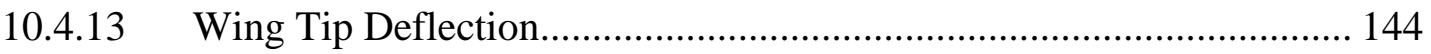

10.4.14 Flutter Code Inputs....................................................................... 145

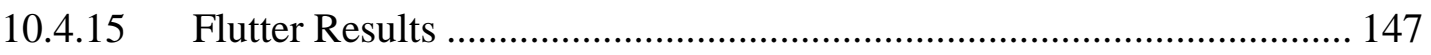

10.4.16 Investigation into the Effect of Battery Positioning on Flutter ............. 148

10.5 Selection of Battery Packaging configuration for future development ............ 153

10.6 Structural redesign to accommodate traction Batteries in the wing................. 155

10.6.1 Wing Deflections …………………………...................................... 159

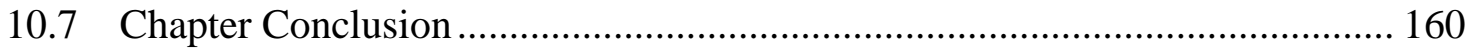

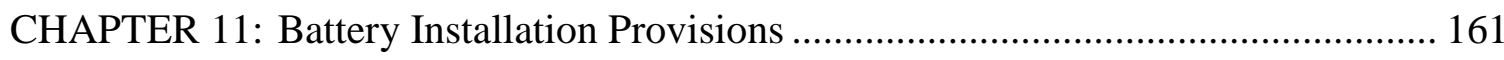

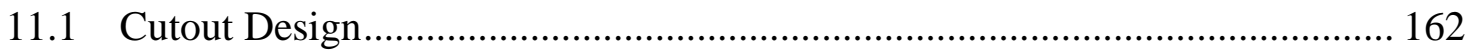

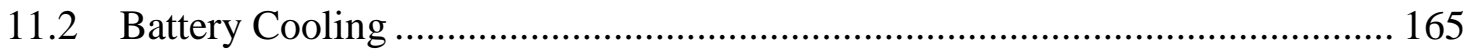

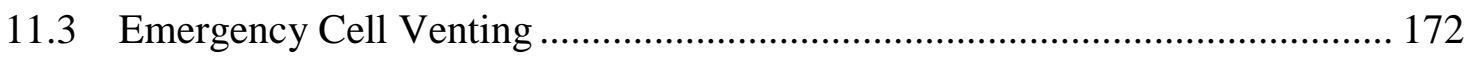

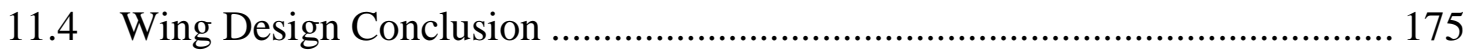

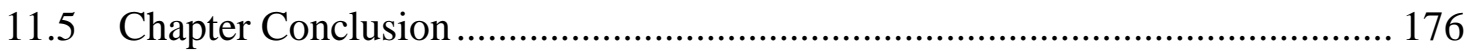

CHAPTER 12: Finalized Aircraft Concept Summary .................................................. 177

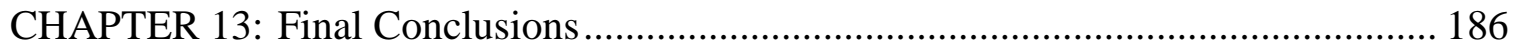

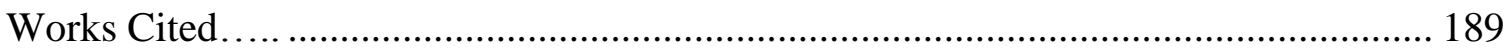




\section{LIST OF TABLES}

Table 2.1 NASA Greenflight Challenge Prize Requirements (1) ………………............ 7

Table 2.2 Battery electric aircraft performance: NASA Greenflight Challenge (5) .......... 7

Table 2.3 Pipistrel Taurus G4 and Stuttgart e-Genius published specifications (7).......... 8

Table 2.4 Airbus Siemens E-Star 2 hybrid specifications (11) ....................................... 11

Table 2.5 Airbus E-Fan specifications (13) ……………........................................ 12

Table 3.1 Electric Vehicle Nominal Pack Voltage ………………................................. 21

Table 3.2 Comparison of various prismatic and cylindrical battery cells......................... 24

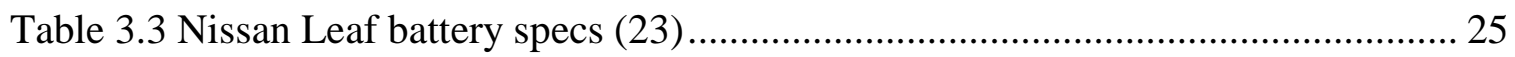

Table 3.4 Chevy Volt battery specs (29) ............................................................... 27

Table 3.5 BMW Mini-E battery specs (20) ............................................................ 28

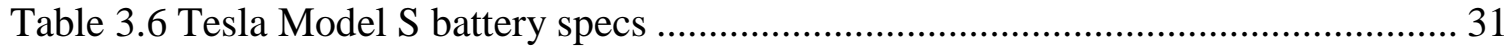

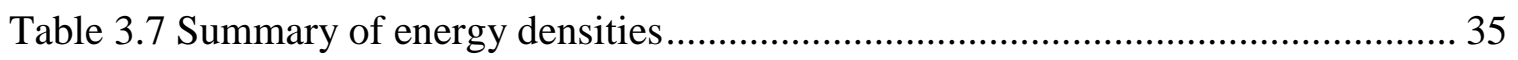

Table 4.1 Electric aircraft motor data (39)................................................................. 41

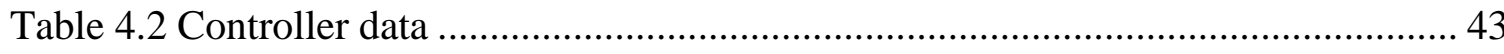

Table 4.3 Liquid cooling system components (42)..................................................... 44

Table 4.4 Motor and Controller Metrics ....................................................................... 46

Table 5.1 Rubber component properties for battery, motor and controller ...................... 48

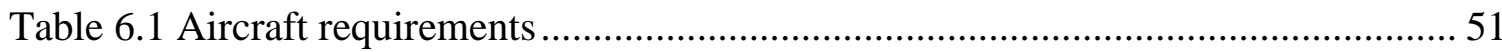

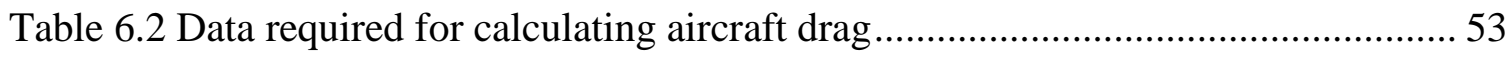

Table 6.3 Efficiencies and energy densities used for cruise analysis ...............................59

Table 6.4 Input Parameters for Performance Analysis ..................................................... 60

Table 6.5 Maximum airspeed attainable for continuous operation................................... 64 


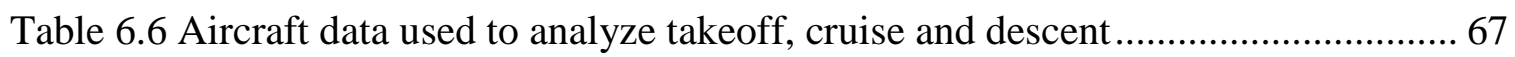

Table 6.7 Reduction in range due to conversion to battery electric propulsion .............. 70

Table 6.8 Reduction in endurance due to conversion to battery electric propulsion ........ 71

Table 7.1 Pipistrel Sinus specification overview (47) …......................................... 75

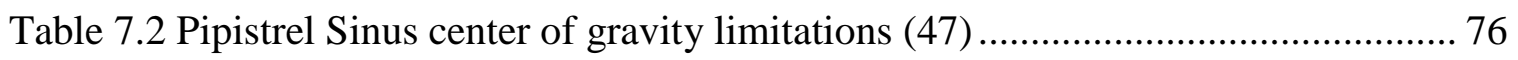

Table $7.3 \mathrm{CG}$ position of battery electric Sinus without baggage ............................... 78

Table 7.4 CG position of battery electric Sinus with baggage ................................... 78

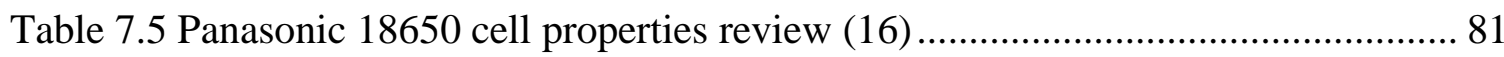

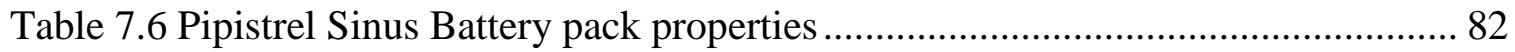

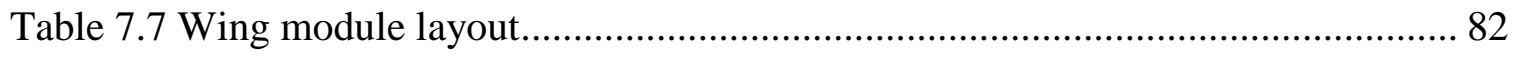

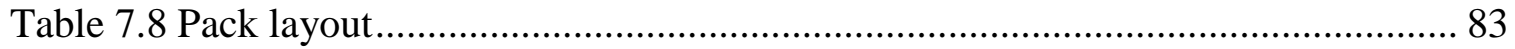

Table $7.9 \mathrm{I}^{2} \mathrm{R}$ losses for the battery pack for various system power draws .................... 83

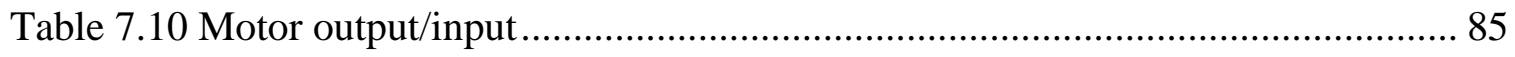

Table 7.11 Controller power requirements and resulting efficiency ............................. 85

Table 8.1 Table of various aircraft zero speed frequencies (53) ............................... 102

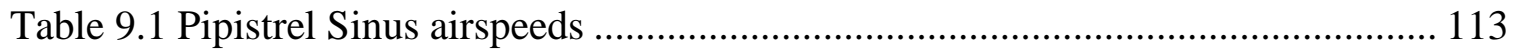

Table 9.2 Structural Load Requirements .......................................................... 118

Table 9.3 Structural Load Requirements used in Thesis. ........................................ 118

Table 10.1 ETW material properties used for subsequent design work ..................... 120

Table 10.2 Rohacell 71 WF foam properties ....................................................... 120

Table 10.3 Method of Successive Approximation Example ...................................... 136

Table 10.4 Spar laminate specs for a standard wing without batteries ........................ 143

Table 10.5 Total wing weight for wing without batteries........................................ 143 
Table 10.6 Wing tip vertical deflection for wing without batteries ............................ 144

Table 10.7 Torsional deflection of the wingtip for wing without batteries ................... 145

Table 10.8 Wing properties input into flutter code ................................................ 146

Table 10.9 Spar specs for a standard wing with batteries ....................................... 158

Table 10.10 Wing with battery total component weight......................................... 159

Table 10.11 Wing Tip vertical deflection for wing with batteries ............................. 159

Table 10.12 Angular wing tip deflection for a wing with batteries. ........................... 160

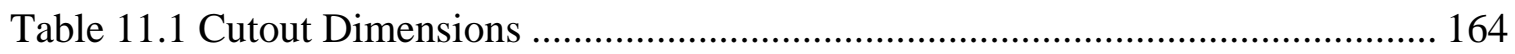

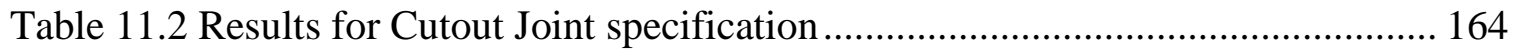

Table 11.3 Heat generated for each wing as a function of discharge power ................. 165

Table 11.4 Maximum allowable battery temperatures during discharge (18) ............... 166

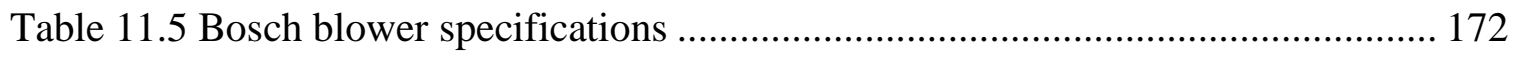

Table 11.6 Properties of battery during venting episode (67) ................................. 172

Table 12.1 Electric Aircraft Summary .................................................................. 181

Table 12.2 Electric Aircraft Performance Summary .............................................. 181

Table 12.3 Electric Aircraft Drive System Summary ............................................ 182

Table 12.4 Electric Aircraft Motor and Controller Summary..................................... 182

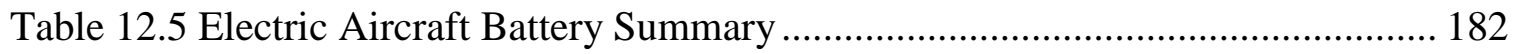




\section{LIST OF FIGURES}

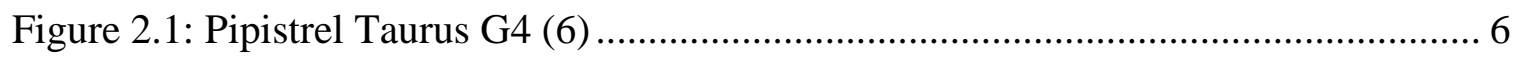

Figure 2.2: University of Stuttgart e-Genius (6) ................................................. 7

Figure 2.3: Twin fuselage derivation (8) of the two seat Taurus G2 (9) ......................... 9

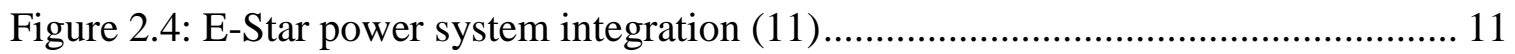

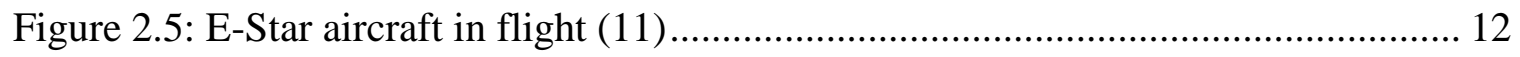

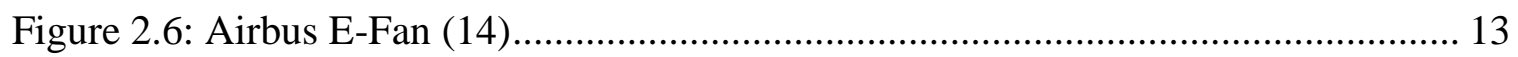

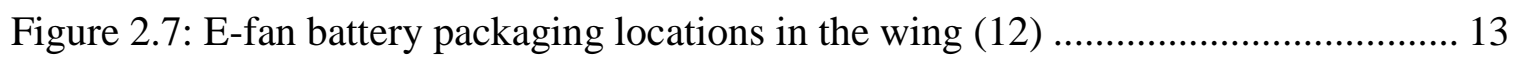

Figure 2.8: Battery modules being installed through the bottom of the wing skin (12) ... 14

Figure 2.9: Mechanical fasteners used for lower wing skin cutouts (12) ...................... 14

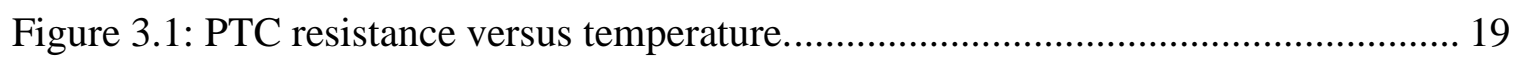

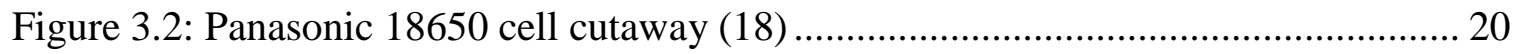

Figure 3.3: Depiction of aluminum cooling fin in the Chevy Volt battery pack (30) ...... 26

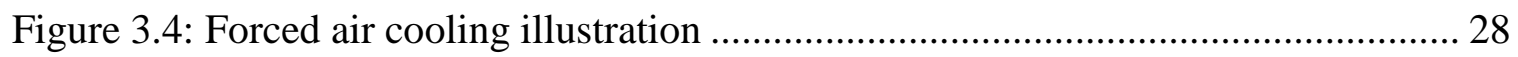

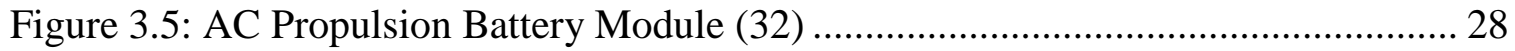

Figure 3.6: AC Propulsion electric vehicle battery pack (32) ................................... 29

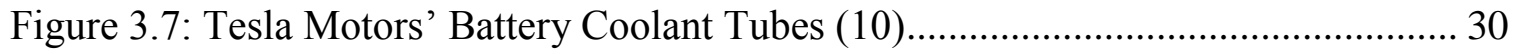

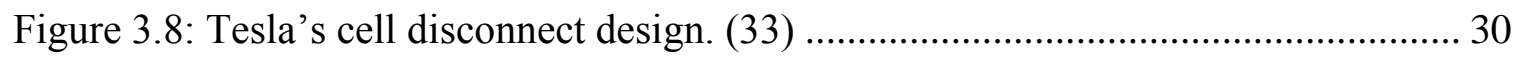

Figure 3.9: Scorch marks consistent with rupture plate location (34)......................... 32

Figure 3.10: New battery enclosure with venting system (35) ................................. 33

Figure 3.11: Diagram of Boeing's modified battery enclosure system. (35)................. 34

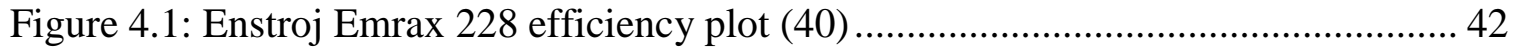

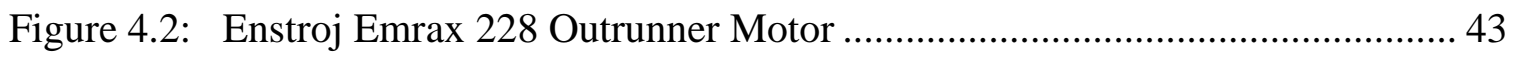




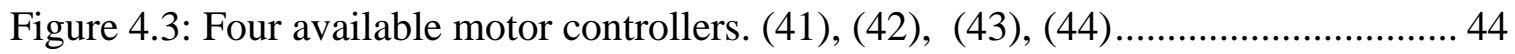

Figure 4.4: Tritium WaveSculptor 200 efficiency plot for a 450 VDC bus (42)............. 45

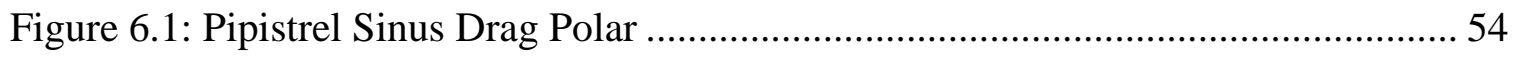

Figure 6.2: Required thrust (drag) power in kilowatts for various airspeeds at sea level. 55

Figure 6.3: Maximum endurance for airframes with electric propulsion conversion...... 61

Figure 6.4: Maximum range for airframes with electric propulsion conversion ............. 62

Figure 6.5: Forces acting on an aircraft during descending flight. ............................. 66

Figure 6.6: Endurance including time aloft during climb and descent. ........................ 69

Figure 6.7: Range including miles traveled during climb and descent......................... 69

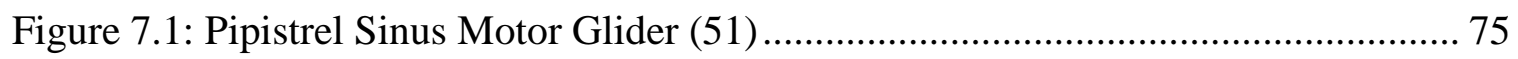

Figure 7.2: C.G. locations for the internal combustion Pipistrel Sinus. (47)................... 79

Figure 7.3: Center of Gravity locations for battery electric Pipistrel Sinus.. (47) ........... 80

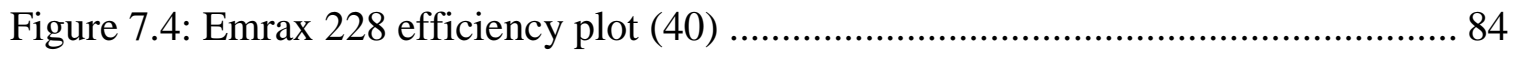

Figure 7.5: Controller Efficiency Plot : (42).......................................................................... 86

Figure 8.1: Center of Pressure and Elastic Axis .................................................... 92

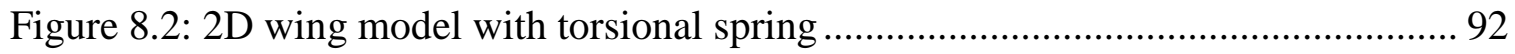

Figure 8.3: Divergence trends for various dynamic pressures................................... 93

Figure 8.4: Example of a V-g for a large transport category aircraft. ........................... 96

Figure 8.5: Depiction of possible damping results ............................................. 98

Figure 8.6: Wing sections discretized into lumped masses. ..................................... 99

Figure 9.1: Flight Envelope depiction found in FAR 23.333 .................................. 115

Figure 10.1:Comparison between 2D airfoil theory and lifting line theory. ................ 123

Figure 10.2: Shear load along wing semispan for 2D airfoil and lifting line theory..... 124 
Figure 10.3: Bending moment along semi span for 2D airfoil and lifting line theory. .. 124

Figure 10.4:Pressure distribution resolved as a force and moment (60)...................... 125

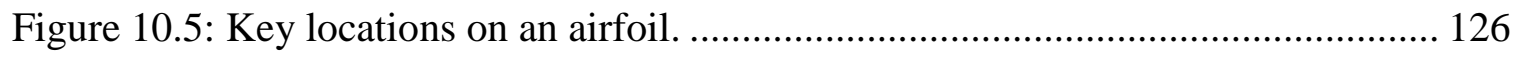

Figure 10.6: Computed wing skin buckling stress with variation in rib spacing........... 129

Figure 10.7: Lengths used in buckling equation................................................. 130

Figure 10.8: Geometry used for Buckling Analysis ............................................. 131

Figure 10.9: Approximate the shape of the wing as a 3 cell rectangular box beam ....... 133

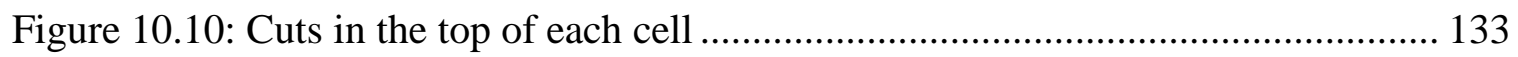

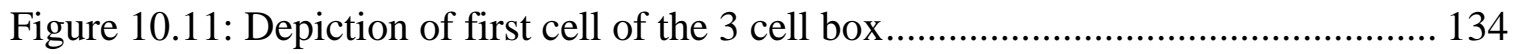

Figure 10.12: Depiction of first cell of the 3 cell box........................................... 135

Figure 10.13: Label of the three enclosed areas ...................................................... 139

Figure 10.14: The variation of the wing effective EI with relation to wing semispan ... 146

Figure 10.15: Effective GJ was held constant for simplicity.................................. 147

Figure 10.16: The torsion mode is stable at the $168 \mathrm{MPH} \mathrm{V}_{\mathrm{D}}$ Speed......................... 148

Figure 10.17: Batteries packaged between the leading edge and the spar.................... 149

Figure 10.18: Batteries packaged immediately behind the wing spar ........................ 150

Figure 10.19: Batteries packaged on both sides of the spar..................................... 150

Figure 10.20: Flutter damping curves with the batteries in front of the spar................ 151

Figure 10.21: Flutter damping curves with the batteries aft of the spar ...................... 152

Figure 10.22: Flutter damping curves with the batteries near the wing root, ............... 153

Figure 10.23: Distributed load change due to packaging the batteries in the wing....... 156

Figure 10.24: Direct shear load change from packaging batteries in the wing.............. 157

Figure 10.25: Bending moment change from packaging the batteries in the wing. ....... 157 
Figure 11.1: Batteries installed through cutout panel ............................................ 162

Figure 11.2:Bottom view of wing showing installed battery cutouts .......................... 162

Figure 11.3: Battery Temperature Rise in Fahrenheit ........................................... 166

Figure 11.4: Estimated heat rejected for varying volumetric flow rate on a $100^{\circ} \mathrm{F}$ day. 168

Figure 11.5: Power required for given amount of heat rejection............................... 169

Figure 11.6: Cooling air flow map for the entire wing ....................................... 170

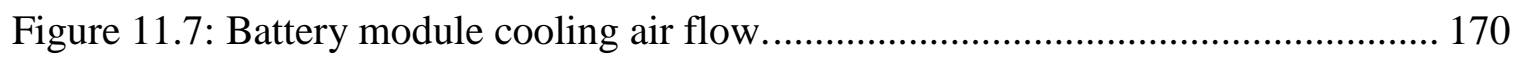

Figure 11.8: Exhaust ducts are located at the trailing edge on the bottom wing skin .... 171

Figure 11.9: Battery emergency venting flow map ............................................. 173

Figure 11.10: Emergency venting ducts on upper wing skin................................. 174

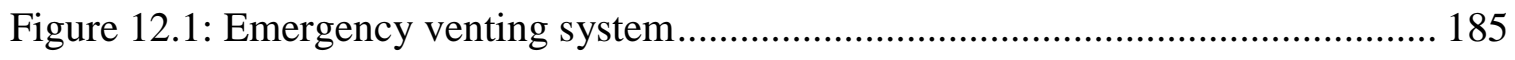




\section{List of Symbols}

a Representation of the position of the elastic axis

relative to wing chord

a

Line Integral

A Area

AR Aspect ratio

b Wingspan

b One half of the wing chord

$b_{r} \quad$ One half of the wing semispan at the $3 / 4$ span

position

c Chord Length

C Mean Geometric Chord

$\mathrm{C}_{1 \rightarrow 2} \quad$ Carryover Factor

$\mathrm{C}_{\mathrm{D}} \quad$ Coefficient of Drag

$\mathrm{C}_{\text {DO }} \quad$ Parasite Drag Coefficient

$\mathrm{C}_{\mathrm{L}} \quad$ Coefficient of lift

$\mathrm{C}_{\mathrm{L} \alpha} \quad$ Slope of lift versus angle of attack curve

$\mathrm{C}_{\mathrm{M}} \quad$ Pitching Moment Coefficient

$\mathrm{C}^{\mathrm{ZZ}} \quad$ Torsion influence coefficient matrix

$\mathrm{C}^{\theta \theta} \quad$ Bending influence coefficient matrix

D Structural Damping

$\mathrm{D}_{\mathrm{P}} \quad$ Propeller Disk Loading

e Oswald Efficiency Factor

e Distance between aerodynamic center and elastic axis

$\mathrm{E}_{1} \quad$ Longitudinal Modulus of Elasticity

EI Bending Rigidity

f Equivalent Parasite Area

$f(x) \quad$ Uncoupled normalized bending mode shape

$\mathrm{F}(\mathrm{x}) \quad$ Uncoupled normalized torsion mode shape 


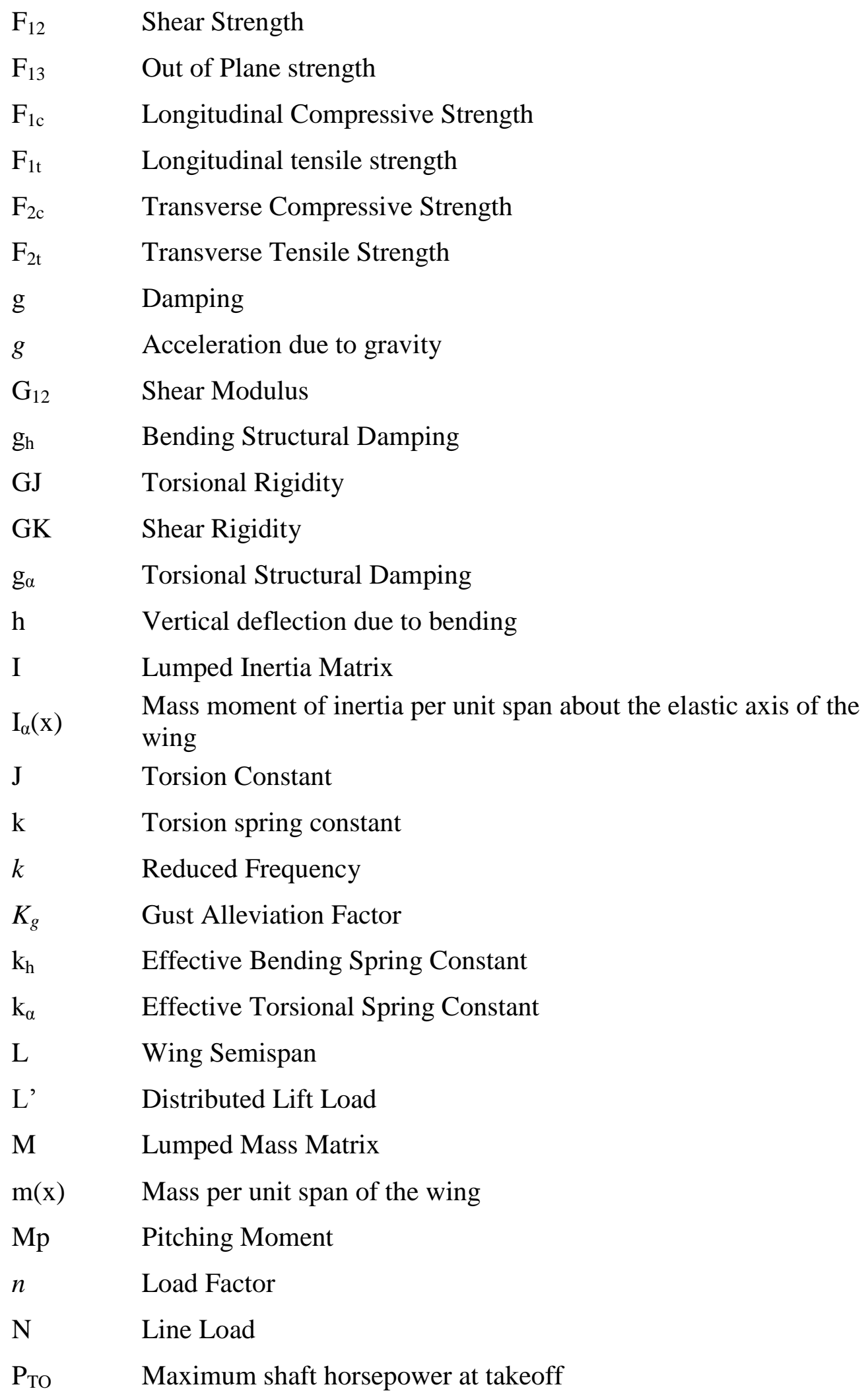




\begin{tabular}{|c|c|}
\hline q & Shear Flow \\
\hline $\mathrm{q}_{1 \rightarrow 2}$ & Carryover Shear Flow \\
\hline $\mathrm{Q}_{\mathrm{h}}$ & Oscillatory aerodynamic lift \\
\hline $\mathrm{Q}_{\alpha}$ & Oscillatory aerodynamic moment \\
\hline $\mathrm{S}$ & Wing area \\
\hline $\mathrm{S}_{\alpha}$ & Effective Static Unbalance \\
\hline $\mathrm{S}_{\alpha}(\mathrm{x})$ & Static mass moment of inertia per unit span about the elastic axis \\
\hline $\mathrm{T}^{\prime}$ & Distributed Torque Load \\
\hline $\mathrm{t}_{\mathrm{ply}}$ & Ply thickness \\
\hline $\mathrm{U}$ & Velocity \\
\hline $\mathrm{U}$ & Potential Energy \\
\hline$U_{d e}$ & Derived gust velocities \\
\hline$\mu_{\mathrm{g}}$ & Airplane Mass Ratio \\
\hline $\mathrm{V}$ & Airspeed \\
\hline $\mathrm{v}_{12}$ & Major Poisson's Ratio \\
\hline $\mathrm{V}_{\mathrm{D}}$ & Design dive speed \\
\hline $\mathrm{V}_{\mathrm{NE}}$ & Never exceed speed \\
\hline Vs & Stall speed \\
\hline $\mathrm{W}$ & Weight \\
\hline $\mathrm{W}$ & Deflection \\
\hline$W / S$ & Wing Loading \\
\hline $\mathrm{X}_{\mathrm{ac}}$ & Distance from the wing leading edge to the aerodynamic center \\
\hline $\mathrm{X}_{\mathrm{cg}}$ & $\begin{array}{l}\text { Distance from the wing leading edge to the wing center of } \\
\text { gravity }\end{array}$ \\
\hline $\mathrm{x}_{\mathrm{o}}$ & Distance from the wing leading edge to the wing torsional axis \\
\hline $\mathrm{y}$ & Wing station locations along wing span \\
\hline$\alpha$ & Angle of attack \\
\hline$\alpha$ & Rotational deflection due to torsion \\
\hline$\alpha_{\mathrm{r}}$ & Rigid Angle of Attack \\
\hline$\varepsilon$ & Strain \\
\hline$\theta$ & Angular Deflection \\
\hline
\end{tabular}




$\begin{array}{cl}\rho & \text { Air density } \\ \sigma & \text { Stress } \\ \omega & \text { Frequency } \\ \omega_{\mathrm{h}} & \text { Bending Frequency } \\ \omega_{\alpha} & \text { Torsional Frequency } \\ Z & \text { Flutter Determinant } \\ & \text { Root }\end{array}$




\section{CHAPTER 1: Introduction}

The general aviation industry is under pressure to develop the next generation of propulsion systems and fuels for small aircraft. Pilots and passengers are demanding power plants with increased fuel efficiency and reduced cost. Airports are threatened with closure as neighboring communities react to toxic lead emissions and noise pollution (1). Many operators are asking why aircraft engines have not seen the improvements in fuel efficiency and reliability that have advanced the automotive industry over the past fifty years. In response, the aviation industry is investigating alternative aviation gasoline (avgas) formulations as well as developing a new generation of certified aircraft diesel engines. The next generation of avgas will be free from the carcinogenic tetraethyl lead currently used to increase octane ratings in today's fuel formulations. Tomorrow's FAA certified aircraft diesel engines will offer significant improvements in fuel and maintenance costs while at the same time increasing reliability (2). While these recent efforts to develop new piston aircraft fuels and new diesel engine technology will likely prove to be successful, there is another power system technology that is gaining traction in the automotive world but has not yet seen large scale implementation in the aircraft industry. This technology is the battery electric propulsion system.

The automobile industry has faced several of the same pressures as the light aircraft industry in the last ten years. Drivers are asking for increased reliability, fuel efficiency and reduced maintenance cost. Modern automobile passengers also expect high levels of refinement and minimum vibration or noise. In certain ground vehicle applications, the battery electric propulsion system has shown itself to be the solution for these demands. This is due to the electric propulsion system's ability to deliver high 
power levels and high efficiency at the same time while creating no direct emissions and increasing overall system reliability.

While several ground vehicles using battery electric propulsion systems are in production, the aircraft industry has seen only a very limited number of one- off experimental battery electric aircraft. The goal for this thesis is to develop a better understanding of the feasibility of using battery electric propulsion systems in aircraft through the development of a conceptual design of a battery electric airplane. The motivation for this project results from the sentiment that aircraft piston engines are antiquated, inefficient, unreliable and require too much management from the pilot. This is evidenced from the fact that $9 \%$ of all general aviation accidents in 2010 were caused by power plant or related systems failures. An additional 5\% of all 2010 general aviation accidents were caused by pilot mismanagement of power plant systems (3). The switch to electric propulsion has the potential to significantly reduce the frequency of these power plant related accidents. Compared to the single rotating part in an electric motor, the internal combustion engine has several reciprocating parts of which failure of any single component would lead to a complete power loss. The electric propulsion system can be designed such that failure of a single component causes only a partial power loss, enabling the aircraft to limp home under at a reduced power setting. A well designed electric propulsion system would also significantly reduce pilot workload by eliminating the systems pilots are currently required to management with internal combustion engines. Pilots would no longer be required to monitor fuel balance, anticipate induction system icing, adjust air/fuel mixtures or worry about thermally shocking the engine from rapidly changing power settings. 


\subsection{Thesis Roadmap and Scope}

Battery electric aircraft have the potential to be cleaner, safer, quieter and cheaper to operate when compared to conventional internal combustion aircraft engines. However, the performance that is possible from an electric aircraft is not well understood, nor are potential propulsion system packaging requirements and solutions publically

documented. The motivation for this thesis is to explore what type of performance may be expected from an electric aircraft, and what that type of aircraft and its associated systems may look like. Eventually, it may be economically viable to develop a clean sheet aircraft design to leverage the advantages of electric propulsion technology. In the short term, however, converting an existing airframe from internal combustion to battery electric power and using commercial off the shelf power system components can significantly reduce the time and cost required to produced a flying electric airplane. Such a conversion aircraft was therefore chosen to be the focus of this thesis. A conversion airplane can be used to gather real world data on battery electric aircraft performance and this experience could then eventually be applied to the design of a clean airframe design that leverages the lessons learned from the conversion airplane.

The goal of this thesis is to understand which type of existing airframe would make best use of a battery electric propulsion system and what the battery electric propulsion might look like when integrated into the existing airframe. This includes a detailed high level analysis of electric propulsion system performance in various types of existing airframes, selection of the airframe deemed most suitable for conversion, and a detailed electric system packaging layout. 
The roadmap for this thesis is as follows:

- Existing electric propulsion systems currently in use in the aerospace industry are explored.

- Existing battery, motor and controller technologies from the aerospace and automotive industries are explored to produce metrics that can be used in an aircraft performance analysis.

- The expected performance of various existing airframes converted to battery electric power is predicted and an airframe chosen as a reference airframe for future study.

- The focus of the thesis transitions to the study of a conversion of an existing airframe from a reciprocating internal combustion engine to a battery electric propulsion system.

- The battery electric propulsion system is laid out for the reference aircraft. Center of gravity requirements drive the packaging of some of the traction batteries in the wing structure.

- The focus of the thesis transitions to whether it is technically feasible to package the batteries in the wing. Technical concerns addressed include:

- Aerodynamic flutter

- Wing strength

- Battery accessibility

- Battery heat rejection

- Battery safety

- A final overview of the conceptual electric aircraft conversion is presented. 


\section{CHAPTER 2: Existing Electric Aircraft}

In recent years, a limited number of proof of concept electric aircraft have been produced. The general performance specifications for these aircraft are summarized in the following chapter in order to develop an understanding of the current state of the art of the electric aircraft industry.

\subsection{NASA Green Flight Challenge}

The potential ability of battery electric aircraft to reinvigorate the industry by reducing many of the common detractions from general aviation lead to NASA's development of the Green Flight Challenge in the spring of 2011. Prize money has a long history of encouraging innovation in the aviation industry. For example, in 1927 Charles Lindbergh claimed the $\$ 25,000$ Orteig Prize for completing the first nonstop flight across the Atlantic Ocean.

The NASA Greenflight Challenge was founded with the same spirit of encouraging innovation through prize money. The challenge, sponsored by Google, offered a main prize of 1.3 million dollars for an aircraft that could maintain an average speed greater than $100 \mathrm{mph}$ over a 200 statute mile course while being subject to noise, efficiency and other performance standards. The aircraft could use any fuel type, but had to average greater than 200 passenger miles per gallon equivalent (5). Passenger miles per gallon equivalent (MPGe) is a metric used by the Environmental Protection Agency to convert the energy usage of alternative fuel vehicles to miles per gallon of gasoline. This allows for easier comparisons of the efficiency of vehicles that use different fuel sources. The aircraft of the green flight challenge were also subject to stringent noise requirements and fuel efficiency standards. The challenge required less than $78 \mathrm{dBA}$ 
measured at 250 feet during takeoff. A typical piston powered general aviation aircraft will create approximately $90 \mathrm{dBA}$ at the same distance during takeoff (5).

High level contest specifications are summarized in Table 2.1. Several aircraft were initially entered, but only two were able to meet the performance goals. These two aircraft were the Taurus G4, designed and fabricated by Slovenian aircraft company Pipistrel and shown below in Figure 2.1, and the E-Genius, created by the University of Stuttgart in Germany and shown below in Figure 2.2. The contest performance of these aircraft is summarized in Table 2.2.

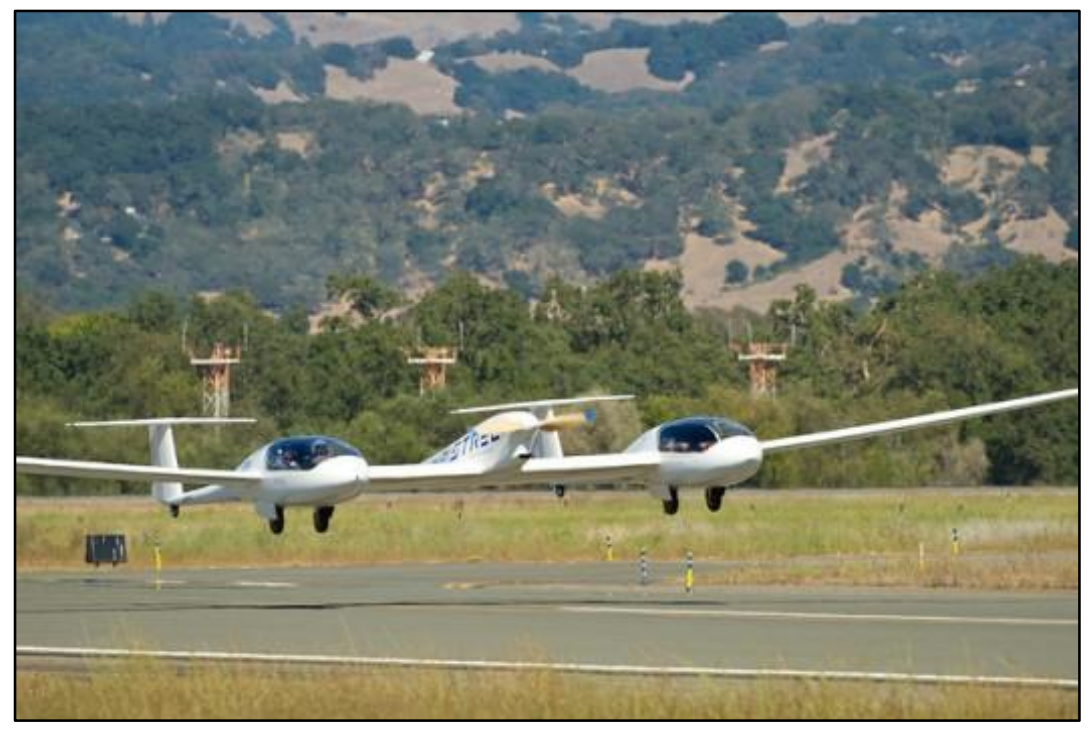

Figure 2.1: Pipistrel Taurus G4 (6) 


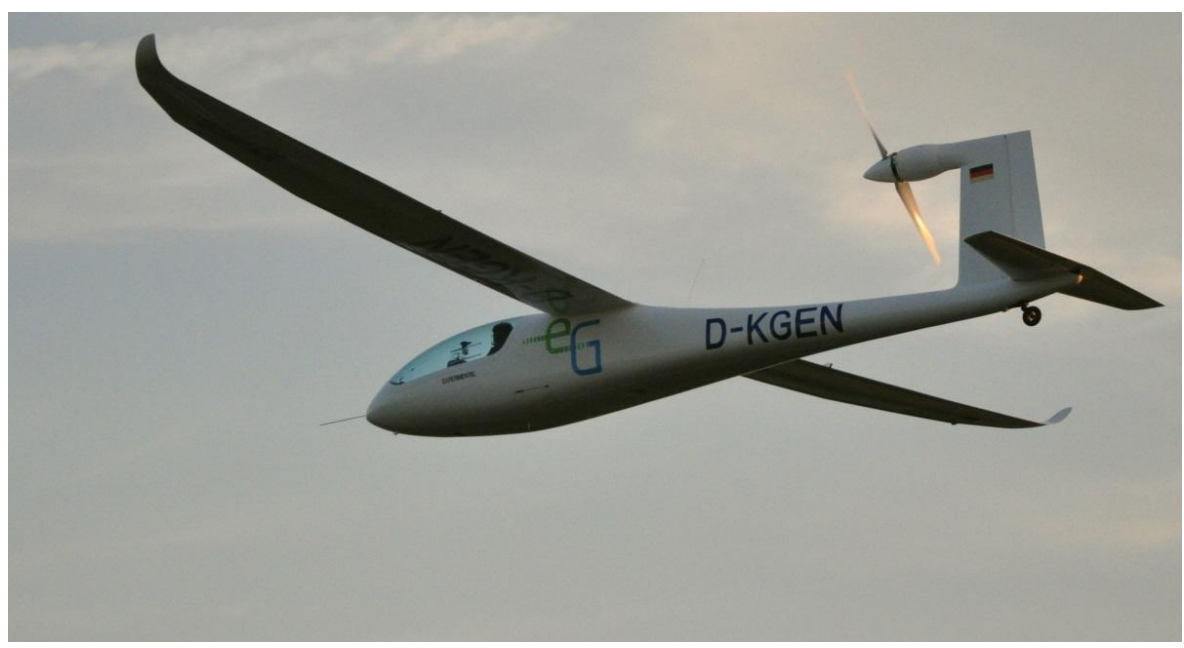

Figure 2.2: University of Stuttgart e-Genius (6)

Table 2.1 NASA Greenflight Challenge Prize Requirements (1)

\begin{tabular}{lc}
\hline \hline Range & 200 statute miles \\
Energy Reserve & 30 minutes of flight time (required for day VFR) \\
Min. Ave. Speed & $100 \mathrm{mph}$ \\
Takeoff Distance & Less than $2000 \mathrm{ft}$ over obstacle \\
Noise at takeoff & Less than $78 \mathrm{dBA}$ from $250 \mathrm{ft}$. \\
\hline
\end{tabular}

Table 2.2 Battery electric aircraft performance: NASA Greenflight Challenge (5)

\begin{tabular}{lcc}
\hline \hline & Pipistrel Taurus G4 & Stuttgart e-Genius \\
\hline \# of Passengers & 4 & 2 \\
Energy Used (KWh) & 65.4 & 34.7 \\
Average Speed (MPH) & 107.4 & 105.7 \\
Total Distance (statute miles) & 195.9 & 193.7 \\
Calculated Passenger MPGe & 403.5 & 375.7 \\
Measured Takeoff Noise from 250 ft (dB) & 71.1 & 59.5 \\
\hline \hline
\end{tabular}

While the calculated passenger MPGe for both the Taurus G4 and the e-Genius are fairly close, each team took very different approaches towards achieving these 
numbers. The G4 is a four place airplane with a twin fuselage design, while the e-Genius is a two place side by side aircraft. This means that the G4 must have a much larger battery and motor than the e-Genius. Specifications for each aircraft are summarized in Table 2.3. Since both aircraft are custom made prototypes not intended for production, no cost data has been publically released.

Table 2.3 Pipistrel Taurus G4 and Stuttgart e-Genius published specifications (7)

\begin{tabular}{lcc}
\hline \hline Spec & Pipistrel Taurus G4 & Stuttgart e-Genius \\
\hline Wingspan & $70 \mathrm{ft}$ & $55.4 \mathrm{ft}$ \\
Wing Area & -- & $156.7 \mathrm{ft}^{2}$ \\
Gross Weight & $3306 \mathrm{lb}$ & $1874 \mathrm{lb}$ \\
Empty Weight & $2495 \mathrm{lb}$ & $1477 \mathrm{lb}$ \\
Stall Speed & $51 \mathrm{mph}$ & $48 \mathrm{mph}$ \\
Cruise Speed & $100 \mathrm{mph}$ & $100 \mathrm{mph}$ \\
Max Speed & $134 \mathrm{mph}$ & $168 \mathrm{mph}$ \\
Number of & 4 & 2 \\
Seats & $890 \mathrm{ft} / \mathrm{min}$ & $890 \mathrm{ft} / \mathrm{min}$ \\
Rate of Climb & & Brushless DC \\
\hline \multicolumn{3}{c}{} \\
Motor Type & Brushless DC & $60 \mathrm{~kW}$ \\
Peak Power & $150 \mathrm{~kW}$ & 2000 \\
Motor RPM & 5500 (propeller gear reduction) \\
\hline \multicolumn{2}{c}{} \\
\hline \hline
\end{tabular}



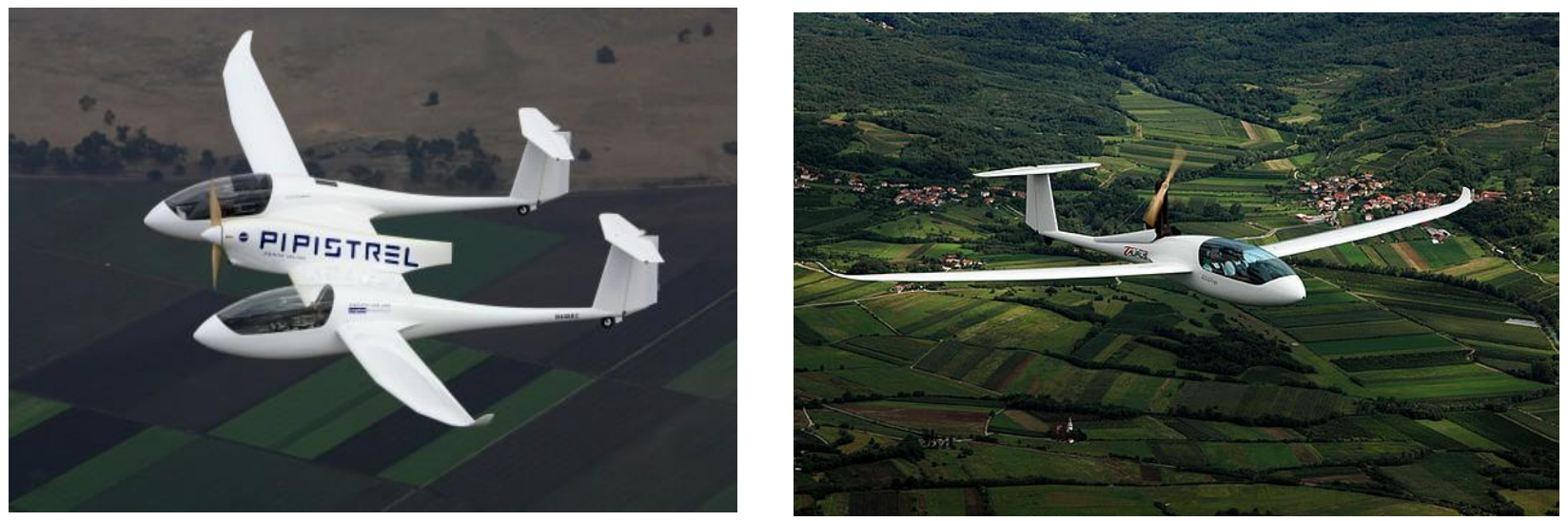

Figure 2.3: Twin fuselage derivation (8) of the two seat Taurus G2 (9)

The Pipistrel Taurus G4 is of composite construction and is based upon Pipistrel's production self-launching motor glider, the Taurus G2. The Taurus G4 has two Taurus G2 fuselages and outboard wings connected by a center wing section for a total payload of 4 people. Figure 2.3 shows the two-seat Taurus G2 on the left from which the four-seat Taurus G4 was derived (right). In the Taurus G4, the drive motor and controller are housed in a nacelle in the center wing section. The drive motor produces its peak power of $150 \mathrm{~kW}$ at $5500 \mathrm{RPM}$ and drives the fixed pitch propeller through a gearbox to reduce the propeller speed. The motor is a custom unit manufactured by Sineton of Slovenia.

The Taurus G4 battery is split into three equal groups, with one pack in the center motor nacelle and one pack in each of the 2 fuselage sections behind the seating area (7).

The University of Stuttgart e-Genius is a clean sheet, 2 seat, side by side motor glider design of composite construction. A key design feature of the e-Genius is the leveraging of the small size of the electric motor by mounting the motor and propeller at the top of the vertical stabilizer. This allows a larger diameter, more efficient propeller to be used while still maintaining adequate propeller ground clearance with very short (and therefore low weight) landing gear. The drive motor is custom developed by Sineton of 
Slovenia and makes peak power of $60 \mathrm{~kW}$ at $2000 \mathrm{RPM}$. Due to the slow motor speed, the propeller is directly driven by the motor with no gear reduction box. The e-Genius battery pack is assembled as one large pack in the fuselage, located behind the passenger seating area.

The NASA green flight challenge succeeded in its goal to demonstrate that it is possible to construct a general aviation battery electric aircraft with usable real world performance. It is important to note however, that the efficiency achieved was during closely monitored flying. The teams utilized precise simulations combined with current wind data to develop the most efficient flight profile possible for the current weather conditions. These models combined with precise flying professional pilots likely greatly improved upon the overall aircraft range. It is probably unrealistic to expect the typical amateur pilot without the sophisticated real time modeling ability of the Green Flight teams to achieve the competition efficiency numbers in day to day flying .

\subsection{Airbus Siemens E-Star 2 Hybrid Aircraft}

Airbus in conjunction with Siemens has developed a series hybrid aircraft based on the Diamond H36 Dimona. The aircraft is currently flying as can be seen in Figure 2.5 The E-Star 2 uses a rotary generator running on AVGas to provide continuous power for cruise operations. The propeller shaft is driven by a BLDC electric motor without using a speed reduction unit. The power electronics is integrated into the motor housing and the entire motor/controller assembly weighs only $29 \mathrm{lbs}$ (10). This is an extremely large power to weight ratio compared to most motor and controller combinations currently on the market. Specifications for the E-Star 2 are summarized below in Table 2.4. Firewall forward integration of the electric motor and combustion generator assembly is visible in 
Figure 2.4. It can be seen that the firewall forward integration of the hybrid drive system is much more cluttered than a single electric motor or gasoline engine would be.

Table 2.4 Airbus Siemens E-Star 2 hybrid specifications (11)

\begin{tabular}{lc}
\hline \hline Generator & Austro Engine AE50R gasoline powered rotary engine \\
Generator peak power & $40.4 \mathrm{~kW}$ \\
Generator cont. power & $30 \mathrm{~kW}$ \\
Generator weight & $61.3 \mathrm{lb}$ \\
Motor/controller & Siemens prototype "Integrated Drive System" \\
Motor/controller peak power & $80 \mathrm{~kW}$ \\
Motor/controller cont. power & $65 \mathrm{~kW}$ \\
Motor/controller weight & $29 \mathrm{lb}$ \\
\hline \hline
\end{tabular}

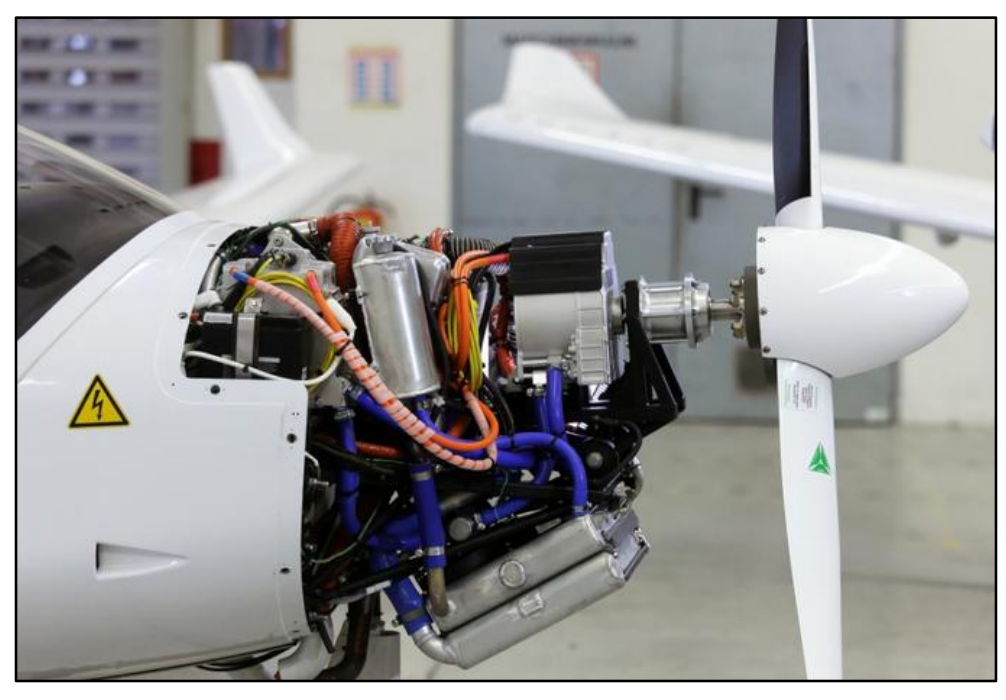

Figure 2.4: E-Star power system integration (11) 


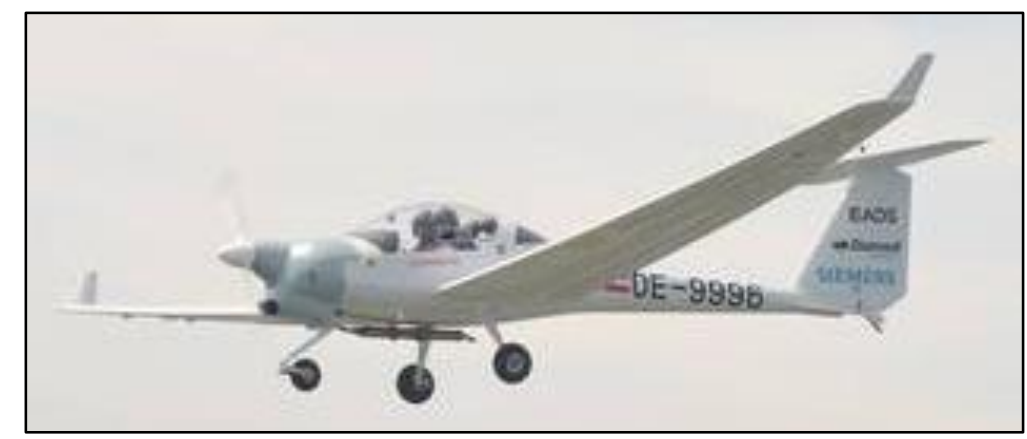

Figure 2.5: E-Star aircraft in flight (11)

\subsection{Airbus/EADS E-Fan}

In April 2014, after the majority of the layout work was done for this thesis, Airbus conducted the first flight of their battery electric technology demonstrator aircraft shown in Figure 2.6, the E-Fan. The E-Fan is a battery powered training aircraft and was developed as a way for Airbus to gain experience with electric aircraft. The most relevant part of the E-Fan to this thesis is that the batteries are packaged in the wing and accessed through cutouts in the lower wing skin (12) as shown in Figure 2.7, Figure 2.8 and Figure 2.9. General E-Fan specifications are summarized in Table 2.5.

Table 2.5 Airbus E-Fan specifications (13)

\begin{tabular}{lc}
\hline \hline Airframe material & Composite \\
Wingspan & $31.2 \mathrm{ft}$ \\
Max Takeoff Weight & $1210 \mathrm{lb}$ \\
Cruise Speed & $100 \mathrm{mph}$ \\
Peak Combined Motor Power & $60 \mathrm{~kW}$ \\
Battery Pack Capacity & $19.2 \mathrm{kWh}$ \\
Endurance & $45-60 \mathrm{~min}$. \\
Battery Pack Voltage & $250 \mathrm{v}$ \\
\hline \hline
\end{tabular}




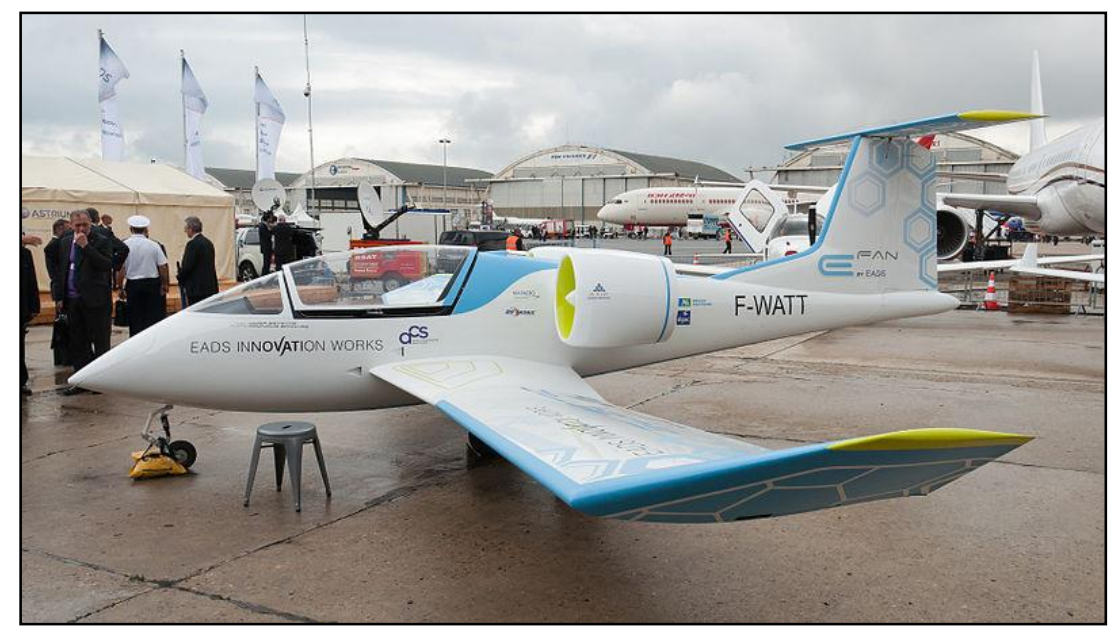

Figure 2.6: Airbus E-Fan (14)

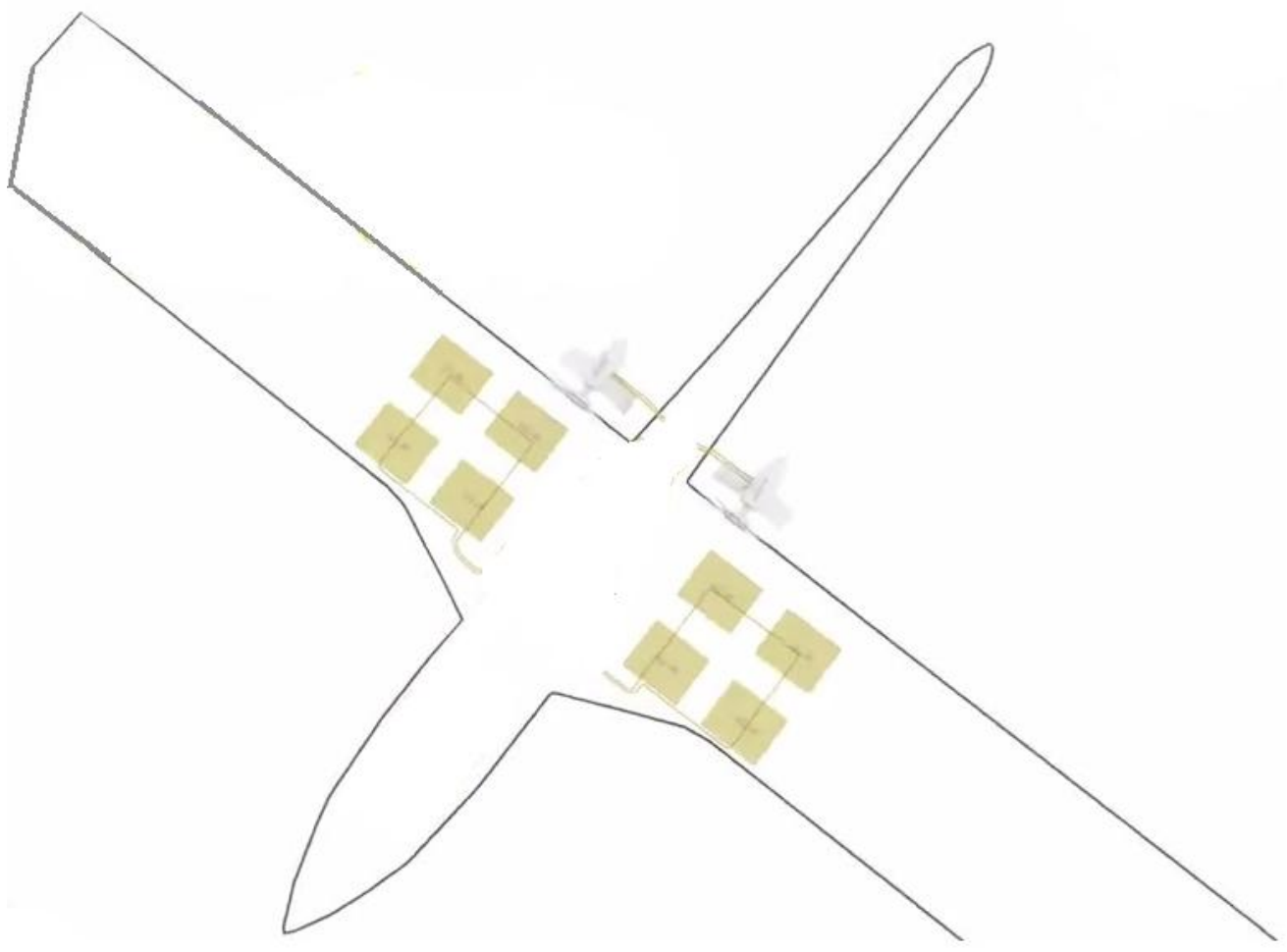

Figure 2.7: E-fan battery packaging locations in the wing (12) 


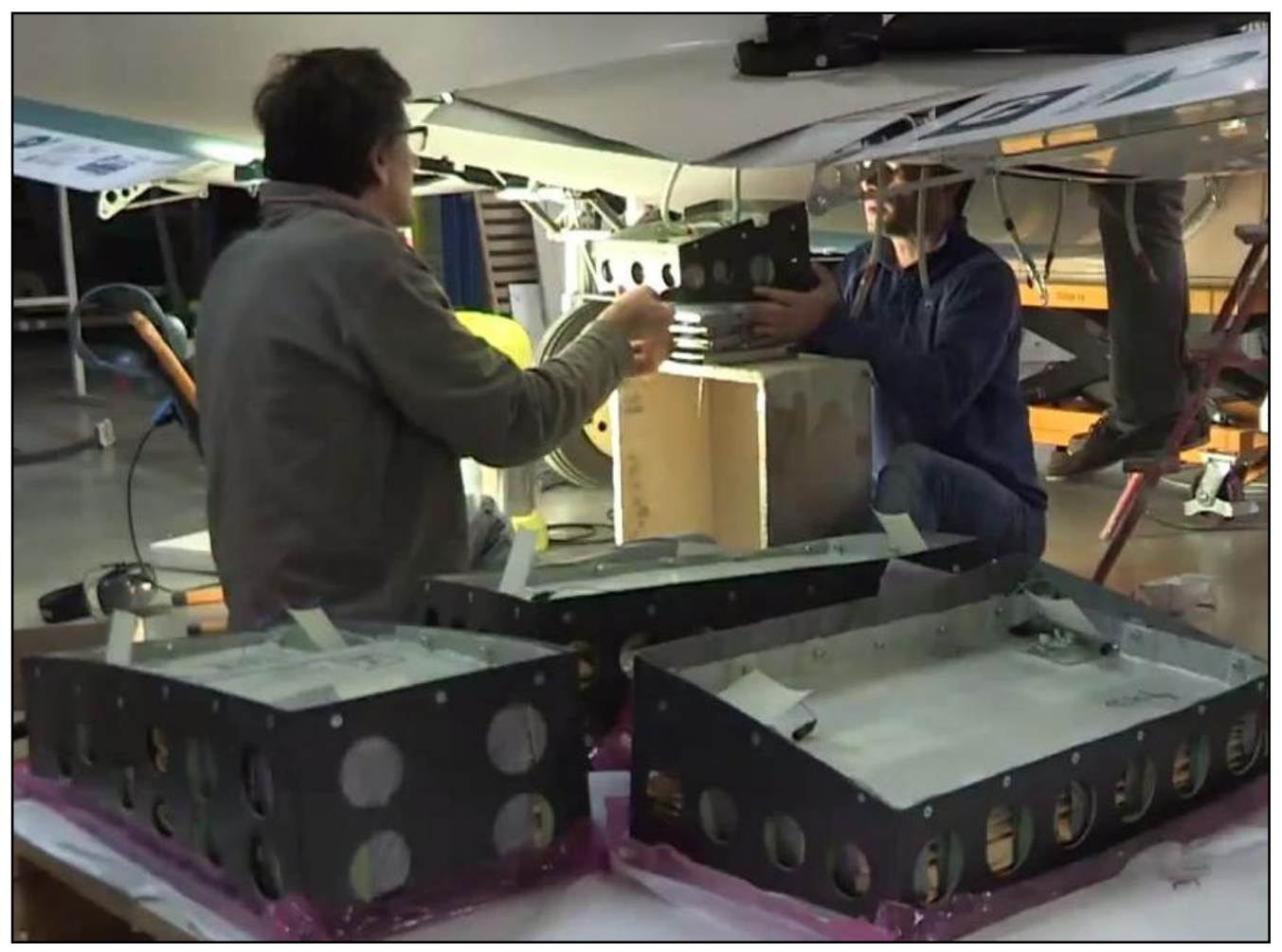

Figure 2.8: Battery modules being installed through the bottom of the wing skin (12)

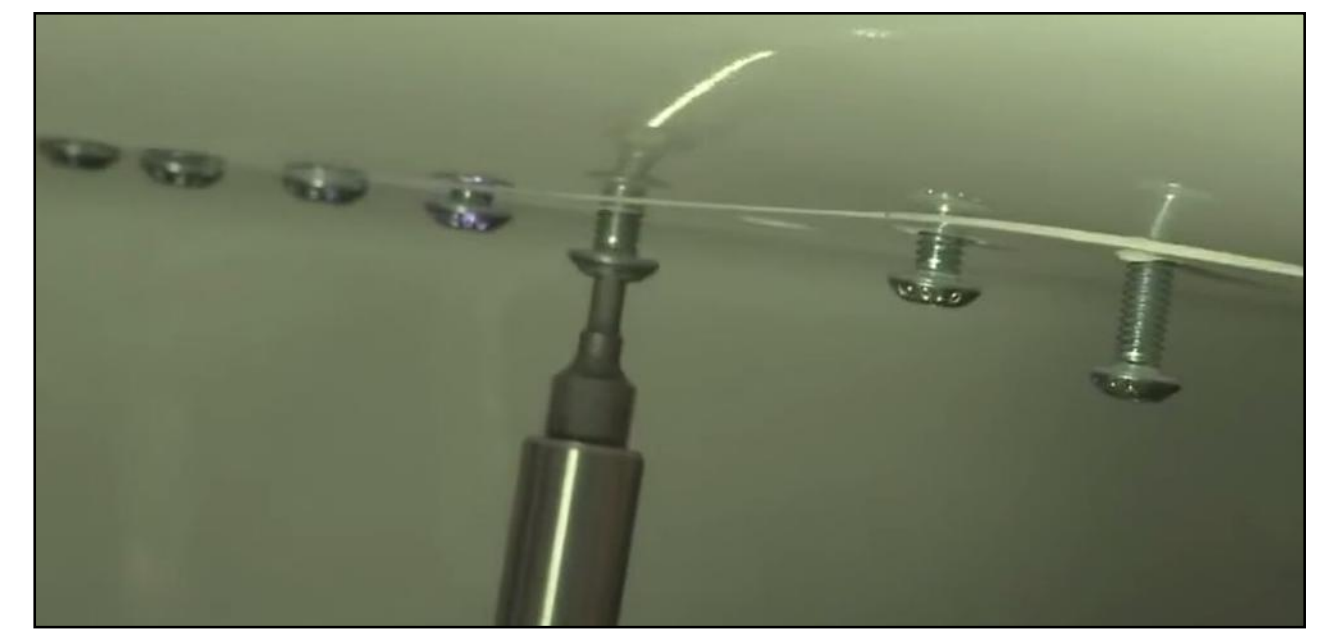

Figure 2.9: Mechanical fasteners used for lower wing skin cutouts (12) 


\subsection{Chapter Conclusion}

The electric aircraft of this chapter are all designed around very efficient airframes in order to extend range. They fly slowly and have minimal allowances for the weight of the passengers and baggage. These aircraft have a typical endurance of between 1 to 2 hours and maximum ranges of 200 miles or less. This illustrates that it is unlikely for the mission of an electric aircraft to be specified as a high speed cross country machine or a utility aircraft carrying large amount of people or cargo. Instead, any future electric aircraft mission is likely to be centered around local flights with low cruise speeds that require low power levels. 


\section{CHAPTER 3: Battery Technology}

After researching electric aircraft that are already flying, the next step is to develop an understanding of current battery electric system technology. This chapter focuses on batteries and includes both aspects of best practices designs as well as important metrics for sizing electric propulsion systems. These metrics and best practices will be used in later chapters for performance analysis of various airframes as well as for conceptual layout of the electric propulsion system.

Chapter goals:

- Develop an understanding of best design practices including

- Battery cell safety

○ Battery module safety

$\circ$ Battery heat rejection requirements

- Develop metrics to be used for batteries

○ Gravimetric energy density

\subsection{Battery Cells}

\subsubsection{Battery Technology}

The lithium ion battery was proposed as early as the 1970's (15). Today many types of lithium ion batteries are in production and used in a variety of products from cell phones and laptops to electric automobiles. They are attractive due to their energy and power density compared to other battery chemistries, as well as their lack of memory effect commonly experienced by users of nickel cadmium and nickel-metal hydride batteries. 
Lithium ion batteries come in several different chemistries and different form factors. A common form factor for cylindrical cells is referred to as the 18650 form factor.

The 18650 cell references the dimensions of the batteries cylindrical casing. The battery is 18.6 millimeters in diameter and 65.2 millimeters in height. Multiple companies make 18650 form factor cells, but one of the models with the greatest energy density is the Panasonic NCR18650 using lithium nickel cobalt aluminum chemistry (16). This is the battery cell used by the Tesla Model S sedan currently in production (17). Other form factors include prismatic cells of various dimensions and pouch cells. Pouch cells are battery cells with a soft casing instead of a harder metal casing common to 18650 cells. This saves weight but requires additional external support. Prismatic simply means a cell of rectangular geometry.

\subsubsection{Battery Cell Safety Features}

No matter the form factor chosen, safety features must be incorporated into the battery pack at the cell level. Lithium cells are manufactured with or without incorporated safety features. It is important to make sure that the battery cell chosen for any manned vehicle incorporates the safety features described in this section. Anytime a large amount of energy is stored the possibility exists for the energy to be dissipated in a violent, destructive manner. This is evidenced throughout history by property damage or injuries from burst pressure vessels, fertilizer plant explosions, grain elevator explosions, gasoline fires in automobiles and most recently lithium ion battery fires in aircraft and several battery electric vehicles. It is the responsibility of the system designer to reduce to an 
acceptable level the chances that stored energy can be liberated in an uncontrolled fashion, no matter the form of stored energy being used.

The safety of a lithium ion battery pack starts at the individual cell level and then continues up to the design of the battery enclosure and battery management system. A battery cell that is safe to use for an electric vehicle contains several safeguards to reduce the risk of a catastrophic fire. They are outlined below:

Positive Temperature Coefficient device (PTC device) (18): The PTC device is a current limiting device and serves to protect the cell from short circuits. The PTC device is composed of a nonconductive matrix suspending conductive particles. When a short circuit occurs, the drastically increased resistive heating in the PTC device due to the increased current flow causes the matrix to expand. The expanding matrix causes the conductive particles in the matrix to move apart until they no longer make contact with each other. This creates a high-resistance state in the PTC device, essentially isolating the individual cell from the rest of the battery pack. If a cell remains shorted, the PTC device produces enough heat to remain in the high resistance state.

If the short circuit is removed from the PTC device, the matrix contracts and conductivity is restored to the cell. The matrix has a memory however, and after several over current situations the matrix will no longer contract when the short is removed, permanently isolating the cell from the rest of the battery pack. The PTC devices typically begin to trip around 110 to $120{ }^{\circ} \mathrm{C}$ and are fully tripped at $135{ }^{\circ} \mathrm{C}$. The National Renewable Energy Laboratory (NREL) has released data PTC performance. Figure 3.1 shows NREL data on PTC resistance versus temperature for three previously untripped (virgin) PTC devices and one PTC device that had already been previously tripped. The 
PTC devices used in the NREL test were from a Molicell ICR-18650J battery cell of the 18650 form factor.

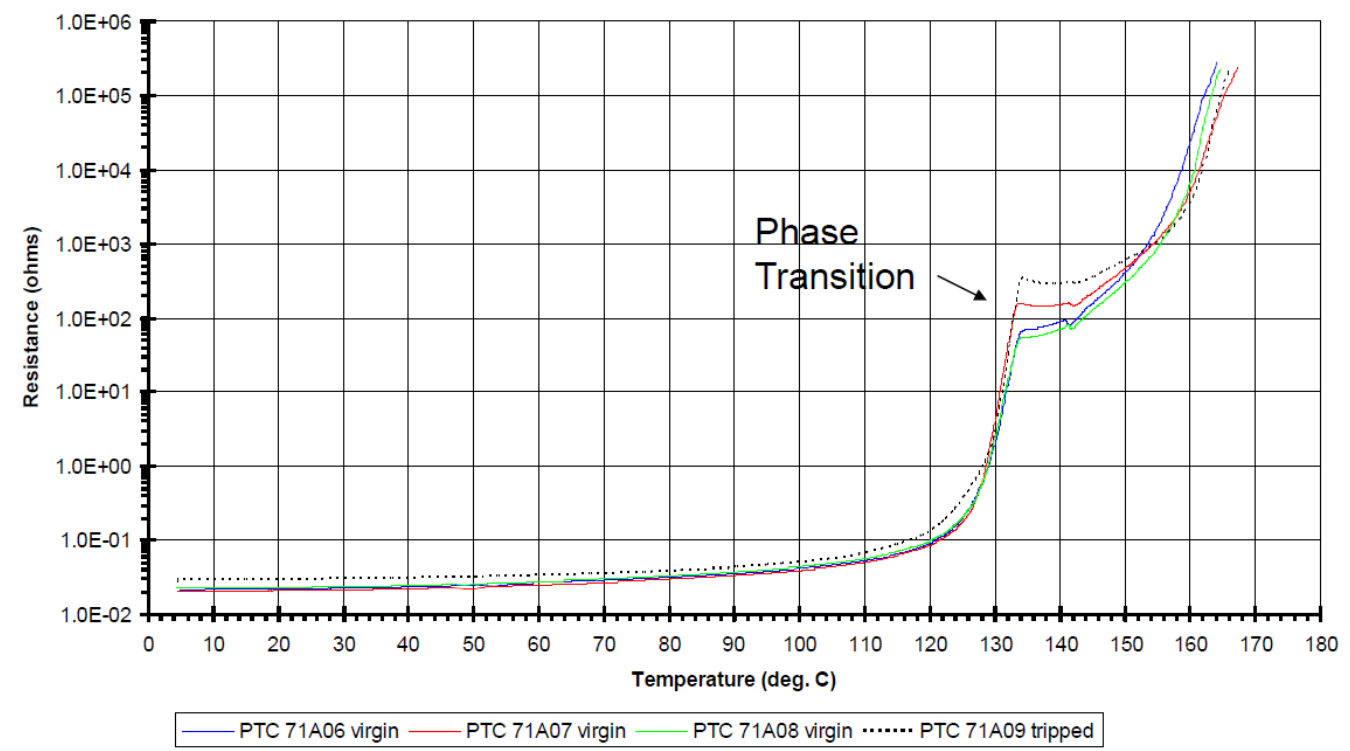

Figure 3.1: PTC resistance versus temperature.

Current Interrupt Device (CID) (18): The CID is essentially a pressure switch designed to electrically disconnect an individual cell from the rest of the battery pack when pressures inside of the cell casing become too large. The goal is to prevent the pressure from reaching a level that would cause the cell casing to burst. Large pressures within the cell are typically caused by over temperatures within the cell as a result of internal resistive heating due to a short circuit. A cell can also be heated from an external source, also causing a rise in pressure. Once the CID is tripped, it is not reversible.

Exhaust Gas Vent Hole (18): The exhaust gas vent hole releases gas in a controlled manner when pressure inside of the cell casing reaches a certain design level. While the PID and CID devices protect the cell against high temperatures and pressures caused by the cell's internal resistive heating, it is possible they could fail or that the cell could be heated by an external source, such as a nearby cell that is failing. The exhaust 
gas vent hole is designed to provide a predictable and repeatable location for the hot exhaust gasses to vent from the cell. If there were no vent hole, the cell casing could fail in any number of unpredictable locations, likely spewing hot gasses onto a nearby cell and potentially causing the nearby cell to fail as well.

Knowing the most likely location that a cell may vent exhaust gasses, the battery pack enclosure may be designed to evacuate these gasses outside of the battery pack and away from other critical structures. This helps to prevent the hot gasses from one cell heating another and causing thermal runaway of the entire pack.

Figure 3.2 is a cutaway of an 18650 form factor cell construction as produced by Panasonic. It shows the general location of the exhaust gas vent hole as well as the CID and PTC device.

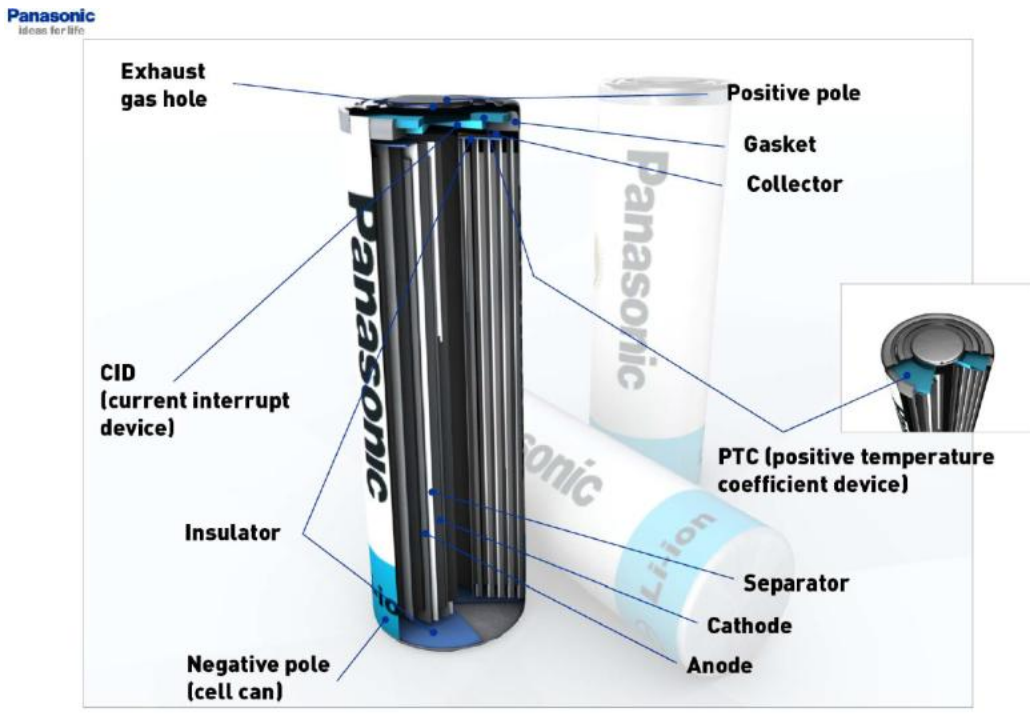

Figure 3.2: Panasonic 18650 cell cutaway (18) 


\subsubsection{Battery Pack Assembly}

Several cells must be assembled together in series to produce battery packs of the appropriate voltage. A survey of electric vehicles currently produced and summarized in Table 3.1 shows most automotive battery packs use a nominal voltage of between 350 to 370 volts. Once the voltage is reached, successive cells are added in parallel to produce a battery with the required current capability and energy storage capability. These individual groups of cells in parallel will be referred to as bricks. Groups of bricks assembled in series will be referred to as modules.

Table 3.1 Electric Vehicle Nominal Pack Voltage

\begin{tabular}{lccc}
\hline \hline Vehicle & \# of cells & Energy Storage $(\mathrm{kWh})$ & Pack Nominal Voltage \\
Tesla Roadster & 6831 & 53 & 366 \\
Tesla Model S & 7104 & 85 & 355 \\
BMW Mini E & 5088 & 35 & 355 \\
Nissan Leaf & 192 & 24 & 360 \\
Chevy Volt & 288 & 16 & 360 \\
AC Propulsion eBox & 5088 & 35 & 355 \\
\hline \hline
\end{tabular}

The individual lithium battery cell used the vehicles in the above table typically has a nominal voltage of 3.6 or 3.7 volts. It is usually capable of maximum charge of 4.2 volts and a minimum charge of 3.0 volts (18). In some applications, the maximum and minimum voltage excursions will be made closer to the nominal voltage to extend battery life. A typical rule of thumb is to limit battery state of charge to the middle $80 \%$ of total capacity for battery longevity (20). This means that the battery is charged to a maximum 
of $90 \%$ state of charge. It is then discharged to a minimum of $10 \%$ state of charge, leaving a useable charge of $80 \%$ in the middle.

\subsubsection{Battery Management System}

Due to the large numbers of individual cells in a battery pack, an effective battery management system (BMS) that monitors parameters at the individual cell or module level is critical to the safety of the assembled battery pack. The main feature of the BMS is to monitor individual module or brick voltages and temperatures as well as safeguard against voltage or temperature extremes. The BMS also performs battery pack balancing. Since the impedance of individual modules will never be exactly the same, it is likely that over several charge and discharge cycles, individual modules will no longer charge to the same voltage level. To ensure that the modules are all kept at the same voltage, the BMS will turn on resistors wired in parallel for any particular module that is at a higher voltage than the other modules. Ensuring that the battery is balanced is important for both safety and battery pack performance. If an unbalanced pack is charged to its maximum pack voltage, it is possible that an individual module could exceed maximum voltage limitations due to the unbalanced state of the battery pack, damaging the batteries and possibly creating a fire hazard. The opposite could also occur during battery discharging. These excursions outside of the cells operating voltage degrade the cells ability to store energy. Overtime, these excursions will reduce the energy storage potential of the battery (21).

\subsubsection{Battery Cell Selection}

In order to perform an aircraft layout, the battery parameters must first be defined. The key parameters concerning an electric airplane are energy density, power density, 
thermal management and safety. To understand current battery options available on the market, individual cells were examined as well as battery packaging methodologies currently used in modern electric automobiles.

Two commonly used shapes by electric vehicles are prismatic and cylindrical cells. They are compared below. It can be seen from the following table that from a cell perspective, Ithe 18650 cells offers far greater energy density than the prismatic cells. However, the prismatic cells can be purchased in larger sizes. The larger size of the prismatic cell simplifies packaging and integration design as well as reducing labor to assemble the battery pack. While the larger prismatic cells are cheaper to assemble into a battery pack, the large size of the individual prismatic cells mean that if a single cell fails, much more energy is released than if a single 18650 cell fails.

The performance of several prismatic and cylindrical battery cells is summarized below in Table 3.2. It can be seen that the cylindrical 18650 cell offers the best specific weight (energy density) compared to the other cylindrical and prismatic cells in Table 3.2. 
Table 3.2 Comparison of various prismatic and cylindrical battery cells

\begin{tabular}{|c|c|c|c|c|c|c|}
\hline Cell & Shape & Voltage & $\begin{array}{l}\text { Capacity } \\
\text { (amp-hr) }\end{array}$ & $\begin{array}{l}\text { Energy } \\
\text { (Wh) }\end{array}$ & $\begin{array}{l}\text { Weight } \\
\text { (lb) }\end{array}$ & $\begin{array}{l}\text { Specific Weight } \\
(\mathrm{Wh} / \mathrm{Lb})\end{array}$ \\
\hline $\begin{array}{c}\text { Panasonic } \\
\text { NCR18650B } \\
(18)\end{array}$ & Cylindrical & 3.6 & 3.35 & 12.06 & 0.1067 & 113 \\
\hline $\begin{array}{c}\text { Panasonic } \\
18650^{*}\end{array}$ & Cylindrical & 3.6 & 4.00 & 14.4 & 0.1067 & 135 \\
\hline $\begin{array}{c}\text { Panasonic } \\
\text { UR14500P } \\
(18)\end{array}$ & Cylindrical & 3.7 & 0.84 & 3.108 & 0.0462 & 67 \\
\hline $\begin{array}{c}\text { Panasonic } \\
\text { UF103450P } \\
\text { (18) }\end{array}$ & Prismatic & 3.7 & 2.00 & 7.4 & 0.0847 & 87 \\
\hline $\begin{array}{c}\text { Panasonic } \\
\text { UF495255ST } \\
\text { (18) }\end{array}$ & Prismatic & 3.8 & 1.87 & 7.106 & 0.07106 & 100 \\
\hline $\begin{array}{l}\text { Kokam } 216 \\
\text { Series (22) }\end{array}$ & Prismatic & 3.7 & 40 & 148 & 1.98 & 75 \\
\hline $\operatorname{AESC}(23)$ & Prismatic & 3.75 & 32.5 & 122 & 1.735 & 70 \\
\hline $\begin{array}{l}\text { GSYUAHA } \\
\text { LVP-10 (24) }\end{array}$ & Prismatic & 3.7 & 10 & 37 & 1.1 & 33.6 \\
\hline
\end{tabular}

\subsection{Existing Automotive Battery Pack Methods}

Now that technology has been explored for individual battery cells, the next step is to observe current battery pack designs. The electric automobile industry has made several advances in this area in recent years. In order to learn from these recent advances, the battery pack layouts of several electric automobiles are presented in the following sections.

\subsubsection{Nissan Leaf Battery Pack}

The Nissan Leaf is a fully battery electric vehicle with a EPA rated range of 84 miles (26). The battery cells and modules are built by Automotive Energy Supply 
Corporation (AESC) of Japan (23). The cells are prismatic in type and are assembled into modules of 4 cells, which are then installed in the larger battery back. The Nissan leaf is fairly unique among production electric automobiles in that it does not have any sort of active battery thermal management system. There is no forced air cooling or water cooling. This lack of thermal management is reported to be the cause of a number of complaints of reduced battery range by owners of vehicles in hot climates such as Arizona (27). The Nissan Leaf battery pack specifications are summarized below in Table 3.3.

Table 3.3 Nissan Leaf battery specs (23)

\begin{tabular}{lc}
\hline \hline Total Pack Capacity (kWh) & 24 \\
Pack Voltage & 360 \\
Number of Cells & 192 \\
Cell Type & Prismatic \\
Cell Supplier & AESC \\
Number of Modules & 48 \\
Module Layout & $2 \mathrm{P}-2 \mathrm{~S}$ \\
Module Spec Energy (Wh/lb) & 58 \\
Pack Layout & $1 \mathrm{P}-48 \mathrm{~S}$ \\
Thermal Management System & N/A \\
\hline \hline
\end{tabular}

\subsubsection{Chevrolet Volt Battery Pack}

The Chevrolet Volt is an extended range plug in hybrid electric vehicle. It is essentially an electric car with a small battery giving about 38 miles of range (28). After the battery is depleted, the gasoline engine is started to provide power for driving and charging the battery. 
The Volt's battery pack is rated for $16 \mathrm{kWh}$, but in an effort to extend battery life and increase safety Chevrolet only uses the middle $10.3 \mathrm{kWh}$ of this pack. In a further effort to increase longevity and safety, Chevrolet has a thermal management system that keeps variations in temperature across the entire battery pack to less than $2{ }^{\circ} \mathrm{C}$. The Volt's thermal management system consists of 144 aluminum fins sandwiched between every other of the 288 prismatic battery cells, providing cooling for one side of each cell. The fins consist of two aluminum plates with channels cut into them. The plates are then sealed together to form a fin, with the channels forming coolant passageways inside of the fin as shown in Figure 3.3. (29) The Chevrolet Volt battery pack specifications are summarized in Table 3.4.

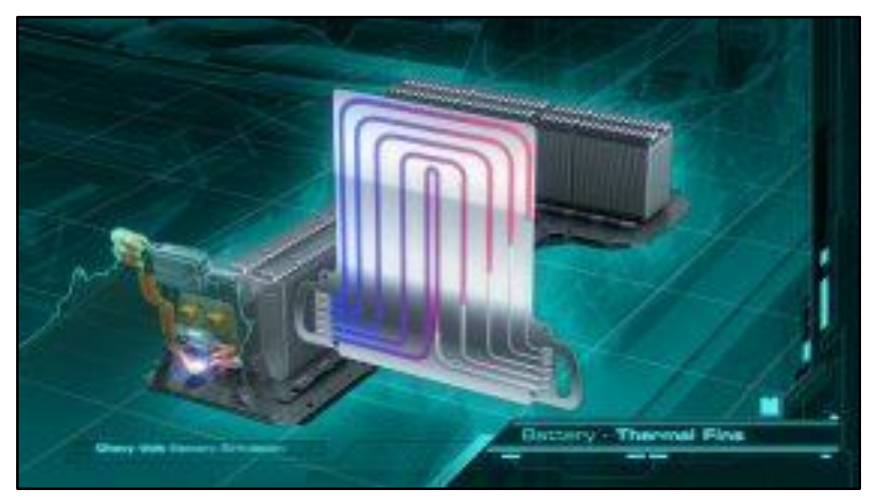

Figure 3.3: Depiction of aluminum cooling fin in the Chevy Volt battery pack (30) 
Table 3.4 Chevy Volt battery specs (29)

\begin{tabular}{lc}
\hline \hline Rated Capacity $(\mathrm{kWh})$ & 16 \\
Useable Capacity $(\mathrm{kWh})$ & 10.3 \\
Pack Voltage & 360 \\
Number of Cells & 288 \\
Cell Type & Prismatic \\
Cell Supplier & LG Chem \\
Number of Modules & 9 \\
Pack Weight (lbs) & 435 \\
Thermal Management & Liquid Cooling \\
Rated Spec Energy (Wh/lb) & 36.8 \\
Useable Spec Energy (Wh/lb) & 23.7 \\
\hline \hline
\end{tabular}

\subsubsection{AC Propulsion and the BMW Mini E Battery Pack}

The BMW Mini-E was a series of several hundred battery electric Mini Coopers that BMW produced as an electric vehicle test program. The Mini-E battery module was designed and manufactured for BMW by AC Propulsion of San Dimas, California (31). The BMW Mini-E was one of the few production electric vehicles to utilize forced air cooling. The forced air cooling leveraged the small size and circular cross section of the cylindrical cell by simply flowing cool air over the staggered cell configuration as illustrated in Figure 3.4. This is similar to a bank of tubes in cross flow of a heat exchanger, except that in the battery pack the tubes are the individual battery cells and are generating resistive heat. Table 3.5 summarizes the Mini-E battery pack specifications. 


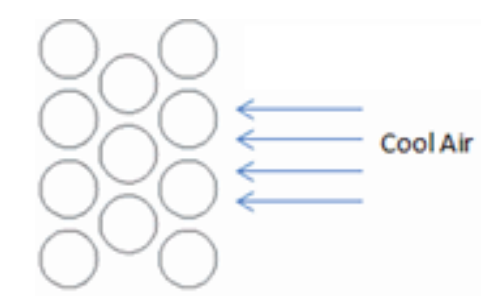

Figure 3.4: Forced air cooling illustration

Table 3.5 BMW Mini-E battery specs (20)

\begin{tabular}{lc}
\hline \hline Rated Capacity $(\mathrm{kWh})$ & 35 \\
Useable Capacity $(\mathrm{kWh})$ & 28 \\
Pack Voltage & 355 \\
Number of Cells & 5088 \\
Cell Type & Cylindrical 18650 \\
Cell Supplier & Molicel \\
Number of Modules & 24 \\
Module Layout & $53 \mathrm{P}-4 \mathrm{~S}$ \\
Module Spec Energy (Wh/lb) & 61.2 \\
Pack Weight (lbs) & 572 \\
Thermal Management System & Forced Air Cooling \\
\hline \hline
\end{tabular}

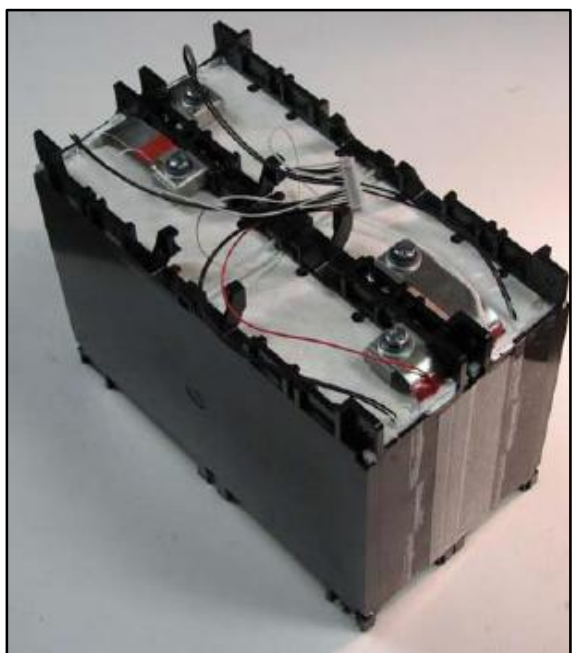

Figure 3.5: AC Propulsion Battery Module (32) 


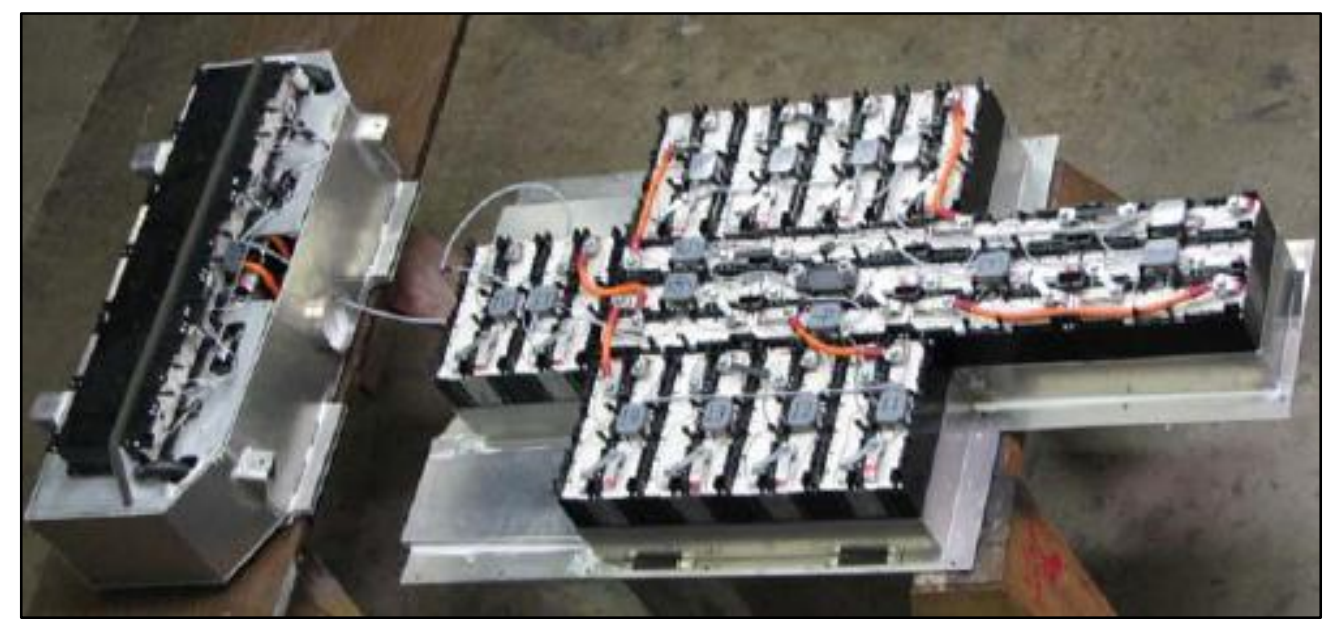

\section{Figure 3.6: AC Propulsion electric vehicle battery pack (32)}

The 18650 cells are assembled into AC Propulsion's battery modules, as shown in Figure 3.5, and then assembled into a complete electric vehicle battery pack, shown in Figure 3.6.

\subsubsection{Tesla Motors Battery Pack}

The battery pack in the Tesla Motors Model $\mathrm{S}$ is one of the few packs in a production electric automobile to utilize the 18650 cell form factor besides the Mini E. Tesla has a relatively advanced pack design consisting of liquid cooling for thermal management and numerous safeguards to prevent a single cell failure from causing an entire pack thermal runaway. These techniques are patented and therefore available for public scrutiny. The liquid cooling system consists of several liquid channels that snake their way through the staggered arrangement of the battery cells as shown in Figure 3.7. These liquid cooling channels allow the pack to be discharged at a higher continuous power level than the air cooled battery packs of the BMW Mini-E, but come at the expense of increased complexity and weight. In theory, liquid cooling also allows for more uniform 
temperature distribution across the pack. This allows for better temperature control of individual cells and better pack longevity.

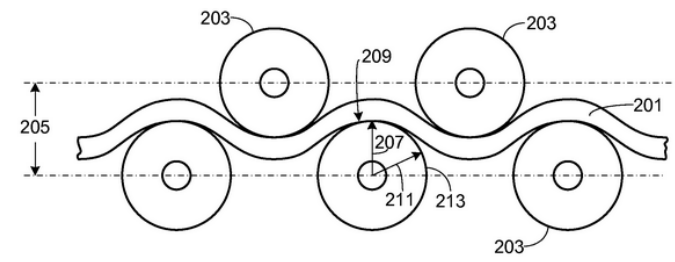

Figure 3.7: Tesla Motors' Battery Coolant Tubes (10)

Tesla attempts to mitigate the potential for a single cell failure to cause cascading failure in the rest of the pack through several methods. The first method consists of a specially designed electrical connection to electrically isolate any cell that experiences a venting situation and is shown in Figure 3.8. The connection from module buss to the individual cell is made by a thin wire. When the battery vent opens the thin wire is broken, electrically isolating the cell and preventing a short in a single cell from shorting the rest of the battery module (10).

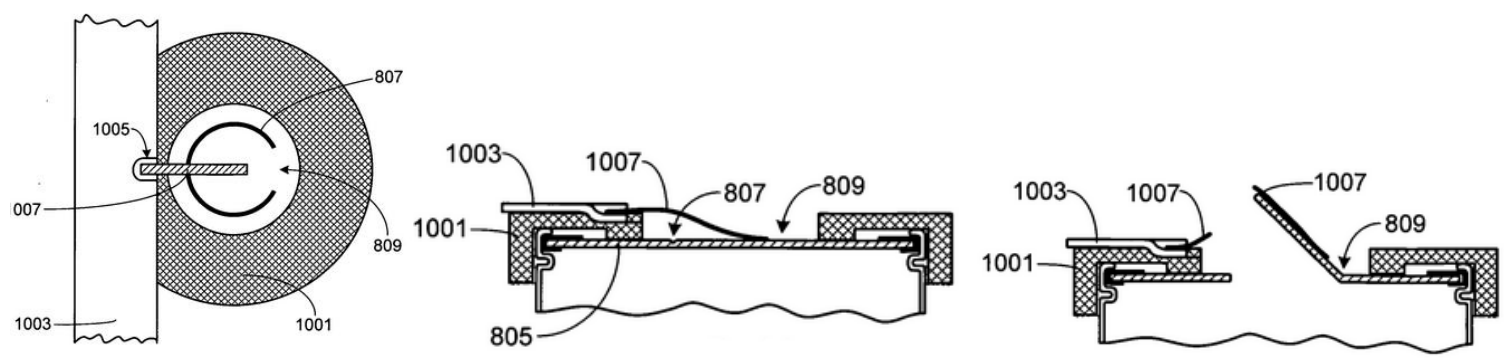

Figure 3.8: Tesla's cell disconnect design. (33)

Another critical safety component is Tesla's battery pack gas exhaust system. This system is designed to prevent the hot exhaust gas of a single cell from heating the neighboring cells. The gases are routed through channels in the pack that mix the hot exhaust gasses with cooler air while at the same time transferring the heat energy to the thermal mass of the rocker panels and other parts of the vehicle structure. At the same 
time the hot gas is kept away from other battery cells. The gasses are eventually exhausted to the ambient environment in a manner that does not put the passenger compartment of the vehicle at risk. The specifications for the Tesla Model S battery are summarized in Table 3.6.

Table 3.6 Tesla Model S battery specs

\begin{tabular}{lc}
\hline \hline Rated Capacity $(\mathrm{kWh})$ & 85 \\
Pack Voltage & 355 \\
Number of Cells & 7104 \\
Cell Type & Cylindrical 18650 \\
Cell Supplier & Panasonic \\
Number of Modules & 16 \\
Module Layout & $74 \mathrm{P}-6 \mathrm{~S}$ \\
Thermal Management System & Liquid Cooling \\
Pack Weight (lb) & 1323 \\
Pack Spec Energy (Wh/lb) & 64.2 \\
\hline \hline
\end{tabular}

\subsubsection{Boeing 787 Battery Design and Safety}

To demonstrate the results of not having a battery gas exhaust system, the Boeing Dreamliner's battery fire problem will be used. Recent well publicized events regarding battery fires on the Boeing 787 Dreamliner and the subsequent grounding of the entire 787 fleet brought attention to the potential hazards of lithium batteries on aircraft. The 787 carries two of the same lithium battery packs. One is used to start the auxiliary power unit during ground and flight operations while the other battery is used to power certain electrical systems on the ground and in the air. In January 2013 a battery fire on the ground followed one week later by a separate incident of an in-flight battery fire on a different airframe caused the FAA to ground the 787 fleet. The fleet remained grounded 
for three months until a new battery packaging system was devised and tested. During these fires a significant amount of smoke was present in the electronics bay and components nearby the battery were damaged. (34)

The original 787 battery design consisted of eight GS Yuasa LVP10-65 lithium battery cells in series for a nominal capacity of $2.2 \mathrm{kWh}$. These eight cells were sealed in an aluminum case with no active thermal management system to control cell temperature or an emergency venting system to exhaust hot gasses that could occur should a cell fail (34).
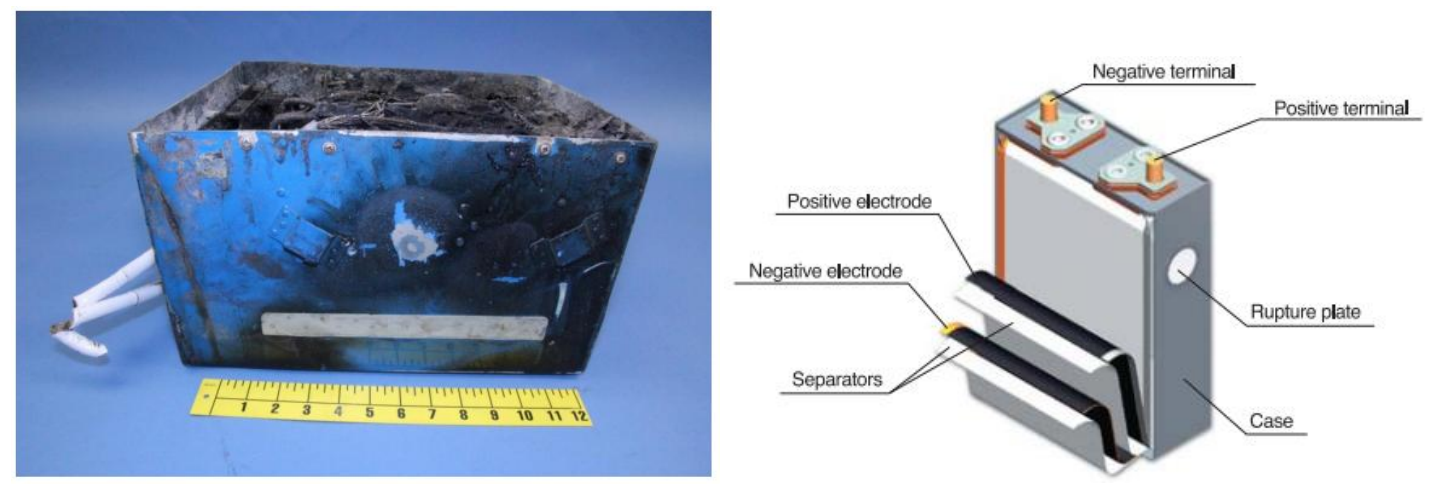

Figure 3.9: Scorch marks consistent with rupture plate location (34).

While the NTSB has not released a final report on the cause of the battery failures, the damage to the battery illustrated in the NTSB interim factual report lends some information into how the battery pack enclosure could have been designed differently to prevent a potentially catastrophic fire resulting from a single cell failure. The 787's battery enclosure did not contain any provision for exhausting hot gasses should a battery venting occur. Looking at the scorch marks on the incident battery case in Figure 3.9, it can be seen that scorch marks line up with the vent locations of the 
LBP10-65 battery cells, meaning that cells vented in the location they were designed to vent. A system could have been designed to exhaust these gases instead of trapping them in the battery enclosure. On the incident battery packs, instead of sending the hot gasses overboard, the hot gasses were retained within the battery enclosure. This likely promoted a thermal runaway event as the heat generated by the failure of one cell was absorbed by the remaining cells, causing successive cell failures. The large amount of heat generated by the failure of multiple cells eventually transferred through the aluminum case to the surrounding equipment in the aircraft's electronics bay.

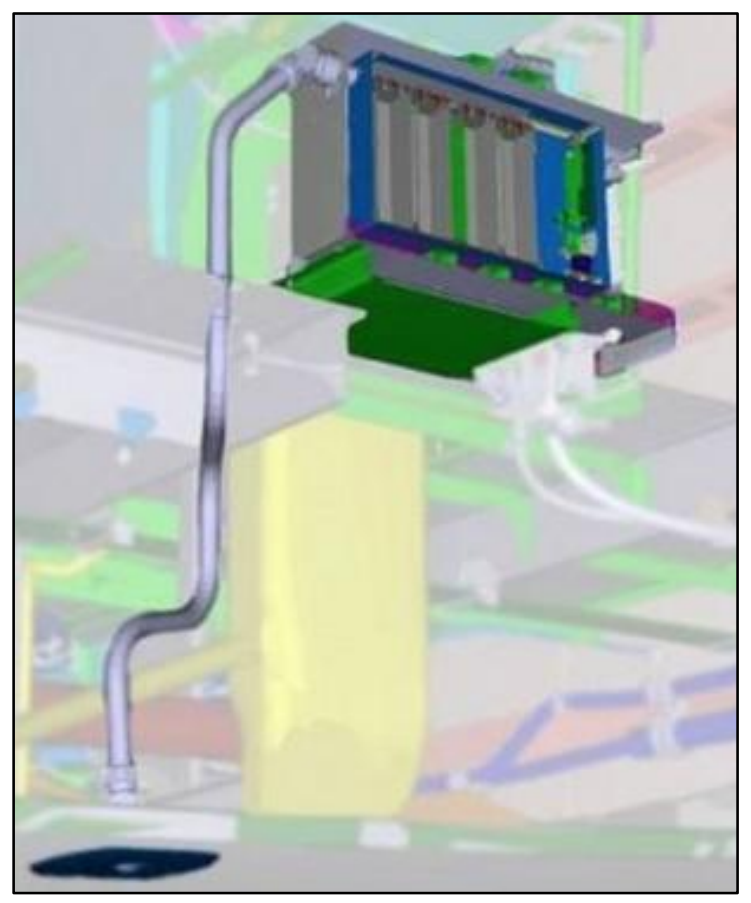

Figure 3.10: New battery enclosure with venting system (35).

To date no initial cause of the battery fires has been publically released (34). To return the 787 to service, Boeing devised a much more robust battery enclosure system that incorporated an exhaust gas venting system shown in Figure 3.10 and Figure 3.11 as well as insulation between individual battery cells. The venting system was designed so 
that if any cell vented, the gasses would be directed through a vent tube to the outside of the fuselage. The insulation prevented heat from being conducted from one cell to the next.

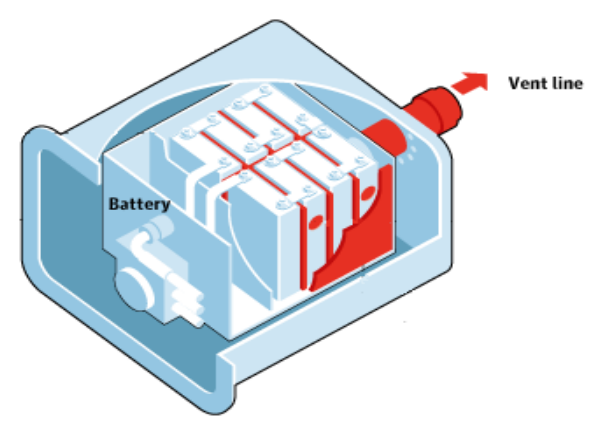

Figure 3.11: Diagram of Boeing's modified battery enclosure system. (35).

The success of these modification efforts were proven in a $3^{\text {rd }}$ battery fire experienced on the ground by a Japan Airlines 787 in January 2014, after the battery modifications had been made. In this instance, a single cell failed and vented hot exhaust gases. These gases were then directed overboard using the new vent system. The surrounding cells did not vent and the surrounding equipment in the electrical bay remained undamaged, proving the merits of developing a battery enclosure with provisions for ensuring safety in the event of a cell failure. (36)

Lessons learned from examining automotive packaging methodologies as well as the real world battery failures that occurred on the Boeing Dreamliner can be used to develop a list of requirements for a battery pack design. These requirements are presented later in section 3.4. The weight of the various automotive modules presented in the previous section can be combined with the weight of state of the art battery cells to produce energy density metrics. These metrics are presented in the following section. 


\subsection{Battery Energy Density for Design Study}

In order to develop an energy density to use for an electric aircraft layout, it is assumed that the modern Panasonic 18650 cells with a 4Ah capacity could be used in the BMW Mini E air cooled battery as well as the Tesla Model S water cooled battery. Both the Tesla Model S and BMW Mini E use the 18650 form factor cell. Since the form factor has been around for so many years, the internal battery chemistry has changed while the exterior casing has remained the same size. It should therefore be possible to utilize modern 18650 battery cells with modern cell chemistries in the Mini E and Model S battery modules. Substituting the modern 18650 Panasonic $4 \mathrm{Ah}$ cell into the above enclosures yields the following energy densities, summarized in Table 3.7.

\section{Table 3.7 Summary of energy densities}

\begin{tabular}{lc}
\hline \hline Pack Type & Wh/lb \\
\hline Cells Only & 114 \\
Air Cooled Modules & 99 \\
Liquid Cooled Modules & 67 \\
\hline \hline Note: The BMW and Tesla battery constructions are used \\
to determine overall cell and enclosure combined density.
\end{tabular}

In future sections, it will be shown that for a touring motor glider application, air cooling the batteries will be adequate. Therefore $99 \mathrm{Wh} / \mathrm{lb}$ will be used as battery energy density for the remainder of the design study. 


\subsection{Battery Design Requirements and Best Practices}

This chapter explored several features of a battery cell and battery module that serve to increase the safety of the battery pack and reduce the chance of a catastrophic failure. The following requirements will be used for future battery pack design in this thesis.

I. Battery Cell: The battery cell used in traction battery pack shall include the following safety features:

a. Positive Temperature Coefficient Device (PTC): Each cell shall have an integrated PTC device to restrict current flow in the event of a cell overtemperature event.

b. Current Interrupt Device (CID): Each cell shall have an integrated CID to electrically isolate the cell in the case of an over pressure event.

c. Vent: Each cell shall have an integrated venting device that ensures the cell will vent any exhaust gases at an known location.

II. Battery Module and Pack: The battery module or battery pack shall include the following features and design practices:

a. Emergency cell venting exhaust system: The battery module design shall allow any vented hot exhaust gases from a cell to pass overboard of the aircraft. The exhaust gas system shall not allow the hot exhaust gases to compromise other portions of the battery pack or any other critical system or structure of the aircraft.

b. Cell disconnect feature: The integration of an individual cell into the battery pack shall have a provision to electrically isolate that cell from the 
remainder of the battery pack should that cell experience a venting situation.

c. Battery Management System (BMS). The battery pack shall include a BMS that performs the following functions:

i. Cell balancing

ii. Temperature monitoring

iii. Voltage monitoring

iv. Current monitoring

d. The battery pack design shall tolerate a single cell failure without catastrophic battery pack failure.

e. The BMS shall ensure that any part of the battery pack does not exceed any temperature, voltage or current limits.

f. The battery pack shall be equipped with a heat rejection system capable of maintaining the battery temperature within the battery cell manufacturer's specified temperatures throughout all parts of the operating envelope. 


\section{CHAPTER 4: $\quad$ Electric Motor and Controller Technology}

\subsection{Motors}

Similar to the chapter on battery technology, existing electric motor and controller technology is explored in this chapter. The goals for this chapter are the following: Chapter Goals:

- Develop an understanding of the electric motor type or types most suited to an electric aircraft.

- Develop the following metrics for motor and controller performance

○ Continuous and peak power densities

○ Motor and controller efficiency

- Motor and controller cooling requirements

Two electric motor types were considered for the electric airplane application, brushless DC (BLDC) motors and AC induction motors. The basic principle for operation of both motors is that the magnetic field from the rotor interacts with the magnetic field produced by currents moving through the stator windings. The interaction of these magnetic fields produces a force which is responsible for the motor output torque. The principal

difference between the brushless DC motor and the AC induction motor is the method by which the magnetic fields in the rotor are produced. While the rotors are very different, the stators for a BLDC and AC induction motor are essentially the same. (37)

A brushless DC motor uses permanent magnets fixed to the rotor to create the rotor's magnetic field. The strength of the magnetic field of the rotor therefore cannot be changed during operation of the motor. The orientation of the magnetic field is based 
upon angular position of the rotor so a brushless DC motor controller requires a rotor angular position sensor. With information from the angular position sensor, the motor controller then varies the magnitude and polarity of the current in the stator in order to maintain a uniform output torque as the rotor's magnetic field rotates. (37)

The AC induction motor uses the currents moving through the stator windings to produce the rotor's magnetic field. There are no permanent magnets in an AC induction motor. The magnetic field in the stator windings induces a rotating magnetic field in the rotor. A voltage differential in the rotor is then produced that is proportional to the rotational frequency. This voltage differential produces a current and therefore a magnetic field in the rotor. The rotor's magnetic field then interacts with the stator's magnetic field to create the output torque. The difference in frequency between the rotor's magnetic field and the rotating magnetic field of the stator is known as the slip angle. By varying the slip angle, the motor controller can vary the magnetic field in the rotor and therefore the torque produced. (37)

An AC induction motor will always have lower peak efficiencies than a BLDC motor due to the resistive heating losses present in the AC induction rotor as a result of the current flowing in the rotor. These losses do not occur in the BLDC motor because there is no current flow in the rotor since the magnetic field is created by permanent magnets. However, the ability for the AC induction motor to optimize the magnetic field in the rotor for a broad range of operating conditions can give the AC induction motor an overall efficiency advantage in certain applications with broad torque and speed requirements. The ability to reduce the strength of the rotor's magnetic field in an AC induction motor reduces losses from eddy currents and hysteresis when the AC induction 
motor is operating off its peak efficiency point. This ability to produce better efficiencies over a broad range of speeds and torque levels is why some high performance electric automobiles such as the Tesla Model S and General Motors EV1 used AC induction motors (37). An automobile is typically operating over a varying range of speed and load conditions. An electric aircraft is different from a ground vehicle. Its motor will spend the majority of its time at the same speed and power setting. The electric aircraft can therefore benefit from the increased peak point efficiency of the brushless DC motor.

In an $\mathrm{AC}$ induction motor, both the rotor and the stator generate resistive heat since both have current flowing in them. Rejecting heat from the rotor is difficult since it is surrounded by the already hot stator. The amount of time the AC induction motor can operate at peak power is therefore typically limited by rotor thermal limits. (38) A brushless DC motor does not generate any heat in the rotor since there is no current flow in the rotor. It is therefore easier to operate a brushless DC motor at high current levels without exceeding the temperature limits of various components.

To leverage the relatively steady state operation of an aircraft in cruise flight and to minimize cooling drag, the brushless DC motor seems to be the best selection for an electric aircraft. Several companies build production motors for aircraft applications and some custom designs have been developed. A survey of these motors was performed to develop power to weight relationship and is summarized in Table 4.1. 
Table 4.1 Electric aircraft motor data (39)

\begin{tabular}{|c|c|c|c|c|c|c|c|}
\hline Manufacturer & Model & $\begin{array}{c}\text { Continuous } \\
\text { Power } \\
(\mathrm{kW})\end{array}$ & $\begin{array}{l}\text { Peak } \\
\text { Power } \\
(\mathrm{kW})\end{array}$ & $\begin{array}{l}\text { Weight } \\
\text { (lb) }\end{array}$ & $\begin{array}{c}\text { Continuous } \\
\text { Spec } \\
\text { Power } \\
(\mathrm{kW} / \mathrm{lb}) \\
\end{array}$ & $\begin{array}{c}\text { Peak } \\
\text { Spec } \\
\text { Power } \\
(\mathrm{kW} / \mathrm{lb}) \\
\end{array}$ & $\begin{array}{l}\text { Max } \\
\text { RPM }\end{array}$ \\
\hline \multirow{2}{*}{ Enstroj } & Emrax 207 & 35 & 70 & 20 & 1.8 & 3.6 & 5000 \\
\hline & Emrax 228 & 38 & 100 & 26 & 1.4 & 3.8 & 4000 \\
\hline \multirow{2}{*}{ Flytec } & HPD-10 & 10 & 12 & 8 & 1.2 & 1.5 & 2300 \\
\hline & HPD-13.5 & 14 & 17 & 10 & 1.3 & 1.6 & 2300 \\
\hline \multirow{2}{*}{ FES } & LAK M100 & 20 & 23 & 16 & 1.2 & 1.4 & 4500 \\
\hline & SIL-M100 & 20 & 23 & 18 & 1.1 & 1.3 & 4500 \\
\hline \multirow{4}{*}{ JOBY } & JM15 & 8 & 13 & 4 & 2.1 & 3.2 & 9000 \\
\hline & JM1 & 13 & 20 & 6 & 2.2 & 3.3 & 9000 \\
\hline & $\mathrm{JM} 2 \mathrm{~S}$ & 11 & 16 & 7 & 1.4 & 2.1 & 3500 \\
\hline & JM2 & 14 & 21 & 9 & 1.6 & 2.4 & 3500 \\
\hline \multirow{2}{*}{ Lynch } & $\begin{array}{l}\text { LEM170- } \\
\text { D127 }\end{array}$ & 7 & 21 & 19 & 0.4 & 1.1 & 3720 \\
\hline & $\begin{array}{c}\text { LEM200- } \\
\text { D135RAGS }\end{array}$ & 18 & 36 & 24 & 0.7 & 1.5 & 4400 \\
\hline \multirow{5}{*}{ Rotex } & RET 30 & 10 & 12 & 9 & 1.1 & 1.3 & 2500 \\
\hline & RET 60 & 20 & 25 & 15 & 1.3 & 1.6 & 4500 \\
\hline & REX 30 & 15 & 18 & 11 & 1.3 & 1.6 & 3600 \\
\hline & REX 50 & 20 & 25 & 18 & 1.1 & 1.4 & 2200 \\
\hline & REX 90 & 60 & 60 & 37 & 1.6 & 1.6 & 2300 \\
\hline \multirow{2}{*}{ Sineton } & A37K154 & 37 & 52 & 35 & 1.1 & 1.5 & 4000 \\
\hline & A60K284 & 60 & 90 & 57 & 1.0 & 1.6 & 4000 \\
\hline \multirow[t]{2}{*}{ YASA } & 400 & 85 & 90 & 48 & 1.8 & 1.9 & 8000 \\
\hline & 750 & 75 & 100 & 59 & 1.3 & 1.7 & 4000 \\
\hline \multirow{4}{*}{ Yuneec } & $\begin{array}{c}\text { Power } \\
\text { Drive } 10\end{array}$ & 4 & 12 & 13 & 0.3 & 0.9 & 2400 \\
\hline & $\begin{array}{c}\text { Power } \\
\text { Drive } 24\end{array}$ & 12 & 22 & 22 & 0.6 & 1.0 & 2200 \\
\hline & $\begin{array}{c}\text { Power } \\
\text { Drive } 40\end{array}$ & 24 & 40 & 42 & 0.6 & 1.0 & 2450 \\
\hline & $\begin{array}{c}\text { Power } \\
\text { Drive } 60 \\
\end{array}$ & 37 & 57 & 66 & 0.6 & 0.9 & 2400 \\
\hline
\end{tabular}


The Enstroj Emrax motors offer exceptional power to weight ratio when compared to the other motors available on the market. They are available in air or liquid cooled versions and are specifically designed to support axial thrust loads from a propeller as shown in Figure 4.2. A typical aircraft propeller turns at 2000-3000 RPM during cruise, and the Enstroj motors are capable of operating with $96 \%$ efficiency at their maximum rated continuous torque values and typical propeller rotational speeds as illustrated in the efficiency map of Figure 4.1.

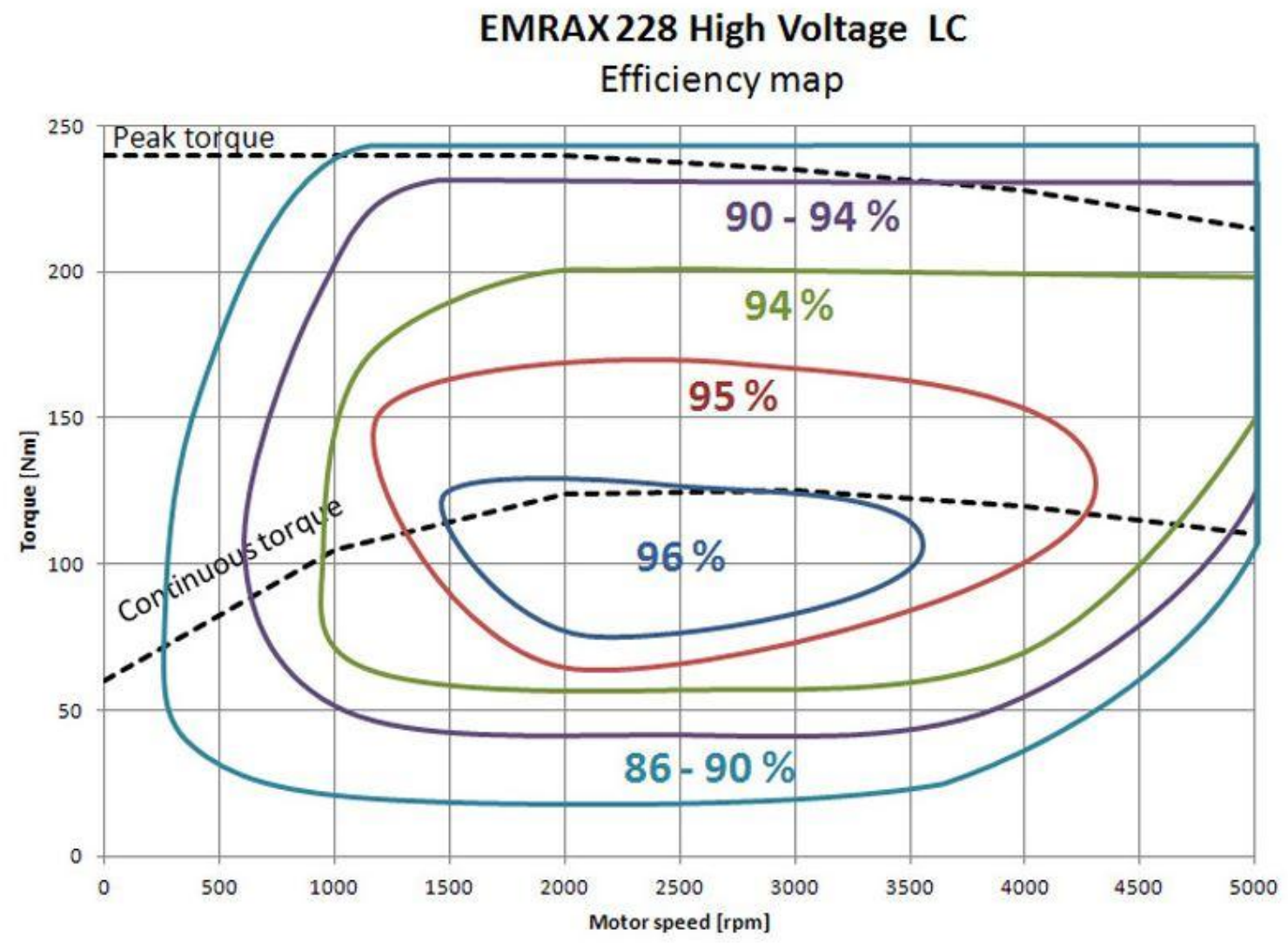

Figure 4.1: Enstroj Emrax 228 efficiency plot (40) 


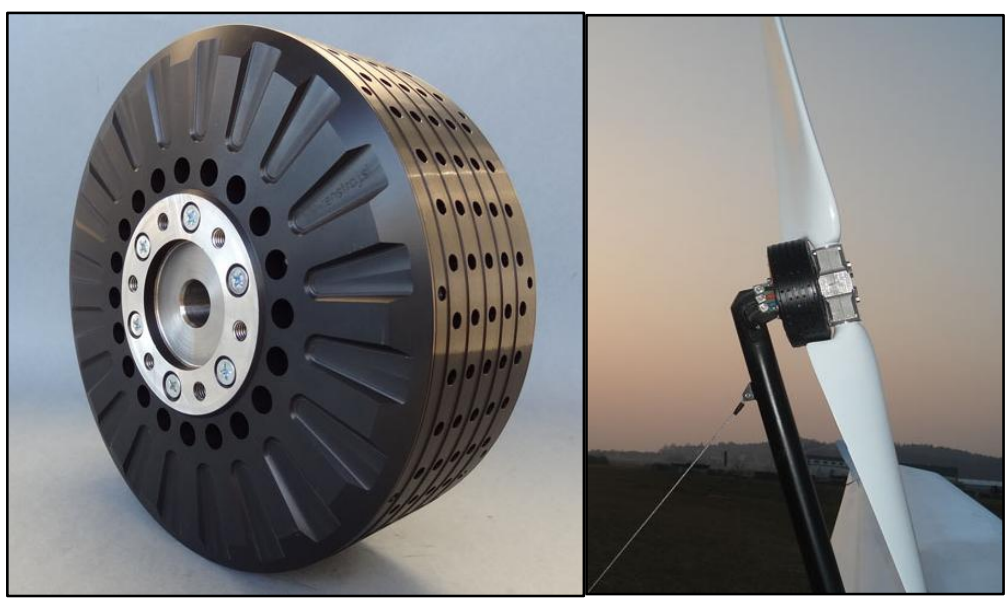

Figure 4.2: Enstroj Emrax 228 Outrunner Motor

\subsection{Controllers}

There are several motor controllers available on the market. They are relatively small in both volume and weight when compared to the electric motors they will be driving. Data for various controllers on the market are summarized below in Table 4.2.

Table 4.2 Controller data

\begin{tabular}{|c|c|c|c|c|c|c|c|c|}
\hline Manuf. & Model & $\begin{array}{c}\text { Cont } \\
\text { Powe } \\
\text { r } \\
(\mathrm{kW})\end{array}$ & $\begin{array}{c}\text { Peak } \\
\text { Power } \\
(\mathrm{kW})\end{array}$ & $\begin{array}{l}\text { Weight } \\
\text { (lb) }\end{array}$ & $\begin{array}{c}\text { Cont } \\
\text { Spec } \\
\text { Power } \\
(\mathrm{kW} / \mathrm{lb})\end{array}$ & $\begin{array}{c}\text { Peak } \\
\text { Spec } \\
\text { Power } \\
(\mathrm{kW} / \mathrm{lb})\end{array}$ & $\begin{array}{c}\text { Max } \\
\text { Bus } \\
\text { Voltage }\end{array}$ & $\begin{array}{l}\text { Cooling } \\
\text { Method }\end{array}$ \\
\hline $\begin{array}{l}\text { Unitek } \\
(41)\end{array}$ & $\begin{array}{c}\text { BAMO } \\
\text { D3 }\end{array}$ & 72 & 144 & 15 & 4.8 & 9.6 & 400 & Liquid \\
\hline $\begin{array}{l}\text { Tritium } \\
(42)\end{array}$ & $\begin{array}{c}\text { Wave } \\
\text { Sculptor } 200\end{array}$ & 76 & 165 & 18.7 & 4.1 & 8.8 & 450 & Liquid \\
\hline $\begin{array}{l}\text { Piktron } \\
\text { ik (43) }\end{array}$ & SAC50 & 110 & 140 & 28.6 & 3.8 & 4.9 & 370 & Liquid \\
\hline $\begin{array}{l}\text { Yuneec } \\
(44)\end{array}$ & $\begin{array}{c}\text { Power Drive } \\
40\end{array}$ & 24 & 46.6 & 42 & 0.6 & 1.1 & 150 & $\begin{array}{l}\text { Heat } \\
\text { Sink }\end{array}$ \\
\hline
\end{tabular}



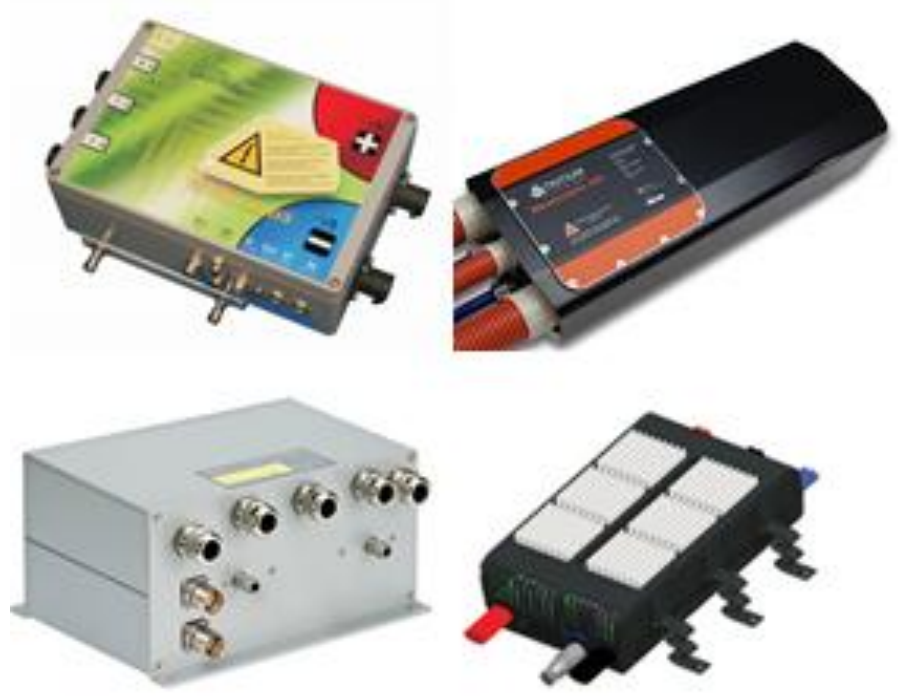

Figure 4.3: Four available motor controllers. (41), (42), (43), (44)

The most power dense motor controllers require liquid cooling in order to achieve their continuous and peak power ratings. Fortunately the weight of the liquid cooling system is relatively small compared to a water cooled internal combustion engine. For example Tritium recommends the components in Table 4.3 for use in a cooling system.

Table 4.3 Liquid cooling system components (42)

\begin{tabular}{lccc}
\hline \hline Component & Make and Model & Dimensions & Weight \\
Radiator & Koolance HX-1020 & $4.7 " x 15.6 " x 1.2^{\prime \prime}$ & $1.75 \mathrm{lb}$ \\
Pump & Koolance PMP-400 & $2.5 " \mathrm{~b} 2.5^{\prime \prime} \times 1.5 "$ & $0.44 \mathrm{lb}$ \\
Coolant & water based & 0.37 gallons & $3.1 \mathrm{lbs}$ \\
\hline \hline
\end{tabular}

The total weight of the cooling system is 5.3 pounds neglecting the reservoir and tubing. 
The efficiency of the controller depends on input bus voltage and the controller output voltage and current. The output voltage current is directly related to the desired torque and speed of the electric motor. Using the following efficiency plot in Figure 4.4 as a reference, it is assumed for initial airframe comparisons that the controller can be operated in a manner that produces $96 \%$ or greater efficiency during cruise and takeoff power. More detailed analysis will be performed for the final airframe integration in later sections.

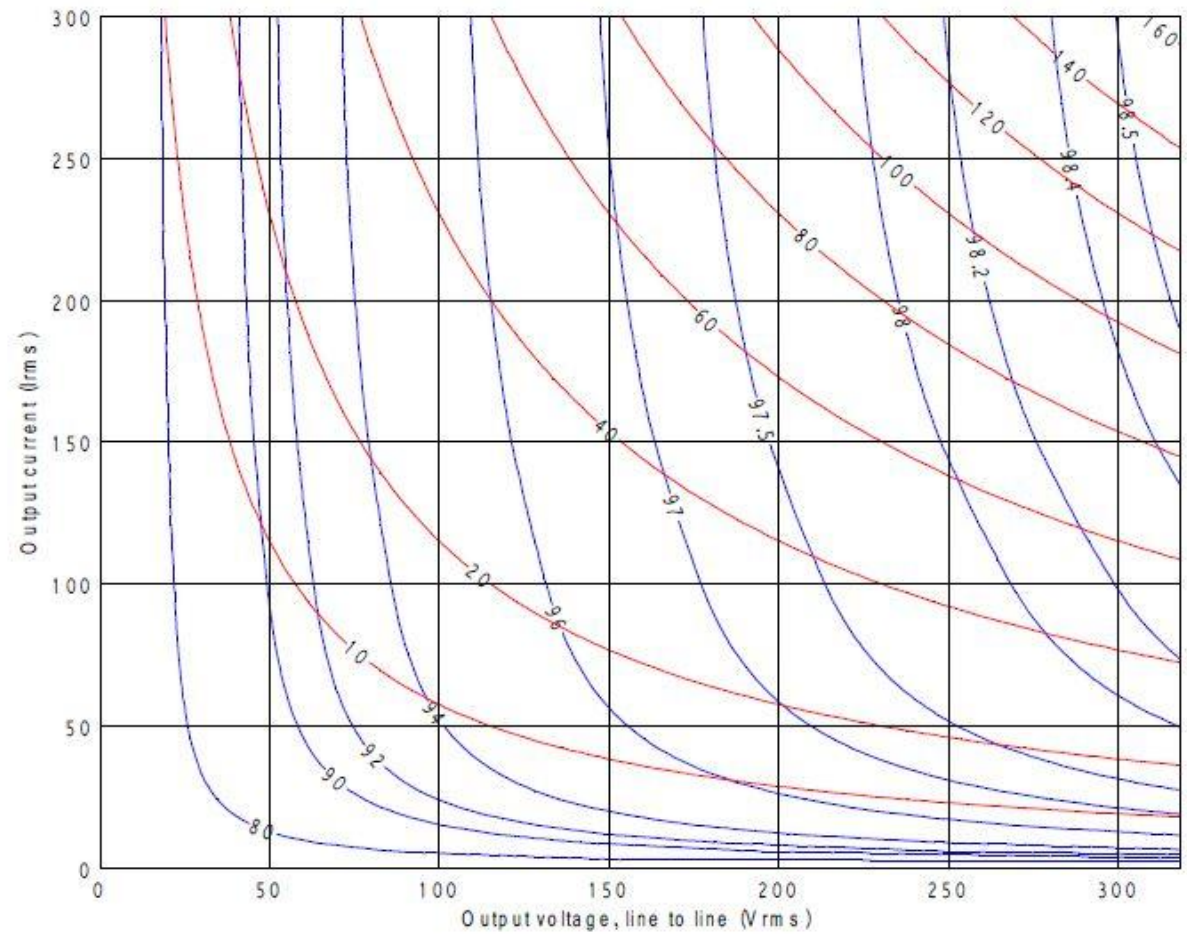

Figure 4.4: Tritium WaveSculptor 200 efficiency plot for a 450 VDC bus (42) 


\subsection{Motor and Controller Requirements}

The motor selected shall have the following characteristics:

- Brushless DC motors will be used for higher peak point efficiency and better cooling properties.

- The motor and controller shall be selected such that cruise power settings are below the continuous power limits for both devices.

- The motor and controller shall be capable of an adequate rate of climb at gross weight under continuous power limits

- The motor and controller shall be selected to operate at peak efficiency during cruise flight but still make the required peak power for takeoff.

- The motor shall be capable of turning a propeller at an appropriate speed so as not to require a gear reduction box.

\subsection{Motor and Controller Metrics}

The metrics presented in the following Table 4.4 are a summary of the information explored in this chapter. These metrics will be used for future airframe design studies.

\section{Table 4.4 Motor and Controller Metrics}

\begin{tabular}{cc}
\hline \hline Motor Peak Power Density & $3.8 \mathrm{~kW} / \mathrm{lb}$ \\
Motor Continuous Power Density & $1.4 \mathrm{~kW} / \mathrm{lb}$ \\
Motor Efficiency & $96 \%$ \\
Controller Peak Power Density & $9.6 \mathrm{~kW} / \mathrm{lb}$ \\
Controller Continuous Power Density & $4.8 \mathrm{~kW} / \mathrm{lb}$ \\
Controller Efficiency & $96 \%$ \\
\hline \hline
\end{tabular}




\section{CHAPTER 5: Rubber Component Concept}

A concept used in the aerospace industry is that of the "rubber engine." The rubber engine simply means that certain performance parameters of interest for an engine can be scaled for various applications. It is typically used in conceptual design before an actual powerplant has been specified. For example, an engineer designing a new aircraft could scale the power to weight ratio of existing jet engines to determine what a newly designed jet engine might weigh that meets the required power levels for a new aircraft design. The idea is that the engineer is assuming that an existing powerplant technology could be manipulated and shaped like rubber to conform to the requirements of the conceptual aircraft design.

For this thesis, the "rubber engine concept" is extended to a "rubber component concept" for the motor, controller and batteries. It is assumed that the energy or power densities explored in the battery and motor chapters can be scaled linearly. This enables an estimation of the weight of a battery electric propulsion system for different airframes and those airframes' differing power and energy requirements. The rubber component properties for batteries, motors and controllers used for future aircraft performance analysis are produced below in Table 5.1. 
Table 5.1 Rubber component properties for battery, motor and controller

\begin{tabular}{cc}
\hline \hline Battery Energy Density & $99 \mathrm{Wh} / \mathrm{lb}$ \\
Motor Peak Power Density & $3.8 \mathrm{~kW} / \mathrm{lb}$ \\
Motor Continuous Power Density & $1.4 \mathrm{~kW} / \mathrm{lb}$ \\
Motor Efficiency & $96 \%$ \\
Controller Peak Power Density & $9.6 \mathrm{~kW} / \mathrm{lb}$ \\
Controller Continuous Power Density & $4.8 \mathrm{~kW} / \mathrm{lb}$ \\
Controller Efficiency & $96 \%$ \\
\hline \hline
\end{tabular}




\section{CHAPTER 6: Airframe Performance Analysis}

Many different types of aircraft have been produced over the last 100 years of flight. When contemplating converting an existing airframe from reciprocating internal combustion to battery electric power, an early question becomes "Which category of aircraft is best suited to battery electric power?" Now that sizing metrics have been developed in previous chapters for the various components in an electric propulsion system, a high level performance analysis can be developed for various airframes to understand how several different types of aircraft might perform if converted to battery electric power. The results of this analysis can then be used to select a reference aircraft for future conceptual design work.

Chapter goals:

- Evaluate the thrust power required to maintain level flight at different speeds for various aircraft.

- Size a battery electric propulsion system for each airframe based upon the metrics developed for batteries, motors and controllers in the previous chapters.

- Calculate predicted endurance and range of the various airframes when converted to battery electric propulsion for a specified mission profile.

- Decide on a airframe to use as a reference airframe for future design work. 


\subsection{Airframe Selection}

From a development cycle risk reduction standpoint, the least risky method to create a successful electric aircraft is one that uses the least amount of developing technologies. Using a mature, proven airframe will eliminate numerous challenges encountered during construction and flight test when compared to the alternative of developing a clean sheet airframe design. This will allow the development team to focus on vetting the electric drive system technology. Once an electric aircraft based on an existing airframe has been completed and the electric propulsion system proven effective, a clean sheet airframe design can be performed as a second generation design study. The clean sheet airframe can be designed to optimally integrate the electric propulsion system. This could include a distributed electric propulsion system consisting of several small propulsive units located in the wings or electrically driven landing gear for more efficient taxi and takeoff. This thesis focuses only on converting an existing airframe from internal combustion to battery electric power.

\subsection{Airframe requirements and feasibility evaluation}

The energy densities of current battery technology limits the range of an electric aircraft. It will likely not be practical to take a long distance cross country trip in an electric aircraft due to the limited range compared to gasoline powered aircraft. Initial electric aircraft will likely be used for shorter duration local flights. These flights could be for local sightseeing or for flight training. For flight training, the electric airplane must be able to carry two passengers, but since all of the flights are local, no space or weight allowance for baggage or cargo needs to be made. For this thesis, an allowance was made for two $190 \mathrm{lb}$ adults, or $380 \mathrm{lbs}$ total and no baggage. Since the flights are local, time 
aloft, or endurance, is valued more highly over distance traveled, or range. Therefore the most feasible airframe will be determined to be the aircraft with the greatest endurance that can carry a minimum of $380 \mathrm{lbs}$ of people. The typical pilot training flight is between 1.0 to 1.5 hours, so a feasible airplane must have at least 1.5 hours of endurance with appropriate reserves. In summary, a feasible airplane will be considered one that meets the following requirements in Table 6.1.

Table 6.1 Aircraft requirements

\begin{tabular}{cc}
\hline \hline \# of Passengers & 2 \\
Combined Passenger Weight & $380 \mathrm{lbs}$ \\
Minimum endurance & 1.5 hours with reserve \\
\hline \hline
\end{tabular}

\subsection{Electric Propulsion System for various Airframes}

To compare various airframe types, a concept electric propulsion system was outlined for several existing airframes originally built with internal combustion engines. To determine the weight available for an electric propulsion system, the installed weight of the internal combustion engine and associated systems was added to the useful load of the airframe. An allowance was then made for $380 \mathrm{lbs}$ of pilot and passenger. The remaining useful load could then be used to size an electric propulsion system.

$$
\begin{aligned}
& \text { Electric Propulsion System Max Weight }= \\
& \text { Usefull Load + ICE installed weight }-(\text { Pilot }+ \text { Pass. })
\end{aligned}
$$

The motor and controller were sized to provide the same peak power level as the originally equipped internal combustion engine. This ensures that an electric version of an airplane would meet the performance requirements of FAR Part 23. 
For example, a Beechcraft Bonanza model 35 has a useful load of 1050 lbs. The original internal combustion engine has a weight of $507 \mathrm{lbs}$. Adding the useful load and the internal combustion engine weight, but subtracting $380 \mathrm{lbs}$ the combined passenger weight gives a total allowable electric propulsion system weight of $1177 \mathrm{lbs}$. An example calculation is shown below.

\begin{tabular}{lc} 
Useful Load & $+1050 \mathrm{lb}$. \\
Internal Combustion Weight & $+507 \mathrm{lb}$. \\
Combined Passenger Weight & $-380 \mathrm{lb}$. \\
\hline Allowable Electric Propulsion Weight & $+1177 \mathrm{lb}$.
\end{tabular}

The combined weight of the electric motor, controller and batteries must weigh no more than 1177 pounds in a conversion of the Beechcraft Bonanza to battery electric power.

\subsection{Drag, Thrust Power and Traction Battery Drain}

In order to predict range, the power required to fly at various speeds must be estimated. The power required is a function of the airframe drag at a given speed. An airframe's total drag is the sum of the parasite drag of the fuselage, protuberances and wings as well as the induced drag produced by the wing flying at various angles of attack. Roskam (45) provides a method of estimating an airframe's drag coefficient at various cruise speeds using the following equation.

$$
C_{D}=C_{D O}+\frac{C_{L}^{2}}{\pi * A R * e}
$$

Where:

The parasitic drag coefficient component: $\quad C_{D O}=\frac{f}{S}$ 
The induced drag coefficient: $\quad \frac{C_{L}^{2}}{\pi * A R * e}$

Coefficient of lift: $\quad C_{L}=\frac{\text { Lift }}{0.5 * \rho * v^{2} * S}$

$\rho:$ Density of air

V: True Airspeed

f: equivalent parasitic area

S: Wing area

$$
A R=\frac{b^{2}}{S}=\frac{\text { Wingspan }^{2}}{\text { Wing Area }}
$$

e: Oswald Efficiency Factor

Roskams (45) and Black (46) provide the following drag data in Table 6.2 for several aircraft:

Table 6.2 Data required for calculating aircraft drag

\begin{tabular}{lccccccc}
\hline \hline Variable & $\begin{array}{c}\text { Cessna } \\
150\end{array}$ & $\begin{array}{c}\text { Cessna } \\
172\end{array}$ & $\begin{array}{c}\text { Cessna } \\
180\end{array}$ & $\begin{array}{c}\text { Beechcraft } \\
\text { Bonanza 35 }\end{array}$ & $\begin{array}{c}\text { Rutan } \\
\text { Long } \\
\text { EZ }\end{array}$ & $\begin{array}{c}\text { Lancair } \\
235\end{array}$ & $\begin{array}{c}\text { Vans } \\
\text { RV-4 }\end{array}$ \\
\hline $\mathrm{f}\left(\mathrm{ft}^{2}\right)$ & 5.4 & 6.0 & 4.1 & 3.3 & 2.0 & 1.2 & 2.3 \\
$\mathrm{~S}\left(\mathrm{ft}^{2}\right)$ & 160.0 & 174.0 & 174.0 & 181.0 & 95.5 & 76.0 & 110.0 \\
$\mathrm{e}$ & 0.77 & 0.77 & 0.75 & 0.82 & 0.93 & 0.94 & 0.96 \\
Span (ft) & 33.3 & 36.1 & 35.8 & 32.8 & 26.1 & 23.4 & 23.0 \\
Aspect Ratio & 6.9 & 7.5 & 7.4 & 6.0 & 8.1 & 7.2 & 4.8 \\
MTOW (lb) & 1600 & 2450 & 2800 & 3650 & 1325 & 1400 & 1500 \\
\hline \hline
\end{tabular}

Using the above data, aircraft drag force for any speed can be computed using the following equation:

$$
\text { Force }_{D}=\frac{1}{2} \rho v^{2} A C_{D}
$$


Where $\mathrm{A}$ is the wing area of the aircraft. The required thrust power can then be calculated using:

$$
\text { Thrust Power }=\left(\text { Force }_{D}\right) *(\text { Velocity })
$$

The data in Table 6.2 was not readily available for a touring motor glider. For the Pipistrel Sinus motor glider, the drag data was taken from the drag polar graph provided in the Sinus Flight Manual (47) and reproduced below in Figure 6.1. In level flight, the lift required is the same as the weight of the aircraft. Assuming the Pipistrel Sinus to be operated at gross weight, the lift force is therefore known. Then for any speed of interest, the $\mathrm{L} / \mathrm{D}$ ratio (lift to drag ratio) can be read from the drag polar chart below. The drag force on the aircraft can then be calculated from the known lift and the L/D ratio.

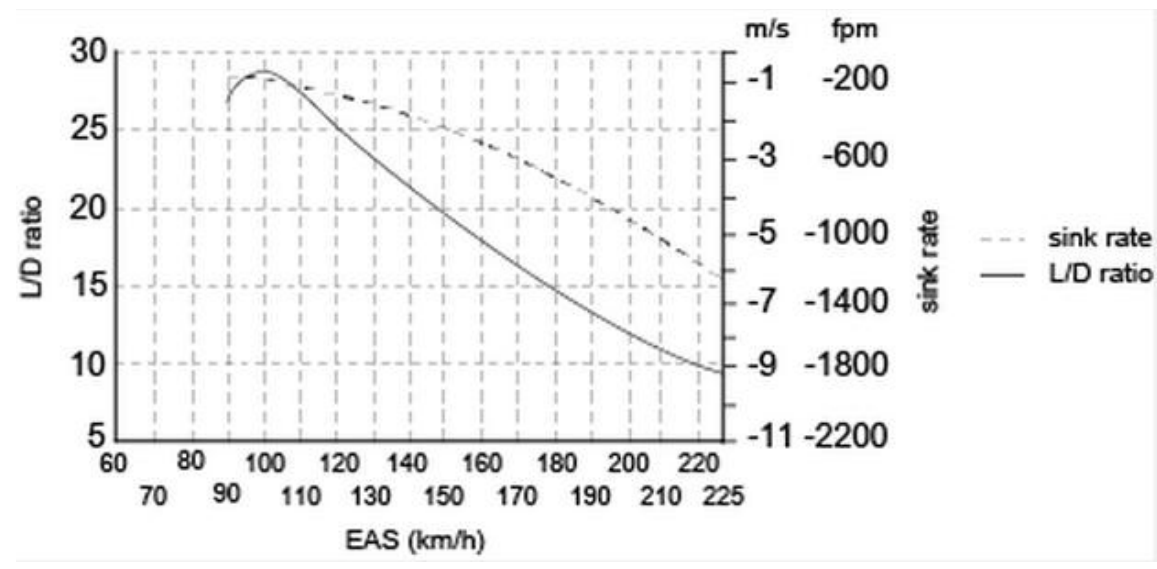

Figure 6.1: Pipistrel Sinus Drag Polar

Using the drag data Roskams and the drag polar for the Pipistrel Sinus, the required thrust power for various aircraft can be calculated for any airspeed. Figure 6.2 is a plot of the required thrust power for various aircraft at their published gross weight. 


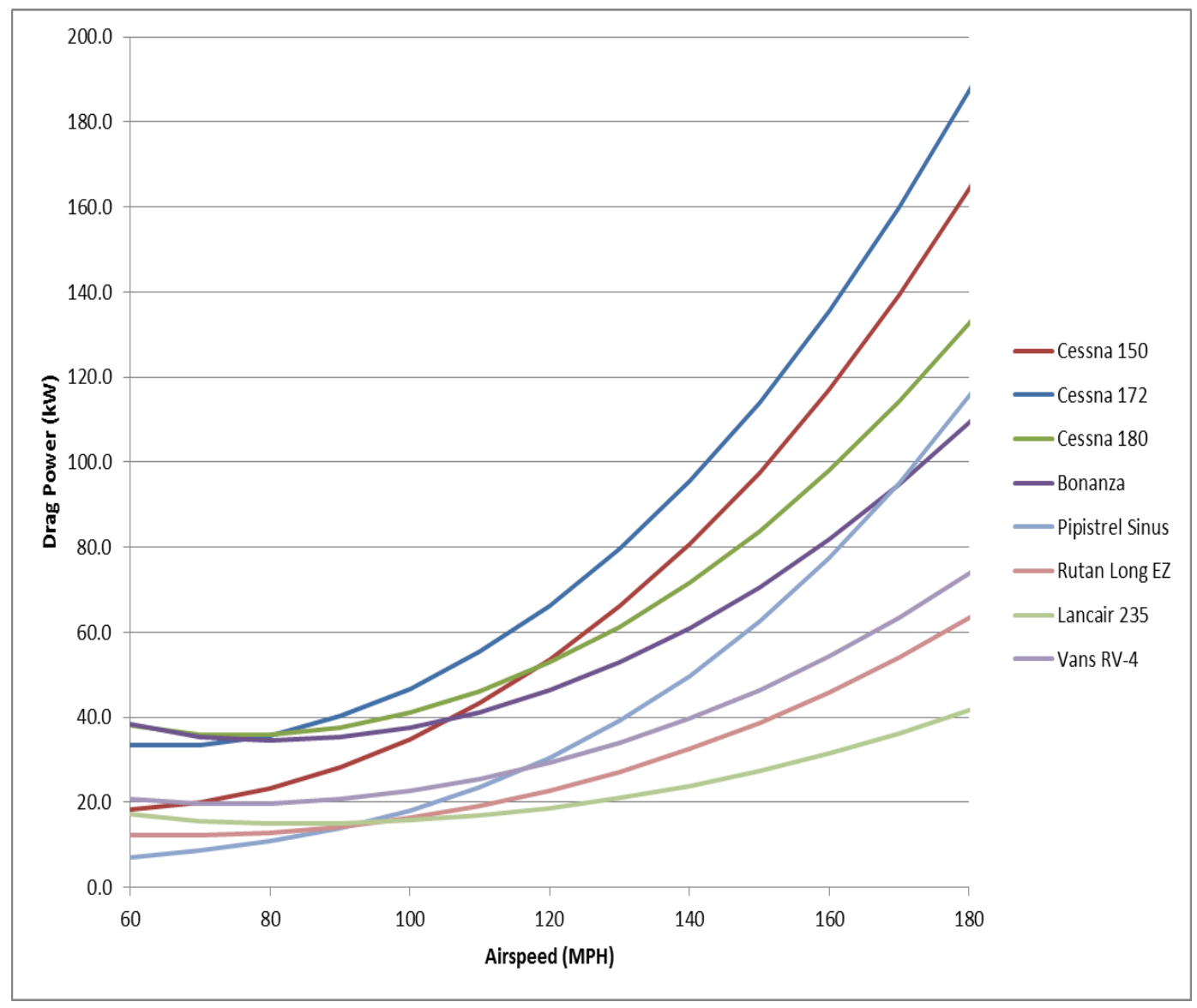

Figure 6.2: Required thrust (drag) power in kilowatts for various airspeeds at sea level

While the thrust power is now known for various aircraft, this does include various system efficiencies. The power draw from the batteries must be known in order to develop a performance profile for the aircraft that includes range and endurance. The required electric power to sustain cruise at a particular airspeed is substantially higher than the thrust power required due to losses in the propeller, motor, controller, cabling and batteries. According to Roskam (45), it is appropriate for conceptual design to assume that for specified cruise airspeed, a propeller can be sourced with $85 \%$ efficiency. Peak motor and controller efficiencies are assumed to be $96 \%$ and $94 \%$ respectively, as quantified previously in the rubber component chapter, CHAPTER 5: Losses through 
traction cabling are around $0.1 \%$ for takeoff power depending on aircraft configuration and significantly lower during cruise as battery current is reduced. They are therefore neglected.

\subsection{Battery Pack Efficiency}

The battery discharge efficiency is related to the current draw on the battery through the following equation:

Battery Efficiency $=1-\frac{I^{2} R_{P a c k}}{V I}$

Where: I=Current Draw from batteries

$$
\begin{aligned}
& \text { V=Battery Voltage } \\
& R_{\text {Pack }}=\text { Equivalent Battery Pack Resistance }
\end{aligned}
$$

The battery voltage is determined by the number of battery cells in series. The higher the voltage, the greater the battery discharge efficiency due to lower current draws for the same output power. The pack voltage will vary with state of charge and droop when a load is applied, but to simplify future efficiency estimation pack nominal voltage will be used.

A typical resistance of 18650 cells is 0.05 ohms per cell (48). To determine battery pack effective resistance, a nominal pack voltage of 355 volts is used as is consistent with all of the electric vehicle battery packs surveyed in Table 3.1. Dividing the nominal battery pack voltage by the nominal voltage per cell determines the number of cells that must be in series to achieve the correct pack voltage. To form a battery module, more cells are put in parallel with the cells connected in series until the 
maximum weight of the battery is reached. The battery pack resistance can then be determined as follows:

$$
\begin{aligned}
& \frac{1}{R_{\text {Module }}}=\sum \frac{1}{R_{\text {Cell }}} \\
& R_{\text {Pack }}=\sum R_{\text {Module }}
\end{aligned}
$$

\subsection{Estimation of Electric Propulsion System Component Weight}

Now that the allowable weight of the propulsion system has been determined along with the required propulsion system power, the electric motor, controller and battery can be sized and their weight determined. The motor and controller are sized to produce the same peak power as the original internal combustion engine. Using the gravimetric power densities for motors and controllers developed in the rubber component chapter along with the required motor power output, the weight of the motor and controller can be estimated. Subtracting the weight of the motor and controller from the allowable electric propulsion system weight gives the allowable weight of the battery pack.

$$
\text { Motor Weight }=(\text { ICE engine rated power }) *(\text { Motor Power Density })
$$

Controller Weight $=$

$$
\text { (ICE engine rated power }) *(\text { Controller Power Density) }
$$

Battery Pack Weight $=($ Max Electric Propulsion System Weight -

$$
\text { (Motor Weight + Controller Weight) }
$$


The total energy contained in battery pack is then determined using the battery energy density outlined in the rubber component chapter. Pack Energy $(k W)=$ ( Pack Weight) * (Battery Energy Density)

To enable longer battery life and protect the battery from damage, it is typical to use only $80 \%$ of the batteries total rated capacity (49). This means that the battery is charged to $90 \%$ capacity and discharged is stopped when the battery reaches $10 \%$ of total capacity. This is referred to as a battery's usable energy.

$$
\text { Useable Battery Energy = Pack Energy } * 80 \%
$$

\subsection{Aircraft Cruise Endurance and Range at Various Speeds}

The aircraft endurance and range at a particular cruise speed can be calculated by dividing the battery energy by the power required at the specified cruise speed. However, according to FAR 91.145, for flight during day visual flight rules (Day VFR), aircraft are required to maintain a reserve to enable flight at cruise power for 30 minutes (50). The emergency reserve can come out of the bottom $10 \%$ of the battery capacity that exists, but is not used under normal flight conditions. If the $10 \%$ extra capacity is not enough to provide for 30 minutes flight time, the remainder will have to be made up by shortening the flight time of the aircraft.

$$
\begin{aligned}
& \text { Required Electric Power }=\quad \frac{\text { Thrust Power }}{\text { Prop Eff*Motor Eff*Controller Eff*Bat Eff }} \\
& \text { Endurance }=\frac{\text { Useable Pack Energy }}{\text { Required Electric Power }}-\text { Reserve Allowance } \\
& \text { Range }=\text { Endurance } * \text { Velocity }
\end{aligned}
$$




\section{Table 6.3 Efficiencies and energy densities used for cruise analysis}

\begin{tabular}{lc}
\hline \hline Cruise Propeller Efficiency & $85 \%$ \\
Motor Efficiency & $96 \%$ \\
Controller Efficiency & $94 \%$ \\
Battery Cell Resistance & $0.05 \mathrm{Ohms} / \mathrm{Cell}$ \\
Motor Power Density & $3.8 \mathrm{~kW}$ peak/lb \\
Controller Power Density & $9.6 \mathrm{~kW}$ peak/lb \\
Battery Energy Density & $99 \mathrm{kWh} / \mathrm{lb}$ \\
\hline \hline
\end{tabular}

The parameters in Table 6.3 and Table 6.4 are used to produce the endurance and range versus airspeed plots of Figure 6.3 and Figure 6.4. These plots assume that the internal combustion engine and associated systems are removed from the airplane. They then assume that an electric propulsion system is installed. The electric propulsion system is capable of providing the same peak power levels as the internal combustion engine that was removed from the aircraft. An allowance is made for $380 \mathrm{lbs}$ of people and luggage, and the remaining useful load is used for the weight of the battery pack. 
Table 6.4 Input Parameters for Performance Analysis

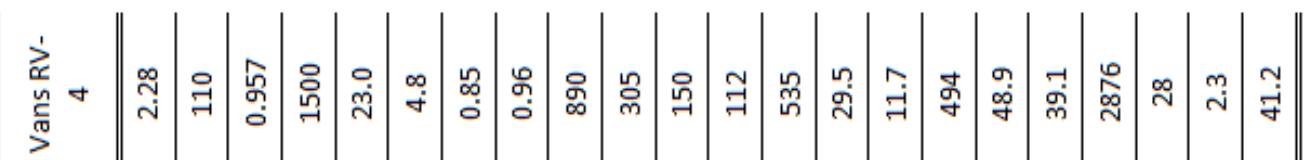

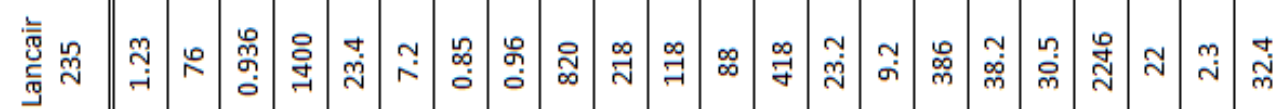

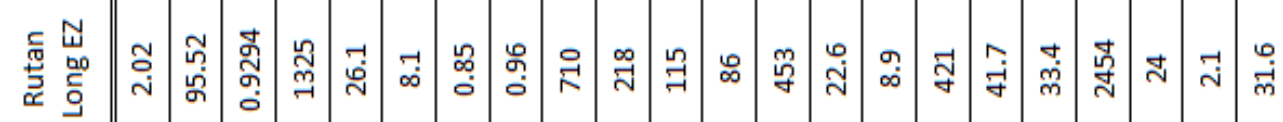

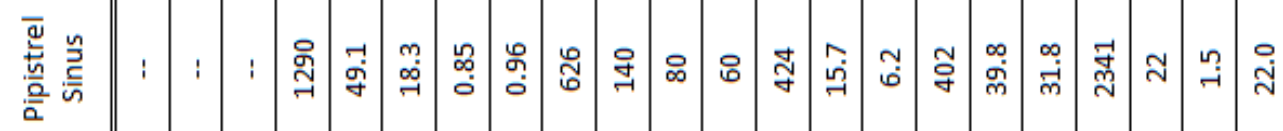

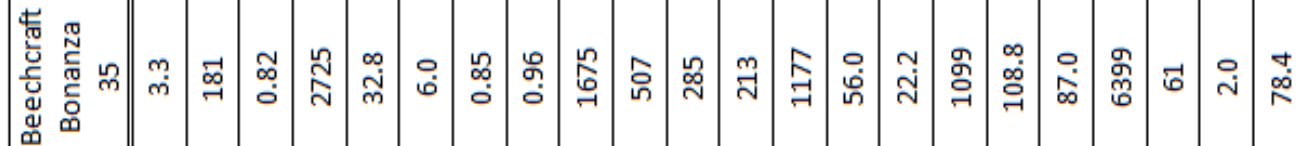

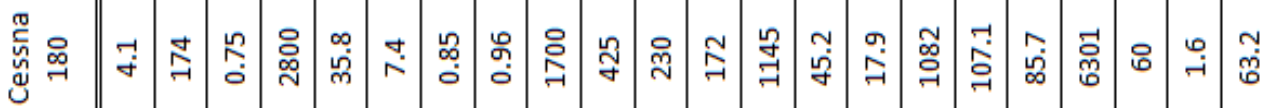

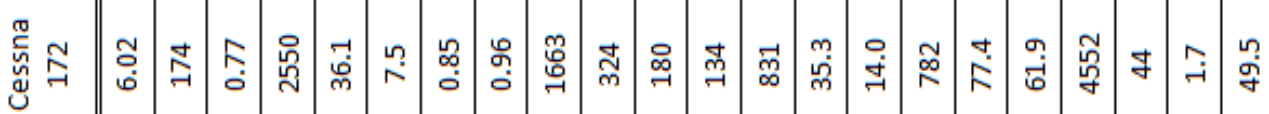

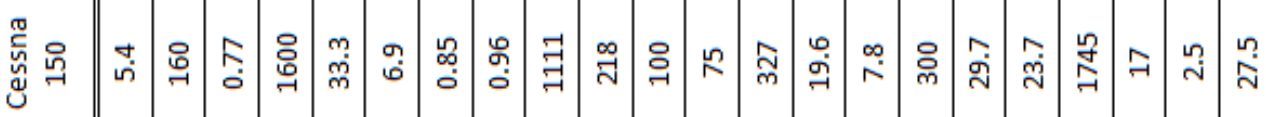

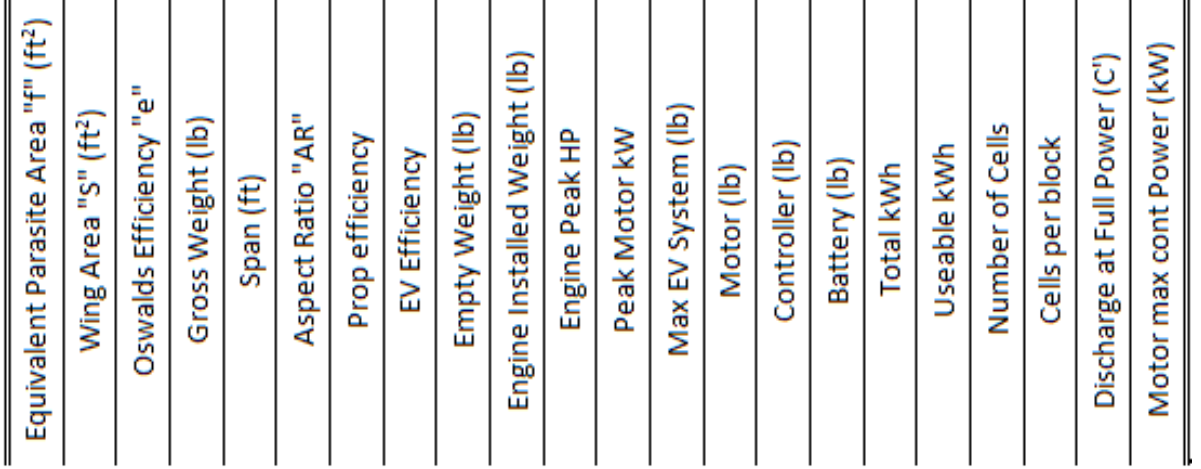




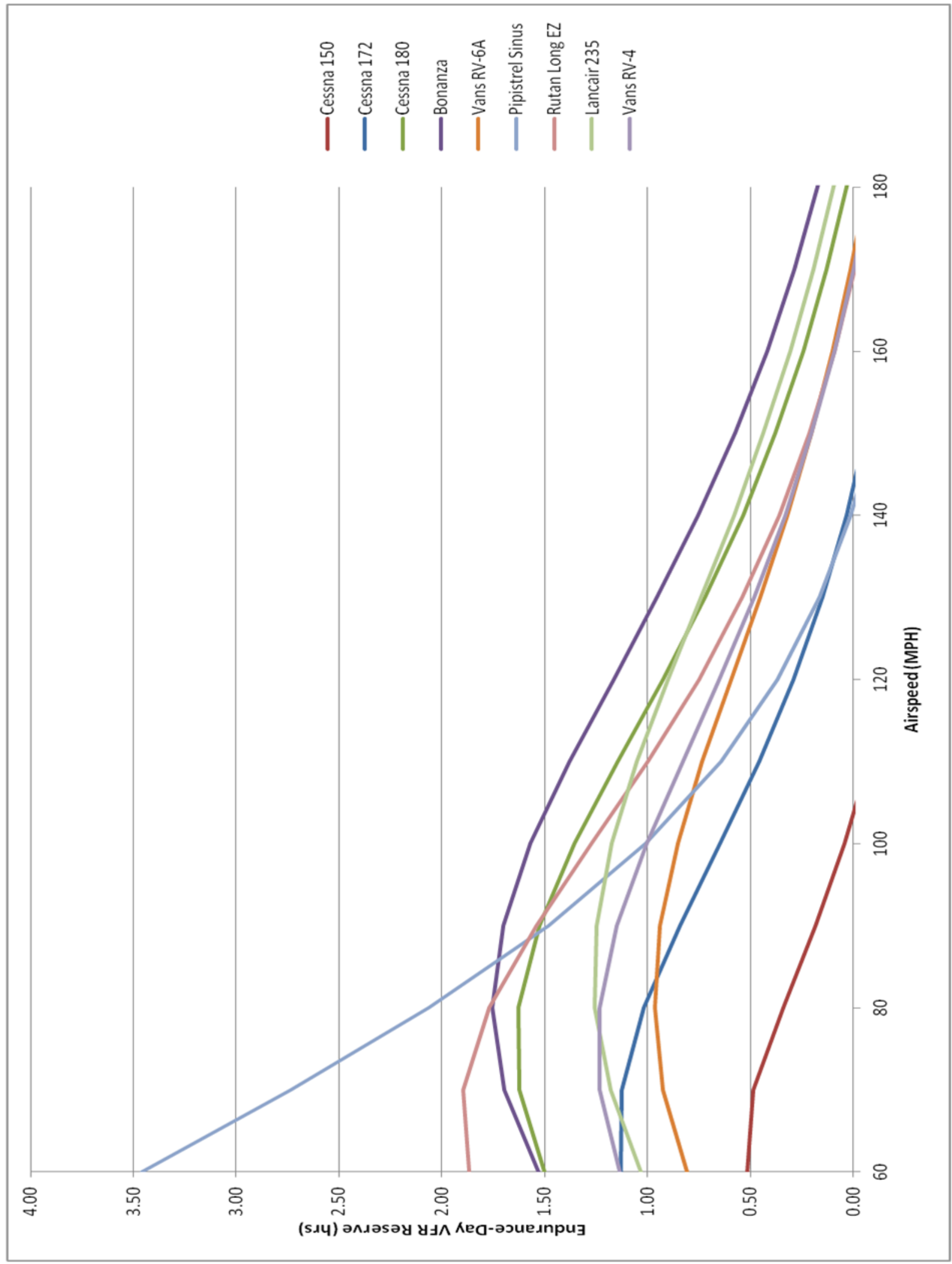

Figure 6.3: Maximum endurance for airframes with electric propulsion conversion 


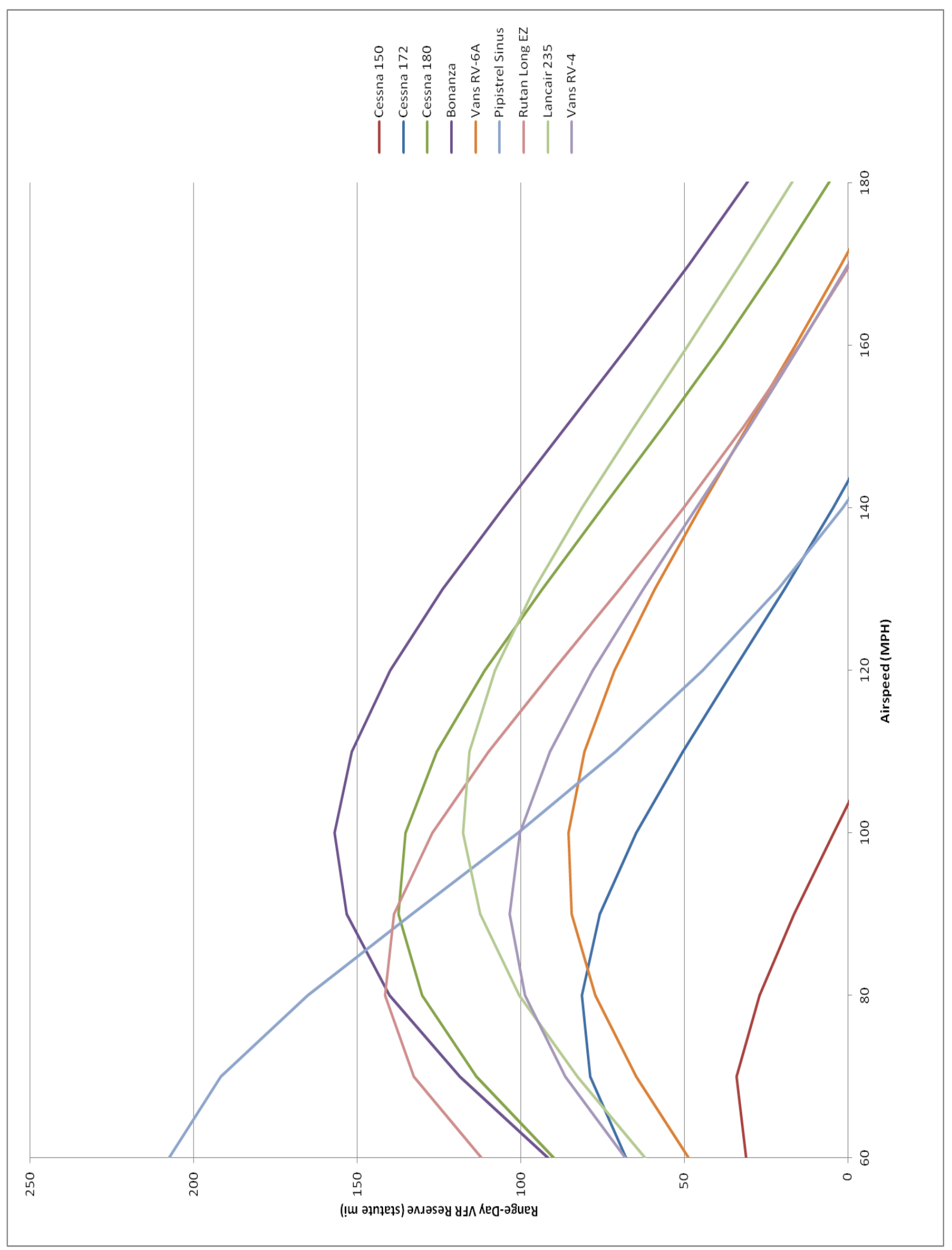

Figure 6.1: Maximum range for airframes with electric propulsion conversion 
It is important to note that the above figures display range and endurance for constant operation at certain cruise airspeed. No allowance has been made for taxi, take off, climb, or descent. The real world range and endurance performance would therefore be significantly lower. The higher speeds in the above chart are also not attainable for continuous operation due to motor and controller thermal limitations. Electric propulsion systems typically cannot operate at their rated peak power setting indefinitely because they cannot reject the heat developed at high power settings. To prevent components from overheating, the continuous power limits are typically much lower than the peak power limits. This means that while an aircraft may be able to attain high airspeeds for short periods of time, it cannot sustain those speeds indefinitely without overheating its propulsion system. A larger motor with higher continuous power limits or a liquid cooled motor could be incorporated into the design, but this would increase the mass of the motor, necessitating a reduction in battery capacity and a corresponding reduction in range. Since the maximum continuous speeds were higher than the best cruise speeds for endurance and range for all aircraft, this motor upsizing was not deemed beneficial. Max continuous airspeeds based on propulsion system thermal limits are shown in the following Table 6.5 for various airspeeds. 


\section{Table 6.5 Maximum airspeed attainable for continuous operation.}

\begin{tabular}{lc}
\hline Airframe & $\begin{array}{c}\text { Max Continuous } \\
\text { Speed (MPH) }\end{array}$ \\
\hline Cessna 150 & 80 \\
Cessna 172 & 100 \\
Cessna 180 & 120 \\
Beechcraft Bonanza 35 & 150 \\
Pipistrel Sinus & 110 \\
Rutan Long EZ & 130 \\
Lancair 235 & 150 \\
Vans RV4 & 130 \\
\hline \hline
\end{tabular}

The cruise performance charts enable comparisons to be made as to the appropriateness of a particular airframe for conversion to electric propulsion. The Pipistrel Sinus Motor glider has superior performance in the endurance category due to significantly lower drag at slow airspeeds. It also exhibits $25 \%$ greater range than the next best airframe considered, the Beechcraft Bonanza, although at the expense of slower cruise speeds.

A real aircraft cannot just immediately start a flight at cruise altitude and airspeed. Instead it must use energy to accelerate on takeoff and climb to cruise altitude and speed. The aircraft must then descend to a landing. The performance analysis is now expanded to include the effects of takeoff, climb and descent.

An aircraft powerplant is typically operated at maximum power during takeoff. However the thrust available, and therefore rate of acceleration, changes as the aircraft velocity increases on the runway. This is due to changes in propeller efficiency with 
changing airspeed as well as the simple relationship between power, speed and thrust. Roskam (45) provides a simple methodology to estimate the average thrust and acceleration of an aircraft on takeoff roll.

$$
\text { Average Thrust }=5.75 P_{T O}\left\{\frac{\left(D_{p}^{2}\right)}{P_{T O}}\right\}^{1 / 3}
$$

Where: $P_{T O}$ : maximum shaft horsepower at takeoff

$$
D_{P}: \text { Propeller Disk Loading }
$$

Roskam (45) provides a chart to estimate propeller disk loading as a function of $\mathrm{P}_{\mathrm{TO}}$ and the stall speed in the takeoff configuration. Fitting a curve to this chart produces the following equation.

$$
\frac{P_{T O}}{D_{P}^{2}}=0.1053 \sqrt{P_{T O} V_{S}}
$$

During takeoff, the weight of the aircraft is reacted by the wheels and landing gear. The wing is not producing lift to support the airplane. The coefficient of lift is therefore assumed to be zero, meaning that there is no induced aerodynamic drag, only parasite drag. The remaining forces acting on the aircraft's longitudinal axis are thrust from the propeller and rolling resistance from the wheels.

Summing the forces in the longitudinal direction then allows for calculation of the required amount of time to accelerate to rotation speed. The amount of energy used can be determined by multiplying the time to accelerate to rotation speed times the power required during acceleration (including system inefficiencies). After takeoff speed is 
reached, it is assumed that the aircraft climbs at its best rate of climb speed to $4000 \mathrm{ft}$ MSL where it cruises at a given cruise speed.

The descent profile is assumed to be flown at a three degree glideslope at an airspeed of 1.3 times the stall speed $\left(\mathrm{V}_{\mathrm{s}}\right)$. In level flight, the lift force equals the weight of the aircraft and the thrust force equals the drag force. In descending flight, the drag, thrust and lift vectors are rotated by the angle of descent. Using an airspeed of $1.3^{*} \mathrm{Vs}$ and assuming Lift=Weight and that the drag is equivalent to the drag at the same airspeed in level flight, the required thrust force can be determined by summing the forces about the aircraft's center of gravity as shown in Figure 6.5.

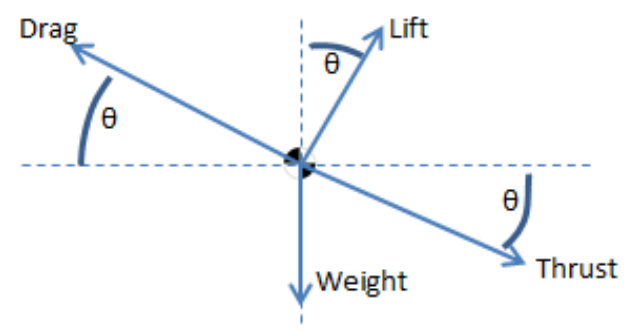

Figure 6.5: Forces acting on an aircraft during descending flight.

The following data in Table 6.6 was used to analyze takeoff, cruise and landing performance: 
Table 6.6 Aircraft data used to analyze takeoff, cruise and descent

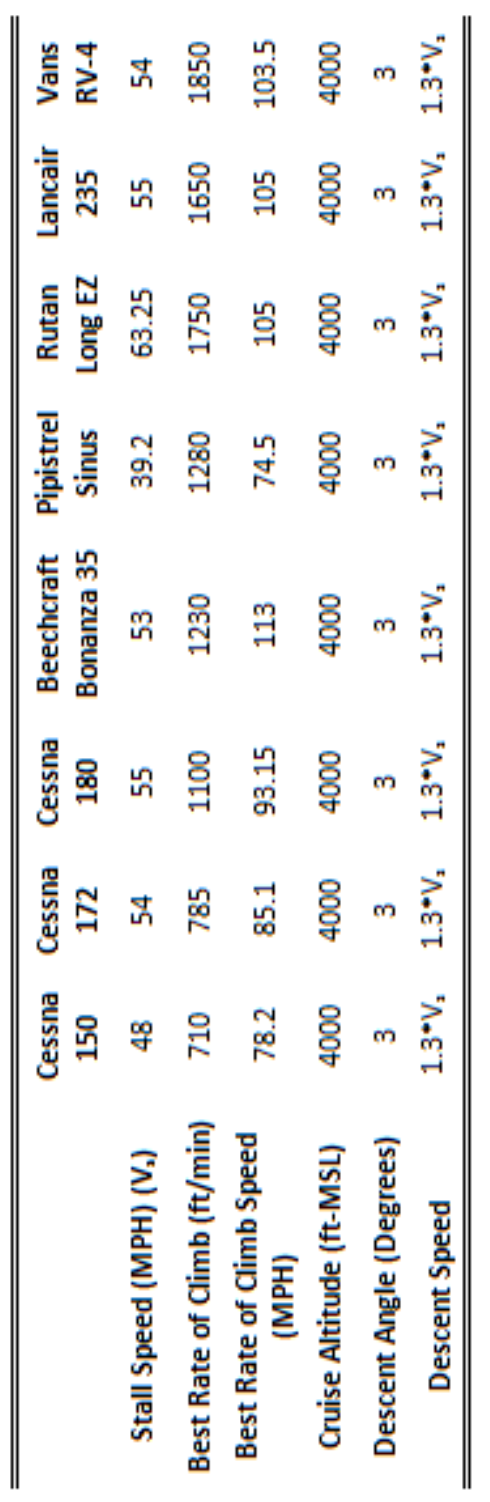

The mission modeled in the following two charts is summarized below:

1.) The aircraft accelerates on the runway from a standstill at full power. The runway altitude is at sea level

2.) The aircraft climbs at its best rate of climb speed to 4000 feet above sea level. Full power is assumed during the climb. 
3.) The aircraft cruises at the various airspeed shown in the plots until a descent is required due to the depletion of the battery pack energy.

4.) The aircraft descends on a three degree glide path at a speed of 1.3 times the stall speed.

5.) The aircraft lands with 30 minutes of flight time remaining in reserve, as is consistent with the FAA specified reserve requirements for flight during daytime conditions under visual flight rules (Day VFR). The runway for landing is at sea level.

Figure 6.6 and Figure 6.7 show maximum electric aircraft range and endurance for flights at various cruise airspeeds. These range and endurance calculations take into account the affect of takeoff, climb, descent and required reserves. The sudden end of a line indicates a cruise airspeed selection for which maintaining the required 30 minute reserve is not possible. 


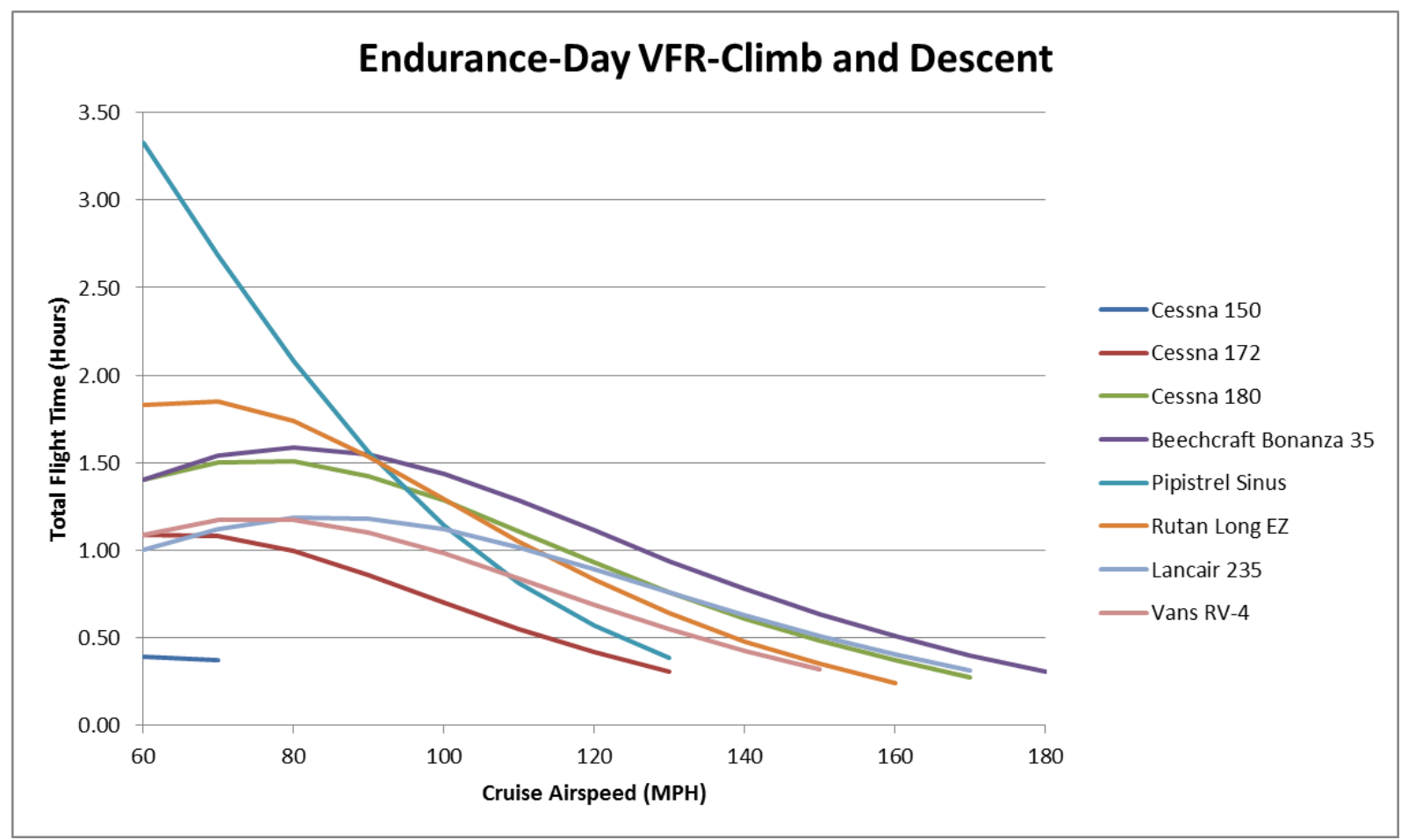

Figure 6.6: Endurance including time aloft during climb and descent.

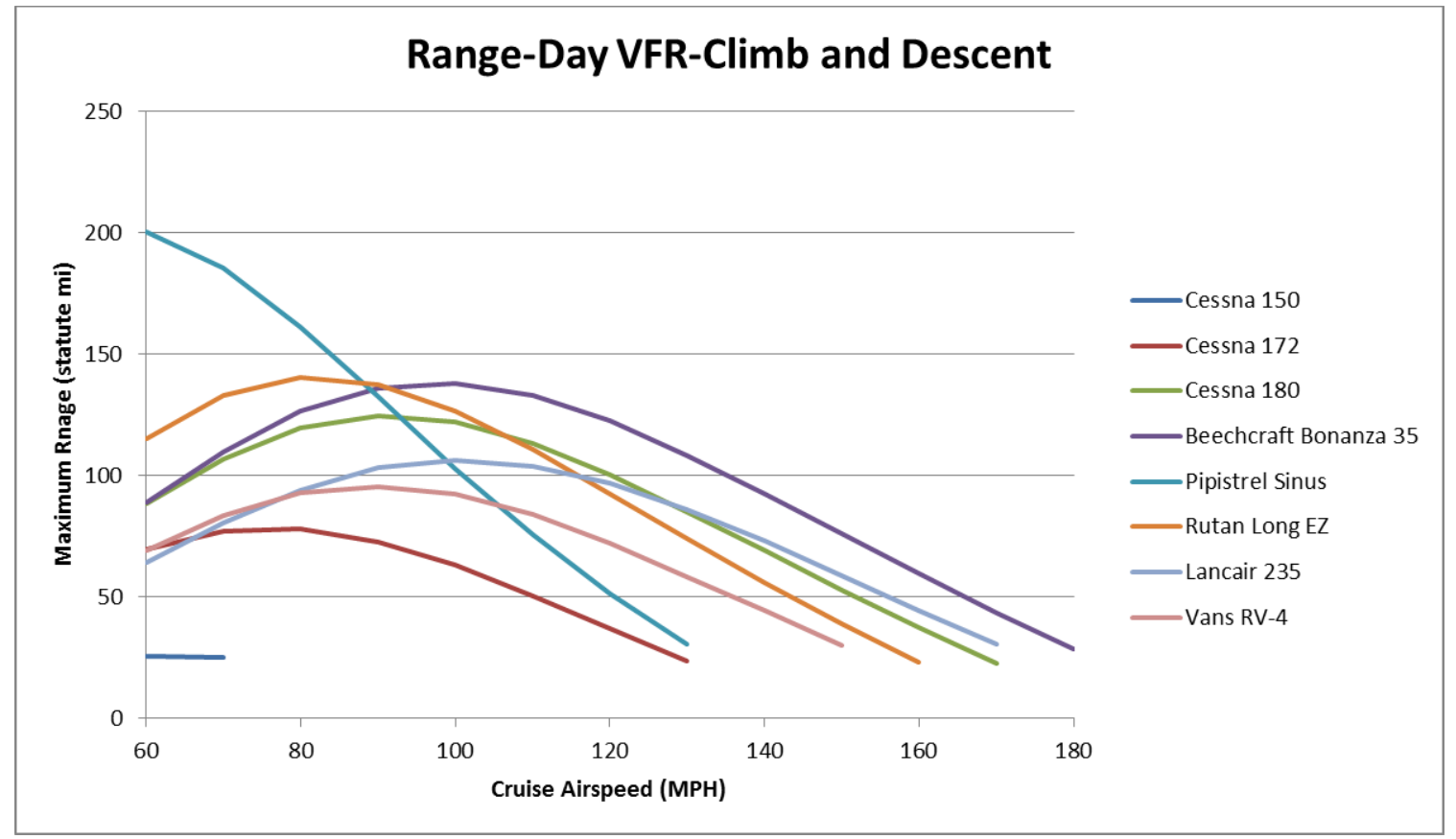

Figure 6.7: Range including miles traveled during climb and descent. 
Table 6.7 compares the reduction in range that results from converting an internal combustion powered aircraft to battery electric propulsion. It can be seen that all aircraft examined experience a reduction in range of greater than $70 \%$.

Table 6.7 Reduction in range due to conversion to battery electric propulsion

\begin{tabular}{cccc}
\hline \hline & $\begin{array}{c}\text { Predicted Electric } \\
\text { Range (miles) }\end{array}$ & $\begin{array}{c}\text { Advertised ICE } \\
\text { Range (miles) }\end{array}$ & $\begin{array}{c}\text { Percent } \\
\text { Difference }\end{array}$ \\
Cessna 150 & 25 & 421 & $-94 \%$ \\
Cessna 172 & 70 & 801 & $-91 \%$ \\
Cessna 180 & 125 & 1024 & $-88 \%$ \\
Beechcraft Bonanza 35 & 145 & 543 & $-73 \%$ \\
Pipistrel Sinus & 200 & 745 & $-73 \%$ \\
Rutan Long EZ & 146 & 1100 & $-87 \%$ \\
Lancair 235 & 105 & 1150 & $-91 \%$ \\
Vans RV-4 & 95 & 748 & $-87 \%$ \\
\hline \hline
\end{tabular}

Table 6.8 shows compares the reduction in endurance that results from converting an internal combustion powered aircraft to battery electric propulsion. The battery electric conversions of the various airframes studied experienced significant decreases in endurance. 
Table 6.8 Reduction in endurance due to conversion to battery electric propulsion

\begin{tabular}{cccc}
\hline \hline & $\begin{array}{c}\text { Predicted Electric } \\
\text { Endurance (hours) }\end{array}$ & $\begin{array}{c}\text { Advertised ICE } \\
\text { Endurance (hours) }\end{array}$ & $\begin{array}{c}\text { Percent } \\
\text { Difference }\end{array}$ \\
Cessna 150 & 0.4 & 3.4 & $-88 \%$ \\
Cessna 172 & 1.1 & 5.2 & $-79 \%$ \\
Cessna 180 & 1.5 & 6.3 & $-76 \%$ \\
Beechcraft Bonanza & 1.6 & 3.0 & $-47 \%$ \\
Pipistrel Sinus & 3.4 & 5.8 & $-41 \%$ \\
Rutan Long EZ & 1.8 & 5.3 & $-66 \%$ \\
Lancair 235 & 1.2 & 4.8 & $-75 \%$ \\
Vans RV-4 & 1.2 & 3.5 & $-66 \%$ \\
\hline \hline
\end{tabular}

Of the eight aircraft analyzed, four aircraft meet the requirements specified in this thesis for carrying $380 \mathrm{lbs}$ of passengers with an endurance of 1.5 hours or greater. They are the Beechcraft Bonanza, the Rutan Long EZ, the Cessna 180 and the Pipistrel Sinus. Aircraft such as the Beechcraft Bonanza and Cessna 180 are valued for their high cruise speeds, long range and useful load. The Long EZ is valued for its long range and high cruise speeds. In the conversion to electric aircraft, these characteristics have been essentially eliminated. The large useful load characteristic of the internal combustion engine version is used to carry a large battery pack in the electric version, eliminating the ability to carry extra people or heavy payloads. The 4 seat Bonanza, 172 and 180 are reduced to two passenger aircraft due to the extra weight of the battery pack. These aircraft must also be flown at their most efficient lift to drag ratio to enable the longest possible range and endurance, which is still minimal compared to the internal combustion version. The maximum range airspeed for the electric version is also significantly lower than the airspeeds at which the internal combustion versions typically cruise. In essence, 
these aircraft with electric propulsion systems do not have the performance to adequately perform their intended mission. There would be no benefit to converting them to electric propulsion as the market for an electric version of these airplanes likely does not exist.

A touring motor glider, on the other hand, is intended for slow, efficient cruise flight. There is limited expectation for cargo or baggage capacity in a touring motor glider. The Pipistrel Sinus touring motor glider, converted from internal combustion to electric propulsion, is capable of performing to these requirements with a powered flight endurance of over 3 hours and a maximum range of 200 statute miles at an airspeed of 60 miles per hour with reserves.

For the intended mission as specified for electric aircraft in Table 6.1, the Pipistrel Sinus converted to battery electric power has the best endurance when carrying the same passenger weight as any of the other aircraft studied. An electric Sinus, out of all the aircraft surveyed, performs the closest to its originally intended mission of slow, efficient flight for two people. In converting from ICE to electric propulsion, the endurance of the Sinus is reduced $40 \%$, however even with this reduction the electric endurance is still over 3 hours of powered flight with reserves. This is more than adequate for several missions, including local sightseeing or pilot training. While the gliding performance is not evaluated in this thesis, an electric Sinus touring motor glider could also feather the propeller in flight and soar in thermals. This could significantly extend overall time aloft if weather conditions permitted.

While also not technically within the scope of this thesis, the cost of developing the conversion of the Pipistrel Sinus to battery electric power would be significantly less 
than the Beechcraft Bonanza or Cessna 180. The Pipistrel Sinus airframe costs less, and the Pipistrel Sinus would require a smaller motor, controller and battery pack for the same endurance. Lastly, the touring motor glider has the increased value that comes with the ability to shut off the propulsion system, feather the propeller, and soar in thermals. For these reasons the Pipistrel Sinus motor glider will be considered as the reference airframe for future conversion to battery electric propulsion.

While the Pipistrel Sinus appears to have sufficient performance from a high level analysis, no concern as yet been paid to the ability to package an electric propulsion system within the airframe. The next chapter builds upon the selection of the Sinus motor glider by determining where the various electric system components would have to be placed from a weight and balance perspective. After determining where the components will be located, actual off-the-shelf hardware is selected for the battery, motor and controller and the propulsion system is laid out. 


\section{CHAPTER 7: Battery Electric Propulsion System Layout in a Motor Glider}

This chapter develops a high level aircraft and propulsion system layout. Components of the high level layout include locations for packaging the various propulsion system components, as well as selection of the shelf hardware for the motor, controller and battery cells.

Chapter Goals:

- Determine, from a weight and balance perspective, where the electric propulsion system components must be positioned to ensure that the center of gravity remains within the manufacturer's limits

- Select off the shelf hardware for the motor, controller and the battery cell

- Layout a conceptual battery module and battery pack architecture

- Determine the efficiency of the selected off the shelf propulsion system hardware.

\subsection{Pipistrel Sinus Motorglider Overview}

The Pipistrel Sinus is a 2 place, side by side touring motor glider and is shown in Figure 7.1. It is one of the most efficient aircraft in its class, capable of $125 \mathrm{mph}$ cruise speeds using only 3.1 gallons of gasoline per hour (47). The Sinus also comes equipped with a feathering propeller. With the propeller feathered, the 30:1 glide ratio enables the Sinus to fly well as a glider (47).

The Sinus also has a relatively high useful load compared to most other motor gliders. This is important for a battery electric aircraft as it allows for increased battery capacity and therefore greater range and endurance. Its specifications are summarized in Table 7.1. 


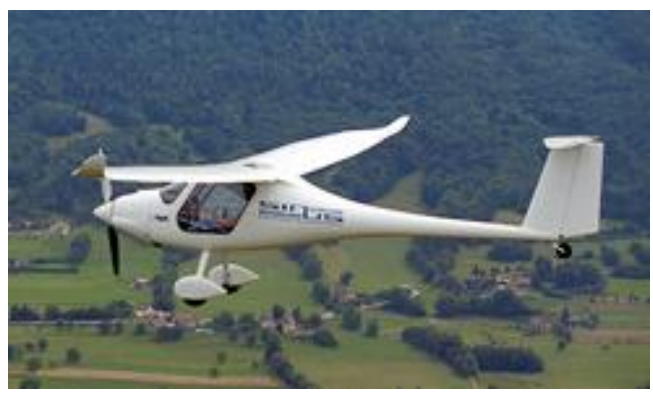

Figure 7.1: Pipistrel Sinus Motor Glider (51)

Table 7.1 Pipistrel Sinus specification overview (47)

\begin{tabular}{lclc}
\hline \hline Engine & Rotax 912 & Useful Load & $664 \mathrm{lb}$ \\
Max Power & $80 \mathrm{hp}$ & Stall Speed (flaps) & $39.2 \mathrm{mph}$ \\
Wing Span & $49.125 \mathrm{feet}$ & Cruise Speed & $125 \mathrm{mph}$ \\
Wing Area & $131.97 \mathrm{ft}^{2}$ & Cruise Fuel Burn & $3.1 \mathrm{gph}$ \\
Aspect Ratio & 18.3 & $\mathrm{~V}_{\mathrm{NE}}$ & $140 \mathrm{mph}$ \\
Empty Weight & $626 \mathrm{lb}$ & Max Climb Rate (Gross Weight) & $1280 \mathrm{fpm}$ \\
Gross Weight & $1290 \mathrm{lb}$ & Take Off Roll (Gross Weight) & $288 \mathrm{ft}$ \\
\hline \hline
\end{tabular}

\subsection{Weight and Balance}

The ability to carry the weight of the batteries depends not only on the maximum allowable gross weight of the aircraft, but also the ability to package the batteries in locations that maintain the overall aircraft center of gravity in the appropriate location. During the conversion process, the large weight of the internal combustion engine (approximately $140 \mathrm{lbs}$ ) in the nose of the aircraft is replaced by the much smaller weight of an electric motor and controller (approximately $50 \mathrm{lb}$ ). The battery pack therefore must be appropriately positioned to prevent the airplane from being tail heavy. 
Allowing the aircraft to be flown outside of the center of gravity limits could mean that the elevator might not have the authority to appropriately control aircraft pitch throughout all parts of the flight envelope. A forward center of gravity could lead to the inability to flare the aircraft appropriately on landing, possibly leading to aircraft damage and injury. An aft center of gravity could reduce the ability to recover from an aerodynamic stall. Further, flying an aircraft outside of center of gravity limitations increases the amount of elevator deflection required to level the aircraft in cruise flight. This deflection of the elevator increases drag.

After performing a weight and balance analysis, it was determined that out of the total battery weight about $40 \%$ of the battery mass would have to be located under the engine cowling between the electric motor and the firewall and the remainder of the battery located inside the wing structure. This will prevent the aircraft from becoming tail heavy, which would have happened if the entirety of the battery pack was packaged in the wing structure. Weight and balance calculations follow over the next several pages. Pipistrel uses the leading edge of the wing as the datum line for weight and balance calculations. The center of gravity limits are presented in Table 7.2.

Table 7.2 Pipistrel Sinus center of gravity limitations (47)

\begin{tabular}{lcc}
\hline \hline & Distance aft of datum line & Mean Aerodynamic Chord \\
\hline Forward CG Limit & $9.57^{\prime \prime}$ & $20 \%$ \\
Aft CG Limit & $16.06^{\prime \prime}$ & $39 \%$ \\
\hline \hline
\end{tabular}

Pipistrel designed the Sinus such that the passenger's center of gravity is within the allowable center of gravity range. Therefore the passengers do not have an 
appreciable effect on the aircraft's center of gravity. The baggage compartment however, is located behind the seat backs. Carrying the maximum allowable baggage weight of 50 pounds does affect the aircraft center of gravity. In the following Table 7.3 and Table 7.4 the center of gravity location is checked with and without baggage using 145 pounds of batteries under the engine cowling. Figure 7.2 and Figure 7.3 show the positions of the weights of important components in the internal combustion powered Pipistrel Sinus as well as the proposed battery electric version. 
Table 7.3 CG position of battery electric Sinus without baggage

\begin{tabular}{cccc}
\hline Final Values & Arm (in) & Weight (lb) & $\begin{array}{c}\text { Moment (lb- } \\
\text { in) }\end{array}$ \\
\hline Engine Less Airframe & -33.0 & 486 & -16038 \\
Electric Motor & 70.0 & 51 & 3570 \\
Cowl Battery & 51.2 & 145 & 7439 \\
Wing Battery & -22.0 & 226 & -4972 \\
Baggage & -45.7 & 0 & 0 \\
\hline \hline Totals & & 908 & -10000 \\
\hline \hline CG Position aft of datum & & -11.0 & \\
\hline \hline
\end{tabular}

Table 7.4 CG position of battery electric Sinus with baggage

\begin{tabular}{cccc}
\hline Final Values & Arm (in) & Weight (lb) & $\begin{array}{c}\text { Moment (lb- } \\
\text { in) }\end{array}$ \\
\hline Engine Less & -33.0 & 486 & -16038 \\
Airframe & 70.0 & 51 & 3570 \\
Electric Motor & 51.2 & 145 & 7439 \\
Cowl Battery & -22.0 & 226 & -4972 \\
Wing Battery & -45.7 & 50 & -2285 \\
Baggage & & 958 & -12285 \\
\hline Totals & & -14.8 \\
\hline \hline CG Position
\end{tabular}




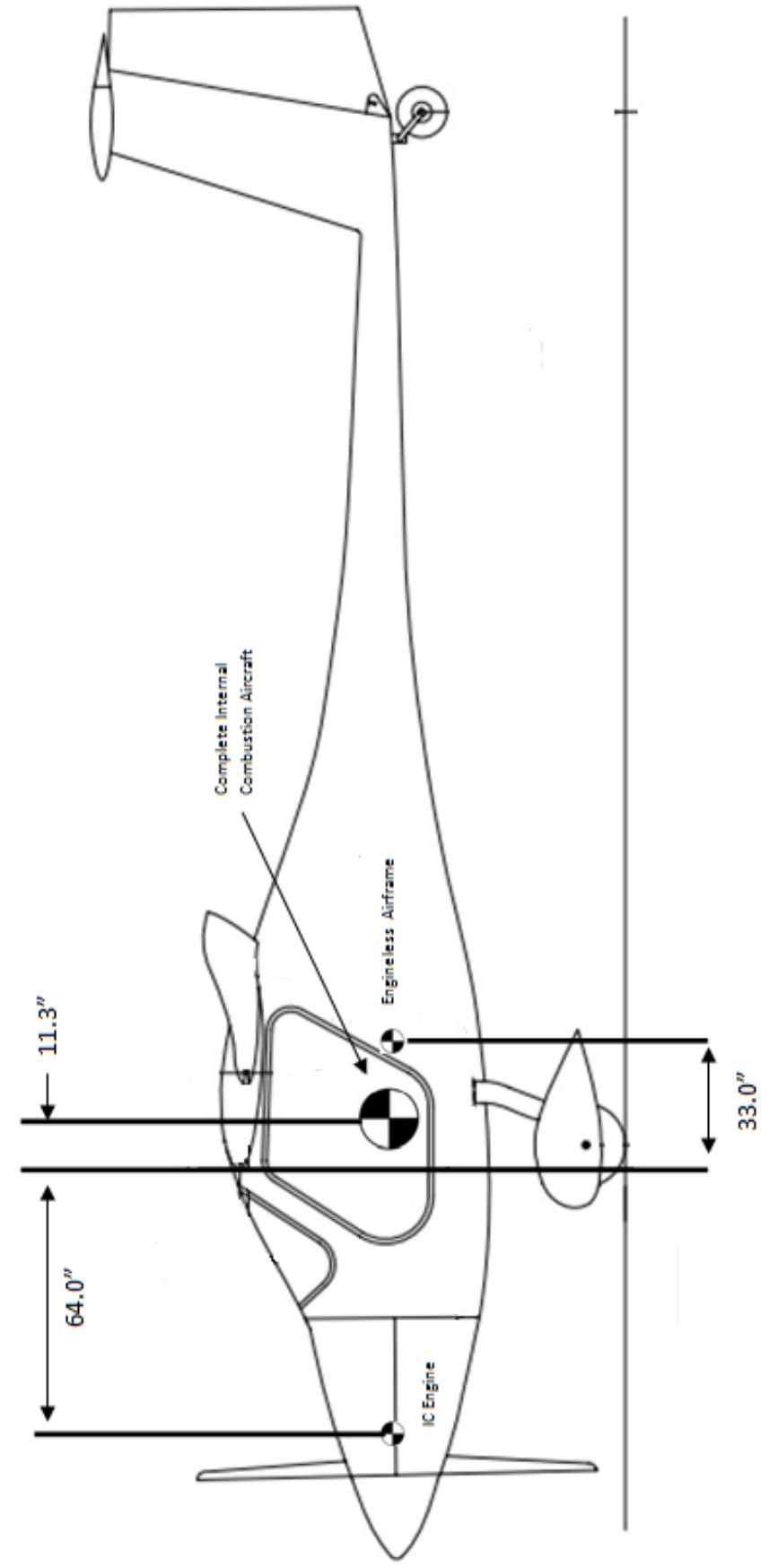

Figure 7.2: C.G. locations for the internal combustion Pipistrel Sinus. (47) 


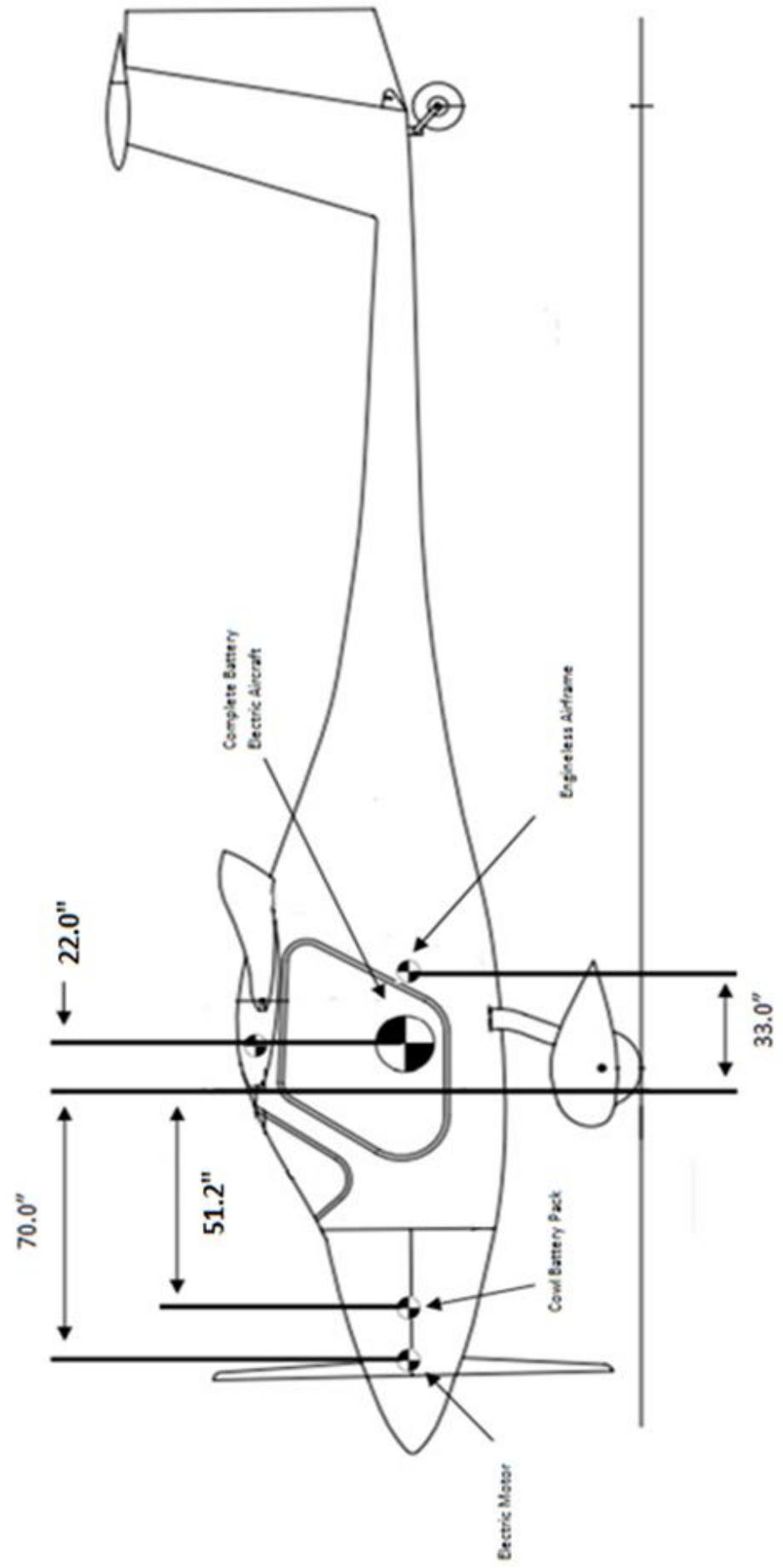

Figure 7.3: Center of Gravity locations for battery electric Pipistrel Sinus.. (47) 


\subsection{Pipistrel Sinus Battery Electric Propulsion System Layout}

Now that a weight and balance analysis has shown were the batteries need to be located from a center of gravity perspective, the detailed battery pack layout can be performed. The detailed battery pack layout must take into account the necessity to split the battery into three parts, one part in each wing and one part in front of the firewall.

\subsubsection{Battery Pack Layout}

In an earlier section, it was shown that several electric automobiles have nominal battery pack voltages of approximately 350 to 370 volts DC. Therefore 360 volts will be assumed as the target nominal battery pack voltage for the Sinus motor glider. To achieve 360 volts, 106 individual cells at 3.4 volts each must be strung together in series. To achieve required energy storage capacity of $38.9 \mathrm{kWh}$, each cell in series must have 26 cells in parallel. Specifications for the individual Panasonic 18650 cells are presented in Table 7.5 Panasonic 18650 cell properties review (16)Table 7.5and a proposed battery pack layout in Table 7.6.

Table 7.5 Panasonic 18650 cell properties review (16)

\begin{tabular}{lc}
\hline \hline Type & Panasonic 18650 \\
Nominal Voltage & 3.4 \\
Capacity (Ah) & 4 \\
\hline \hline
\end{tabular}




\section{Table 7.6 Pipistrel Sinus Battery pack properties}

\begin{tabular}{lc}
\hline \hline Pack Nominal Voltage & 360.4 \\
Pack Capacity (Ah) & 107 \\
Total Energy (kWh) & 38.92 \\
Total number of cells & 2862 \\
Weight (lb) & 393 \\
\# of cells in series & 106 \\
\# of cells in parallel & 27 \\
\hline \hline
\end{tabular}

\subsubsection{Wing Module Layout}

Each battery module will use be of $4 \mathrm{~S}-26 \mathrm{P}$ configuration, meaning that there will be 4 cells in series and 26 cells in parallel for a total of 104 cells per module. There will be a total of 8 modules per wing in series and 10.5 modules in series under the engine cowling. The layout under the engine cowling will consist of 10 wing modules, plus a single cowl module of 2S-26P configuration as specified in Table 7.7 and Table 7.8.

Table 7.7 Wing module layout

\begin{tabular}{lc}
\hline \hline Wing Module Voltage & 13.6 \\
Wing Module Capacity (Ah) & 104 \\
Total Energy (kWh) & 1.414 \\
Total number of cells & 104 \\
Predicted Weight (lb) & 14.3 \\
\# of Cells in Series & 4 \\
\# of Cells in Parallel & 26 \\
\hline \hline
\end{tabular}




\section{Table 7.8 Pack layout}

\begin{tabular}{lc}
\hline \hline \# of Modules in Series in Wing & 8 \\
\# of Modules in Series Under Engine Cowling & 10.5 \\
Battery Weight per Wing (lb) & 113 \\
Battery Weight Under Engine Cowling (lb) & 145 \\
\hline \hline
\end{tabular}

\subsubsection{Battery Pack Discharge Efficiency}

The discharge efficiency of the battery pack depends on the rate at which it is discharged.

Higher current draws result in reduced battery discharge efficiency due to resistive heating. For the battery system proposed for the battery electric Pipistrel Sinus, the discharge efficiency for various battery power draws is presented below in Table 7.9.

Table 7.9 $I^{2} R$ losses for the battery pack for various system power draws

\begin{tabular}{cccccc}
\hline \hline $\begin{array}{c}\text { Battery } \\
\text { Draw } \\
(\mathbf{k W})\end{array}$ & $\begin{array}{c}\text { System } \\
\text { Amps }\end{array}$ & $\begin{array}{c}\text { Discharge } \\
\text { Rate }(\mathbf{C})\end{array}$ & \multicolumn{2}{c}{$\mathbf{I}^{\mathbf{2} R}$ Heat Generated (Watts) } & Discharge \\
& & Each Wing & $\begin{array}{c}\text { Total Battery } \\
\text { Eystem }\end{array}$ & $\begin{array}{c}\text { Efficiency } \\
(\boldsymbol{\%})\end{array}$ \\
\hline 60 & 166 & 1.5 & 1642 & 5441 & 91.7 \\
50 & 139 & 1.3 & 1141 & 3778 & 93.0 \\
40 & 111 & 1.0 & 730 & 2418 & 94.3 \\
30 & 83 & 0.8 & 411 & 1360 & 95.7 \\
25 & 69 & 0.6 & 285 & 945 & 96.4 \\
20 & 55 & 0.5 & 182 & 605 & 97.1 \\
15 & 42 & 0.4 & 103 & 340 & 97.8 \\
10 & 28 & 0.3 & 46 & 151 & 98.5 \\
\hline \hline
\end{tabular}

\subsubsection{Motor Selection and Efficiency}

There are several models of brushless DC motors available that would be appropriate for use on a Sinus battery electric motor glider. One of the major draws of an electric propulsion system is the reduction in moving parts and the associated reduced maintenance and increased reliability. In the spirit of reducing moving mechanical parts, 
it is desirable to avoid using a speed reduction box between the motor and the propeller. Typical aircraft propellers turn between 1800-3000 RPM. It is therefore desirable to select a motor that makes peak torque and peak efficiency within this RPM band. As presented previously in table 2.9, the Enstroj Emrax 228 has one of the best power densities of the motors surveyed. The Emrax 228 can also be operated between $96 \%$ efficiency during cruise and $94 \%$ efficiency during maximum power takeoff and climb as shown by the yellow power curve in Figure 7.4.

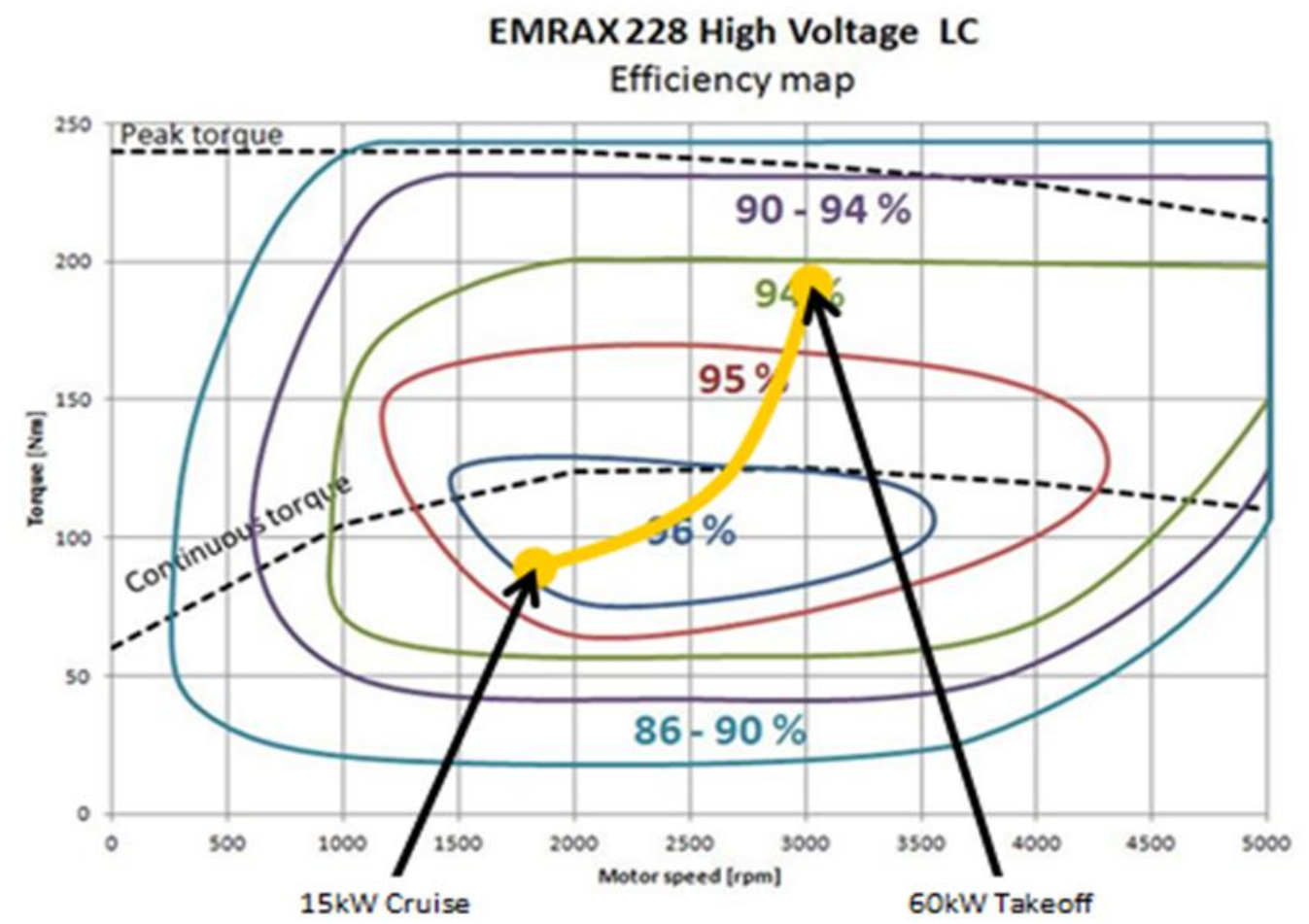

Figure 7.4: Emrax 228 efficiency plot (40)

If the motor thermal limits are reached on climbout, the motor power will have to be reduced to maximum continuous power levels. This reduces the Sinus's climb rate from $120 \mathrm{ft} / \mathrm{min}$ to approximately $700 \mathrm{ft} / \mathrm{min}$ at $75 \mathrm{mph}$ at sea level. This is on par with 
conventional small aircraft performance such as the Cessna 150 and will be considered acceptable.

\subsubsection{Controller Selection and Efficiency}

Efficiency plots for controllers were challenging to procure. As specified previously in Table 4.2, the Unitek motor controller has the best power density of the four controllers surveyed. However, efficiency data could only be obtained for the Tritium WaveSculptor 200. For this thesis, the power density of the Unitek controller was assumed with the efficiency and cooling requirements of the Tritium WaveSculptor 200.

The speed and torque of an electric DC motor are linearly related to input voltage and current. Therefore, the operating characteristics of the motor controller can be determined by the speed and torque requirements of the electric motor. These relationships and efficiencies are reproduced below Table 7.10 and Table 7.11.

Table 7.10 Motor output/input

\begin{tabular}{cc}
\hline \hline Torque/Motor Current & $11.1 \mathrm{~N}-\mathrm{m} / \mathrm{A}_{\mathrm{RMS}}$ \\
\hline Speed/Voltage & $9 \mathrm{RPM} /$ Volt \\
\hline
\end{tabular}

Table 7.11 Controller power requirements and resulting efficiency

\begin{tabular}{lcccccc}
\hline \hline Flight Regime & $\begin{array}{c}\text { Shaft } \\
\text { RPM }\end{array}$ & $\begin{array}{c}\text { Power } \\
(\mathrm{kW})\end{array}$ & $\begin{array}{c}\text { Torque } \\
(\mathrm{Nm})\end{array}$ & $\begin{array}{c}\text { Current } \\
\left(\mathrm{A}_{\mathrm{rms}}\right)\end{array}$ & $\begin{array}{c}\text { Voltage } \\
(\mathrm{V})\end{array}$ & $\begin{array}{c}\text { Controller } \\
\text { Efficiency }\end{array}$ \\
\hline Cruise & 2000 & 15 & 72 & 65 & 222 & $97.5 \%$ \\
Full Power & 2800 & 60 & 191 & 174 & 311 & $98.0 \%$ \\
\hline \hline
\end{tabular}




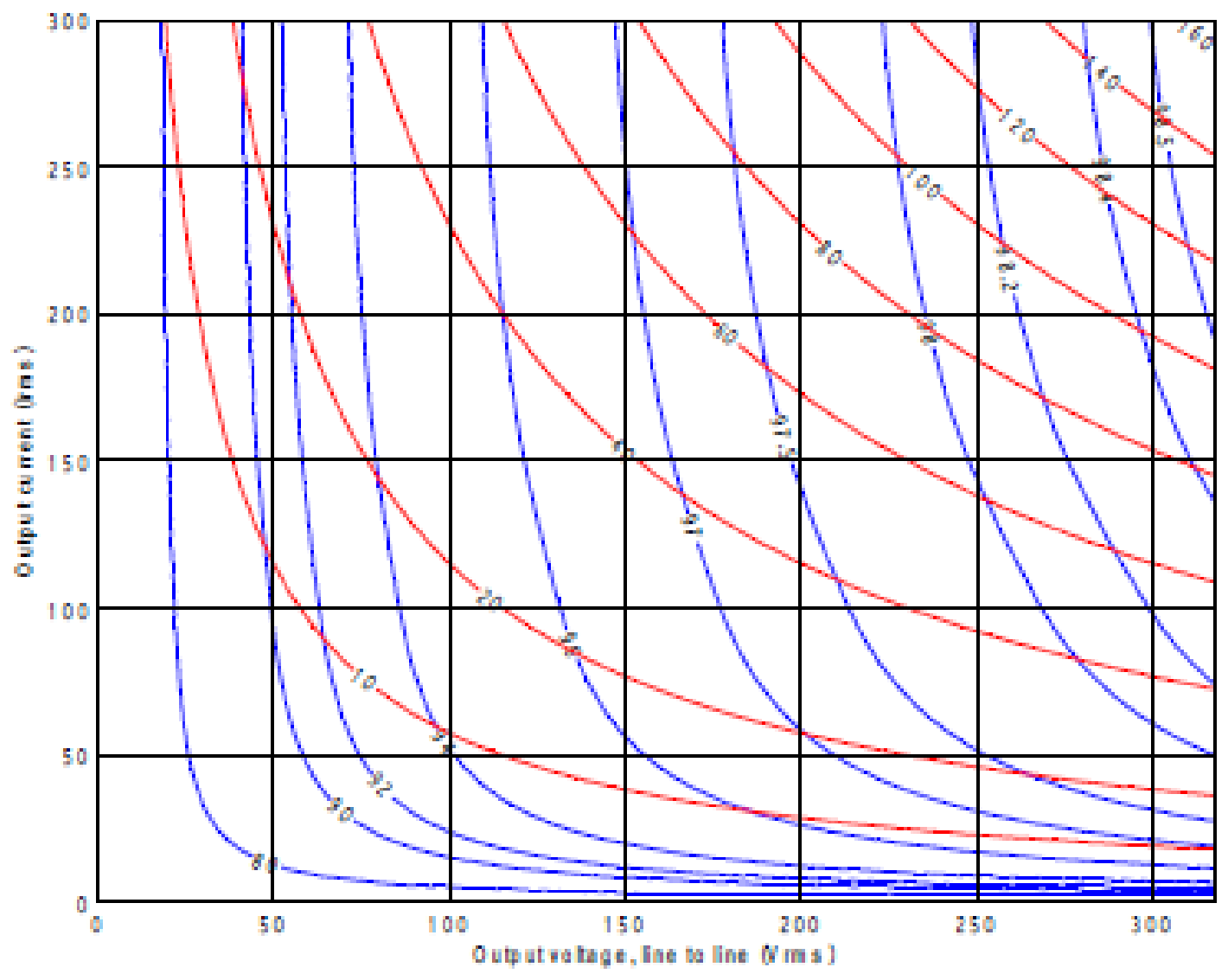

Figure 7.5: Controller Efficiency Plot : (42)

Figure 7.5 is a plot of the efficiency of the Tritium WaveSculptor controller when operating on a high voltage battery bus. The red lines indicate electrical power in kilowatts. The blue lines indicated controller efficiency as a percentage. The efficiency values from Table 7.11 are taken from this chart. The reader can note controller efficiencies for any combination of output voltage and current. Using Table 7.10, the voltage and current can then be converted to the Enstroj motor's shaft torque and RPM.

After layout of the power system, the conceptual design shifts to analysis of the wing structure and the integration of the battery into the wing. The Pipistrel Sinus does not have the space under the engine cowling to package the motor, controller and the entirety of the battery pack in front of the engine firewall, nor would center of gravity 
concerns allow the entirety of the weight to be position in the nose of the aircraft.

Therefore at least some of the battery must be installed aft of the firewall. There are two possible locations for the installation of the battery aft of the firewall. One location for the battery is behind the seats in the fuselage, while the other is inside of the wing structure. Putting the battery in the fuselage behind the seats moves the center of gravity for the airplane behind the aft center of gravity limit, as well as eliminating the small baggage compartment behind the seats. This rules out the possibility of packaging the batteries in the fuselage. The batteries must therefore be integrated into the internal structure of the wing.

The remainder of this thesis focuses on the technical hurdles of integrating the batteries in the wing. If it is not possible to package a portion of the batteries in the wing, then the conversion to battery electric propulsion is not feasible. It is therefore critical to ensure that no technical reasons exist that would prevent the integration of the batteries into the wing structure. The wing structure must be analyzed and modified to ensure that it has the appropriate level of strength to withstand the applied loads. Other concerns that must be accounted for are the accessibility of the batteries in the wing structure, heat rejection of the batteries and emergency venting of the battery pack should one of the cells in the pack fail. Lastly, the wing design must also be analyzed to ensure that changes to the mass and stiffness of the wing do not reduce the aeroelastic flutter margins below acceptable levels. The next chapter develops an aeroelastic flutter theory that can be used for high level trade-offs between various battery packaging layouts in the wing. Subsequent chapters focus on the mechanical design of the wing and utilize the aeroelastic flutter theory developed in next chapter. 


\section{CHAPTER 8: Aeroelasticity Theory}

Packaging the batteries in the wing of an aircraft significantly increases the mass of the wing assembly. An extremely important topic that must be well understood in order to package the traction batteries in the wing of an aircraft is the effect of the increased mass on the aeroelastic flutter properties of the wing. Aeroelastic effects have the potential to drive packaging locations for the batteries, as well as drive the structural design for stiffness reason. As a result the wing structure with the additional battery mass must be analyzed to ensure the packaging configuration is safe from dangerous aeroelastic effects.

The goals for this chapter are as follows:

- Develop an understanding of the different types of aeroelastic effects.

- Develop a mathematical modeling tool to enable quick analysis of the aeroelastic flutter properties of various battery packaging designs.

This chapter is concerned with developing a flutter model for analyzing various wing designs. The tools developed in this chapter of the thesis are then used in subsequent wing design chapters to help select a battery packaging configuration. Using the theory presented in this chapter, a flutter analysis tool was developed in Matlab that enabled experimentation with various battery packaging configurations. In this chapter, FAA flutter requirements are presented, and the theory and equations used to develop the flutter code are presented.

\subsection{Aeroelasticity Definition and Requirements}

Aeroelasticity is a field of structural dynamics that also incorporates the effect of a flowing fluid on an elastic structure. In other words, most topics in aeroelasticity can be 
thought of as a structural vibration problem where the forcing function results from the fluid flowing over the structure. As with any vibration problem, a complete aeroelastic flutter model includes terms for the structural mass, stiffness, damping and the forcing function.

As it is concerned with aircraft wings, there are two important forms of aeroelasticity. The first is static aeroelasticity which consists of the deformation of the elastic wing due to aerodynamic loads but does not depend on the wing inertia or acceleration. Wing divergence and aileron control reversal are forms of static aeroelasticity. Dynamic aeroelasticity depends upon not only the elastic and aerodynamic forces, but also the inertia and acceleration of the structure. Dynamic aeroelasticity is typically referred to as flutter.

Aeroelastic effects must be accounted for in wing design. At a minimum they can lead to a reduction in the allowable maximum speed of the aircraft or expensive redesigns after testing. In certain cases unanticipated aeroelastic effects could lead to sudden catastrophic failure of the aircraft structure during flight testing. Appropriate levels of analysis and physical testing are required by the FAA to ensure that a design is free from aeroelastic effects throughout the planned flight profile.

The Federal Aviation Administration has created requirements for flutter analysis and testing. These are contained in Title 14 of the Code of Federal Regulations, (CFR), known as the Federal Aviation Regulations (FARs). Section 23, paragraph 629 details the requirements for certifying the flutter properties of a design. The requirements of FAR 23.629 are summarized below as it pertains to this thesis. Note: $V_{D}$ is defined as the design diving speed. 
1. Flight tests must show the airplane is free from flutter, divergence and control reversal up to the aircraft maximum dive speed $\left(\mathrm{V}_{\mathrm{D}}\right)$. Proper and adequate attempts to induce flutter must be made within the speed range

a) A proper margin of damping must exist at $V_{D}$

b) As $V_{D}$ is approached, there must be no large or rapid reduction in damping.

2. The flutter analysis must consist of either of the following, but both are not required.

a) A rational analysis used to predict freedom from flutter, control reversal and divergence covering all speeds up to $1.2 \mathrm{~V}_{\mathrm{D}}$.

OR

b) Compliance with the criteria in Airframe and Equipment Engineering Report No. 45 "Simplified Flutter Prevention Criteria" if:

i. $V_{D}$ for the airplane is less than 260 knots

ii. The airplane has no large mass concentrations along the wing span

iii. The airplane does not have unusual mass distributions or other unconventional design features that affect the applicability of the criteria.

In summary, an airplane desired to be certified under FAR part 23 must be flight tested to verify freedom from flutter. Further, some sort of analysis must be performed to ensure freedom from flutter. The FAA has published a document entitled "Simplified Flutter Prevention Criteria" also known as "Airframe and Equipment Engineering Report No. 45." This report is a set of conservative criteria that has generally shown over the 
years to result in aircraft that are free from flutter. However, the criteria is based on the assumptions that a new aircraft design does not deviate from the typical configuration from which the FAA used to produce the criteria. As defined by the FAA, unusual mass distributions or large mass concentrations along the wing span eliminate the option of using the simplified flutter prevention criteria. Large masses of batteries located along the span of a wing surely qualify as an unusual mass distribution. Therefore it is not an option to utilize the FAA's simplified flutter prevention criteria. Instead, a detailed, "rational" flutter analysis must be performed.

Summary of flutter requirements for this thesis:

- A rational analysis must show that the wing is free from flutter and divergence at all speeds up to 1.2 times $\mathrm{V}_{\mathrm{D}}$, the design diving speed.

\subsection{Wing Divergence:}

Wing divergence occurs because the center of lift for the wing is in front of the wing's torsional elastic axis. As the wing generates lift, the lift force creates a moment about the elastic axis that increases the angle of attack of the wing. This increased angle of attack further increases the lift force, which then continues to increase the angle of attack until the wing either reaches an equilibrium position or the deflection becomes so great that the wing fails. The wing must be designed with appropriate torsional stiffness to be sure that the wing reaches equilibrium before structural failure occurs. Figure 8.1is an exaggerated image in which the center of pressure is far in front of the elastic axis. An increase in lift acting at the center of pressure produces an increase in angle of attack (alpha). 


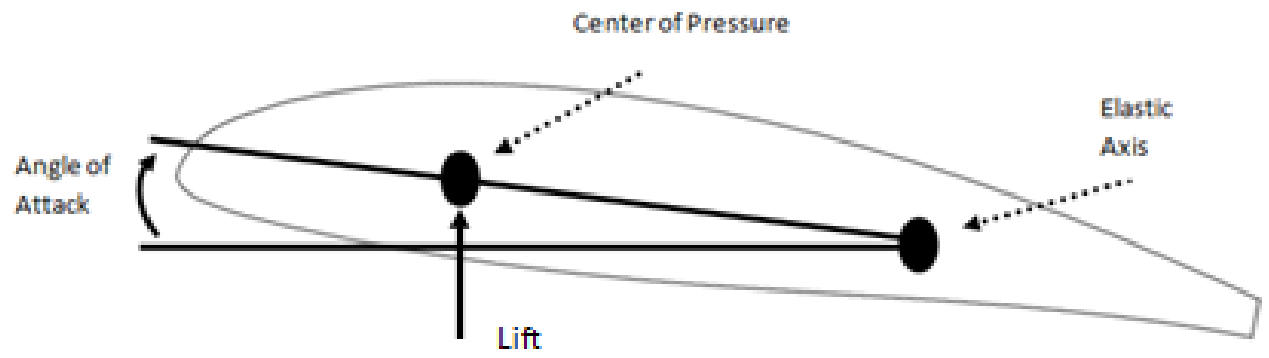

Figure 8.1: Center of Pressure and Elastic Axis

The required torsional stiffness must be specified such that the wing divergence speed is significantly higher than the maximum speed the aircraft will be flown. A simple wing torsional model can be developed using an airfoil strip and torsional spring attached at the elastic axis as shown below in Figure 8.2

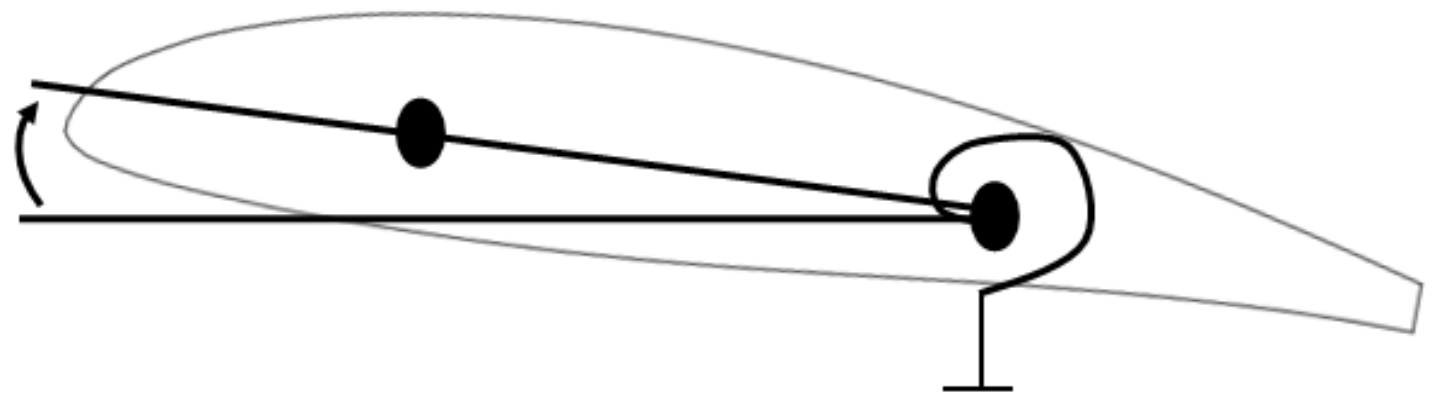

Figure 8.2: 2D wing model with torsional spring

According to Hodges (52), the air speed at which divergence occurs for this model is:

$$
V_{\text {Divergence }}=\sqrt{\frac{2 k}{\rho_{\infty} S C_{L \alpha}\left(x_{o}-x_{a c}\right)}}
$$


Where $\mathrm{k}$ is the torsion spring constant, $\rho_{\infty}$ is the air density, $\mathrm{S}$ is wing planform area, $x_{o}$ is the distance from the leading edge to the torsion spring, and $x_{a c}$ is the distance from the leading edge to the aerodynamic center (assumed to be at quarter-chord). $\mathrm{C}_{\mathrm{L} \alpha}$ is the slope of the lift vs angle of attack curve. The elastic deflection as according to Hodges (52) is defined as follows:

$$
\theta=\frac{q S c C_{M a c}+q S C_{L \alpha} \alpha_{r\left(x_{O}-x_{a c}\right)-W\left(x_{O}-x_{c g}\right)}}{k-q S C_{L \alpha}\left(x_{o}-x_{a c}\right)}
$$

Where $\mathrm{c}$ is the chord length, $\alpha_{\mathrm{r}}$ is the rigid angle of attack and $\mathrm{x}_{\mathrm{cg}}$ is the distance from the leading edge to the center of gravity of the wing. $\mathrm{W}$ is the weight of the wing structure. As the wing dynamic pressure (q) as a result of an increase in free stream air velocity approaches the divergence dynamic pressure $\left(\mathrm{q}_{\mathrm{d}}\right)$ of the particular wing, the torsional deflection tends toward infinity as shown below in Figure 8.3.

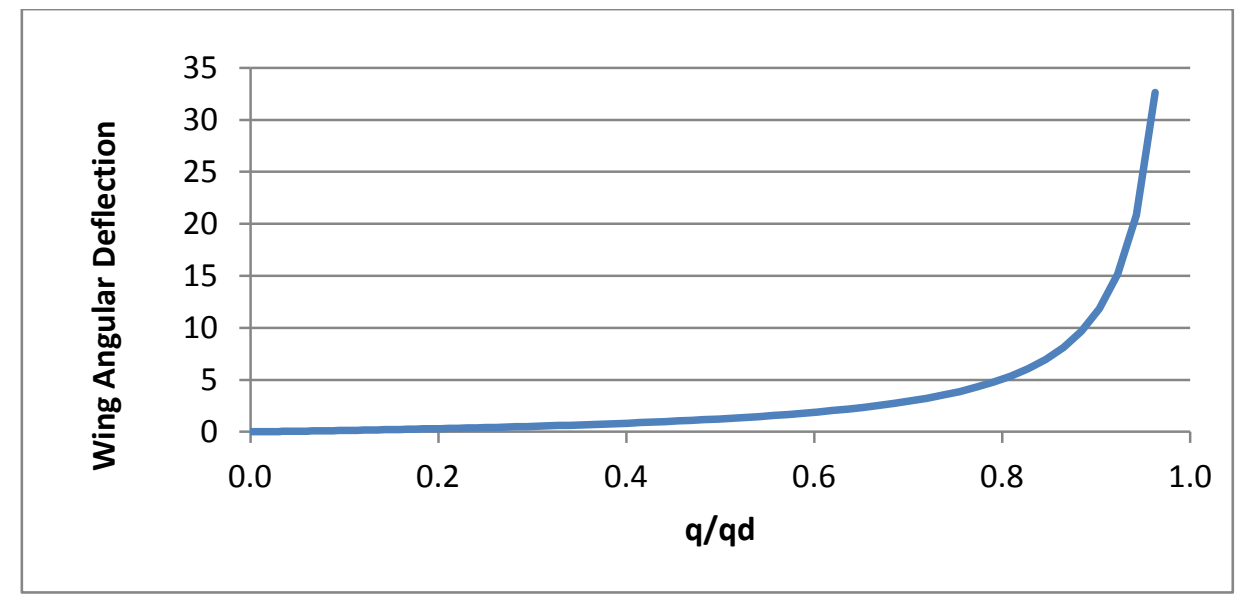

Figure 8.3: Divergence trends for various dynamic pressures.

The above 2D model can be expanded to a uniform continuous lifting surface. Wing twist at a particular station along the span is influenced by the lift force developed 
on the rest of the wing and resulting moment. Hodges (52) states the divergence speed of the wing is given by the following equation (3.54)

$$
V_{\text {Divergence }}=\sqrt{\frac{2(G J)}{\rho e c a}\left(\frac{\pi}{2 l}\right)^{2}}
$$

\section{$\underline{\text { Shortcomings of this approach }}$}

Using 2-dimensional strip theory on a three dimensional uniform lifting body provides a conservative estimate of the actual load distribution and elastic twist of the wing. Two dimensional strip theory does not capture the fact that experimental investigations have shown the lift decreases to zero at the wing tips. The distribution of this lift across the wing span is non-linear. A more accurate but significantly more complicated approach is to use a three dimensional aerodynamic theory such as lifting line theory as a substitute for aerodynamic strip theory.

For the Pipistrel Sinus motor glider, the aerodynamic moment acting on the elastic axis of the wing is always a pitch down moment. This means that the center of pressure is behind the elastic axis. Therefore divergence is not possible and will not be considered further in this thesis.

\subsection{Dynamic Aeroelasticity}

Previously aeroelastic phenomenon independent of the inertia of the wing were discussed. This upcoming section incorporates the effect of the mass of the wing structure.

All elastic structures have a natural frequency at which they will oscillate if displaced. For our purposes, we will call the natural frequency of the wing the zero 
airspeed natural frequency, assuming that this would be the frequencies the particular wing modes would vibrate at if excited in an atmospheric vacuum.

The zero airspeed natural frequency can be determined in several ways including a finite element model of the wing, an assumed modes analysis of the wings, or a ground vibration test on the prototype airframe. Usually a finite element or assumed modes analysis is performed first. A ground vibration test is then performed to verify the fidelity of the mode shapes and natural frequencies predicted by the model.

Once the mode shapes and zero airspeed natural frequencies of the wing have been determined, a flutter analysis can be performed.

\subsection{V-g Flutter Method Using Assumed Modes}

A commonly used methodology for predicting flutter instability is called the $\mathrm{V}-\mathrm{g}$ method. The result of the V-g method is typically a plot of airspeed (V) versus damping (g) required to maintain simple harmonic motion for various flutter modes of interest. The two modes typically analyzed are the first wing bending mode and the first wing torsional mode. An example V-g plot for a large transport category aircraft is shown below in Figure 8.4. Both bending and torsion modes are depicted in this plot. For the large transport category aircraft used as an example, the torsion mode is shown to require positive damping above $500 \mathrm{MPH}$, indicating the aircraft is susceptible to flutter above

that speed. More information on the significance of the V-g plot outputs will be explained over the next several pages. 


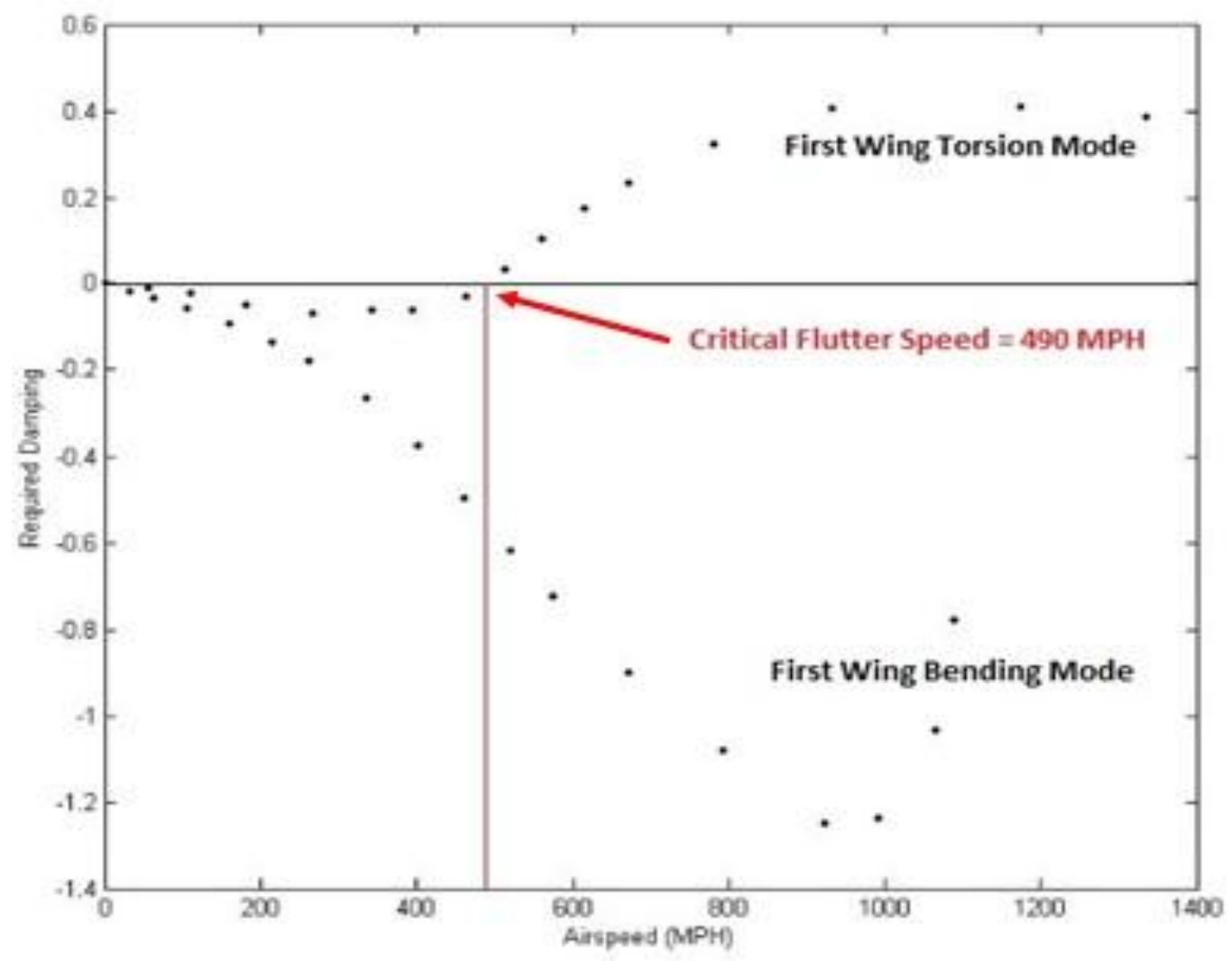

Figure 8.4: Example of a V-g for a large transport category aircraft.

A V-g analysis is performed by first developing the equations of motion of the wing for torsion and bending. It is then assumed that simple harmonic motion occurs, or in other words if the wing is excited in a particular mode, it will continue to vibrate at the same amplitude indefinitely. The mass, stiffness and forcing function are known, so the required damping to maintain simple harmonic motion can be calculated. A V-g analysis therefore calculates the required system damping that would have to be present to allow simple harmonic motion to take place in both the torsion and bending modes for various airspeeds. There are three options for the resultant required damping prediction which are discussed below: 
1. The required damping prediction for a particular mode is indicated as negative. This means that that mode of the system is stable, and any vibrations will decay over time for this airspeed. The negative damping symbolizes that in order for the system to remain in simple harmonic motion, the wing structure would somehow have to add energy to the vibrating system. In reality the structure is not adding energy to the vibrating system, so any vibrations decay over time and flutter is not experienced. In other words, if excited, any oscillations damp out over time.

2. The required damping for a particular mode is indicated as zero. This is considered the critical flutter boundary. At this airspeed, if excited the system will continue to oscillate in simple harmonic motion.

3. The required damping for a particular mode is indicated as positive. This is the flutter region and the system is considered to be unstable. If the system is excited at these airspeeds, the amplitude of oscillations will grow with each cycle. The positive value symbolizes that in order to not experience amplitude growth every cycle, the structure would have to remove energy or dampen the vibrating system. Since there is negligible mechanical damping in a wing structure, any flight at airspeeds in a region predicting positive damping risk catastrophic flutter.

Certain flutter characteristics can be inferred from the V-g plot. Figure 8.5 is an example plot to illustrate possible results from a V-g flutter analysis. It is for descriptive purposes only and does not represent flutter performance on any specific aircraft. In Figure 8.5, the blue line shows the required damping for a particular flutter mode is 
negative throughout the range of speeds investigated for the study. This means that the flutter mode depicted by the blue line does not become unstable or experience flutter.

The red line of Figure 8.5 enters the negative region, or the region of instability, however it may or may not actually become unstable depending upon the amount of physical damping present in the wing structure. The green line of Figure 8.5 not only becomes unstable, it approaches the region of instability very quickly. There may be a difference of only a few miles an hour between stable flight and unstable flight. The large amount of instability will probably result in rapid catastrophic failure of the airframe. Extreme caution must be used if flight tests are performed in this regime of rapidly decreasing damping. The red line approaches the unstable region with a gradual reduction in damping. This gradual reduction in damping makes flight test near the flutter boundary much safer, since the linear reduction in damping makes it easier for the flight test team to predict the critical flutter speed and avoid exceeding it.

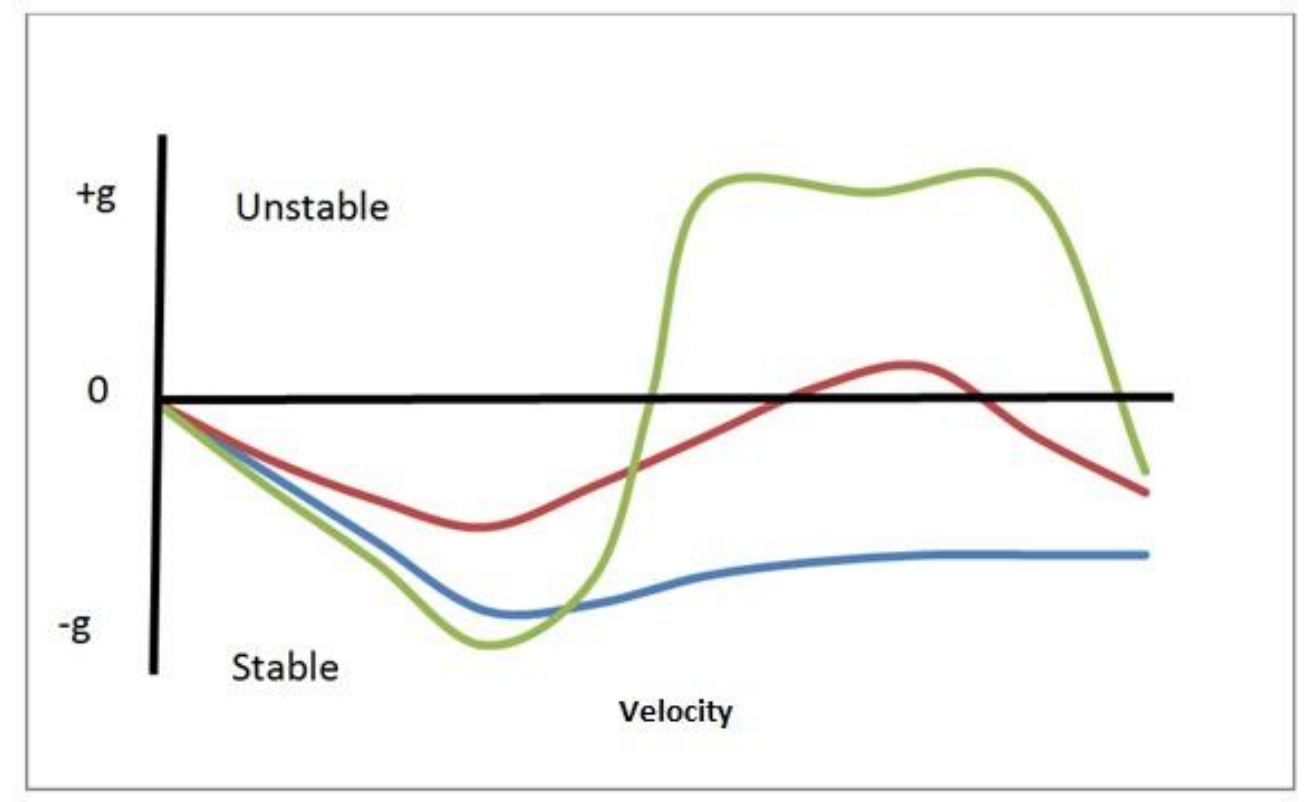

Figure 8.5: Depiction of possible damping results 
Standard values of structural damping range from about 1 to 5\% and are usually a result of various pieces of the wing rubbing together (53). Because these values are both low and generally not known during the preliminary analysis, it is customary to error conservatively by assuming the structural damping is zero for analysis purposes. (53).

\subsubsection{Discretization of the Model}

In order to perform an assumed modes analysis, the continuous model of the wing must be discretized into a series of lumped parameters as shown in Figure 8.6. The wing is divided into several sections and the mass of each section is lumped as a point mass and located at the elastic axis. A similar method is used to lump rotational inertia about the elastic axis for each wing section.

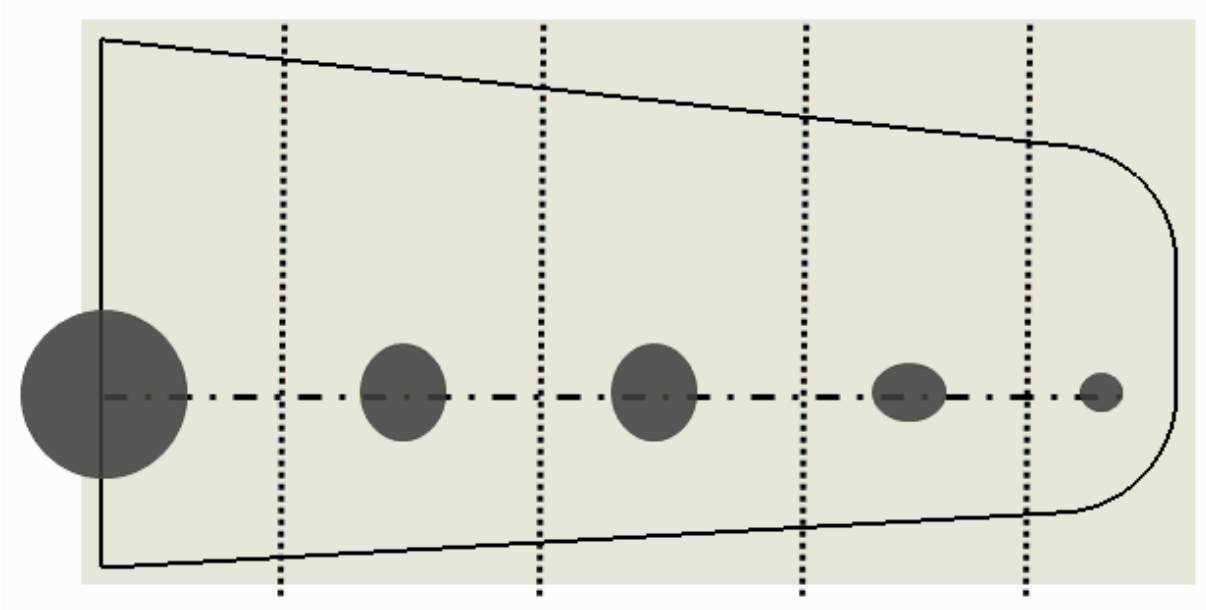

Figure 8.6: Wing sections discretized into lumped masses.

To determine the torsional mode shapes and natural frequencies, the mass moment of inertia of each wing section is lumped as one point inertia per wing section, located along the elastic axis. An assumption used in the assumed modes method is that inertia axis of each section` are located on the elastic axis of the wing. While this is 
appropriate for determination of the torsion mode shapes, it is not appropriate for remainder of the flutter analysis. To compensate, the static unbalance $\left(\mathrm{S}_{\alpha}\right)$ of the wing is calculated as the mass of the wing section times the distance between the inertia axis and the elastic axis for each section.

\subsubsection{Flexibility Influence Coefficient Matrix Calculation}

Wing bending, torsional and shear rigidity are typically specified as a function of wing span. From the rigidity data, the influence coefficient matrices can be developed (54). The influence coefficient matrices are symmetric matrices.

Bending Influence Coefficient Matrix:

$\left[C^{z z}\right] \rightarrow C_{i j}=y_{i} y_{j} \int_{0}^{y_{j}} \frac{d \lambda}{E I}-\left(y_{i}+y_{j}\right) \int_{0}^{y_{j}} \frac{\lambda d \lambda}{E I}+\int_{0}^{y_{j}} \frac{\lambda^{2} d \lambda}{E I}+\int_{0}^{y_{j}} \frac{d \lambda}{G K} \quad\left(y_{i} \geq y_{j}\right)$

Torsion Influence Coefficient Matrix:

$$
\left[C^{\theta \theta}\right] \rightarrow C_{i j}=\int_{0}^{y_{j}} \frac{d \lambda}{G J}
$$

Where $y_{i}$ and $y_{j}$ are wing station locations and EI, GK and GJ are curves describing the bending, shear and torsional rigidity of the wing as a function of distance along the wing semi-span (y)

\subsubsection{Mode Shape and Natural Frequency Development}

To calculate the first mode bending natural frequency and the first mode torsion natural frequency, the influence coefficients matrices, $\left[C^{z Z}\right]$ and $\left[C^{\theta \theta}\right]$ are first calculated. Lumped mass matrices and mass moment of inertia matrices, $[M]$ and $[I]$ are then 
assembled. The mode shapes and natural frequencies are calculated through a matrix iteration process described below.

The bending mode equation is presented below (54):

$$
\left\{W_{n+1}\right\}=\omega^{2}\left[C^{Z Z}\right][M]\{W\}
$$

Which can be rearranged as: $\frac{1}{\omega_{Z}^{2}}\left\{W_{n+1}\right\}=\left[C^{Z Z}\right][M]\{W\}$

Capital $\mathrm{W}$ is the deflection of the beam at the various stations as used in the calculation of the influence coefficients above. The mode shapes and natural frequencies are solved iteratively by first assuming a column matrix of 1's for W. The quantity $\frac{1}{\omega^{2}}\left\{W_{n+1}\right\}$ is then calculated; where $\mathrm{W}_{\mathrm{n}+1}$ is the normalized mode shape (the last position is set equal to 1 ) and $\omega_{Z}$ is the zero airspeed bending frequency of the wing. The newly calculated $\mathrm{W}_{\mathrm{n}+1}$ is then plugged back in for $\mathrm{W}$ and the process repeated until values for $\mathrm{W}$ and $\mathrm{W}_{\mathrm{n}+1}$ have converged. The same process is repeated for torsion using the following equation.

$$
\frac{1}{\omega_{\theta}^{2}}\left\{\theta_{n+1}\right\}=\left[C^{\theta \theta}\right][M]\{\theta\}
$$

For reference, wing bending frequencies for existing aircraft are displayed below in Table 8.1. These frequencies can be used to verify that any frequencies calculated for a new aircraft design are in the same ball park as other aircraft of similar configuration. 
Table 8.1 Table of various aircraft zero speed frequencies (53)

\begin{tabular}{lccc}
\hline \hline Aircraft & Lancair IV & Stallion & Cygnet \\
\hline Description & $\begin{array}{c}\text { place high speed } \\
\text { composite }\end{array}$ & $\begin{array}{c}\text { 4 place utility } \\
\text { composite }\end{array}$ & $\begin{array}{c}\text { single place } \\
\text { sailplane } \\
\text { composite }\end{array}$ \\
Material & 3550 & 3800 & 606 \\
Max Gross (lb) & 315 & 306 & -- \\
Vne (MPH) & 35.5 & 35 & 42.67 \\
Wing Span (ft) & 4.1 & 3.8 & 3.9 \\
1st wing bending (Hz) & 14.8 & 14.1 & 13.1 \\
2nd wing bending $(\mathbf{H z})$ & 19.7 & 18.7 & 24.8 \\
Aileron Flapping $(\mathbf{H z})$ & 27.3 & 26.8 & -- \\
Wing Twisting $(\mathbf{H z})$ & 29.2 & 26.1 & -- \\
3rd wing bending $(\mathbf{H z})$ & & & \\
\hline \hline
\end{tabular}

\subsubsection{Flutter Determinant Development}

The equations of motion for the wing in bending and torsion are developed by writing equations for the kinetic and potential energies of the wing and then using the Lagrange equation to produce the equations of motion. The assumed deflection modes developed in the previous section are presumed to remain unchanged by the aerodynamic forces. The process is detailed in chapter 9 of Scanlan and Rosenbaum (55).

\subsubsection{Potential and Kinetic Energy}

The total kinetic energy of the wing can be written as follows:

$$
\text { Kinetic Energy: } T=\frac{1}{2} M \dot{h}^{2}+\frac{1}{2} I_{\alpha} \dot{\alpha}^{2}+S_{\alpha} \dot{h} \dot{\alpha}
$$




$$
\begin{aligned}
& M=\int_{0}^{L} m(x)[f(x)]^{2} d x \\
& I_{\alpha}=\int_{0}^{L} I_{\alpha}(x)[F(x)]^{2} d x \\
& S_{\alpha}=\int_{0}^{L} S_{\alpha}(x) f(x) F(x) d x
\end{aligned}
$$

Where:

$M$ is the effective mass of the wing structure

$I_{\alpha}$ is the effective mass moment of inertia

$S_{\alpha}$ is the effective static unbalance of the wing structure

$\mathrm{m}(\mathrm{x})$ is the mass per unit span of the wing

$\mathrm{I}_{\alpha}(\mathrm{x})$ is the mass moment of inertia per unit span about the elastic axis of the wing

$\mathrm{S}_{\alpha}(\mathrm{x})$ is the static mass moment of inertia per unit span about the elastic axis

$f(x)$ is the uncoupled normalized bending mode shape

$\mathrm{F}(\mathrm{x})$ is the uncoupled normalized torsion mode shape

$\mathrm{L}$ is the wing semispan

$\mathrm{h}$ is the vertical deflection due to bending

$\alpha$ is the rotational deflection due to torsion

The total potential energy of the wing can be written as follows with the bending and torsional stiffness expressed in terms of the uncoupled frequencies. 
Potential Energy: $U=\frac{1}{2} M \omega_{h}^{2} h^{2}+\frac{1}{2} I_{\alpha} \omega_{\alpha}^{2} \alpha^{2}$

$$
\begin{aligned}
& k_{h}=\int_{0}^{L} E I(x)\left\{\frac{\partial^{2}}{\partial x^{2}}[f(x)]\right\}^{2} d x \\
& k_{\alpha} \int_{0}^{L} G J(x)\left\{\frac{\partial}{\partial x}[F(x)]\right\}^{2} d x \\
& k_{\alpha}=I_{\alpha} \omega_{\alpha}^{2} \\
& k_{h}=M_{h} \omega_{h}^{2}
\end{aligned}
$$

Where:

EI is the effective bending stiffness of the wing structure at a particular location along the semispan

GJ is the effective torsional stiffness of the wing structure at a particular location along the semispan

$\mathrm{k}_{\mathrm{h}}$ is the effective bending spring constant

$\mathrm{k}_{\alpha}$ is the effective torsional spring constant

$\omega_{\mathrm{h}}$ is the bending frequency

$\omega_{\alpha}$ is the bending frequency

\subsubsection{Structural Damping}

The structural damping in the wing can be expressed as follows:

Structural Damping: $D=\frac{1}{2} \frac{M g_{h} \omega_{h}{ }^{2} h^{2}}{\omega}+\frac{1}{2} \frac{I_{\alpha} g_{\alpha} \omega_{\alpha}{ }^{2} \alpha^{2}}{\omega}$

Where: 
$\mathrm{g}_{\mathrm{h}}$ is the bending structural damping

$\mathrm{g}_{\alpha}$ is the torsional structural damping

$\omega$ is the flutter frequency

\subsubsection{Generalized Forces}

The generalized forces for the oscillatory aerodynamic lift and moment are written as follows: (55)

$$
\begin{aligned}
& Q_{h}=\pi \rho \omega^{2}\left(A_{h h} h+A_{h \alpha} \alpha\right) \\
& Q_{\propto}=\pi \rho \omega^{2}\left(A_{\propto h} h+A_{\propto \alpha} \alpha\right) \\
& A_{h h}=\int_{0}^{l} b^{2}[f(x)]^{2} d x+b_{r} \mathrm{~K}_{2}\left(\mathrm{~L}_{\mathrm{h}}\right) \int_{0}^{l} b[f(x)]^{2} d x \\
& A_{h \alpha}=\int_{0}^{l} a b^{3} f(x) F(x) d x+b_{r} \mathrm{~K} 2(\mathrm{~L} \alpha) \int_{0}^{l} b^{2} f(x) F(x) d x+ \\
& b_{r}^{2} \mathrm{~K} 3(\mathrm{~L} \alpha) \int_{0}^{l} b f(x) F(x) d x-b_{r} \mathrm{~K} 2(\mathrm{Lh}) \int_{0}^{\mathrm{l}}\left(\frac{1}{2}+\mathrm{a}\right) \mathrm{b}^{2} \mathrm{f}(\mathrm{x}) \mathrm{F}(\mathrm{x}) \mathrm{dx} \\
& A_{\alpha h}=-\int_{0}^{l} a b^{3} f(x) F(x) d x-b_{r} K 2(L h) \int_{0}^{l}\left(\frac{1}{2}+a\right) b^{2} f(x) F(x) d x \\
& A_{\propto \alpha}=\int_{0}^{l}\left(\frac{1}{8}+a^{2}\right) b^{4}[F(x)]^{2} d x+b_{r} \mathrm{~K} 2(\mathrm{M} \alpha) \int_{0}^{l} b^{3}[F(x)]^{2} d x+ \\
& \mathrm{b}_{\mathrm{r}} \mathrm{K} 2(\mathrm{Lh}) \int_{0}^{\mathrm{l}}\left(\frac{1}{2}+\mathrm{a}\right)^{2} \mathrm{~b}^{3}[\mathrm{~F}(\mathrm{x})]^{2} \mathrm{dx}+\mathrm{b}_{\mathrm{r}} \mathrm{K} 2(\mathrm{Lh}) \int_{0}^{\mathrm{l}}\left(\frac{1}{2}+\mathrm{a}\right)^{2} \mathrm{~b}^{3}[\mathrm{~F}(\mathrm{x})]^{2} \mathrm{dx}- \\
& b_{r}^{2}+\mathrm{K} 3(\mathrm{~L} \alpha) \int_{0}^{l}\left(\frac{1}{2}+a\right) b^{2}[F(x)]^{2} d x-b_{r} \mathrm{~K} 2\left(\mathrm{~L} \alpha \int_{0}^{\mathrm{l}}\left(\frac{1}{2}+\mathrm{a}\right) \mathrm{b}^{3}[\mathrm{~F}(\mathrm{x})]^{2} \mathrm{dx}\right.
\end{aligned}
$$


$\mathrm{Q}_{\mathrm{h}}$ and $\mathrm{Q}_{\alpha}$ are the oscillatory aerodynamic lift and moment expressions.

The terms $A_{h h}, A_{h \alpha}, A_{\alpha h}$, and $A_{\alpha \alpha}$ are functions in the generalized force expressions that include the wing geometric and structural properties, as well as the four aerodynamic constants, $\mathrm{K}_{2}\left(\mathrm{~L}_{\mathrm{h}}\right), \mathrm{K}_{2}(\mathrm{~L} \alpha), \mathrm{K}_{3}(\mathrm{~L} \alpha), \mathrm{K}_{2}(\mathrm{M} \alpha)$. The four aerodynamic constants were determined empirically several decades ago. They are related to the airspeed, wing chord and flutter frequency by a constant called the reduced frequency, $\mathrm{k}$

$$
\text { Reduced Frequency: } k=\frac{b_{r} \omega}{v}
$$

Where:

$\mathrm{b}$ is one half of the wing chord dimension. For a tapered wing this varies with respect to wing semispan

$b_{r}$ is one half of the wing semispan at the $3 / 4$ span position

"a" is a representation of the position of the elastic axis relative to wing chord $\mathrm{v}$ is the velocity of the airstream

$\omega$ is the flutter frequency

\subsubsection{Equation of Motion Development}

Now that the potential energy, kinetic energy and structural damping equations have been developed, the Lagrange equation for non-conservative systems can be used to produce the two equations for the two different vibration modes. 


$$
\text { Lagrange Equation: } \frac{d}{d t}\left(\frac{\partial T}{\partial \dot{q}}\right)+\frac{\partial U}{\partial q}+\frac{\partial D}{\partial \dot{q}}=Q
$$

Where $\mathrm{q}$ is the degree of freedom. This produces the following equations of motion for the bending and torsion modes.

$$
\begin{aligned}
& M \ddot{h}+S_{\alpha} \ddot{\alpha}+M \omega_{h}^{2} h+\frac{g_{h \omega_{h}^{2} M}}{\omega} \dot{h}=\pi \rho \omega^{2}\left\{A_{h h} h+A_{h \alpha} \alpha\right\} \\
& S_{\alpha} \ddot{h}+I_{\alpha} \ddot{\alpha}+I_{\alpha} \omega_{\alpha}^{2}+\frac{g_{\alpha} \omega_{\alpha}^{2} I_{\alpha}}{\omega} \dot{\alpha}=\pi \rho \omega^{2}\left\{A_{\alpha h} h+A_{\alpha \alpha} \alpha\right\}
\end{aligned}
$$

\subsubsection{Assumption of Simple Harmonic Motion}

A critical part of the flutter analysis method is to assume that the system vibrates in simple harmonic motion. Therefore, in the above equations of motion 8.25 and 8.26 , the following substitutions can be performed:

$$
\begin{aligned}
& \ddot{h}=-\omega^{2} h \\
& \dot{h}=i \omega h \\
& \ddot{\alpha}=-\omega^{2} \alpha \\
& \dot{\alpha}=i \omega \alpha
\end{aligned}
$$

Another critical assumption is a constant structural damping for both the bending and torsion modes.

$$
g_{h}=g_{\alpha}=g
$$

The above assumptions in equations 8.27 to 8.31 are substituted into the previously developed equations of motion in equation 8.25 and 8.26. These equations are then rearranged so that the right hand side is equal to zero (55). This results in the following two equations of motion for wing bending and torsion, equations 8.32 and 8.33 


$$
\begin{aligned}
& {\left[M+\pi \rho A_{h h}-M(1+i g)\left(\frac{\omega_{h}}{\omega}\right)^{2}\right] h+\left(S_{\alpha}+\pi \rho A_{h \alpha}\right) \alpha=0} \\
& \left(S_{\alpha}+\pi \rho A_{\alpha h}\right) h+\left[I_{\alpha}+\pi \rho A_{\alpha \alpha}-I_{\alpha}(1+i g)\left(\frac{\omega_{\alpha}}{\omega}\right)^{2}\right] \alpha=0
\end{aligned}
$$

The determinant of the coefficients in the above equation must equal zero in order for there to be a solution to the simultaneous equations. The flutter determinant then becomes

$$
\begin{aligned}
& {\left[\begin{array}{cc}
1+\frac{\pi \rho A_{h h}}{M}-\left(\frac{\omega_{h}}{\omega_{\alpha}}\right)^{2} Z & \left(\frac{S_{\alpha+} \pi \rho A_{h \alpha}}{M}\right) \\
\frac{S_{\alpha}+\pi \rho A_{\alpha h}}{I_{\alpha}} & \frac{1+\pi \rho A_{\alpha \alpha}}{I_{\alpha}}-Z
\end{array}\right]=0} \\
& \text { Where } Z=\left(\frac{\omega_{\alpha}}{\omega}\right)^{2}(1+i g)
\end{aligned}
$$

The two roots of the determinant, $\mathrm{Z}$ are solved for various values of the reduced frequency, $\mathrm{k}$. The two roots, $\mathrm{Z}_{1}$ and $\mathrm{Z}_{2}$ correspond to the two modes of vibration, bending and torsion. From the two Z's the flutter frequency and required damping for a particular mode can be easily solved using equation (8.35). The flutter frequency, $\omega$, is then used along with the reduced frequency used to calculate the airspeed $(v)$ using the relationship below:

$$
v=\frac{b_{r} \omega}{k}
$$

In order to populate the flutter determinant, a reduced frequency, $\mathrm{k}$, is assumed. The aerodynamic constants, $\mathrm{K}_{2}\left(\mathrm{~L}_{\mathrm{h}}\right), \mathrm{K}_{2}(\mathrm{~L} \alpha), \mathrm{K}_{3}(\mathrm{~L} \alpha), \mathrm{K}_{2}(\mathrm{M} \alpha)$, corresponding to the particular $\mathrm{k}$ are then used to calculate the components of the aerodynamic forces, $A_{h h}, A_{h \alpha}, A_{\alpha h}$, and $\mathrm{A}_{\alpha \alpha}$, that are used in the construction of the flutter determinant. 
The roots of the flutter determinant are complex numbers due to the phase differences between the motion of the structure and the aerodynamic loads. Each root of the determinant gives the flutter analyst both the required damping for a particular mode as well as the flutter frequency, $\omega$, corresponding to the damping value. The flutter frequency is the real portion of the complex root and the damping is the imaginary portion of the root. The flutter frequency and the reduced frequency can be used to determine the corresponding airspeed.

\subsubsection{Summary of Flutter Methodology}

1. Determine wing structural and geometric properties

2. Determine wing natural frequencies and normalized mode shapes

3. Develop potential and kinetic energy equations

4. Develop damping equations

5. Develop generalized forces equations using the tabulated aerodynamic constants for a given reduced frequency, $\mathrm{k}$

6. Determine the equations of motion using Lagrange's equation

7. Assume the wing oscillates in simple harmonic motion

8. Set the flutter determinant equal to zero

9. Solve the determinant roots

10. Calculate the damping and corresponding airspeeds from the determinant roots. 


\subsection{Flutter Flight Testing}

FAR part 23.629 requires that aircraft must be test flown and shown to be free from flutter through all parts of the speed and loading envelope. The first step is to perform a ground vibration test to confirm static natural frequencies and mode shapes (53). If there is any discrepancy between the ground vibration test and the flutter model, the stiffness and mass used in the flutter model must be adjusted until the model adequately predicts the static natural frequencies.

FAR 23.629 requires attempts to made to excite flutter at various speeds. The pilot is generally not able to adequately attempt to excite flutter manually through control surface deflections. Instead methods such as a rotating unbalance or explosive charges are used to excite flutter. If no rational analysis has been performed, attempts must be made to excite all of the various frequencies that can reasonably be expected to be critical. This can become very expensive and time intensive. If a high fidelity flutter model has been developed, efforts can be concentrated on the modes predicted to be the most critical, saving time and potentially justifying the expense of the flutter analysis. (56). Further, as flutter frequencies are generally above $5 \mathrm{~Hz}$, a pilot does not have the ability to manually damp flutter. Not performing a rational analysis, although allowed by the certification standards, is highly discouraged by the FAA since flutter could be experienced unexpectedly during flight testing. 


\subsection{Chapter Summary}

In this chapter, dynamic aeroelasticity was defined as the effect of a flowing fluid on an elastic structure. The structure can be mathematically modeled as a standard vibration problem is which the air flowing over the structure provides the forcing function. This effect is known as aeroelastic flutter in the aviation industry.

In order to model a dynamic structure in an airstream, the structure is discretized into lumped mass, torsional inertia and stiff nesses. The structure is then assumed to oscillate in simple harmonic motion, and the structural damping required to achieve simple harmonic motion solved for. This required damping versus velocity of the air stream are plotted on a V-g diagram and used to solve for the critical flutter speed of the aircraft.

The theories and methodologies explained in this chapter were used to develop a mathematical flutter model in Matlab. This Matlab script is used in subsequent wing design chapters to enable quick analysis of multiple possibilities for battery weight distributions and ultimately ensure that the weight distribution chosen would not produce undesired flutter effects. Now that a method to analyze the flutter properties of a wing has been developed, the next chapter develops the structural wing design requirements. 


\section{CHAPTER 9: Wing Structural Design Requirements}

In order to perform a structural design and analysis, the structural requirements must first be understood. The structural design of an aircraft component should be driven by the goal of obtaining certification from the appropriate regulatory body. Obtaining certification requires meeting the design and testing requirements defined by the appropriate regulatory body. In the United States, the Federal Aviation Administration has outlined design and testing requirements for several different categories of airplanes. Normal, utility and aerobatic aircraft fall under the veil of FAR Part 23. There is no specific category for a glider or powered glider, they are instead designed to the normal, utility or aerobatic category as appropriate. In Europe, a group of authorities of certain countries have created the Joint Aviation Requirements, of which there is a specific sailplane category, JAR 22. For this thesis, FAR Part 23 will be used.

Many of the regulations in FAR Part 23 refer to certain design airspeeds. For this thesis, the published airspeeds for the Pipistrel Sinus Motor Glider Flight Manual are used for the design airspeeds. It is important to note that Pipistrel treats the never exceed speed as true airspeed, as opposed to the indicated airspeed displayed to the pilot during the flight and used for the maneuvering speed and max speed in rough air. This means that when the aircraft flies at an altitude higher than sea level, indicated never exceed speed must be reduced to ensure the true airspeed limit is not exceeded. For this thesis, the published never exceed speed, $\mathrm{V}_{\mathrm{NE}}$ and the design diving speed, $\mathrm{V}_{\mathrm{D}}$ are assumed to be the same and used interchangeably. The design airspeeds used for this thesis are summarized in Table 9.1. 
Table 9.1 Pipistrel Sinus airspeeds

\begin{tabular}{lccc}
\hline Description & Symbol & Knots & MPH \\
\hline Maneuvering Speed (IAS) & $\mathrm{V}_{\mathrm{A}}$ & 76 & 87 \\
Max speed in rough air (IAS) & $\mathrm{V}_{\mathrm{C}}$ & 76 & 87 \\
Never Exceed Speed (TAS) & $\mathrm{V}_{\mathrm{ne}}$ & 122 & 140 \\
\hline \hline
\end{tabular}

Chapter Goals:

- Present an overview of the applicable structural design criteria that will be used for this thesis

- Summarize the applicable load and speed criteria into a concise table for future reference.

The components of FAR 23 as they pertain to the structural design of a wing for this thesis are reproduced in the following sections 9.1 through 9.5 .

\subsection{Factor of Safety: FAR 23.303}

Unless otherwise provided, a factor of safety of 1.5 must be used.

\subsection{Strength and Deformation: FAR 23.305}

(a) The structure must be able to support limit loads without detrimental, permanent deformation. At any load up to limit loads, the deformation may not interfere with safe operation. 
(b) The structure must be able to support ultimate loads without failure for at least three seconds, except local failures or structural instabilities between limit and ultimate load are acceptable only if the structure can sustain the required ultimate load for at least three seconds. However when proof of strength is shown by dynamic tests simulating actual load conditions, the three second limit does not apply.

\subsection{Flight Envelope: FAR 23.333}

(a) General. Compliance with the strength requirements of this subpart must be shown at any combination of airspeed and load factor on and within the boundaries of a flight envelope (similar to the one in paragraph (d) of this section) that represents the envelope of the flight loading conditions specified by the maneuvering and gust criteria of paragraphs (b) and (c) of this section respectively.

(b) Maneuvering envelope. Except where limited by maximum (static) lift coefficients, the airplane is assumed to be subjected to symmetrical maneuvers resulting in the following limit load factors:

(1) The positive maneuvering load factor specified in $\$ 23.337$ at speeds up to $V_{D}$;

(2) The negative maneuvering load factor specified in $\$ 23.337$ at $V_{C}$; and

(c) Gust envelope. (1) The airplane is assumed to be subjected to symmetrical vertical gusts in level flight. The resulting limit load factors must correspond to the conditions determined as follows: 
(i) Positive (up) and negative (down) gusts of 50 f.p.s. at $V_{C}$ must be considered at altitudes between sea level and 20,000 feet. The gust velocity may be reduced linearly from 50 f.p.s. at 20,000 feet to 25 f.p.s. at 50,000 feet.

(ii) Positive and negative gusts of 25 f.p.s. at $V_{D}$ must be considered at altitudes between sea level and 20,000 feet. The gust velocity may be reduced linearly from 25 f.p.s. at 20,000 feet to 12.5 f.p.s. at 50,000 feet.

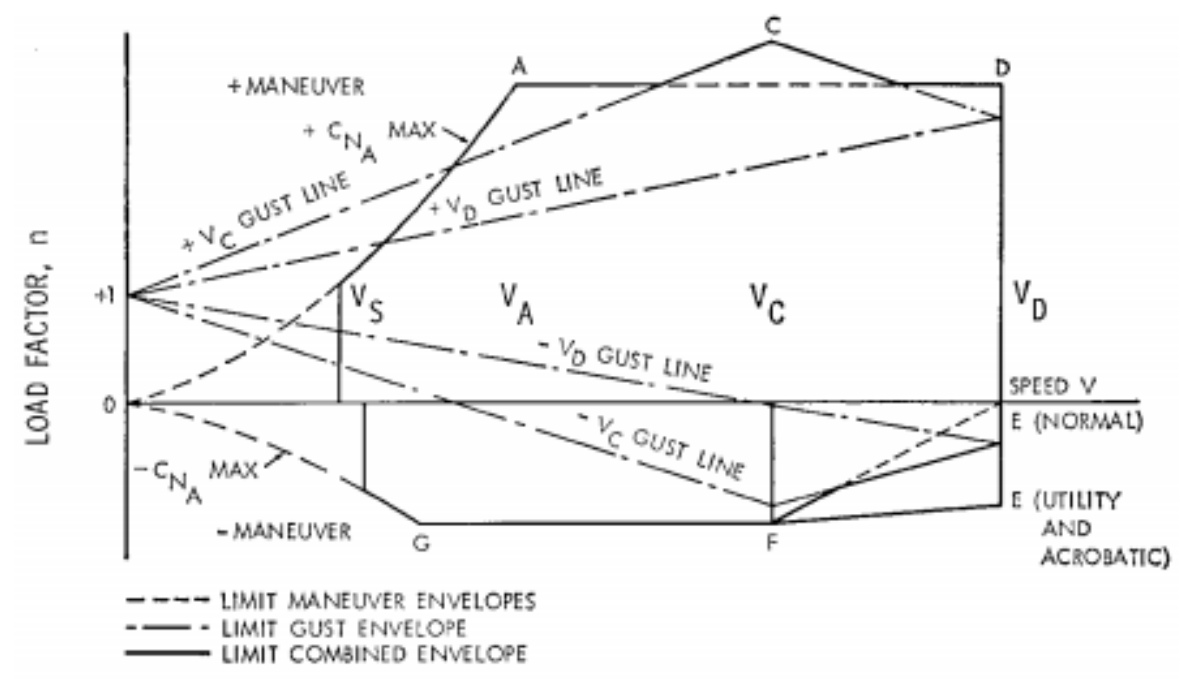

Figure 9.1: Flight Envelope depiction found in FAR 23.333

\subsection{Maneuvering Envelope:}

FAR 23.337-Limit Maneuvering Load Factors

(a) The positive limit maneuvering load factor $n$ may not be less than:

1) 3.8 for normal category airplanes

2) 4.4 for utility category airplane 
(3) 6.0 for acrobatic category airplanes

b) The negative limit maneuvering load factor may not be less than-

(1) 0.4 times the positive load factor for the normal utility

(2) 0.5 times the positive load factor for the acrobatic category

\subsection{Gust Load Factors:}

FAR 23.341-Gust Load Factors

(a) Each airplane must be designed to withstand loads on each lifting surface resulting from gusts specified in $\S 23.333(c)$.

(b) In the absence of a more rational analysis, the gust load factors must be computed as follows-

$$
n=1+\frac{K_{g} U_{\dot{e g}} V a}{498(W / S)}
$$

Where:

$K_{g}=0.88 \mu_{\mathrm{g}} / 5.3+\mu_{\mathrm{g}}=$ gust alleviation factor;

$\mu_{\mathrm{g}}=2(\mathrm{~W} / \mathrm{S}) / \rho$ Cag=airplane mass ratio;

$U_{d e}=$ Derived gust velocities referred to in §23.333(c) (f.p.s.);

$\rho=$ Density of air (slugs/cu.ft.);

$W / S=$ Wing loading (p.s.f.) due to the applicable weight of the airplane in the particular load case. 
$W / S=$ Wing loading (p.s.f.);

$C=$ Mean geometric chord (ft.);

$g=$ Acceleration due to gravity (ft./sec. ${ }^{2}$ )

$V=$ Airplane equivalent speed (knots); and

$a=$ Slope of the airplane normal force coefficient curve $C_{N A}$ per radian if the gust loads are applied to the wings and horizontal tail surfaces simultaneously by a rational method. The wing lift curve slope $C_{L}$ per radian may be used when the gust load is applied to the wings only and the horizontal tail gust loads are treated as a separate condition.

\subsection{Summary of Applicable Regulations}

In summary, a normal category aircraft must be designed for a load factor of positive 3.8 and negative 1.52 . Further, the aircraft must be able to experience a \pm 50 foot per second vertical gust at $V_{C}$ and a 25 foot per second vertical gust at $V_{D}$. The resulting load factor from a vertical gust is calculated with the following equation:

$$
n=1+\frac{K_{g} U_{d e} V a}{498(W / S)}
$$

If the load factor $\mathrm{n}$ resulting from the vertical gust is greater than positive 3.8 or negative 1.52 , the airframe will have to be designed to handle the larger load factor, or the airspeeds $V_{c}$ and $V_{D}$ will have to be reduced until the load factor produced by a gust load does not exceed 3.8 or -1.52 . The factor of safety required for all structural design is 1.5. The structure must be able to support the limit load without permanent deformation 
or damage. The structure must also be able to support 1.5 times the limit load without catastrophic failure. These load factors from FAR 23 are summarized in Table 9.2.

Table 9.2 Structural Load Requirements

\begin{tabular}{cc}
\hline Max Positive Maneuvering Load Factor: & $3.8 \mathrm{~g}$ 's \\
Max Negative Maneuvering Load Factor & -1.52 g's \\
Max vertical gust at $\mathrm{V}_{\mathrm{c}}$ & 50 f.p.s. \\
Max vertical gust at $\mathrm{V}_{\mathrm{D}}$ & 25 f.p.s. \\
\hline
\end{tabular}

The maximum load factor resulting from vertical gusts at $V_{c}$ and $V_{D}$ must calculated and then compared against the maximum maneuvering load factors. For the Pipistrel Sinus, it is found that the maneuvering load factors are found to be driving. This results in the final load factor requirements tabulated in Table 9.3.

Table 9.3 Structural Load Requirements used in Thesis.

\begin{tabular}{cc}
\hline \hline Maximum Positive Limit Load Factor & 3.8 \\
Maximum Negative Limit Load Factor & 1.52 \\
Ultimate Load Factor (Safety Factor) & 1.5 times limit load \\
Pipistrel Sinus Max Gross Weight & $1290 \mathrm{lb}$ \\
\hline \hline
\end{tabular}




\section{CHAPTER 10: Wing Structural Design}

Now that the load factor requirements are defined and the flutter theory understood, this chapter outlines the process used to perform a structural design of the wing structure as well as selecting locations for packaging the batteries. Goals for this chapter are:

- Indentify material properties to be used for the structural design.

- Examine structural properties of currently flying aircraft

- Develop an understanding of the loads applied to the wing structure

- Outline the iterative process used to design the wing structure

- Analyze the performance of the wing in the following categories:

○ Buckling

- Shear, Bending and Torsion

○ Deflection/Stiffness

- Aeroelastic effects

- Select a packaging configuration for the batteries

\subsection{Existing Structural Design Information}

\subsubsection{Existing Material Database and Existing Aircraft Structural Sizing}

The AGATE Database (Advanced General Aviation Transport Experiments) is a database of A-basis and B-basis allowables that has been developed over the last several years by the National Institute for Aviation Research. The availability of this data allows an engineer to develop an initial structural design without testing and qualifying material and therefore reducing the development costs of an aircraft. From this database, the following material properties presented in Table 10.1 were used. 
Table 10.1 ETW material properties used for subsequent design work

\begin{tabular}{lclc}
\hline \hline Newport 321 Uni Tape Carbon & \multicolumn{2}{l}{ Newport 321 3K Weave Carbon } \\
\hline Density $\left({\left.\mathrm{lb} / \mathrm{in}^{3}\right)}^{\mathrm{N}}\right.$ & 0.1077 & Density $\left(\mathrm{lb} / \mathrm{in}^{3}\right)$ & 0.108 \\
$\mathrm{t}_{\mathrm{ply}}(\mathrm{in})$ & 0.00629 & $\mathrm{t}_{\mathrm{ply}}(\mathrm{in})$ & 0.00823 \\
$\mathrm{~F}_{1 \mathrm{t}}(\mathrm{KSI})$ & 233.93 & $\mathrm{~F}_{1 \mathrm{t}}(\mathrm{KSI})$ & 61.51 \\
$\mathrm{E}_{1}(\mathrm{MSI})$ & 17.76 & $\mathrm{E}_{1}(\mathrm{MSI})$ & 9.62 \\
$\mathrm{v}_{12}$ & 0.321 & $\mathrm{v}_{12}$ & 0.058 \\
$\mathrm{~F}_{2 \mathrm{t}}(\mathrm{KSI})$ & 3.96 & $\mathrm{~F}_{1 \mathrm{c}}(\mathrm{KSI})$ & 45.87 \\
$\mathrm{E}_{2}(\mathrm{MSI})$ & 1.17 & $\mathrm{~F}_{12}(\mathrm{KSI})$ & 9.2 \\
$\mathrm{~F}_{1 \mathrm{c}}(\mathrm{KSI})$ & 97.31 & $\mathrm{G}_{12}(\mathrm{MSI})$ & 0.62 \\
$\mathrm{~F}_{2 \mathrm{c}}(\mathrm{KSI})$ & 20.61 & $\mathrm{~F}_{13}(\mathrm{KSI})$ & 7.16 \\
$\mathrm{~F}_{12}(\mathrm{KSI})$ & 13.36 & & \\
$\mathrm{G}_{12}(\mathrm{MSI})$ & 0.55 & & \\
$\mathrm{~F}_{13}(\mathrm{KSI})$ & 12.59 & & \\
\hline \hline
\end{tabular}

The AGATE database does not currently contain data on any types of core used for sandwich composite structures. For reasons to be explained later, a certain density Rohacell foam core was selected. The material properties used are those provided on the Rohacell datasheet and produced below in Table 10.2.

Table 10.2 Rohacell 71 WF foam properties

\begin{tabular}{lc}
\hline \hline Density $\left(\mathrm{lb} / \mathrm{ft}^{3}\right)$ & 4.67 \\
$\mathrm{~F}_{1 \mathrm{t}}(\mathrm{PSI})$ & 319 \\
$\mathrm{E}_{1}(\mathrm{PSI})$ & 15225 \\
$\mathrm{v}_{12}$ & 0.25 \\
$\mathrm{~F}_{1 \mathrm{c}}(\mathrm{PSI})$ & 246 \\
$\mathrm{~F}_{12}(\mathrm{PSI})$ & 188 \\
$\mathrm{G}_{12}(\mathrm{PSI})$ & 6090 \\
$\mathrm{~F}_{13}(\mathrm{PSI})$ & 188 \\
\hline \hline
\end{tabular}




\subsubsection{Laminate Data for Existing Composite Aircraft}

To provide an initial baseline and to verify that any subsequent structural design calculations are similar to existing aircraft, data on several production and experimental aircraft are summarized below. One important aspect to note is the large skin thickness typically used on composite aircraft. The skin thickness is produced by using a sandwich panel construction with a thick core. This stiffens the skin, which allows it to take more bending and torsion loads without buckling as well as resist damage from handling loads such as a person leaning on the wing skin or impact from rocks or bird strikes.

Cessna 350/400 (57)

Upper Spar Cap: $\quad$ Root: 135 plies UNI carbon prepreg

Tip: 2 plies UNI carbon prepreg

Lower Spar Cap: $\quad$ Root: 72 plies UNI carbon prepreg

Tip: 2 plies UNI carbon prepreg

Upper Wing Skin Root: [5/core/2] Fiberglass and 3 p.s.f. aramid paper core Tip: [2/core/2] Fiberglass and 3 p.s.f. aramid paper core

Cirrus SR22 G3 (57)

Spar Caps: $\quad 0.5$ inches thick UNI carbon prepreg

Wing Skins: [2/core/2] E-glass and Divinycell HT foam .39 inches thick

Epic Escape (57)

Spar Caps: $\quad$ UNI carbon prepreg

Wing Skins: $\quad$ Root: [3/core/3] Divinycell Foam core

Tip: [2/core/2] 
Rutan Long EZ (58)

Upper Spar Cap: $\quad$ Root: 7 plies UNI glass wet. 0.245 inches thick Tip: 1 ply UNI glass wet. 0.035 inches thick

Lower Spar Cap: $\quad$ Root: 5 plies UNI glass wet. 0.175 inches thick Tip: 1 ply UNI glass wet. 0.035 inches thick

Wing Skins: $\quad[ \pm 30] 2$ plies UND glass wet. 0.018 inches thick

\section{Pipistrel Sinus (59)}

Wing Skins: $\quad\left[ \pm 45_{\mathrm{UNI}} / 0_{\text {cloth }} / \text { Core }\right]_{\text {Symmetric }}$ Glass with 0.197 ” thick Herex foam core 4.67 P.S.F density

\subsection{Applied Loads}

For this thesis, the wing was modeled as a cantilever beam with the attachment point between wing and fuselage considered to be fixed. There were two aerodynamic theories that could have been used to predict the lifting load distributed across the span of the wing. The first theory is 2D airfoil strip theory. As its name entails, 2D airfoil theory consists of determining the resulting lift force for a two dimensional airfoil. It does not incorporate any affects from span wise flow. This means that 2D airfoil theory models the distributed lifting load as uniform distributed load across the entire wing span. It also assumes no built in wing twist or wing twist resulting from applied torsion loads.

In reality, there is span wise flow along the wing. The lift force falls off to zero at the wing tips, meaning that the portion of the wing closest to the tips is producing significantly less lift than the portion near the root as shown in Figure 10.1. This reduction in lift near the tips for lifting line theory reduces the shear loads in the outboard portion of the wing when compared with 2D airfoil theory as shown in Figure 10.2. Since 
the lifting force is developed further inboard for lifting line theory compared with $2 \mathrm{D}$ airfoil theory, the total bending moment carried at any wing section is less for lifting line theory as shown in Figure 10.3. This means that 2D airfoil theory over predicts the loads carried by the wing in both bending and shear. It is therefore conservative to use 2D airfoil theory to predict applied loads. Due to the increased simplicity of using a uniform load theory and the fact that 2D airfoil theory has been shown to be conservative, 2D airfoil theory will be used for subsequent structural analysis.

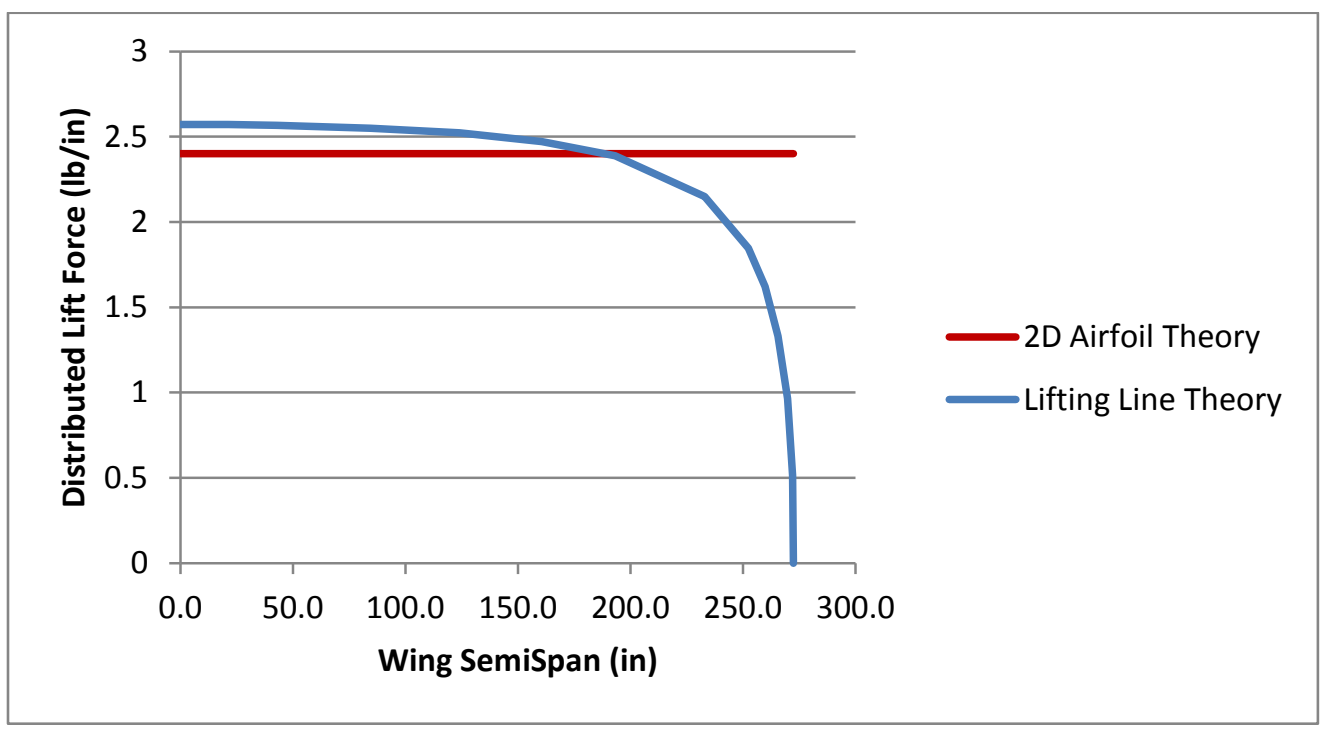

Figure 10.1:Comparison between 2D airfoil theory and lifting line theory. 


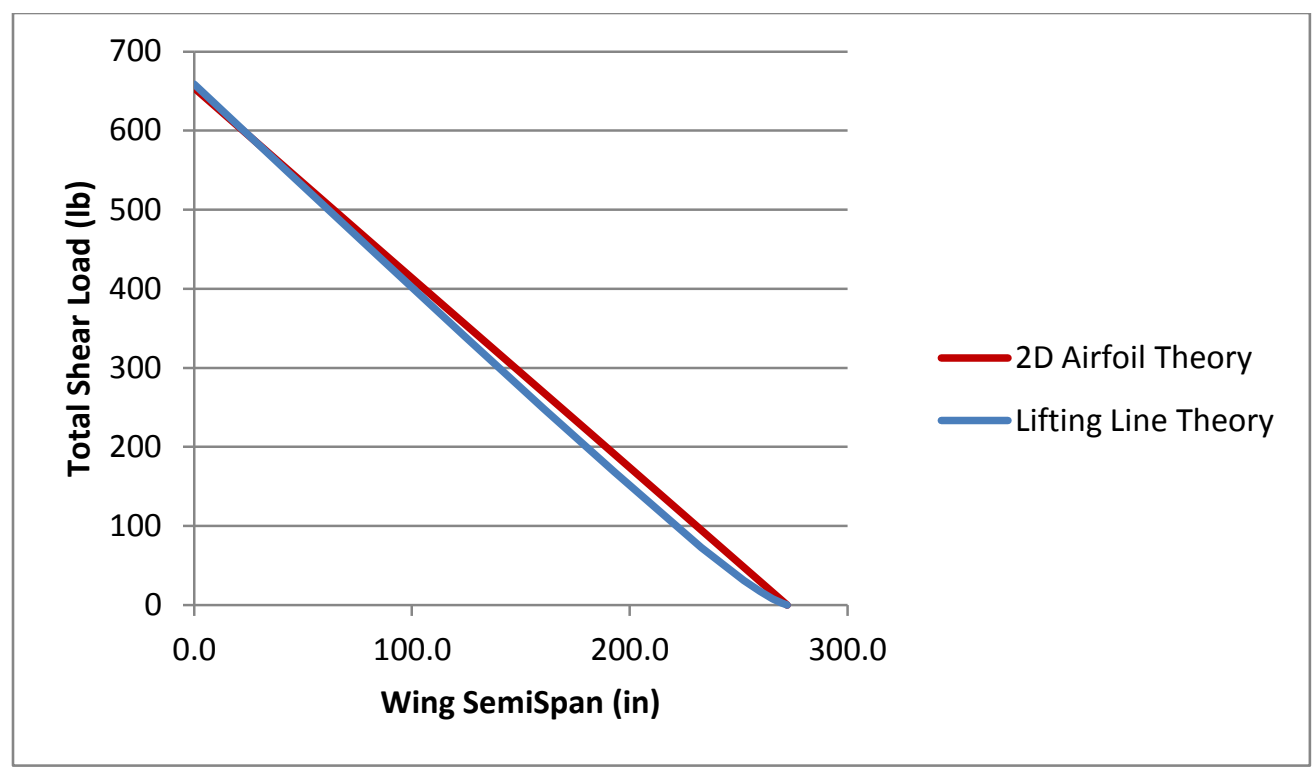

Figure 10.2: Shear load along wing semispan for 2D airfoil and lifting line theory.

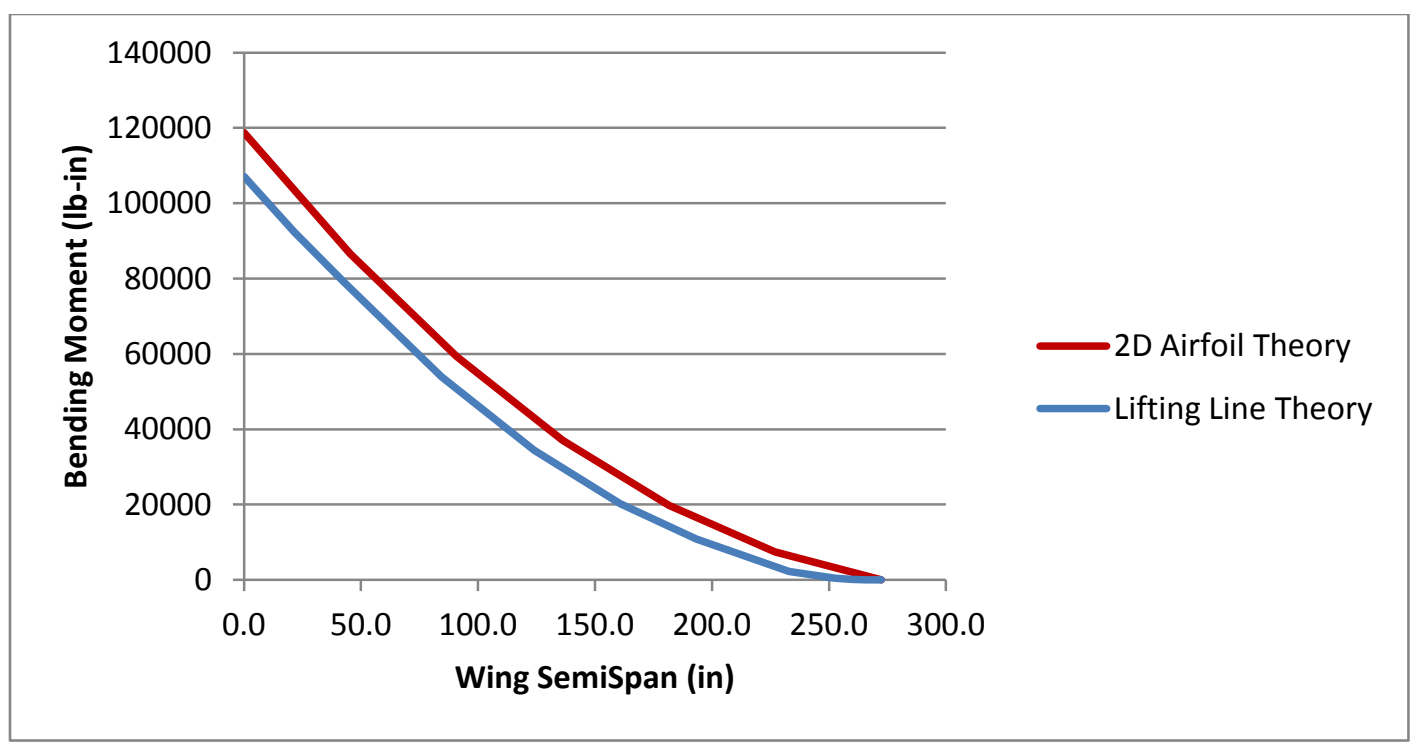

Figure 10.3: Bending moment along semi span for 2D airfoil and lifting line theory. 


\subsection{Chordwise Lift for a 2D Airfoil}

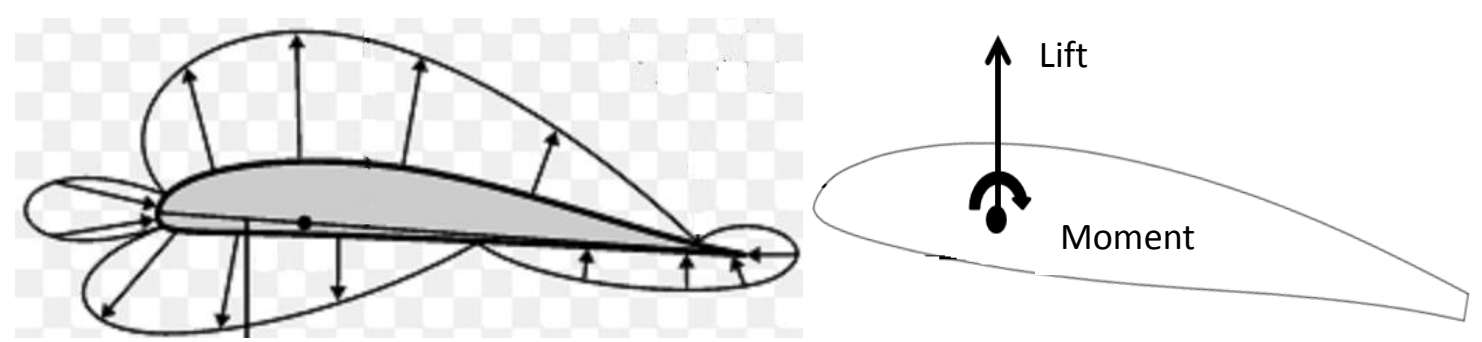

Figure 10.4:Pressure distribution resolved as a force and moment (60)

The image on the left of Figure 10.4 represents the actual pressure distribution on the airfoil surface. These forces can be resolved into a vertical lift force and a horizontal drag force, both of which act through the center of pressure. The problem with resolving the forces through the center of pressure is that for cambered airfoils the center of pressure moves depending on the lift coefficient. The center of pressure starts at an infinite distance behind the leading edge for very low lift coefficients and moves forward toward the $1 / 4$ chord point as the lift coefficient is increased. In order to more easily resolve the pressure acting on the wing, a the aircraft industry has defined a position called the aerodynamic center. The lift and drag forces are presumed to act through the aerodynamic center and a moment is applied to compensate for the fact that the aerodynamic center does not coincide with the center of lift. This is shown to the image on the right of Figure 10.4. To simplify the analysis, the aerodynamic center is defined as the particular point on the wing in which moment remains constant as the lift varies. 2D airfoil theory predicts that the aerodynamic center lies at approximately the airfoil 1/4 chord point. For highly cambered airfoils such as the ones typically used for gliders, the 
pitching moment coefficient is usually negative. This means that the pitching moment is usually nose down. (61)

The pitching moment about the $1 / 4$ chord point is defined as:

$$
M_{P}=C_{m} \frac{1}{2} \rho v^{2} S c
$$

A positive pitching moment is defined as a nose-up moment. The total moment (T) acting on the elastic axis of the wing section is therefore:

$$
T=L \times e+M_{P}
$$

Where e is the distance from the aerodynamic center and the elastic axis. These locations are illustrated in Figure 10.5.

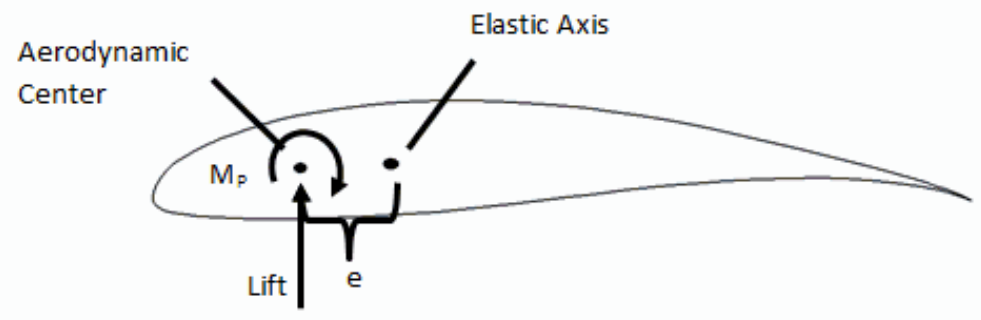

Figure 10.5: Key locations on an airfoil.

\subsection{Wing Development Methodology}

Now that the bending, torsion and spanwise loads are known, the wing structure can be sized. Sizing the various components of the wing is an iterative process. The following process was used to develop a conceptual wing layout. 
1. Size wing skins due to minimum gage requirements

2. Guess an appropriate wing rib spacing based on previous aircraft. Size rib thickness for strength

3. Size the spar caps and shear walls for strength while minding load distribution between skin and spar due to varying stiff nesses.

4. Calculate the elastic axis and torsion constant of the wing

5. Check torsion strength of wing structure

6. Tabulate effective EI, GJ, wing mass, torsional inertias, static moments

7. Check bending and torsional deflections

8. Check flutter properties

\subsubsection{Wing Skin Sizing}

Several loads act on the wing skins during flight. These loads consist of:

1. Out of plane shear loads due to pressure distribution across the wing surface. These loads are very low and are less than 0.5 P.S.I on average. Since they are so low for this conceptual design they are neglected for sizing the wing skin.

2. Wing torsion due to the applied distributed moment on the wing. The wing skins form a torque tube that is much more efficient in carrying torsion when compared to a boxed spar due to the much greater enclosed area of the entire wing structure. 
3. Normal Loads from the wing bending moment. Due to the large area moment of inertia of a wing skin cross section, the wing skins can support a very large bending moment. They are in fact limited not by maximum bending normal stress but by buckling of the wing skin.

4. Foreign object damage and other impact loads.

After studying the wing skin laminates for other composite aircraft skins as referenced in section 10.1.2, it was decided to use the existing Pipistrel Skin laminate as a required minimum gage skin thickness. All of the wing skin laminates are very similar. It is assumed that the aircraft industry has done experimental testing to justify the skin thickness chosen by Pipistrel and that the skin thickness was chosen based on its ability to resist unpredictable loads such as impact damage from hail, stones, wrench drops, bird strikes etc. The following laminate schedule is assumed for the skin thickness, as specified by Pipistrel:

$\left[ \pm 45_{\mathrm{UNI}} / 0_{\text {cloth }} / \text { Core }\right]_{\text {Symmetric }}$ Carbon with 0.197 ” thick Rohacell 71 WF foam core of 4.67 P.S.F density.

\subsubsection{2.) Rib Spacing and Wing Skin Buckling, Rib Thickness}

Rib spacing along the wing span is driven by the prevention of wing skin buckling. The wing skins carry part of the bending overall wing bending moment acting on the wing structure. This bending moment results in a compressive normal force being applied to the upper wing skin. The further apart the ribs are spaced, the lower the wing skin stress that will induce skin buckling. This trend is illustrated in Figure 10.6. 


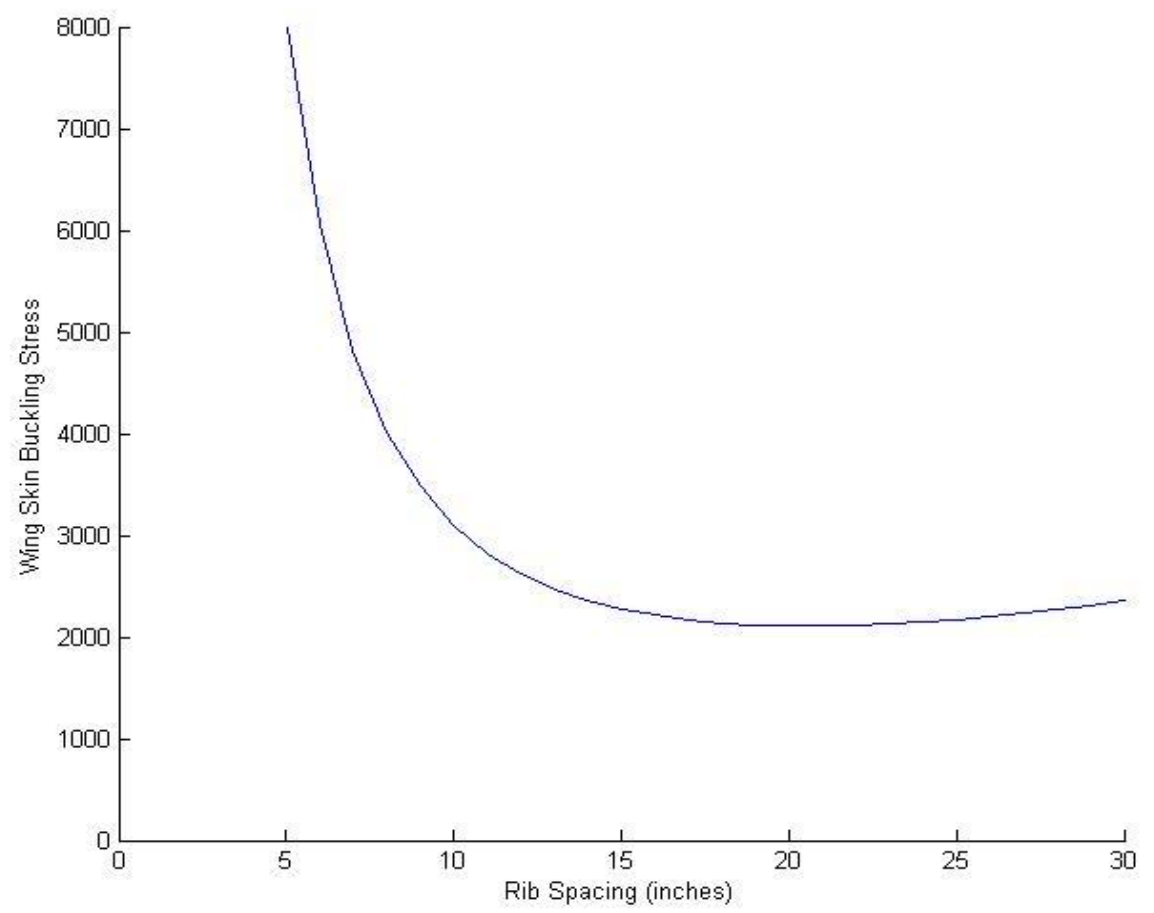

Figure 10.6: Computed wing skin buckling stress with variation in rib spacing

For a laminated plate experiencing first mode buckling $(m=1)$, the following equation is used to predict the line load at which buckling will occur (62)

$$
N_{o}=\pi^{2}\left[D_{11}\left(\frac{m}{a}\right)^{2}+2\left(D_{12}+2 D_{66}\right) \frac{1}{b^{2}}+D_{22} \frac{1}{b^{4}}\left(\frac{a}{m}\right)^{2}\right]
$$

The buckling stress is the line load dividing by the laminate thickness.

$$
\sigma_{\text {Buckling }}=\frac{N_{O}}{t_{\text {laminate }}}
$$

The locations used in the above equations are illustrated below in Figure 10.7. Side "a" is the distance along the wingspan. Side "b" is the distance along the wing chord. The resultant normal stress from the bending moment is applied parallel to the wing spar. First mode buckling is shown 


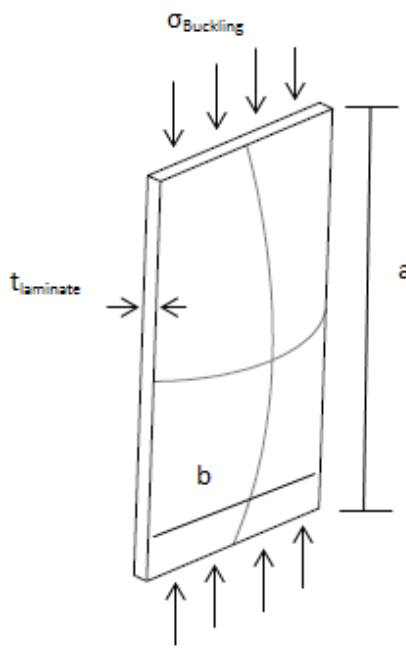

Figure 10.7: Lengths used in buckling equation.

The buckling equations for a laminated plate in compression assume that the buckling stress is applied uniformly across side "b". Since the normal stress in the wing skin is a result of a bending moment, the normal stress in the skin varies as the distance from the wing skin to the bending neutral axis decreases. For the conceptual design performed in this thesis, the average normal stress applied to the wing skin between the spar and the trailing edge is used to determine the maximum bending moment that can be supported by the wing skins before buckling is induced. This is illustrated by Figure 10.8 . The buckling of the wing skin is modeled as a flat plat simply supported on all sides. The average buckling stress is the average stress occurring between the wing spar and the trailing edge. 


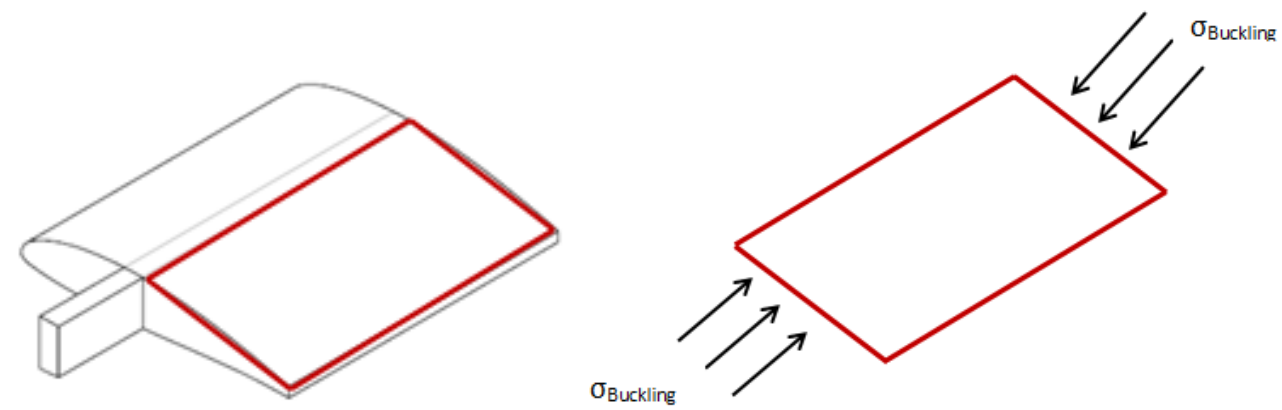

Figure 10.8: Geometry used for Buckling Analysis

\subsubsection{Spar Sizing}

For a conceptual layout, it is assumed that the entirety of the bending moment carried by the spars is resisted by the spar caps. Likewise, it is assumed that the entirety of the direct shear load carried by the spars is reacted by the spar shear walls.

\subsubsection{Spar Cap Sizing}

The fact that the skin and spars are bonded together means that the skin and the spar caps must have the same amount of strain at the location where the skin is bonded to the spars. However, due to the fact that the skins and the spars have different effective stiffnesses, the stresses in the skin and spar will not be the same. The skin geometry is defined by the airfoil shape and the skin laminate is dictated by minimum skin gage requirements. This means that the skin area moment of inertia (Ixx) and the skin effective normal bending stiffness (Ex) are known.

The following methodology was used to determine the portion of the load carried by the spars and by the skins.

$$
\varepsilon_{\text {spar }}=\varepsilon_{\text {skin }}
$$




$$
\begin{aligned}
& \varepsilon_{\text {spar }}=\frac{\sigma_{\text {spar }}}{E_{\text {spar }}}=\frac{M_{\text {spar }} y}{E_{\text {spar }} I_{\text {spar }}}=\varepsilon_{\text {skin }}=\frac{\sigma_{\text {skin }}}{E_{\text {skin }}}=\frac{M_{\text {skin }} y}{E_{\text {skin }} I_{\text {skin }}} \\
& \frac{M_{\text {skin }}}{E_{\text {sparr }} I_{\text {spar }}}=\frac{M_{\text {skin }}}{E_{\text {skin }} I_{\text {skin }}} \\
& M_{\text {Total }}=M_{\text {spar }}+M_{\text {skin }}
\end{aligned}
$$

Solving the last two equations 10.9 and 10.10 simultaneously allows for the determination of the portion of the bending moment applied to the wing that is carried by the spars or the wing skins. It can then be checked that this bending moment does not cause the wing skins to buckle as described in the previous section, or exceed the ultimate tensile or compressive stresses for the spar cap material.

\subsubsection{Shear Center and Torsion Constant Calculation}

Now that a method has been developed to size the spar caps and wing skin, the next step is to determine a method to calculate the shear center and torsion constant of the wing section. The shear center is the location on the wing cross section in which an applied load causes only a shear load and does not cause a moment about the elastic axis. Finding the shear centers of numerous wing cross sections and forming a line between them creates the elastic axis. The elastic axis is the axis the wing will rotate about when a torsion load is applied.

Finding the shear center is necessary in order to determine the torsion load developed from the lifting forces acting on the wing. It is also necessary to know the elastic axis position along the wing for future flutter analysis. 


\subsubsection{Procedure for Determination of Shear Center}

1. Approximate the 3 cell wing box as 3 rectangular cells as shown in Figure 10.9. This simplifies the integration of the shear flow in future steps.

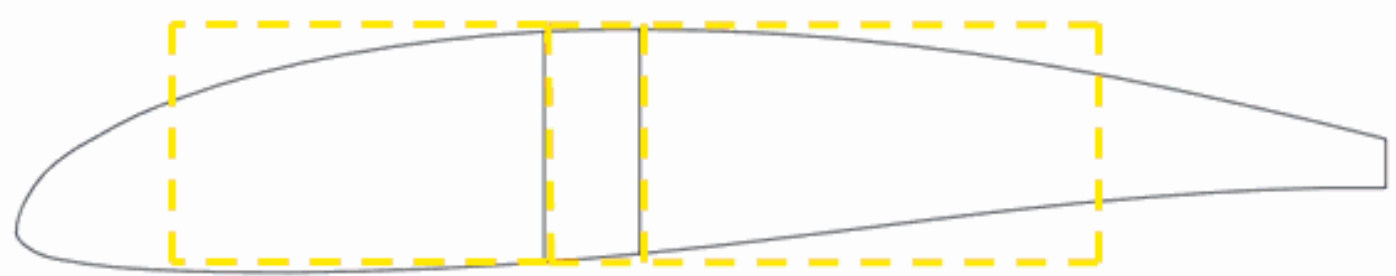

Figure 10.9: Approximate the shape of the wing as a 3 cell rectangular box beam

2. Cut the top of each of the 3 cells as shown in Figure 10.10. It is assumed that the shear flow at each cut is zero. Apply a shear load at the top left corner. Use 102.3 lbs for algebraic simplicity.

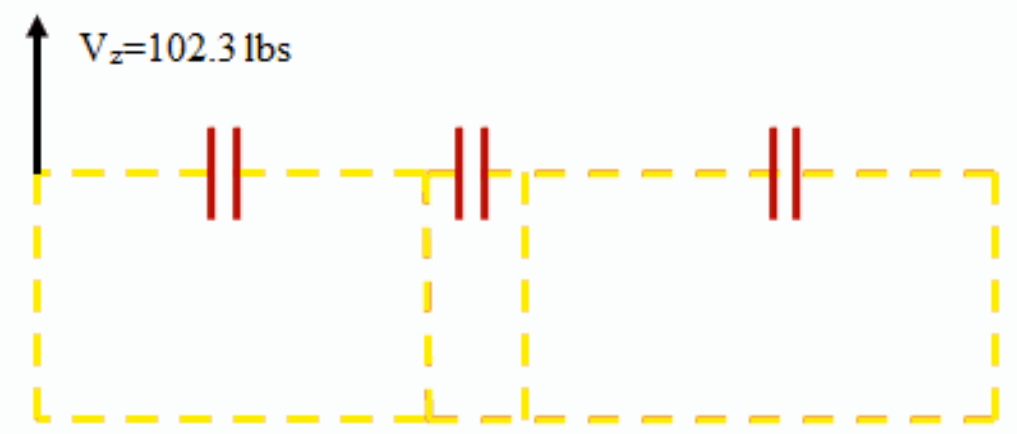

Figure 10.10: Cuts in the top of each cell 
3. Calculate the shear flow for each of these cells using the Method of Successive Approximations technique as developed by Bruhn (63). The reader is referred to Bruhn for more detailed analysis. A portion of the calculations for the first cell are illustrated below. The various points in the following calculations are labeled in Figure 10.11.

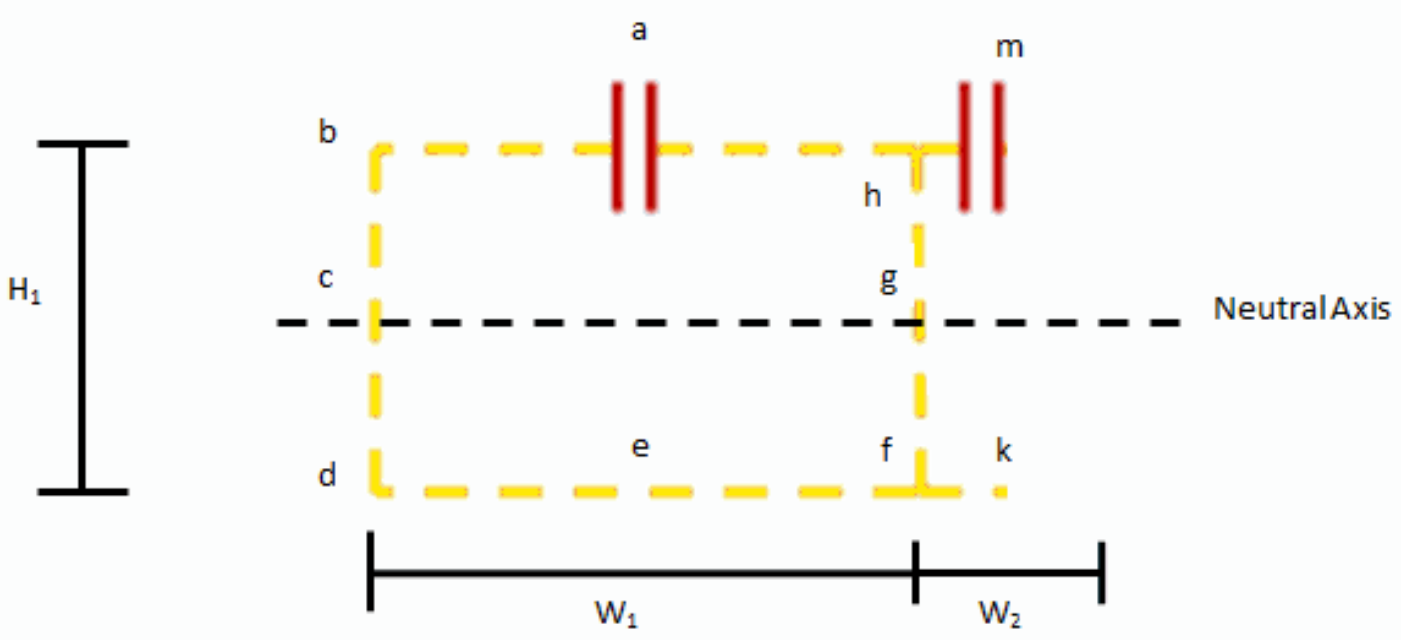

Figure 10.11: Depiction of first cell of the 3 cell box

$$
\begin{gathered}
\qquad \mathrm{V}_{\mathrm{z}}=\text { Applied Shear Load } \\
\mathrm{I}=\text { Area Moment of Inertia for entire wing cross section } \\
\mathrm{A}=\text { Cross Sectional area of web under analysis } \\
\mathrm{z}=\text { distance from neutral axis to centroid of area "A" } \\
\mathrm{q}=\text { shear flow }
\end{gathered}
$$

Calculate the shear flows at all points denoted by lower case letters in figure

10.12 by using the following equation 10.11 .

$$
q=\frac{-V_{z}}{I} \sum z A
$$


Start at point "a" and work counter clockwise. For example, with the following geometric properties:

$$
\begin{aligned}
& \mathrm{H}_{1}=5.29 \text { inch } \\
& \mathrm{W}_{1}=10.5 \text { inch } \\
& \mathrm{W}_{2}=2.165 \text { inch } \\
& \mathrm{W}_{3}=15 \text { inch } \\
& \mathrm{t}_{\text {skin }}=0.235 \text { inch } \\
& \mathrm{I}=102.3 \text { in } \\
& q_{a}=0 \mathrm{lb} / \text { in } \\
& q_{b}=q_{a}+\frac{-102.3}{102.3}(2.645 * .235 * 10.5) l b / \text { in } \\
& q_{b}=-3.26 \mathrm{lb} / \text { in }
\end{aligned}
$$

The remaining shear flows are calculated in the same way. The results for cell 1 are plotted visually in Figure 10.12. The remaining shear flows are calculated in a similar fashion.

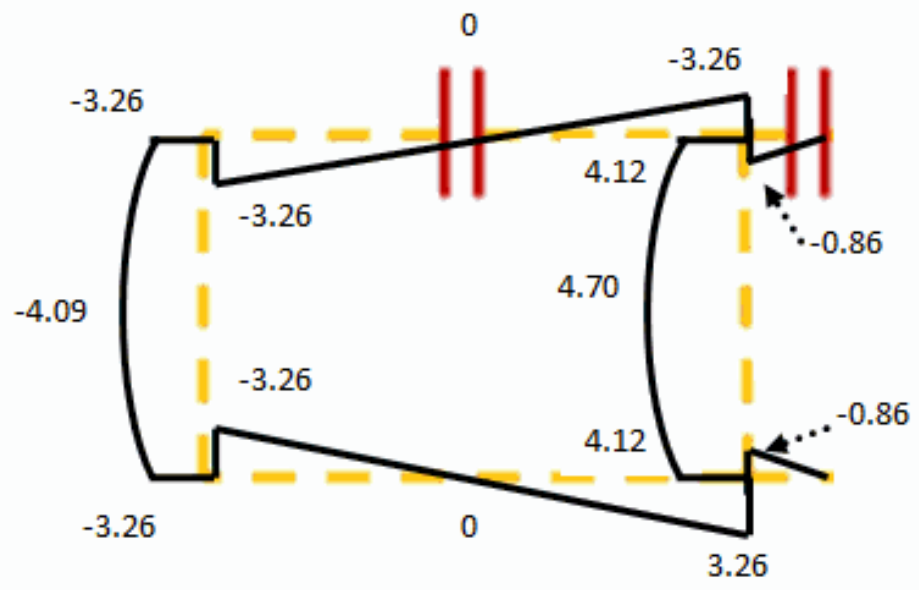

Figure 10.12: Depiction of first cell of the 3 cell box 
4. Start the method of successive approximations. This method of successive approximations calculates a uniform shear flow separately for each cell. These uniform shear flows must be added to the shear flows already calculated for each cell in order to ensure static equilibrium. The addition of a uniform shear flow is necessary due to the cut that was made to the top web of each cell in step 3 . An example is shown in Table 10.3.

Table 10.3 Method of Successive Approximation Example

\begin{tabular}{|c|c|c|c|c|c|}
\hline Row & & Cell 1 & \multicolumn{2}{|c|}{ Cell 2} & Cell 3 \\
\hline 1 & $\sum q \frac{L}{t}$ for each cell & 83.9 & \multicolumn{2}{|c|}{44.9} & -84.8 \\
\hline 2 & $\sum \frac{L}{t}$ for each cell & 144.0 & \multicolumn{2}{|c|}{78.7} & 223.6 \\
\hline 3 & $\frac{L}{t}$ for each shared web & \multicolumn{2}{|c|}{32.1} & \multicolumn{2}{|c|}{32.1} \\
\hline 4 & Carryover factor & 0.41 & 0.22 & 0.14 & 0.41 \\
\hline 5 & First Approximation & -0.58 & \multicolumn{2}{|c|}{-0.57} & 0.38 \\
\hline 6 & Carry Over & -0.13 & -0.24 & 0.15 & -0.08 \\
\hline 7 & Carry Over & -0.02 & -0.05 & -0.03 & -0.01 \\
\hline 8 & Carry Over & -0.02 & -0.01 & -0.01 & 0.00 \\
\hline 9 & Carry Over & 0.00 & -0.01 & 0.00 & 0.00 \\
\hline 10 & Carry Over (converged) & 0.00 & 0.00 & 0.00 & 0.00 \\
\hline 11 & Sum of Carry Overs & -0.75 & \multicolumn{2}{|c|}{-0.76} & 0.28 \\
\hline 12 & First Reiteration & -0.17 & -0.31 & 0.12 & -0.11 \\
\hline 13 & Row 5 Repeated & -0.58 & \multicolumn{2}{|c|}{-0.57} & 0.38 \\
\hline 14 & $\begin{array}{c}\text { Sum of Carry Overs } \\
\text { (Converged })\end{array}$ & -0.75 & \multicolumn{2}{|c|}{-0.76} & 0.27 \\
\hline
\end{tabular}




\subsubsection{Description of Table Operations}

The following is an explanation of the various operations performed in Table 10.3. (63)

Row 1: Sum of the length (L) over thickness ( $\mathrm{t}$ ) for each wall in a cell times the average shear flow (q) for that wall.

Row 2: Sum of the length over the thickness for each cell

Row 3: The length of the thickness for the common webs shared between cells

Row 4: The carryover factor is defined as follows.

$$
C_{1 \rightarrow 2}=\frac{\left(\frac{L}{t}\right)_{1 \rightarrow 2}}{\left(\sum_{\bar{t}}^{L}\right)_{2}}
$$

For example, $C_{1 \rightarrow 2}=\frac{32.1}{78.7}=0.41$

Row 5: The first approximation in the successive approximations solution. This is the first approximation of the closing shear flow that must be added to each cell to ensure equilibrium is maintained.

$$
q_{\text {closing }}=-\frac{\sum q_{\frac{L}{t}}^{L}}{\sum_{t}^{\frac{L}{t}}}
$$

Using cell 1 as an example:

$$
q_{\text {closing }}=-\frac{83.9}{144.0}=-.58
$$

Rows 6-10: Rows 6 through 10 are the carry over shear flow from one cell to the other due to sharing a common web. During the first approximation, different closing shear flows are added to cells on either side of a common web. This is physically impossible 
since the common web cannot have two different shear flow values at the same physically position. To find the correct shear flow to be added to each cell, successive approximations are made by carrying over shear flows between cells.

For example: The carry over shear flow for cell 1 is:

$$
\begin{aligned}
& q_{c o-1}=\frac{C_{2 \rightarrow 1}}{q_{\text {closing }-2}} \\
& q_{c o-1}=\frac{0.22}{-0.57}=-0.13
\end{aligned}
$$

In Row 10, the carry overs have converged to zero.

Row 11: Row eleven is the sum of the first approximation from row 5 plus the carry over shear flows from row 6-10. This is the first approximation of the closing shear flows that must be added to each cell to ensure static equilibrium.

Row 12-17: The Process is repeated until the Successive Approximations have converged. The final closing shear flows are then added to the original shear flows as calculated in step 3 to get the total shear flows in each section

5. Find the total shear force in each web of the box beam. The shear force is average shear flow in a particular web times the length of the web

$$
Q=q_{a v e} * L
$$

6. Sum the Moments about the original shear load application point. In step 2, a shear load was applied in the upper left hand corner. Summing the moments about this point and dividing by the original shear load gives the lateral location of the shear center. For example: 


$$
\begin{aligned}
& M=1371 \mathrm{in}-l b \\
& V=102.3 \mathrm{lb} \\
& x \operatorname{bar}=\frac{M}{V}=13.4
\end{aligned}
$$

The shear center is 13.4 inches to the right of the original shear application point.

\subsubsection{Torsion Constant (J) Calculation for a 3 Cell Beam}

Step 1) Calculate Line Integrals "a" for all lengths of the 3 cell box:

$$
a=\oint \frac{d s}{t}
$$

Where $\mathrm{s}$ is the length of a particular section of the 3 cell box. Next determine the enclosed areas $A_{1}, A_{2}, A_{3}$ of the corresponding cells in the box. These areas are depicted in Figure 10.13.

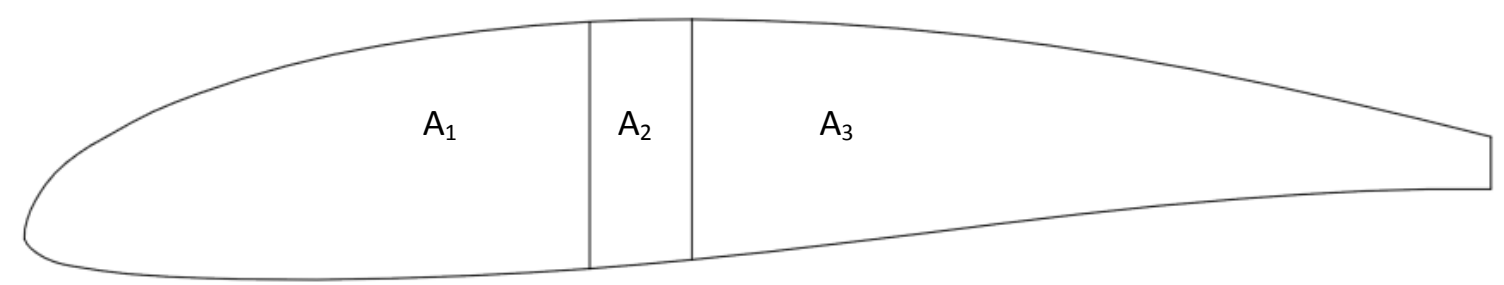

Figure 10.13: Label of the three enclosed areas

Step 2) Solve a system of the following five equations to get the torsion constant J.

$$
\begin{aligned}
& 2 G \theta=\frac{1}{A_{1}}\left[q_{1} a_{10}+\left(q_{1}-q_{2}\right) a_{12}\right] \\
& 2 G \theta=\frac{1}{A_{2}}\left[\left(q_{2}-q_{1}\right) a_{12}+q_{2} a_{20}+\left(q_{2}-q_{3}\right) a_{23}\right] \\
& 2 G \theta=\frac{1}{A_{3}}\left[q_{3} a_{30}+\left(q_{3}-q_{2}\right) a_{23}\right] \\
& 2 A_{1} q_{1}+2 A_{2} q_{2}+2 A_{3} q_{3}+T=0
\end{aligned}
$$




$$
J=\frac{T}{G \theta}
$$

Where:

$\mathrm{a}_{10}$ is the line integral over the sections of cell 1 not shared with another cell $\mathrm{a}_{12}$ is the line integral over the sections shared between cells 1 and 2

$\mathrm{G}$ is the shear modulus of the material. (63)

\subsubsection{Distributed Torsion Load Determination}

Now that the shear center position is known, the distributed torque on a wing can be calculated for different combinations of lift coefficient and pitching moment coefficient as described in a previous section.

The shear flows due to a torsion load can be calculated by solving the following the following 4 equations simultaneously.

$$
\begin{aligned}
& 2 G \theta=\frac{1}{A_{1}}\left[q_{1} a_{10}+\left(q_{1}-q_{2}\right) a_{12}\right] \\
& 2 G \theta=\frac{1}{A_{2}}\left[\left(q_{2}-q_{1}\right) a_{12}+q_{2} a_{20}+\left(q_{2}-q_{3}\right) a_{23}\right] \\
& 2 G \theta=\frac{1}{A_{3}}\left[q_{3} a_{30}+\left(q_{3}-q_{2}\right) a_{23}\right] \\
& 2 A_{1} q_{1}+2 A_{2} q_{2}+2 A_{3} q_{3}+T=0
\end{aligned}
$$

The various skin sections can then be checked for failure due to torsion loads.

These torsion stresses are typically low due the minimum wing skin gage requirements and are not a driving design criteria. However, they still must be known to ensure that the elastic twist of the wing is within reason for all combinations of lift coefficient and pitching moment coefficient. 


\subsubsection{Effective EI and GJ Determination}

The effective Young's Modulus and Shear Modulus for a laminate can be determined by analyzing the laminate constitutive equation:

$$
\left\{\begin{array}{c}
N_{x} \\
N_{y} \\
N_{x y} \\
M_{x} \\
M_{y} \\
M_{x y}
\end{array}\right\}=\left[\begin{array}{llllll}
A_{11} & A_{12} & A_{16} & B_{11} & B_{12} & B_{16} \\
A_{12} & A_{22} & A_{26} & B_{12} & B_{22} & B_{26} \\
A_{16} & A_{26} & A_{66} & B_{16} & B_{26} & B_{66} \\
B_{11} & B_{12} & B_{16} & D_{11} & D_{12} & D_{16} \\
B_{12} & B_{22} & B_{26} & D_{12} & D_{22} & D_{26} \\
B_{16} & B_{26} & B_{66} & D_{16} & D_{26} & D_{66}
\end{array}\right]\left\{\begin{array}{c}
\varepsilon_{x} \\
\varepsilon_{y} \\
\varepsilon_{x y} \\
k_{x} \\
k_{y} \\
k_{x y}
\end{array}\right\}
$$

The effective modulus for a load in the $\mathrm{x}$ direction can be found from the relationship:

$$
N_{x}=A_{11} \varepsilon_{x}
$$

Since $\mathrm{N}_{\mathrm{x}}$ is a line load, dividing through by the laminate thickness produces the following result for the effective modulus in the $\mathrm{x}$ direction:

$$
E_{x_{-} \text {effective }}=\frac{A_{11}}{t_{\text {laminate }}}
$$

The effective shear modulus can be found in a similar manner:

$$
G_{x y \_ \text {effective }}=\frac{A_{66}}{t_{\text {laminate }}}
$$

The wing resists bending in both the spar caps and the skins. The skins and spars can be thought of as a two springs in parallel system. For springs in parallel, the stiffnesses add. The effective bending stiffness, EI, for the wing is therefore

$$
(E I)_{\text {wing }}=\left[(E I)_{\text {spar }}+(E I)_{\text {skin }}\right]
$$

The effective torsional rigidity, GJ, can be approximated from the following equation 


$$
(G J)_{\text {wing }}=G_{\text {skins }} J_{\text {wing }}
$$

Since the wing skins make up the majority of the torque box, the effective GJ calculated is simplified by simply applying the shear modulus for the wing skins to the entire wing structure. To further simplify the calculations, the torsion constant $\mathrm{J}$ was held fixed along the span, although in reality the torsion constant changes slightly as the spar cap thickness tapers towards the wing tips.

\subsubsection{Rib Laminate Determination}

The wing ribs carry the shear load from the wing skin to the wing spars. They help to maintain the shape of the airfoil and stiffen the wing skin to prevent wing skin buckling. The shear loads in the wing ribs are very low such that one ply of carbon cloth would be more than adequate if strength was the only consideration. Considering stiffness and shear buckling requires a sandwich construction. In order to be consistent with the rest of the wing skin, a 5mm Rohacell foam core is used. This results in the following laminate schedule $\left[+45_{\text {carbon cloth }} /\right.$ core/ $\left.+45_{\text {carbon cloth }}\right]$. The total weight of all the wing ribs is 3 pounds per wing.

\subsubsection{Wing Mass, Static Moment, Mass Moment of Inertias}

These properties are necessary for a flutter analysis and are best determined by modeling the wing section in a CAD program with the appropriate materials densities. The desired parameters can then be output by the CAD program.

Calculated laminate sizes and weights of various components of the wing structure are produced in Table 10.4. Weights of the entire structure are tabulated in Table 10.5. 
Table 10.4 Spar laminate specs for a standard wing without batteries

\begin{tabular}{|c|c|c|c|c|c|c|c|c|c|c|}
\hline \multirow[b]{2}{*}{ Station } & \multirow[b]{2}{*}{$\begin{array}{l}\text { Position } \\
\text { (in) }\end{array}$} & \multicolumn{3}{|c|}{ Top Cap } & \multicolumn{3}{|c|}{ Bottom Cap } & \multicolumn{3}{|c|}{ Shear Walls } \\
\hline & & $\begin{array}{c}\text { \# of } \\
\text { Carbon } \\
\text { UNI } \\
\text { plies } \\
\end{array}$ & $\begin{array}{l}\text { thickness } \\
\text { (inch) }\end{array}$ & $\begin{array}{l}\text { weight } \\
\text { (lb) }\end{array}$ & $\begin{array}{l}\text { \# of } \\
\text { Carbon } \\
\text { UNI } \\
\text { plies } \\
\end{array}$ & $\begin{array}{l}\text { thickness } \\
\text { (inch) }\end{array}$ & $\begin{array}{l}\text { weight } \\
\text { (lb) }\end{array}$ & $\begin{array}{l}\text { \# of } \\
\text { carbon } \\
\text { cloth } \\
\text { plies }\end{array}$ & $\begin{array}{c}\text { thickness } \\
\text { (inch) }\end{array}$ & $\begin{array}{l}\text { weight } \\
\text { (lb) }\end{array}$ \\
\hline 1 & 0 & 66 & 0.42 & 4.39 & 28 & 0.18 & 1.86 & 2 & 0.14 & 0.43 \\
\hline 2 & 22.7 & 45 & 0.28 & 3.00 & 19 & 0.12 & 1.27 & 2 & 0.14 & 0.43 \\
\hline 3 & 68.1 & 27 & 0.17 & 1.80 & 12 & 0.08 & 0.80 & 2 & 0.14 & 0.43 \\
\hline 4 & 113.5 & 14 & 0.09 & 0.93 & 6 & 0.04 & 0.40 & 2 & 0.14 & 0.43 \\
\hline 5 & 158.9 & 4 & 0.03 & 0.27 & 2 & 0.01 & 0.13 & 2 & 0.14 & 0.43 \\
\hline 6 & 204.3 & 2 & 0.01 & 0.13 & 2 & 0.01 & 0.13 & 2 & 0.14 & 0.43 \\
\hline Total & & & & 10.52 & & & 4.59 & & & 2.58 \\
\hline
\end{tabular}

Table 10.5 Total wing weight for wing without batteries

\begin{tabular}{cc}
\hline \hline Spar Weight & $17.69 \mathrm{lb}$ \\
Wing Skin Weight & $82.96 \mathrm{lb}$ \\
Total Rib Weight & $3.00 \mathrm{lb}$ \\
\hline \hline Total Wing Structural Weight & $103.65 \mathrm{lb}$ \\
\hline
\end{tabular}

The low shear values of the wing spar relative to the large bending moments carried require only one ply of carbon cloth to carry the shear load. However, to prevent localized shear buckling of the spar shear walls, it was necessary to increase the shear wall thickness by adding a foam core into the shear wall laminate. 
The wing skin laminate was defined in a previous section due to minimum skin thickness requirements. The wing skin has a thickness of 0.235 " and a specific weight/length of $0.3045 \mathrm{lb} / \mathrm{in}$. The total weight per wing of the wing skins is approximately $83 \mathrm{lbs}$. As such, it accounts for the majority of the weight of each wing. The total wing weight of the wing structure is $103.65 \mathrm{lbs}$.

\subsubsection{Wing Tip Deflection}

Once the wing structure has been designed, the wing tip deflections can be calculated for various loading conditions. The deflections for the wing design without batteries are tabulated for various load cases in Table 10.6.

Table 10.6 Wing tip vertical deflection for wing without batteries

\begin{tabular}{lc}
\hline \hline Load Condition & $\begin{array}{c}\text { Wing Tip Vertical } \\
\text { Deflection }\end{array}$ \\
$3.8 \mathrm{G}$ & +22 in \\
Level Flight & +6 in \\
On Ground & -1 in \\
-4.0 G Hard Landing & -3 in \\
\hline \hline
\end{tabular}

The torsional moment is the sum of the pitching moment plus the moment created by the lift force acting at the aerodynamic center, which is a distance from the elastic axis. The pitching moment changes with speed while the lift force changes with load factor. The worst case combination of the two moments can then be determined by analyzing several load cases. The torsional deflection of the wingtips is checked at this worst case scenario to ensure similarity with existing wing designs. The torsional deflections are tabulated in Table 10.7. 
Table 10.7 Torsional deflection of the wingtip for wing without batteries

\begin{tabular}{ll}
\hline Max wing tip angular deflection & $-2.8^{\circ}$ \\
Typical cruise tip angular deflection & $-0.80^{\circ}$ \\
\hline \hline
\end{tabular}

Common practice is to limit sailplane wing torsional deflection to less than four degrees (61). The wing is therefore within specification.

\subsubsection{Flutter Code Inputs}

In order to utilize the flutter code developed from the methodologies in the previous sections, the following properties of the wing at various stations along the wing span are needed. The remaining wing properties necessary to perform a flutter analysis are presented below. The wing is divided up into 6 sections of equal length along the span. The masses are lumped at the center of these sections. The reader will note that the parameters below have seven rows. The first row is the properties of the fuselage. For instance, one half the total fuselage weight is the value in the first column of the weight array. It is divided by two since there are two wings. The flutter properties for the wing without batteries used in the flutter code are produced below in Table 10.8. The effective EI and GJ curves of Figure 10.14 and Figure 10.15 are also used by the flutter code. 
Table 10.8 Wing properties input into flutter code

\begin{tabular}{lccccccc}
\hline Station & $\begin{array}{c}\text { Lumped } \\
\text { Position } \\
\text { (in) }\end{array}$ & $\begin{array}{c}\text { Mass } \\
\text { (slugs) }\end{array}$ & $\begin{array}{c}\text { Static } \\
\text { Moment } \\
\text { (slug-ft) }\end{array}$ & $\begin{array}{c}\text { Mass Moment } \\
\text { of Inertia } \\
\left(\text { slug-ft }^{2}\right)\end{array}$ & $\begin{array}{c}\text { Section } \\
\text { length } \\
(\mathrm{ft})\end{array}$ & $\begin{array}{c}\text { Wing } \\
\text { Semi-Span } \\
(\mathrm{ft})\end{array}$ & $\begin{array}{c}\text { Elastic } \\
\text { Axis } \\
\text { Position } \\
(\mathrm{ft})\end{array}$ \\
\hline 0 & 0 & 13.1000 & 0.000 & 0.000 & 0.000 & 0.000 & 1.12 \\
1 & 22.7 & 0.6503 & 0.198 & 0.09833 & 3.783 & 3.167 & 1.12 \\
2 & 68.1 & 0.5882 & 0.200 & 0.09828 & 3.783 & 3.167 & 1.12 \\
3 & 113.5 & 0.5365 & 0.202 & 0.09823 & 3.783 & 3.167 & 1.12 \\
4 & 158.9 & 0.4973 & 0.203 & 0.09819 & 3.783 & 3.167 & 1.12 \\
5 & 204.3 & 0.4683 & 0.204 & 0.09816 & 3.783 & 3.167 & 1.12 \\
6 & 249.7 & 0.4559 & 0.204 & 0.09815 & 3.783 & 3.167 & 1.12 \\
\hline \hline
\end{tabular}

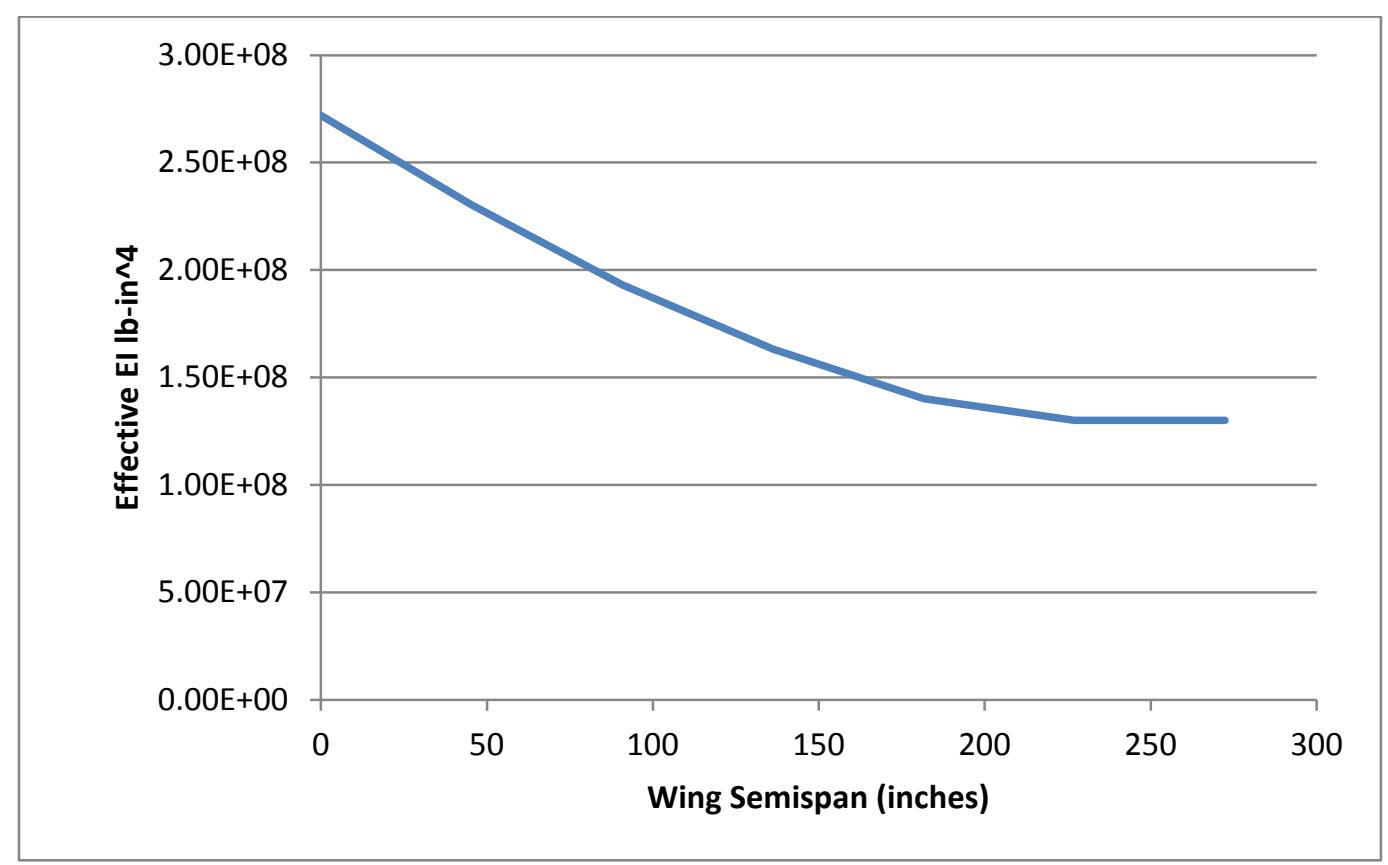

Figure 10.14: The variation of the wing effective EI with relation to wing semispan 


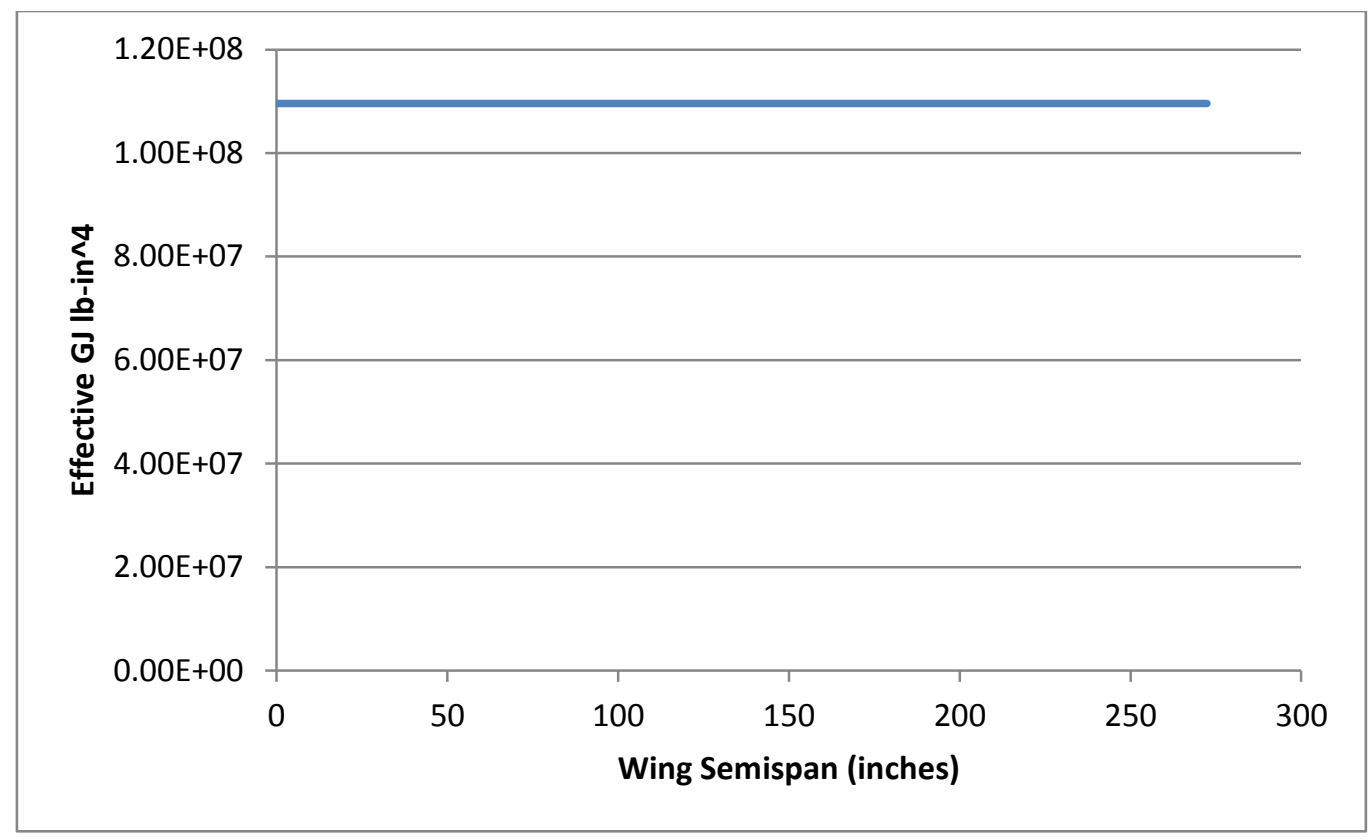

Figure 10.15: Effective GJ was held constant for simplicity.

\subsubsection{Flutter Results}

Pipistrel specifies the flutter speed of the Sinus motor glider in terms of true airspeed as opposed to indicated airspeed. The published never exceed speed for the Sinus motor glider is 140 miles per hour. The FAR's referenced in CHAPTER 9: specify that there must be adequate damping until $1.2 * \mathrm{~V}_{\mathrm{D}}$. This means that the flutter properties of the wing must not become unstable below a speed of $168 \mathrm{mph}$ true airspeed. The calculated bending and torsion flutter properties of the wing are presented below in Figure 10.16 for various altitudes. 


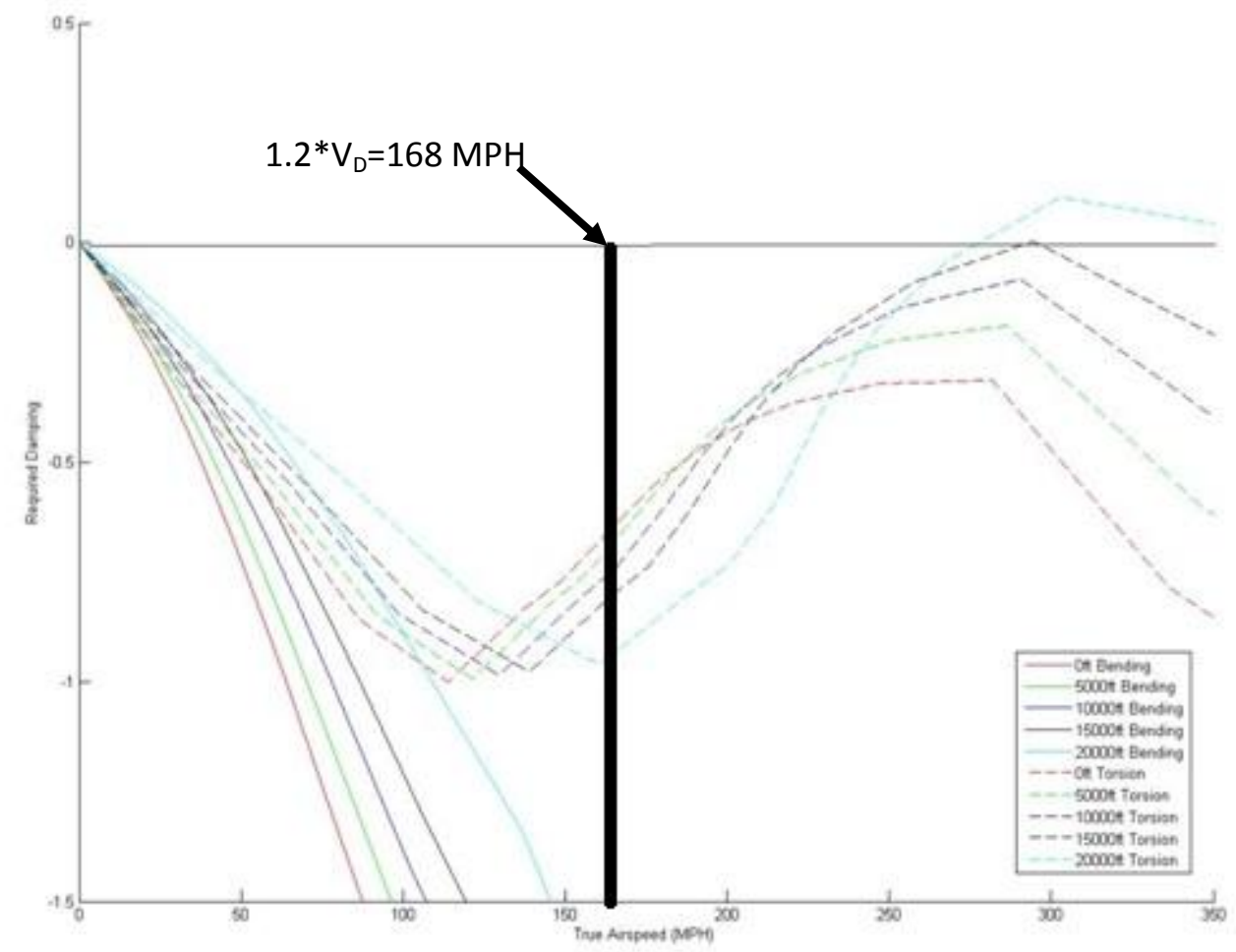

Figure 10.16: The torsion mode is stable at the $168 \mathrm{MPH} \mathrm{V}_{\mathrm{D}}$ Speed.

The flutter analysis results in Figure 10.16 shows the wing is free from flutter in the bending/torsional modes for speeds much greater than $1.2 * \mathrm{~V}_{\mathrm{D}}$. The Pipistrel $\mathrm{V}_{\mathrm{NE}}$ could therefore be set for many other reasons including aircraft handling and dynamics, maximum gust loading, or other types of flutter such as control surface flutter, empennage flutter, etc.

\subsubsection{Investigation into the Effect of Battery Positioning on Flutter}

To understand the effects of positioning the traction batteries in various locations along the wing, the weight of the batteries and the resultant change in wing mass, torsional inertia and static moments were added to the wing properties developed for the original 
wing. Three possible battery packaging configurations were investigated. The first configuration consisted of the battery modules being packaged in the front of the wing, between the leading edge and the wing spar and is shown in Figure 10.17. The second configuration consisted of the batteries packaged immediately behind the spar and is shown in Figure 10.18. The third configuration involved packaging the batteries both in front and behind the spar, keeping the battery mass as close the aircraft fuselage as possible and is shown in Figure 10.19.

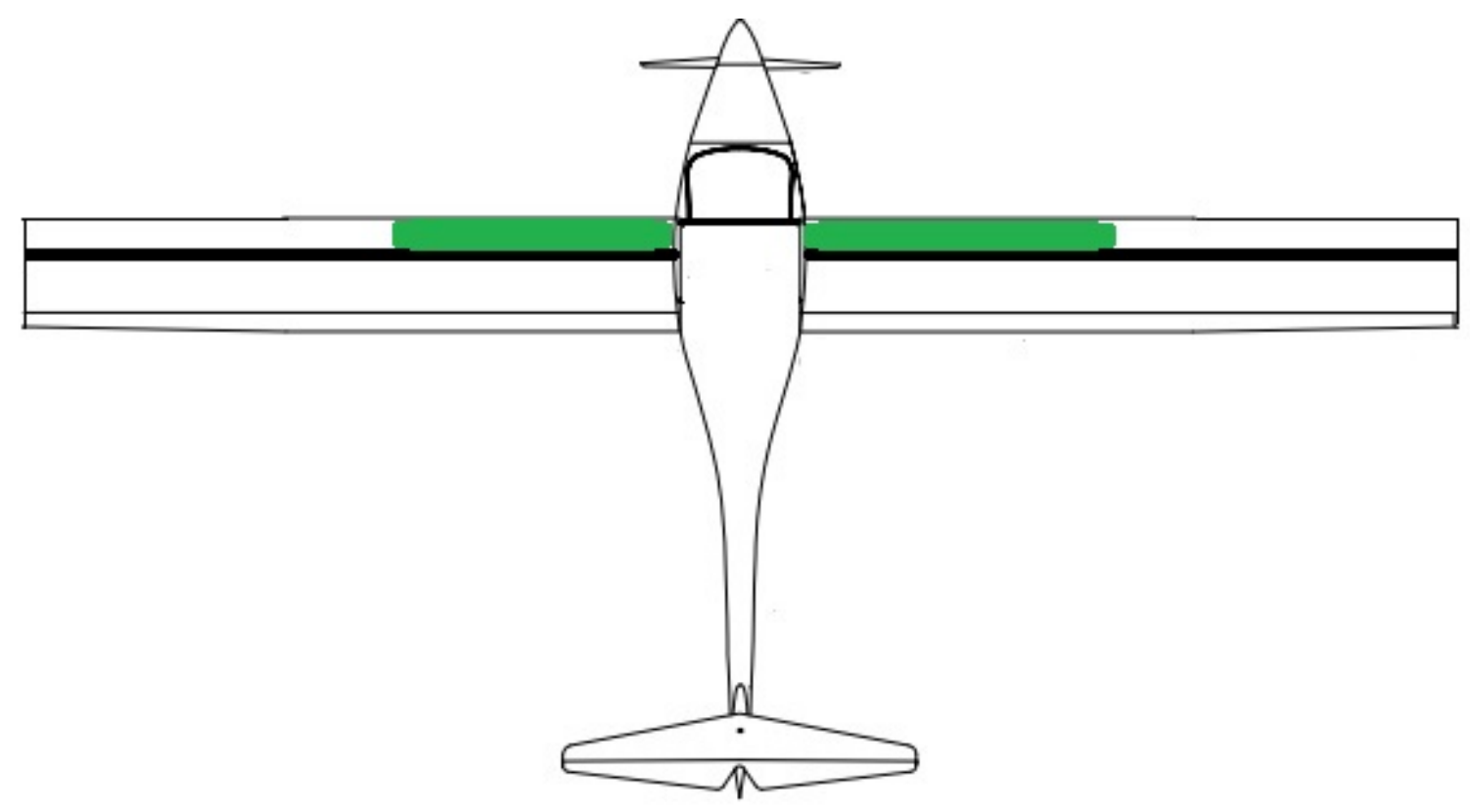

Figure 10.17: Batteries packaged between the leading edge and the spar. 


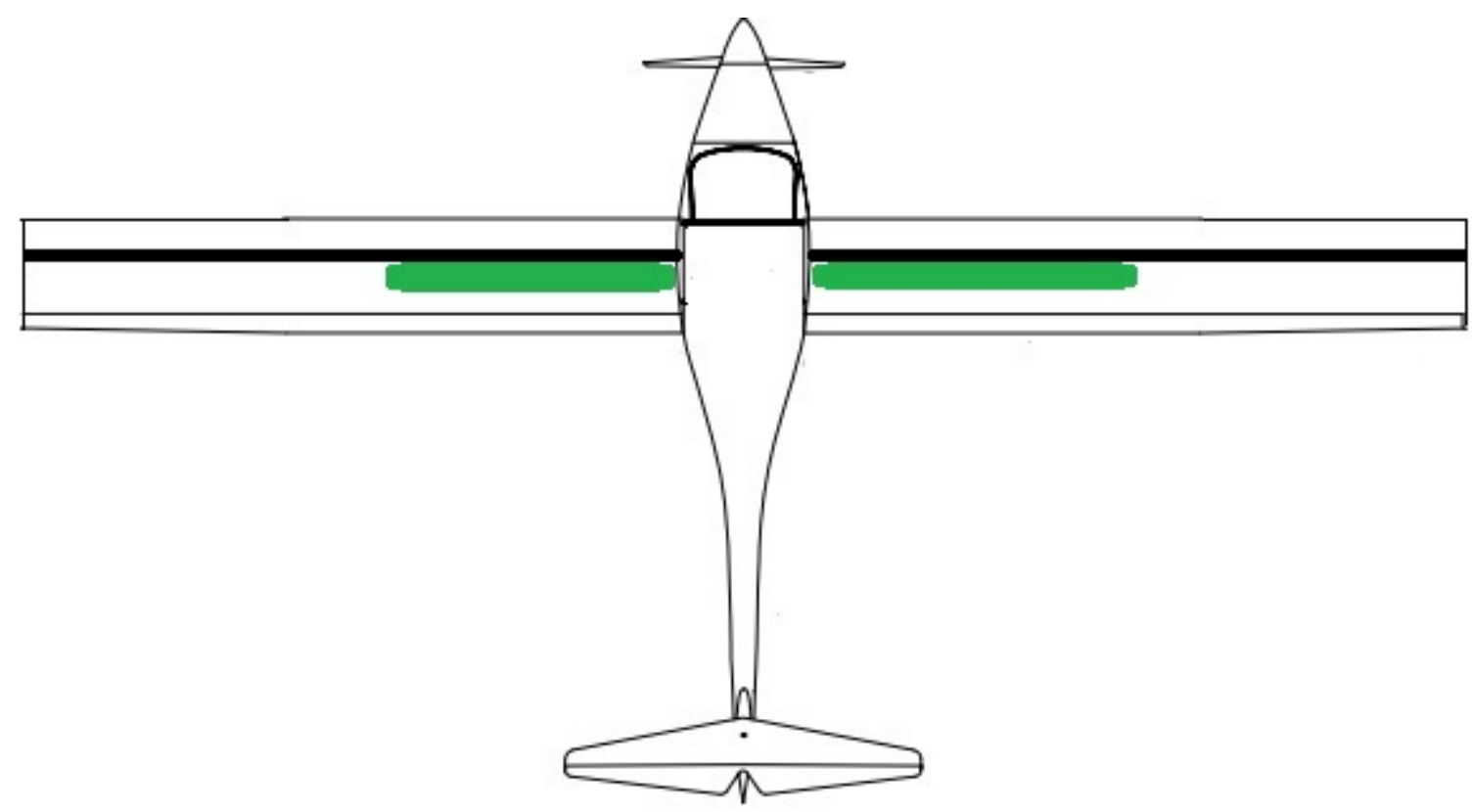

Figure 10.18: Batteries packaged immediately behind the wing spar

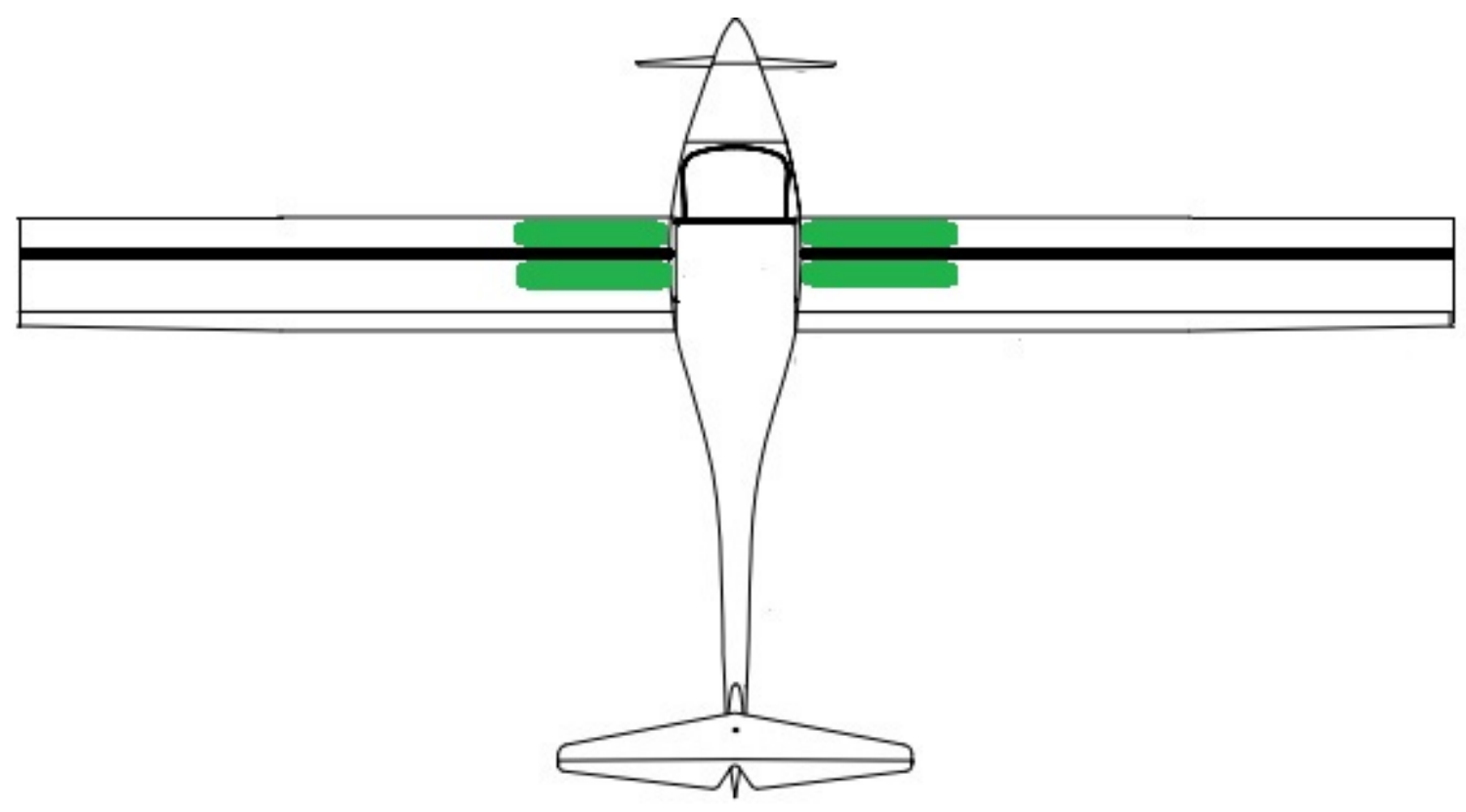

Figure 10.19: Batteries packaged on both sides of the spar

The results of investigating the changes in flutter speed with battery positioning show that adding weight aft of the elastic axis reduces the critical flutter speed. Adding weight 
ahead of the elastic axis can actually improve flutter qualities within reason. Adding weight ahead of the elastic axis reduces the static moment but increases the torsional mass moment of inertia. Reducing the static moment is beneficial to flutter, but increasing the mass moment of inertia is not.

These trends are magnified when weight is added at locations nearer the wing tip and significantly reduced when weight is added nearer the wing root. This corresponds with trends confirmed by professional analyses (64). The results for the three battery positions are displayed in Figure 10.20 to Figure 10.22.

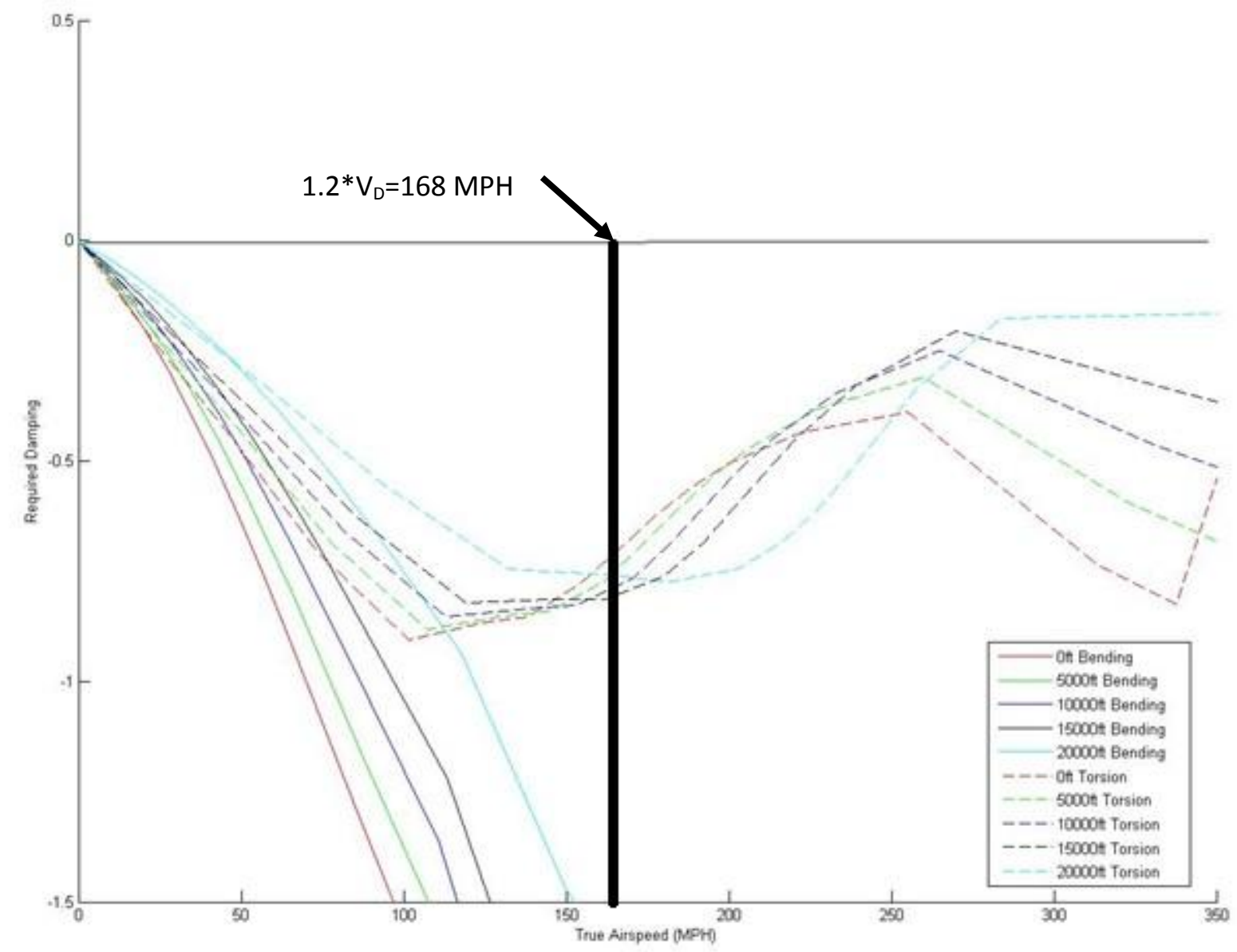

Figure 10.20: Flutter damping curves with the batteries in front of the spar 


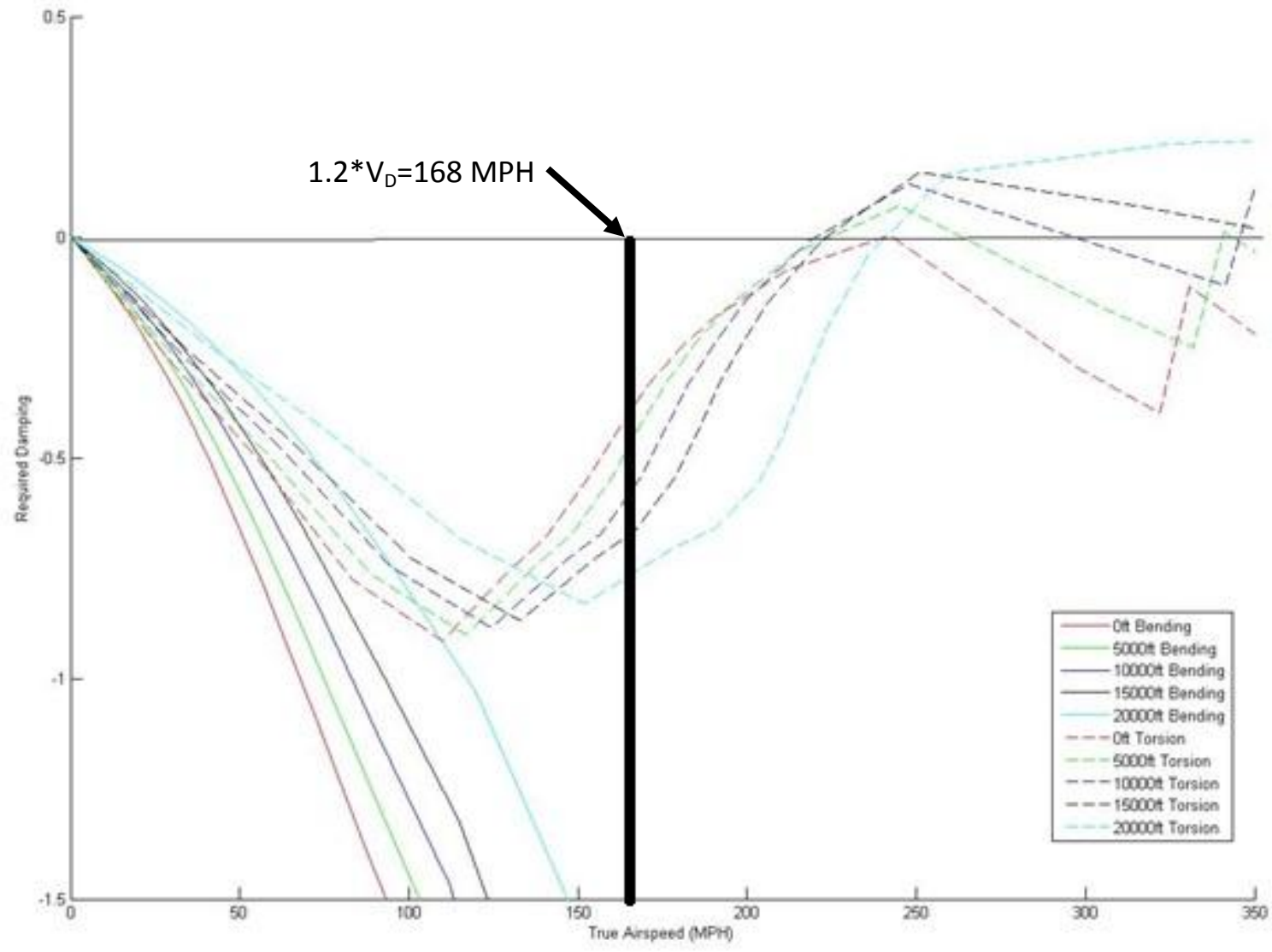

Figure 10.21: Flutter damping curves with the batteries aft of the spar 


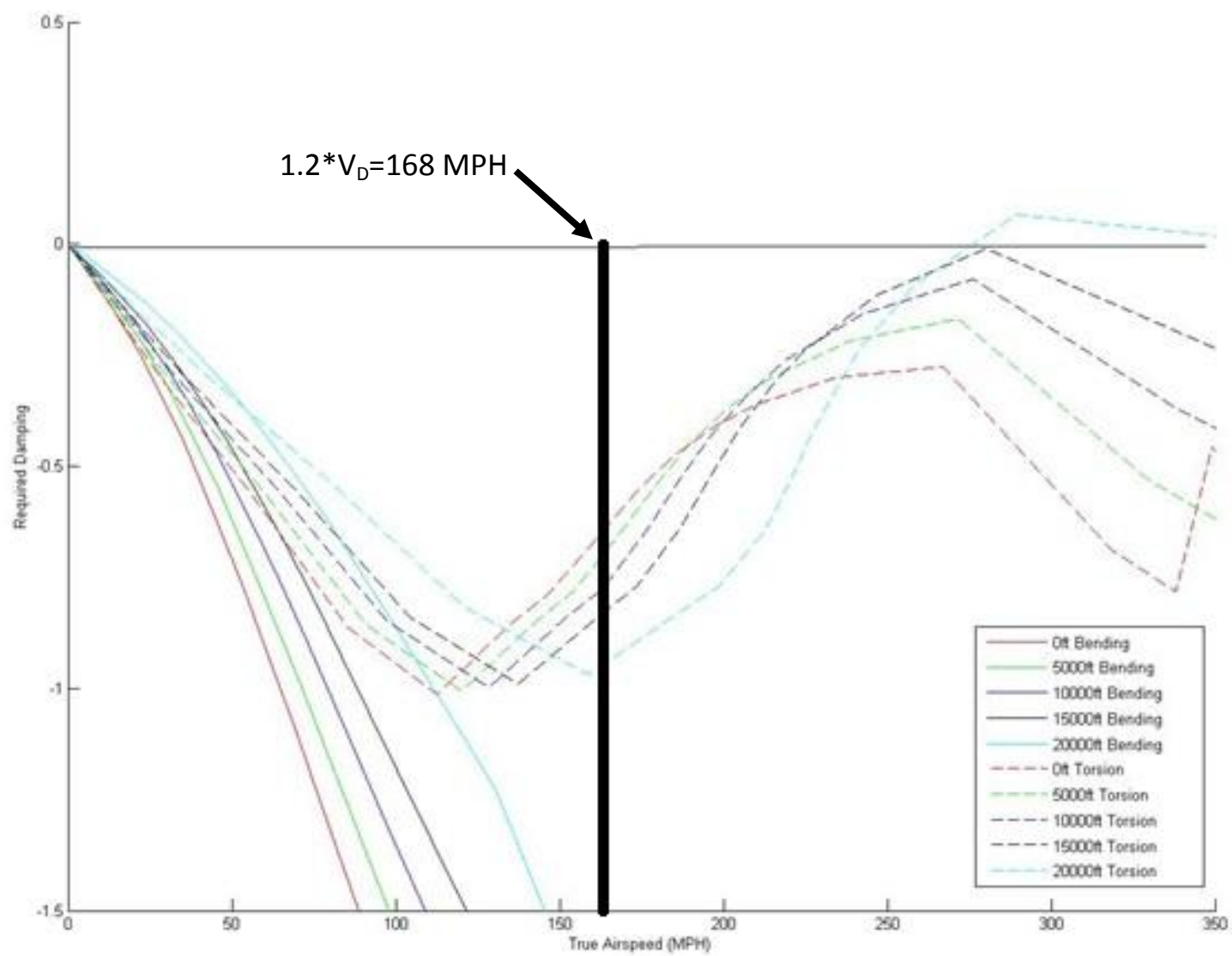

Figure 10.22: Flutter damping curves with the batteries near the wing root,

The expected flutter trends discussed above can be seen in the different battery packaging configurations that were explored. Adding the weight of the batteries behind the spar significantly reduces flutter performance compared with packaging the batteries in front of the spar. While packaging the batteries aft of the spar reduces the flutter performance of the wing, the predicted flutter true airspeed for this configuration of 220 $\mathrm{mph}$ is $55 \%$ higher than the Sinus's $140 \mathrm{mph} \mathrm{V}_{\mathrm{NE}}$. The FARs require only a $20 \%$ margin. Therefore any of the configurations examined above are acceptable from a wing bending and torsion flutter standpoint.

\subsection{Selection of Battery Packaging configuration for future development}


As stated previously, all three configurations analyzed for flutter properties are acceptable from a flutter standpoint. Therefore, the selection of the packaging criteria can be driven by factors other than flutter. The configuration packaging the batteries aft of the spar was chosen to simplify the integration of the battery cooling and emergency ventilation system with the wing structure. It is ideal to exhaust both the cooling air and the emergency ventilation system near the trailing edge of the wing to prevent disturbing the laminar boundary layer of the wing. Packaging the batteries in front of the spar would complicate spar construction as provisions to allow the cooling air and ventilation system to pass through the spar to the trailing edge of the wing would have to be incorporated. Avoiding packaging the batteries in front of the spar results in selecting the configuration of the batteries packaged aft of the wing spar, as shown in Figure 10.18. Detailed images of the configuration will be shown in the next chapter. 


\subsection{Structural redesign to accommodate traction Batteries in the wing.}

While a wing structure was sized in Table 10.4, this sizing did not take into account the changes in wing load resulting from packaging the weight of the batteries in the wing. As shown in figure 5.18, packaging the batteries in the wing reduces the magnitude of the bending moment and shear load the wing is required to support during most load cases. This means that wing strength can be reduced allowing for a corresponding reduction in the weight of the wing structure. The following Figure 10.23 to Figure 10.25 illustrate the changes in the wing loading. Inspection of these graphs reveal that an approximately $25 \%$ reduction in shear and bending moment loads occurs at the wing root due to placing the batteries in the wing as opposed to placing the batteries in the fuselage.

Figure 10.23 depicts the change in the distributed load acting on the wing structure due to packaging the batteries in the wing. Values are for 1-G level flight. The distributed weight of the wing structure and the distributed weight of the batteries is subtracted from the distributed lift force. Figure 10.24 shows the change in direct shear load as a result of packaging the batteries in the wing. Figure 10.25: Bending moment change from packaging the batteries in the wing. shows the change in bending moment. 


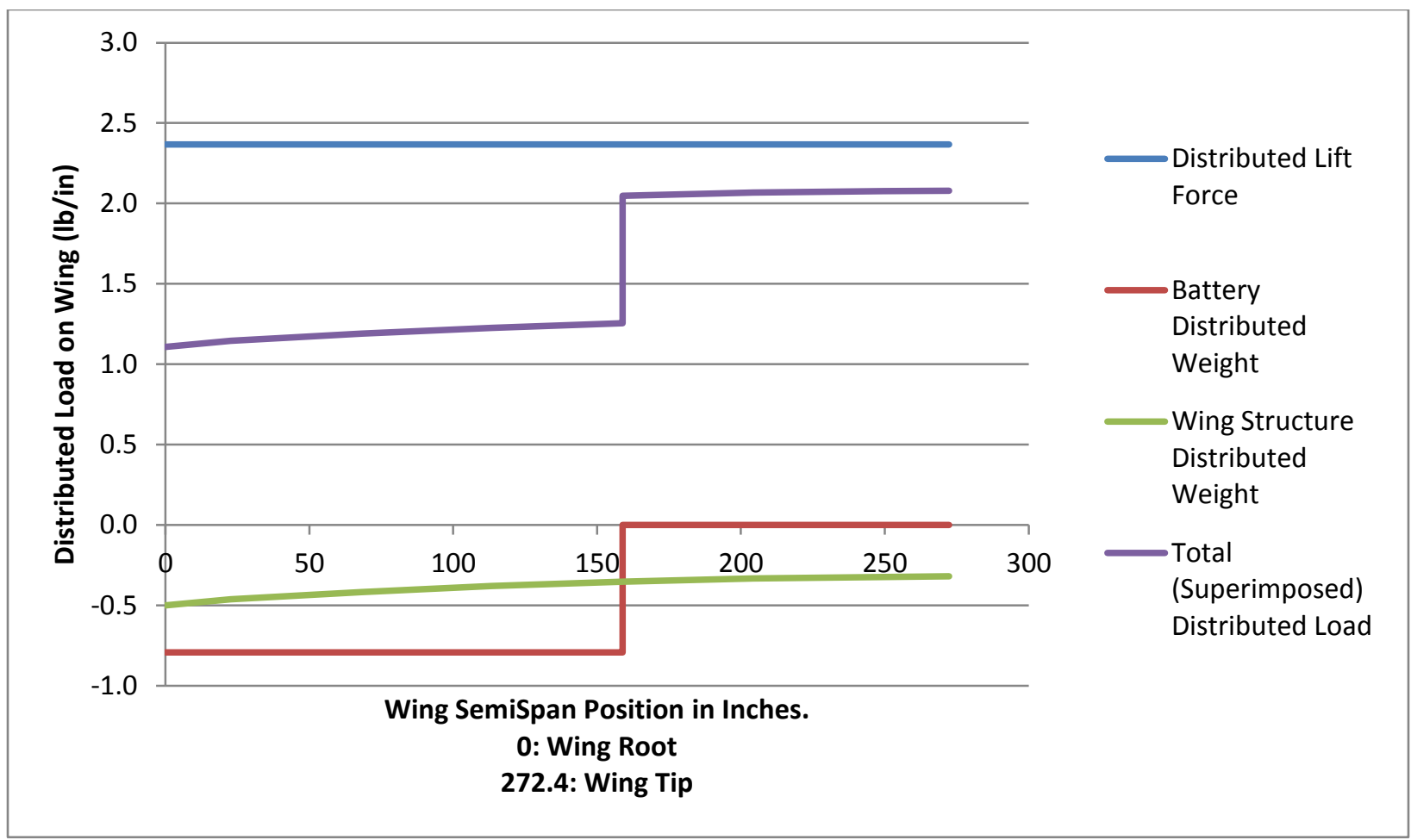

Figure 10.23: Distributed load change due to packaging the batteries in the wing. 


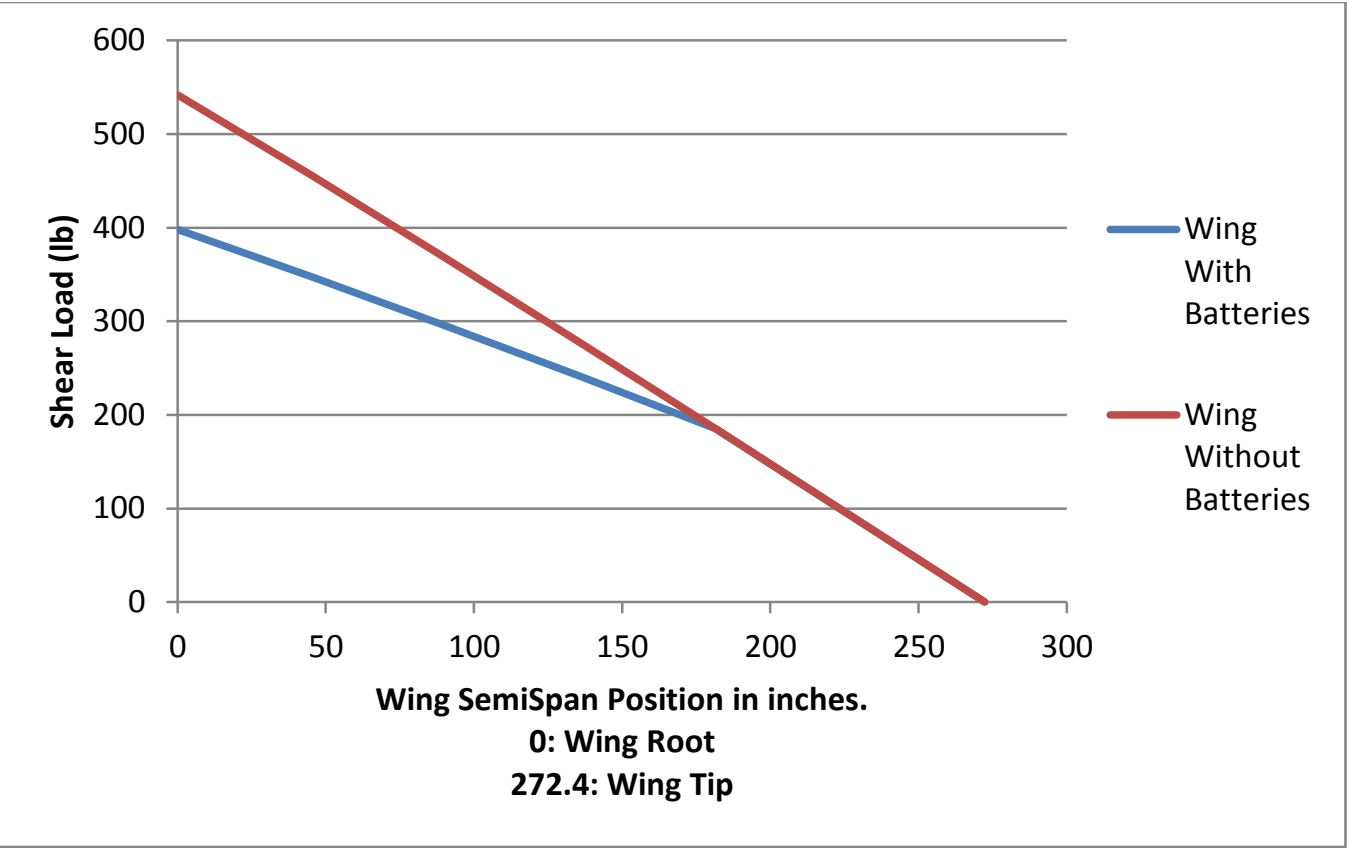

Figure 10.24: Direct shear load change from packaging batteries in the wing.

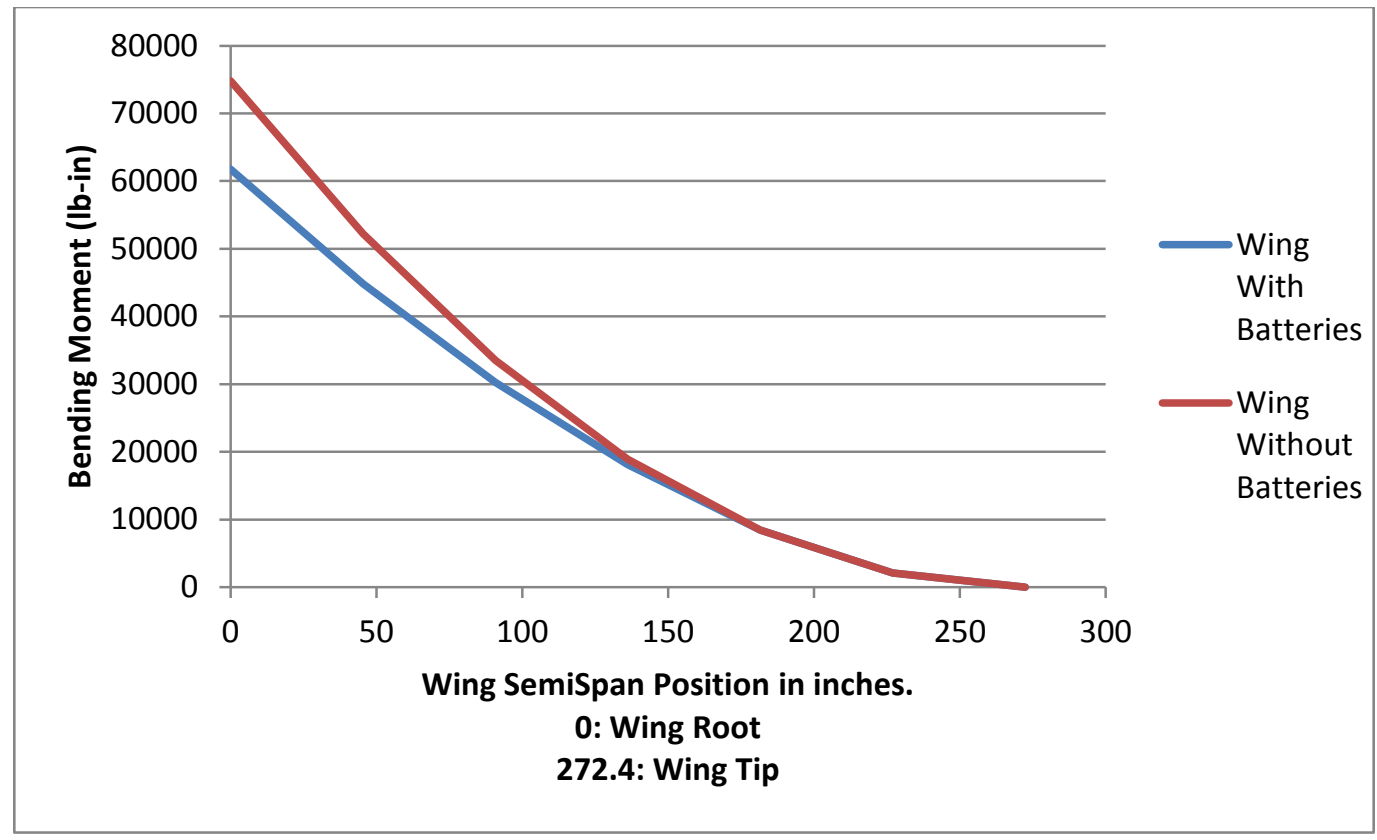

Figure 10.25: Bending moment change from packaging the batteries in the wing. 
Redesigning the wing structure using the above applied loads and FAR 23 guidelines for maximum load factors and gust loads produces the structural sizes and weights tabulated in Table 10.9 and Table 10.10.

Table 10.9 Spar specs for a standard wing with batteries

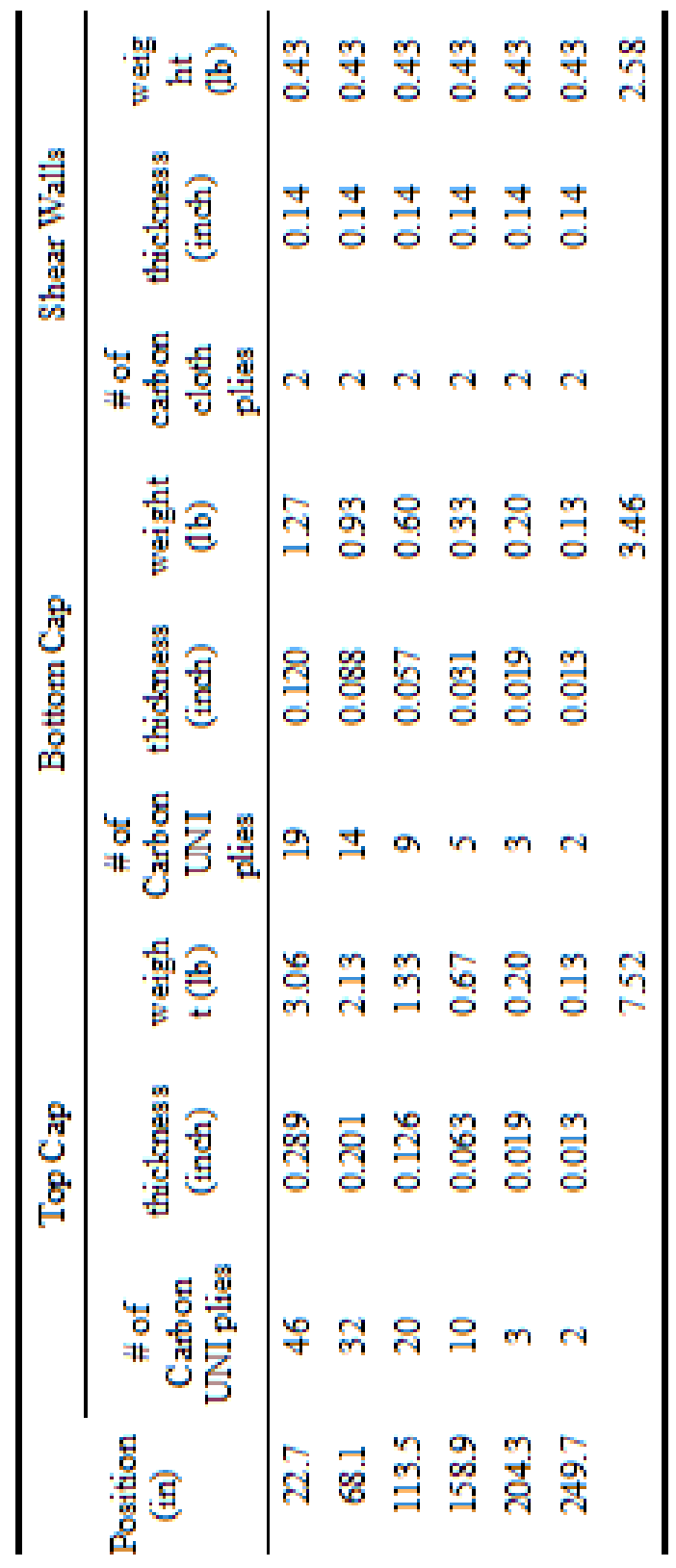


Table 10.10 Wing with battery total component weight

\begin{tabular}{lc}
\hline \hline Total Spar Weight & $13.56 \mathrm{lb}$ \\
Total Rib Weight & $3.00 \mathrm{lb}$ \\
Total Wing Skin & \\
Weight & $82.96 \mathrm{lb}$ \\
Total Wing Weight & $99.52 \mathrm{lb}$ \\
\hline
\end{tabular}

Comparing the above data to the wing without batteries, it can be seen that approximately 3.7 pounds are saved from each wing's structure, or 7.4 pounds are saved from the total of both wings. The total weight of the wing with batteries will be increased, however, once provisions are made for installing and removing the batteries.

The wing skin turned out to be a significant portion of the overall weight of the wing. Due to minimum gage requirements as discussed previously, the skin thickness and therefore skin weight cannot be reduced. If no changes are made to the rib spacing (and therefore the skin buckling stress), maintaining the proper bending moment distribution between spar cap and wing skin allows only a slight reduction in overall spar weight. If the spar cap thickness were reduced too much, too much load would be placed on the wing skins, causing the skins to buckle.

\subsubsection{Wing Deflections}

The wing tip deflections for the wing design with batteries are tabulated below in table Table 10.11 and Table 10.12.

Table 10.11 Wing Tip vertical deflection for wing with batteries

\begin{tabular}{lc}
\hline \hline Load Condition & Wing Tip Vertical \\
$3.8 \mathrm{G}$ & Deflection \\
Level Flight & +22 in \\
\hline \hline
\end{tabular}




\begin{tabular}{ll}
\hline \hline On Ground & -2 in \\
-4.0 G Landing & -8 in \\
\hline \hline
\end{tabular}

Table 10.12 Angular wing tip deflection for a wing with batteries.

\begin{tabular}{lc}
\hline Max wing tip angular deflection & $-2.8^{\circ}$ \\
Typical cruise tip angular deflection & $-0.80^{\circ}$ \\
\hline \hline
\end{tabular}

\subsection{Chapter Conclusion}

In this chapter, a structural design of the wing was produced. The spar, skins and ribs were sized, and a location was selected for the packaging of the batteries. It was determined that the weight of the wing skins accounts for a significant amount of the overall wing weight. The skin sizing is driven by minimum gage requirements and cannot be reduced. Therefore, minimal weight is saved by locating the batteries in the wing structure. Flutter was also shown not to be a driving factor in the battery packaging location for this particular airplane. While packaging the batteries aft of the spar does significantly reduce the flutter speed of the wing, it does not lower the flutter speed below acceptable levels.

The next chapter takes this high level structural design and focuses on the details of packing the batteries in the wing, including maintenance accessibility, cooling and safety. 


\section{CHAPTER 11: Battery Installation Provisions}

The previous chapter performed a structural layout of the wing. This chapter focus on the detailed packaging considerations to see if there is a method to package the batteries in the wing practically from a maintenance, safety and battery cooling system standpoint. The goals for this chapter are:

- Develop a conceptual design of a wing panel cutout system that maintains the mechanical properties of the wing while still allowing access to the batteries for maintenance

- Develop a conceptual design of a battery exhaust gas emergency ventilation system to exhaust any gasses that may be produced in a battery cell to the outside of the aircraft

- Develop a conceptual design of a battery cooling system capable of adequately cooling the battery during flight. 


\subsection{Cutout Design}

The batteries will be inserted and removed from the wing structure by cutouts placed in the bottom wing skin as shown in Figure 11.1 and Figure 11.2. While necessary from a maintenance standpoint, cutouts are never an ideal feature for a load bearing structure.

Since the wing skin functions as the wall of a torque tube resisting the applied torque to

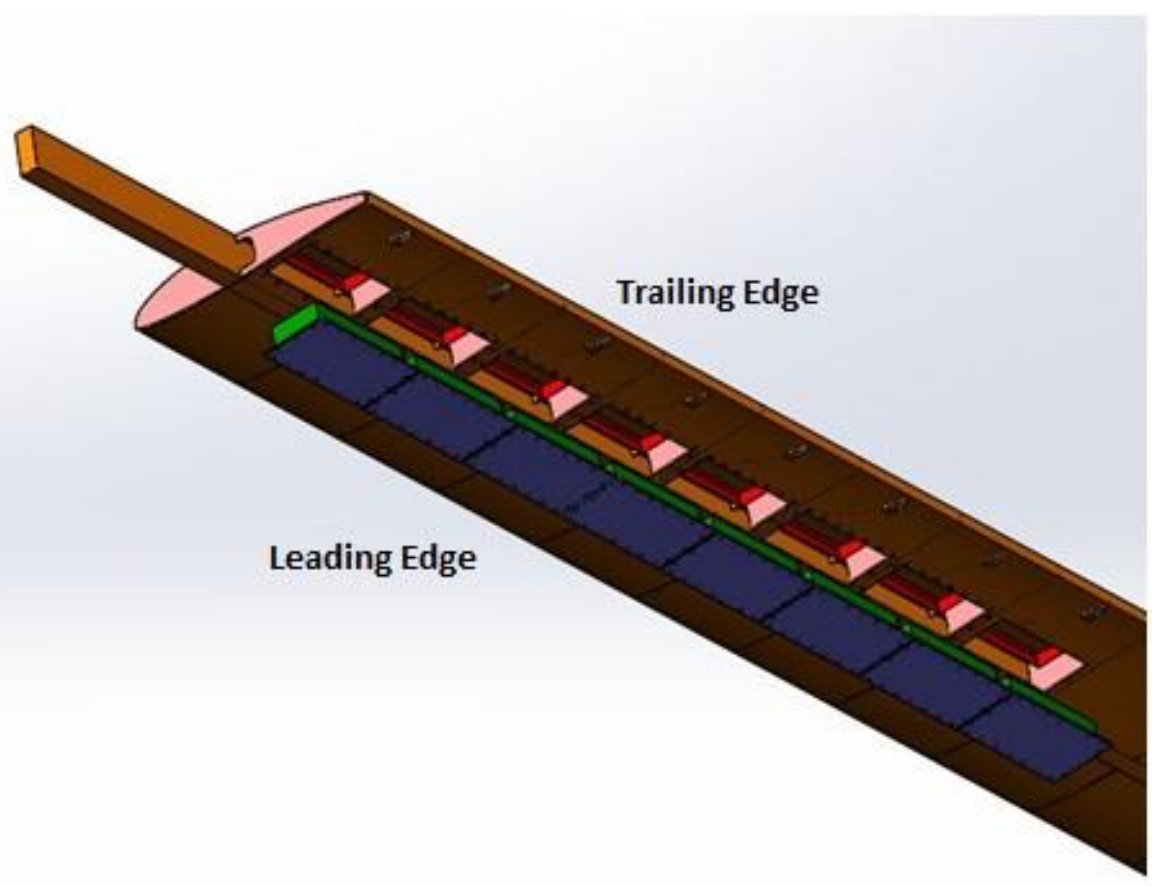

Figure 11.1: Batteries installed through cutout panel

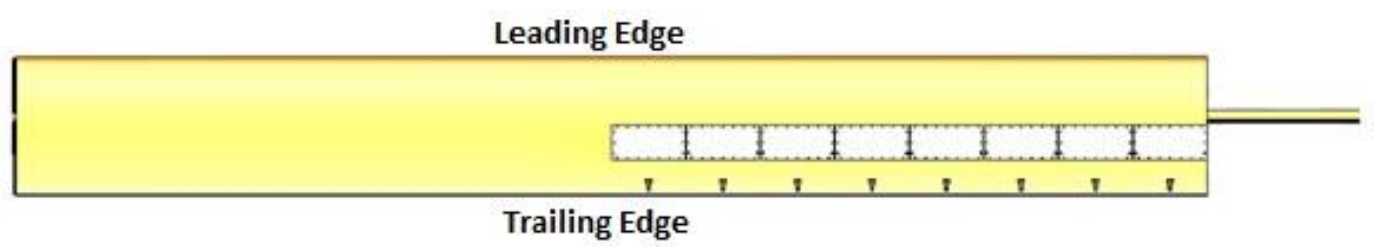

Figure 11.2: Bottom view of wing showing installed battery cutouts

the wing, installing large cutouts in the wing skin significantly reduces the torsional stiffness of the wing structure. To ensure the torsional stiffness of the wing structure is maintained, the wing must be designed to either transfer load into the cutout panel or transfer the load around the cutout panel. Due to the need for already having fasteners to 
secure the panel, it was decided to transfer the shear flow from the wing skin, through joint and into the cutout panel. Therefore the shear flow distribution in the wing skin would not be interrupted.

Another concern with using cutouts on a laminar flow wing is that the joint or protruding fasteners will cause the laminar flow to become turbulent, thereby causing significant increases in drag. For this reason, the cutout panel must be designed to fit flush with the rest of the wing skin and sunken fasteners must be used. Fortunately, the fact that the battery module is bonded to the cutout panel significantly increases the cutout panel's bending stiffness, ensuring that the weight of the battery module does not cause the cutout panel to deform and alter the aerodynamic properties of the wing. If wind tunnel or flight testing shows that the discontinuity between the wing skin and the cutout panel trips the flow from laminar to turbulent, a filler material could be used to reduce the effect of the discontinuity on the local boundary layer.

In summary, the following items must be considered when designing the cutouts for battery installation.

\section{1.) Applied Loads}

a. Shear flow from torsion

b. Normal forces resulting from wing bending moments

c. Out of plane shear from supporting battery module weight

\section{2.) Stiffness Concerns}

a. Wing torsional stiffness reduction

b. Local buckling from bending normal loads 
c. Airfoil Deformation

3.) Detailed Design parameters

a. Screw/Composite Pull Through Loads

b. Bearing Failure in Composite

c. Screw Tensile Loads

d. Screw Shear Loads

The cutout dimensions were sized using the dimensions and weights from Table 11.1 and methodologies for cutout sizing described by Bruhn (63). The reader is encouraged to refer to Bruhn for further details. The joint parameters that result from these considerations are detailed in Table 11.2. It can be seen that inclusion of cutouts adds a considerable amount of weight to each wing.

Table 11.1 Cutout Dimensions

\begin{tabular}{lc}
\hline \hline Cutout Length & 16.9 in \\
Cutout Width & 9 in \\
Battery Module Weight & $14.8 \mathrm{lb}$ \\
\hline \hline
\end{tabular}

Table 11.2 Results for Cutout Joint specification

\begin{tabular}{lc}
\hline \hline Screws & 1/4-28 Flathead machine screw \\
Screw Material & $18-8$ Stainless Steel \\
NutPlate & Clickbond Rivetless 50 cycle \\
\# of Screws Per Module & 24 \\
Joggle Thickness & 10 plies \\
Joint Weight Per Module & $0.91 \mathrm{lb}$ \\
\hline \hline Joint Weight per wing & $10.2 \mathrm{lbs}$ \\
\hline \hline
\end{tabular}




\subsection{Battery Cooling}

After determining that it is possible to install the batteries from the lower wing skin, a method for cooling the batteries must be determined. The heat that must be rejected in each wing is generated from $\mathrm{I}^{2} \mathrm{R}$ losses in the individual battery cells due to the current flowing through the cell. The heat generated in each wing or in each individual battery cell changes as the battery is discharged at different power levels. The heat generated for varying power levels is presented below in

Table 11.3.

Table 11.3 Heat generated for each wing as a function of discharge power

\begin{tabular}{ccccc}
\hline \hline \multirow{2}{*}{$\begin{array}{c}\text { Battery } \\
\text { Draw (kW) }\end{array}$} & System Amps & $\begin{array}{c}\text { Discharge } \\
\text { Rate (C) }\end{array}$ & \multicolumn{2}{c}{ I'R Heat Generated (Watts) $^{\mathbf{2}}$} \\
\cline { 4 - 5 } & & 1.5 & Each Wing & Individual Cell \\
\hline 60 & 166 & 1.3 & 1642 & 1.90 \\
\hline 50 & 139 & 1.0 & 730 & 1.32 \\
\hline 40 & 111 & 0.8 & 411 & 0.84 \\
\hline 30 & 83 & 0.6 & 285 & 0.48 \\
\hline 25 & 69 & 0.5 & 182 & 0.33 \\
\hline 20 & 55 & 0.4 & 103 & 0.21 \\
\hline 15 & 42 & 0.3 & 46 & 0.12 \\
\hline 10 & 28 & & & 0.05 \\
\hline \hline
\end{tabular}

As an initial insight into the magnitude of the cooling system required, a quick analysis can be performed to study the temperature rise of the battery pack under varying discharge levels when the pack is presumed to be fully insulated. Reference (65) performed measurements of 18650 cells in a calorimeter to determine the specific heat of a cell. It was empirically determined that a typical 18650 cell has a specific heat of 0.85 $(\mathrm{J} / \mathrm{gK})$. Assuming the cell is fully insulated, the temperature rise for operation at a certain 
power level over a specified amount of time can be determined. Table 11.4 tabulates the maximum allowable battery operating temperatures as dictated by Panasonic.

Table 11.4 Maximum allowable battery temperatures during discharge (18)

\begin{tabular}{ccc}
\hline \hline & Celsius & Fahrenheit \\
Discharge Min & -20 & -4 \\
Temp & & 140 \\
$\begin{array}{c}\text { Discharge Max } \\
\text { Temp }\end{array}$ & +60 & 140 \\
\hline
\end{tabular}

Figure 11.3 displays predicted battery pack temperature rises at various discharge power levels over time. It assumes that the battery pack is 100\% insulated and all of the heat is stored by the thermal mass of the battery cells.

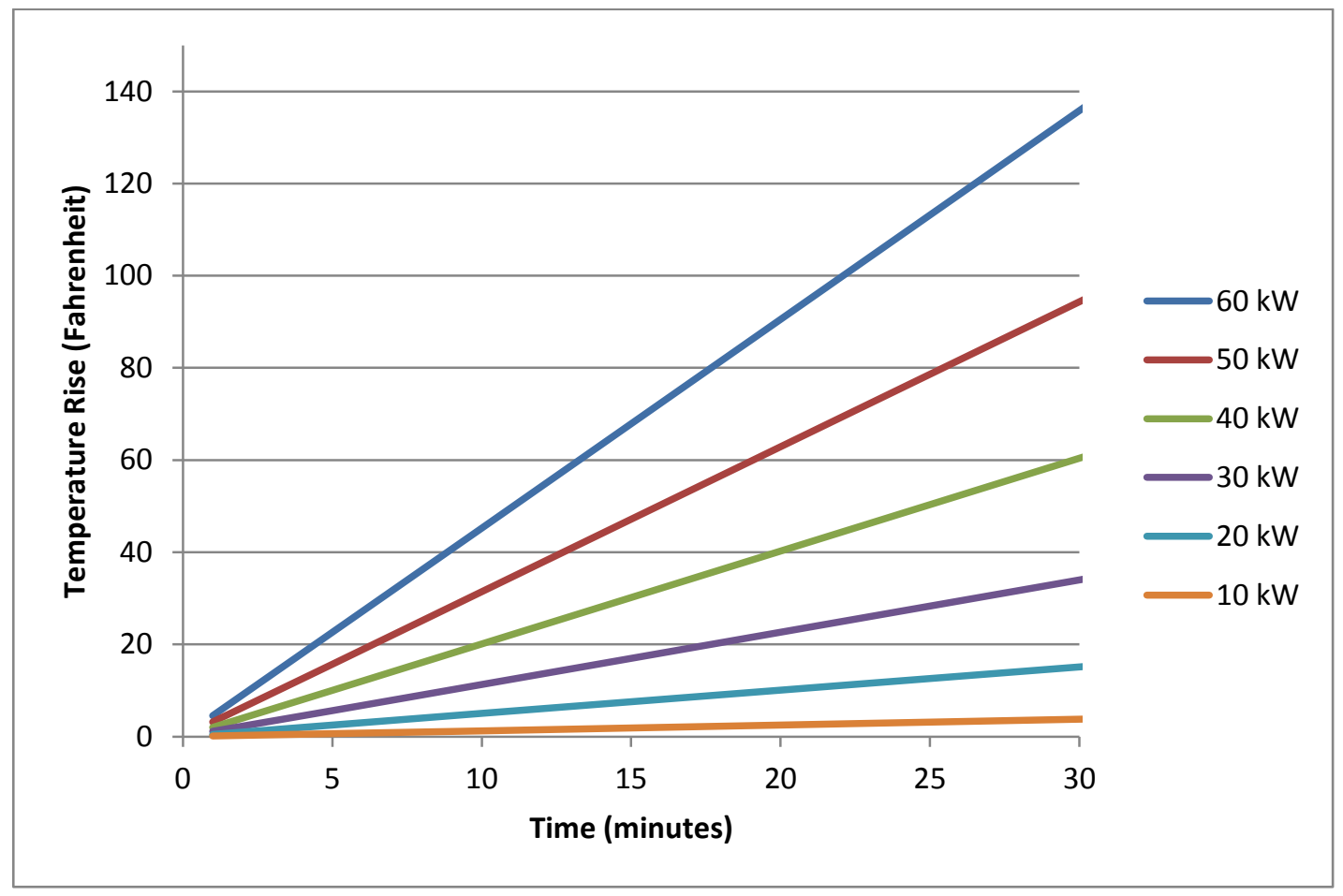

Figure 11.3: Battery Temperature Rise in Fahrenheit 
The above chart demonstrates even when fully insulated with no method for heat rejection, the batteries could start out at $90^{\circ} \mathrm{F}$, operate a full power $(60 \mathrm{~kW})$ for 5 minutes during takeoff and climb, and then operate at 20kW cruise for 60 minutes and just reach maximum operating temperature at the end of the 60 minute cruise. Once again, this assumes a fully insulated battery with absolutely no method for heat transfer. It is therefore apparent that the heat rejection capabilities of the battery cooling system are minimal, especially compared with a standard internal combustion engine. Further, the battery cooling system needn't be sized to dissipate the entirety of the heat generated during full power operation. It can instead be sized to dissipate the heat generated during an anticipated $15 \mathrm{~kW}$ to $20 \mathrm{~kW}$ cruise power level.

Since the cooling requirements are not very great, forced air cooling will be an adequate methodology to cool the pack. Liquid cooling and the increased weight and complexity associated with it should not be necessary. To develop a general concept of the cooling requirements of the battery pack, the convective heat transfer between the battery cell casing and the air flow through the battery modules is modeled using a modified procedure for analyzing heat transfer for a bank of tubes in cross flow detailed by Incropera (66). Incropera's procedure is modified so that instead of a fluid flowing inside the tubes, the tubes become the outer casing of the individual 18650 battery cells. The tubes are then presumed to have an internal heat source, the $\mathrm{I}^{2} \mathrm{R}$ resistance of the battery cell. The reader is encouraged to consult Incropera (66) for relevant methodologies.

The heat rejected in each wing as a function of volumetric flow rate is plotted below in Figure 11.4 as determined using the method described by Incropera (66). The 
ambient air is assumed to enter the wing structure at $100^{\circ} \mathrm{F}$ and the battery cell casings are assumed to be maintained at a maximum of $122^{\circ} \mathrm{F}$. It is important to remember that this method develops a heat transfer rate for the entire bank of tubes. While this is adequate for estimation in the conceptual design phase, it does not predict the ability to maintain individual cells below the maximum operating temperature. Additional analysis will need to be completed at a future date to ensure that no individual cell becomes too hot even if the average module temperature is within specifications.

The theoretical power required to force air cool the batteries for various heat rejection requirements is displayed in Figure 11.5. This power would either result in a direct draw from the electrical system if an electric blower system is used, or result in increased drag if airflow over the fuselage is ducted into the wing for cooling.

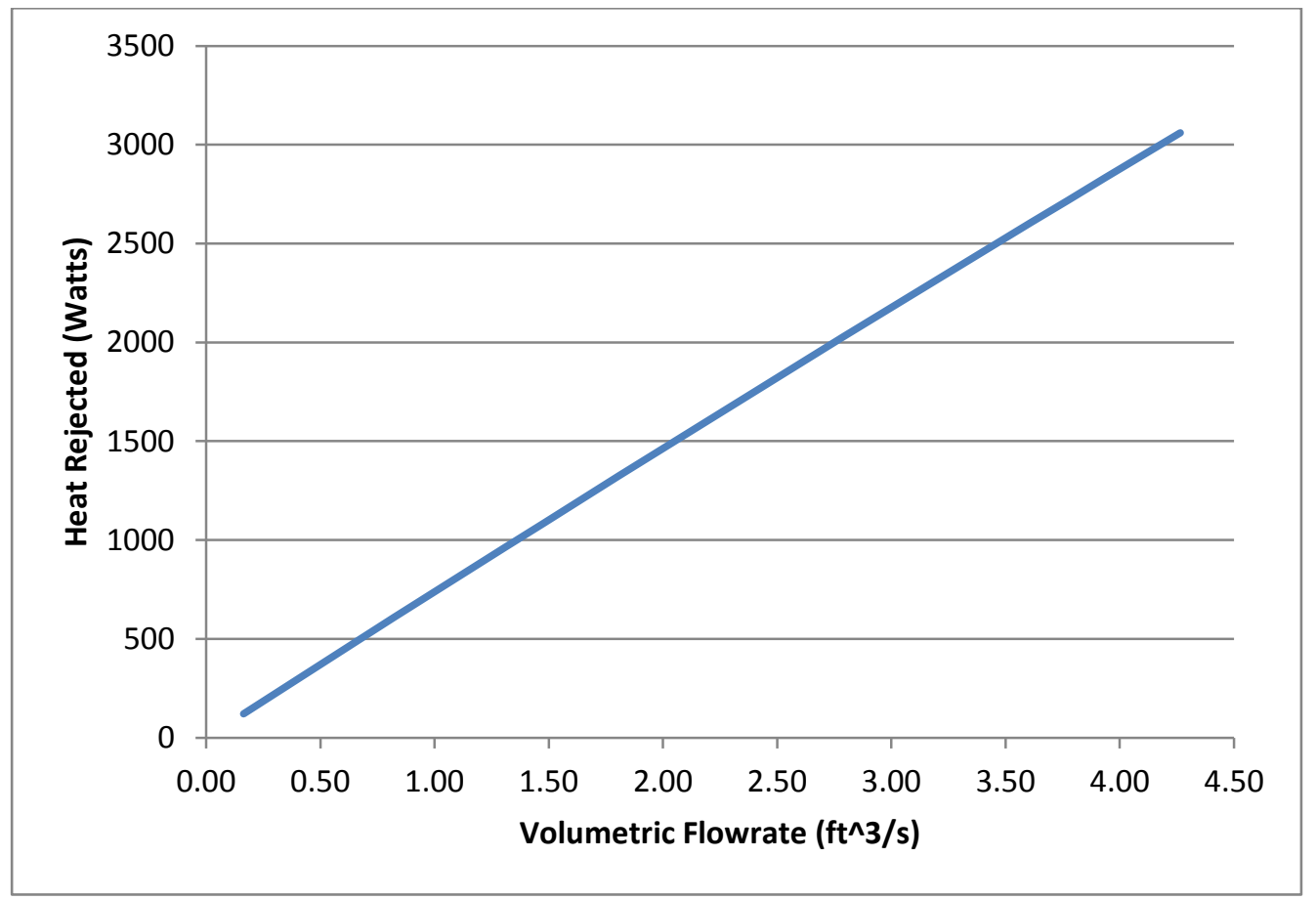

Figure 11.4: Estimated heat rejected for varying volumetric flow rate on a $100^{\circ} \mathrm{F}$ day 


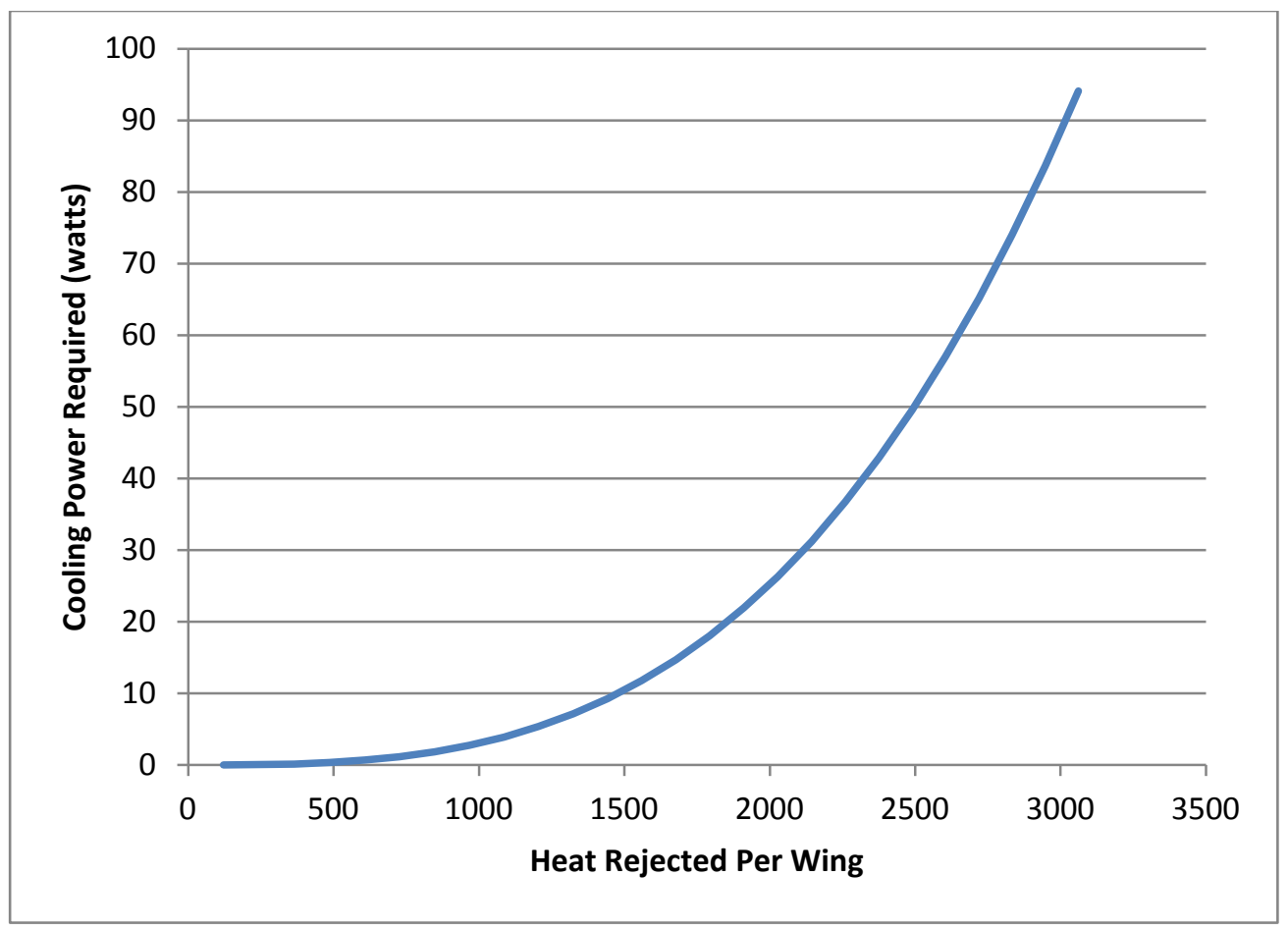

Figure 11.5: Power required for given amount of heat rejection.

The cooling air to the batteries enters the wing at the root through a hole in the root rib as shown in Figure 11.6. It then flows down a plenum between the spar and the battery modules. After flowing through the battery modules as shown in Figure 11.7, the air is exhausted near the trailing edge of the wing on the bottom wing skin as shown in Figure 11.8. In Figure 11.6 below, the module nearest the root is complete with its green enclosure. The remaining modules have had their enclosures removed for visualization purposes. As a result the purple 18650 battery cells can be seen. 


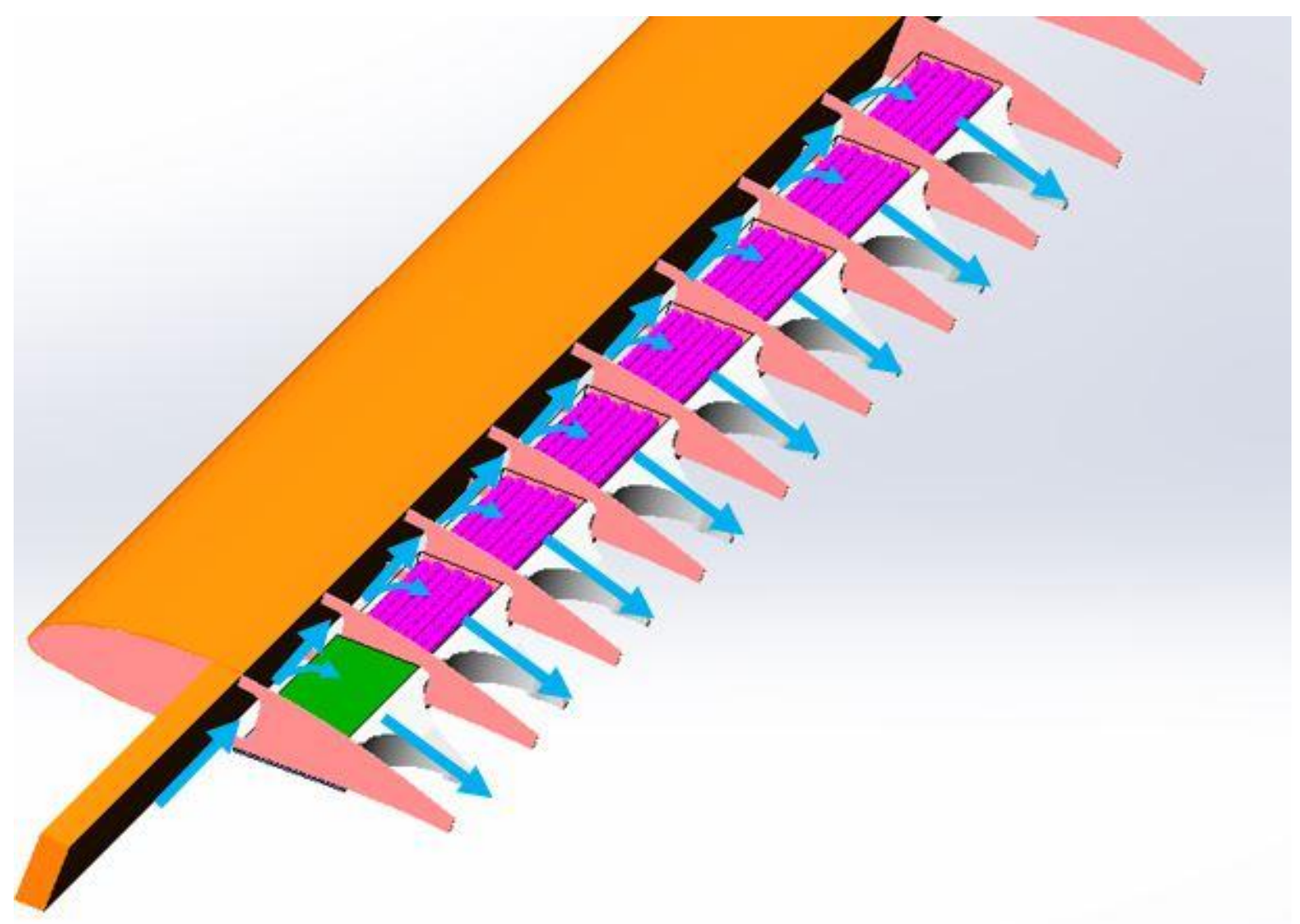

Figure 11.6: Cooling air flow map for the entire wing

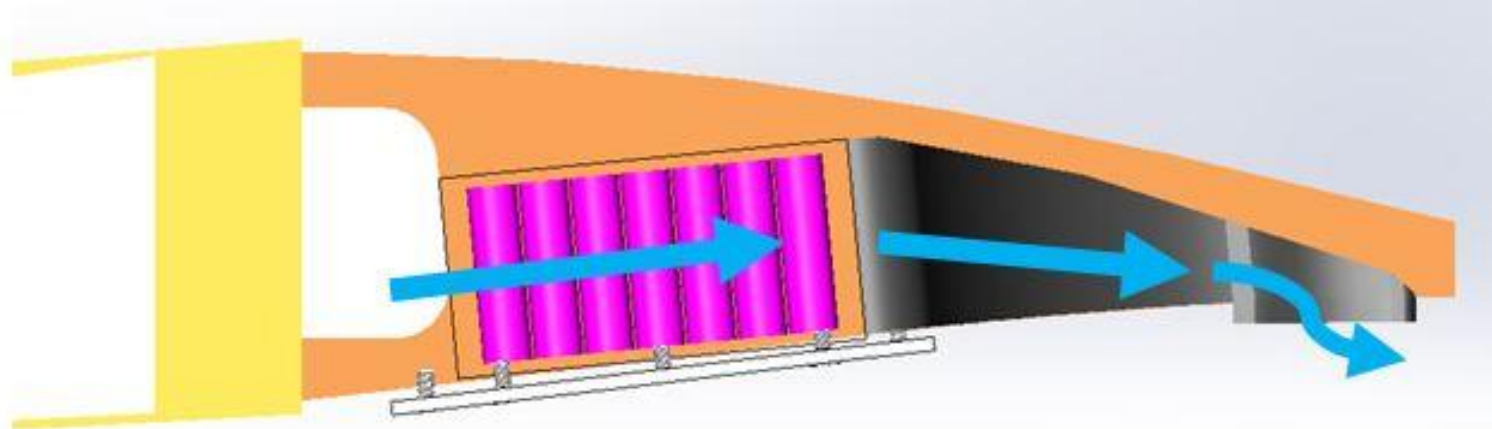

Figure 11.7: Battery module cooling air flow. 


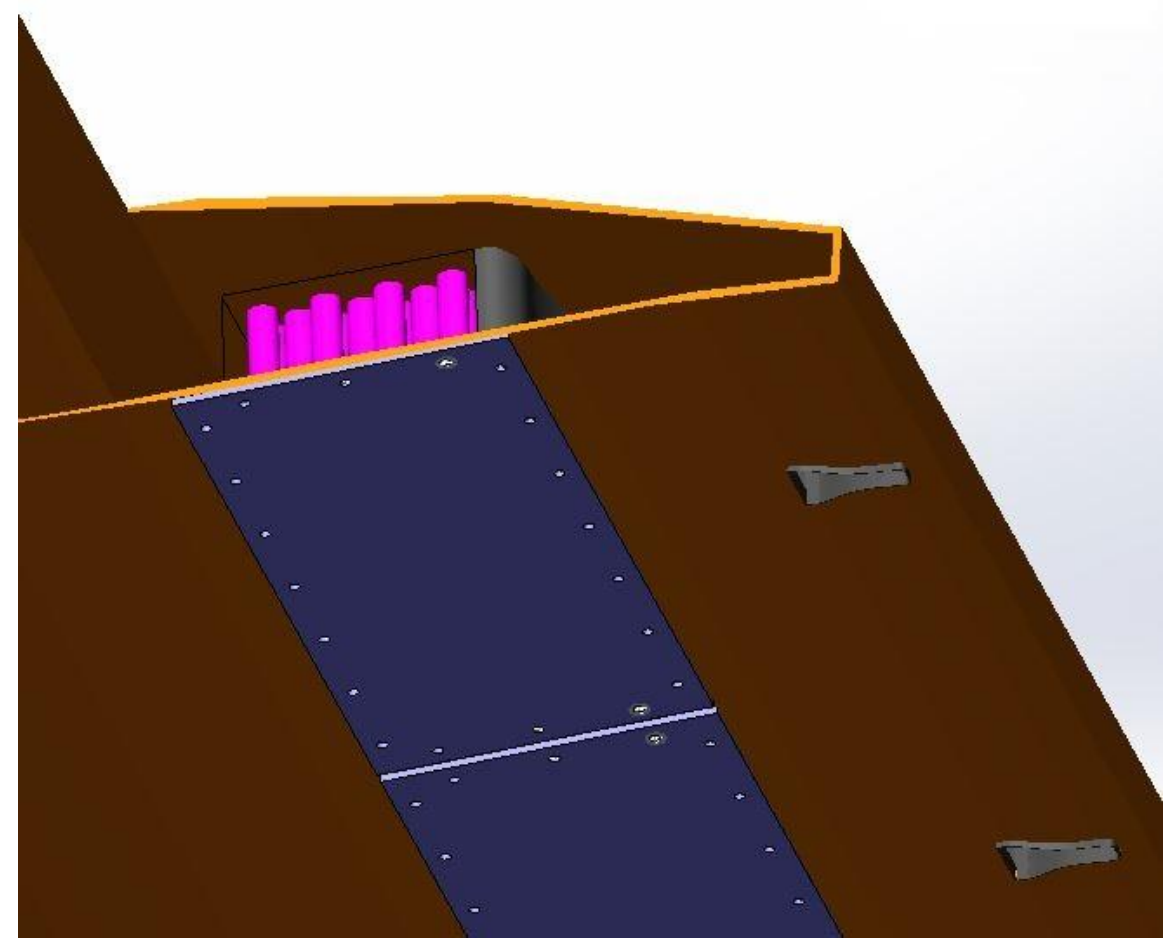

Figure 11.8: Exhaust ducts are located at the trailing edge on the bottom wing skin

In order to maintain the same airflow to all battery modules, it is important to maintain a constant pressure throughout the cooling air plenum. This necessitates reducing the cross section area of the plenum as the air moves away from the wing root towards the outer most modules.

The battery cooling system must be able to provide enough airflow to maintain battery temperatures during cruise power draws. It must be able to do this on a hot day as well. For a $20 \mathrm{~kW}$ cruise power level on a $100^{\circ} \mathrm{F}$, a volumetric airflow requirement of $0.25 \mathrm{ft}^{3} / \mathrm{s}$ is predicted. For the $7 \mathrm{in}^{2}$ opening designed into the first wing rib and depicted on the previous page, a flowrate of $5 \mathrm{ft} / \mathrm{s}$ through the rib is required. This is within the capabilities of a small $12 \mathrm{v}$ centrifugal blower such as the produced by Bosch highlighted in Table 11.5. One blower will be needed for each wing. 


\section{Table 11.5 Bosch blower specifications}

\begin{tabular}{ccc}
\hline \hline Voltage & 12 & volt \\
\hline Current & 1 & $\mathrm{amp}$ \\
\hline Flowrate & 4 & $\mathrm{ft} / \mathrm{s}$ \\
\hline $\begin{array}{c}\text { Volumetric } \\
\text { Flowrate }\end{array}$ & 0.35 & $\mathrm{ft}^{3} / \mathrm{s}$ \\
\hline Delta $\mathrm{P}$ & 0.07 & $\mathrm{psi}$ \\
\hline Weight & 2.5 & $\mathrm{lb}$ \\
\hline \hline
\end{tabular}

\subsection{Emergency Cell Venting}

After the access cutouts have been designed and the cooling system laid out, the last thing to consider from a battery standpoint is battery pack safety. A properly designed battery management system should significantly reduce the risk of a battery venting hot gases by maintaining the battery within charge and temperature limits. However, as shown by the Boeing 787 Dreamliner, sometimes battery cells can vent in spite of a properly functioning battery management system. A provision must therefore be made to exhaust the hot battery gasses overboard without compromising the structural integrity of the wing or heating neighboring battery cells and causing a thermal runaway. The temperatures and pressures experienced by a venting cell are outlined in Table 11.6.

Table 11.6 Properties of battery during venting episode (67)

\begin{tabular}{cc}
\hline $\begin{array}{l}\text { Internal cell pressure } \\
\text { when venting occurs }\end{array}$ & $\begin{array}{c}485-540 \\
\mathrm{psi}\end{array}$ \\
\hline $\begin{array}{c}\text { Vented gas } \\
\text { temperature }\end{array}$ & $1200^{\circ} \mathrm{F}$ \\
\hline
\end{tabular}


As described in the earlier battery chapter, the vent in an 18650 cell is located on a cylinder end cap. All of the cells can therefore be oriented so that the direction of the vented gas is known. An emergency duct can be created that fits over the top of the battery module. The duct is open at the trailing edge of the wing, so that as the airplane moves through the air a low pressure is created in the duct, drawing the gasses out of the back of the duct and out of the wing structure. This system is illustrated in Figure 11.9 and Figure 11.10.

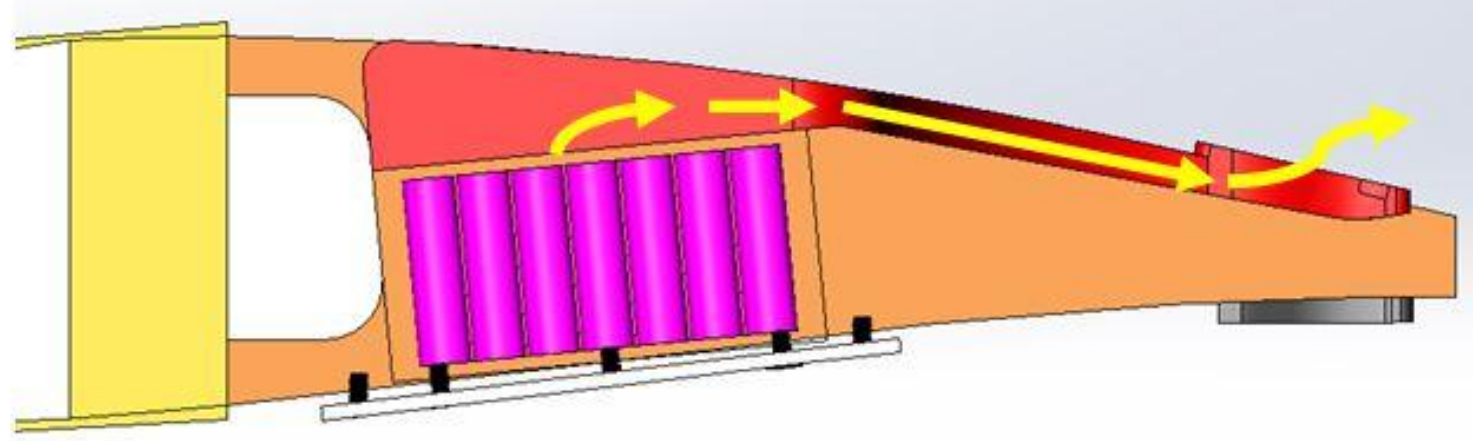

Figure 11.9: Battery emergency venting flow map 


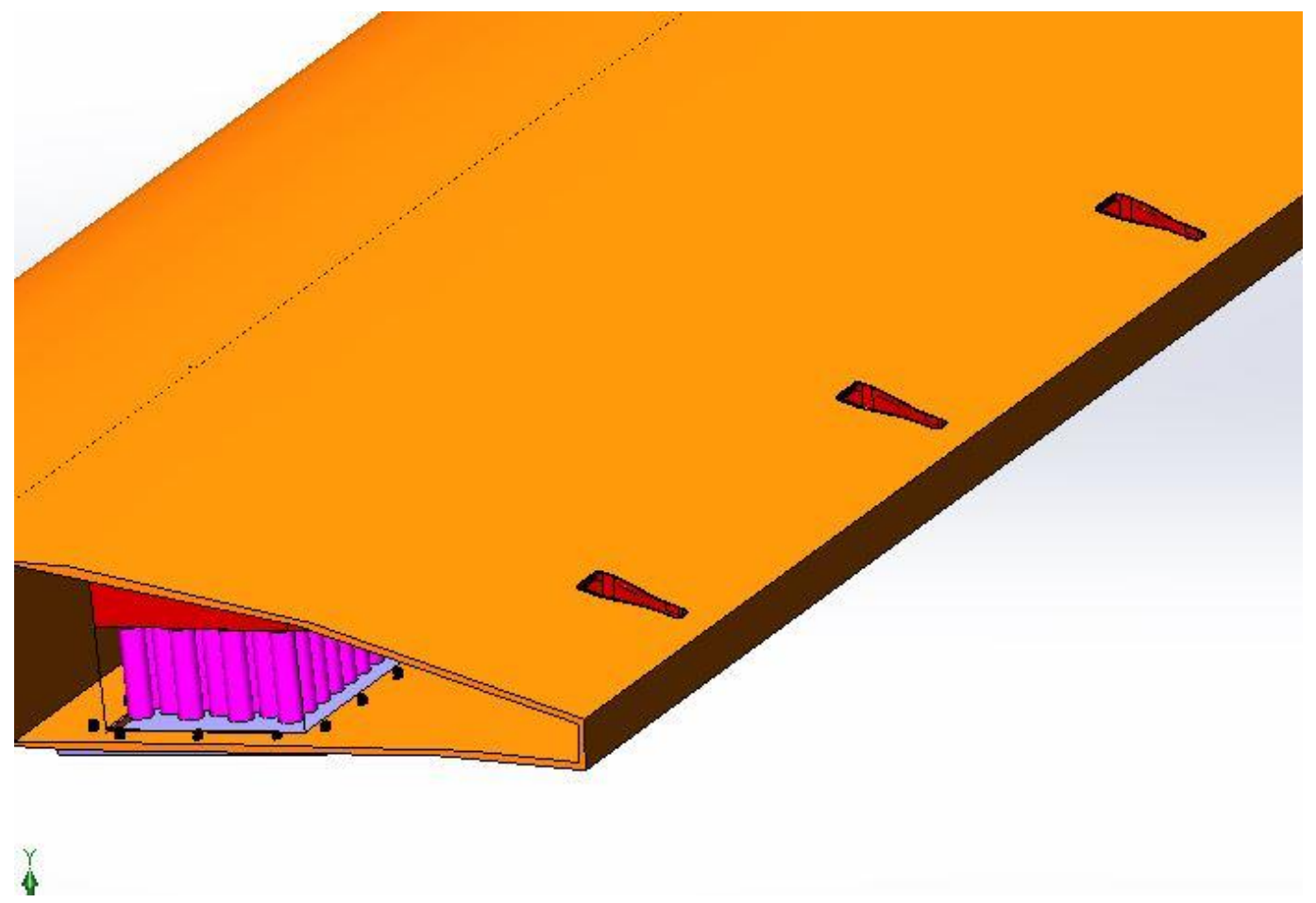

Figure 11.10: Emergency venting ducts on upper wing skin

Future testing and analysis will need to be performed to determine the ability of the duct to withstand the momentary $1200^{\circ} \mathrm{F}$ gas that will pass through it. If it is shown that the conventional composite/resin system used for the rest of the wing is subjected to unsafe temperatures, options exist to lower the temperature of the gas or raise the maximum temperature the composite can sustain. One option is to duct a portion of the battery cooling air flow over the top of the module and past the battery vents. When a cell vents, the hot gasses will mix with the cooling gasses, lowering the overall temperature and thus the temperature that the cooling duct is exposed to. If this does not work, Pyromeral Systems Inc. has developed composite technology that is currently used in aerospace industry that can withstand $1800^{\circ} \mathrm{F}$ continuous temperature (68). 


\subsection{Wing Design Conclusion}

Approximately 4 pounds are saved from each wing due to the reduction in required structural strength of the wing resulting from packaging the batteries in the wing instead of the fuselage. However, 10 pounds are added per wing in order to create cutouts to install and remove the battery for a net structural weight gain of 6 pounds per wing or 12 pounds for the entire aircraft.

Basic packaging issues are the driving design factor for integrating the battery into the wing. This includes finding the available volume to locate the battery modules and the cooling and emergency ventilation system in the wing. The tapering of the wing cross section near the trailing edge of the wing prevents the batteries from being moved far enough aft to detrimentally affect the aeroelastic properties of the wing. For this reason, aeroelastic effects of the wing are not a driving design factor for this particular airframe.

A major conclusion is that the existing wing structure has the appropriate strength and stiffness required to package the batteries in the wing with no modifications to the spar or wingskins. A proof of concept conversion could likely consist of simply taking an existing Pipistrel Sinus wing and cutting the required holes in the lower wing skin to access the batteries.

Packaging the batteries in the wing offers benefits in the overall volumetric efficiency of the entire aircraft platform. It can also be ideal for center of gravity concerns. Future battery electric aircraft designers will have to weigh these benefits against the increased complexity of the wing structure during production and 
maintenance. A major hurdle that will have to be overcome will be the perceived danger of having the traction batteries so close to the wing spar and the ensuing marketability issues of such a design.

Packaging the batteries in the wings is worthwhile for a conversion of an existing internal combustion airframe to battery electric power since there is limited space to package the batteries in the fuselage without upsetting the aircraft's center of gravity. However, for a clean sheet design, the designer would likely be able to adjust the position of the various lift and weight forces acting on the airframe to allow the batteries to be packaged in the fuselage and retain an appropriate center of gravity location. This would likely reduce the complexity of the overall packaging of the electric power system for a clean sheet design.

\subsection{Chapter Conclusion}

This chapter shows that it is feasible to package the batteries in the wing and still maintain accessibility for maintenance as well as incorporating adequate thermal management systems and battery pack safety provisions. 


\section{CHAPTER 12: Finalized Aircraft Concept Summary}

In the previous chapters, a lot of work as been performed on various parts of the overall electric aircraft package. The power required for several aircraft was determined and propulsion systems sized in order to determine what type of aircraft would have the best performance if converted to battery electric propulsion. The Pipistrel Sinus was chosen due to its low drag airframe and high useful load, which produced the longest endurance of any airframe analyzed. This is due to the low power requirements resulting from the low drag and the capability to carry the weight of a large battery pack. After selecting the Sinus, a detailed electric propulsion system layout in the airframe was performed. The motor and controller were sized to provide peak power for short periods on takeoff and climb. The motor and controller were also sized to provide adequate cruise and climb performance under continuous power limits. The requirements developed in this thesis for an appropriate motor and controller selection are reproduced below.

The motor selected shall have the following characteristics:

I. Brushless DC motors will be used for higher peak point efficiency and better cooling properties.

II. The motor and controller shall be selected such that cruise power settings are below the continuous power limits for both devices.

III. The motor and controller shall be capable of an adequate rate of climb at gross weight under continuous power limits

IV. The motor and controller shall be selected to operate at peak efficiency during cruise flight but still make the required peak power for takeoff. 
V. The motor shall be capable of turning a propeller at an appropriate speed so as not to require a gear reduction box.

After selecting an appropriate motor and controller, a detailed battery system layout was performed in the airframe. This layout determined that a significant portion of the battery would have to be installed inside of the wing structure in order to maintain the aircraft's center of gravity at the appropriate location. At this point in the thesis effort, it was determined that the technical feasibility of packaging a large portion of the battery pack in the wing structure would be the key to the feasibility of the overall aircraft. The first step was to investigate the flutter properties of the wing with the added mass of the batteries for various battery packaging configurations. It was found that the critical flutter speed is not reduced to unacceptable levels for any packaging configuration and that therefore flutter is not a driving design consideration for this particular aircraft. The design is therefore driven by other packaging concerns including battery accessibility, battery safety, and battery cooling requirements. The requirements used to ensure the battery packaging design is adequate were determined by analyzing current industry practices as well in-field battery pack case studies. The requirements developed in this thesis for a safe, high performance battery pack design are reproduced below:

I. Battery Cell: The battery cell used in traction battery pack shall include the following safety features:

a. Positive Temperature Coefficient Device (PTC): Each cell shall have an integrated PTC device to restrict current flow in the event of a cell overtemperature event. 
b. Current Interrupt Device (CID): Each cell shall have an integrated CID to electrically isolate the cell in the case of an over pressure event.

c. Vent: Each cell shall have an integrated venting device that ensures the cell will vent any exhaust gases at an known location.

II. Battery Module and Pack: The battery module or battery pack shall include the following features and design practices:

a. Emergency cell venting exhaust system: The battery module design shall allow any vented hot exhaust gases from a cell to pass overboard of the aircraft. The exhaust gas system shall not allow the hot exhaust gases to compromise other portions of the battery pack or any other critical system or structure of the aircraft.

b. Cell disconnect feature: The integration of an individual cell into the battery pack shall have a provision to electrically isolate that cell from the remainder of the battery pack should that cell experience a venting situation.

c. Battery Management System (BMS). The battery pack shall include a BMS that performs the following functions:

i. Cell balancing

ii. Temperature monitoring

iii. Voltage monitoring

iv. Current monitoring

d. The battery pack design shall tolerate a single cell failure without catastrophic battery pack failure. 
e. The BMS shall ensure that any part of the battery pack does not exceed any temperature, voltage or current limits.

f. The battery pack shall be equipped with a heat rejection system capable of maintaining the battery temperature within the battery cell manufacturer's specified temperatures throughout all parts of the operating envelope.

After the battery pack layout was performed, the wing structure was modified in order to allow for the packaging of batteries inside of the wing skin while ensuring proper battery performance and safety. It was found that although it is more structurally efficient to locate the batteries in the wing as opposed to the fuselage, the weight savings from this more efficient location are cancelled by the increased weight of including several cutout panels in the lower wing skin. The overall weight change to the aircraft between packaging the batteries in the wing versus the fuselage is therefore negligible.

The remainder of this chapter pulls all of the above details together and summarizes the expected performance of a battery electric conversion of a Pipistrel Sinus. Converting the Pipistrel Sinus to battery electric propulsion results in an aircraft with decent performance. Takeoff distance and initial climb rates are unchanged from the internal combustion version of the Sinus. The external dimensions of the Sinus are also unchanged. Range and endurance are reduced from the internal combustion version, but are still adequate to perform a variety of missions such as local sightseeing and pilot training. For the electric conversion aircraft, endurance and range are greatly affected by the cruise speed at which the pilot chooses to fly. While the electric propulsion system is capable of sustaining speed of up to $110 \mathrm{MPH}$ in level flight, reducing airspeed to 60 
MPH triples the endurance to a maximum of 3.6 hours and extends the range to a maximum of 215 miles with reserves.

Table 12.1 to Table $\mathbf{1 2 . 5}$ summarize the overall performance specifications of the Sinus and then provide details on the electric propulsion system that makes the performance happen.

Table 12.1 Electric Aircraft Summary

\begin{tabular}{cc}
\hline \hline Max Persons and Luggage Weight & $380 \mathrm{lbs}$ \\
Number of Seats & 2 \\
Max Takeoff Weight & $1290 \mathrm{lbs}$ \\
Empty Weight & $910 \mathrm{lbs}$ \\
Wing Span & $49 \mathrm{feet}$ \\
Wing Area & $132 \mathrm{ft}^{2}$ \\
\hline \hline
\end{tabular}

Table 12.2 Electric Aircraft Performance Summary

\begin{tabular}{cc}
\hline \hline Max Endurance at 60 MPH True Airspeed & 3.6 hours with reserves \\
Max Range at 60 MPH True Airspeed & 215 miles with reserves \\
Max Endurance at 90 MPH True Airspeed & 1.5 hours with reserves \\
Max Range at 90 MPH True Airspeed & 140 miles with reserves \\
Max Climb Rate at Sea Level & 1280 feet per minute \\
Continuous Climb Rate at Sea Level & 700 feet per minute \\
Best Climb Speed & $74 \mathrm{MPH}$ \\
Takeoff Roll, Sea Level, Max Weight & $288 \mathrm{ft}$ \\
Max Continuous Airspeed, Level Flight & $110 \mathrm{MPH}$ \\
Never Exceed Speed $\left(\mathrm{V}_{\mathrm{NE}}\right)$ & $140 \mathrm{MPH}$ \\
\hline \hline
\end{tabular}




\section{Table 12.3 Electric Aircraft Drive System Summary}

\begin{tabular}{cc}
\hline \hline Max Motor \& Controller Power & $60 \mathrm{~kW}$ \\
Continuous Motor \& Controller Power & $40 \mathrm{~kW}$ \\
Battery Energy Capacity & $38.9 \mathrm{kWh}$ \\
Battery Pack Nominal Voltage & 360 volts \\
\hline \hline
\end{tabular}

\section{Table 12.4 Electric Aircraft Motor and Controller Summary}

\begin{tabular}{cc}
\hline Motor & Emrax 228 \\
Motor Cooling & Air Cooled \\
Controller & Unitek Bamocar D3 \\
Controller Cooling & Liquid Cooled \\
Motor/Controller Max Power & $60 \mathrm{~kW}$ \\
Motor/Controller Continuous Power & $40 \mathrm{~kW}$ \\
Motor and Controller Combined Weight & $51 \mathrm{lbs}$ \\
Propeller Drive & Direct Drive \\
RPM range & $0-3000$ \\
\hline \hline
\end{tabular}

Table 12.5 Electric Aircraft Battery Summary

\begin{tabular}{cc}
\hline \hline Cell Type & Cylindrical 18650 \\
Cell Model & Panasonic 18650, 4 Ah \\
Pack Nominal Voltage & 360.4 \\
Pack Capacity (Ah) & 107 \\
Total Energy (kWh) & 38.92 \\
Total number of cells & 2862 \\
Weight (Ib) & 371 \\
Battery Weight in Each Wing (lb) & 113 \\
Battery Weight Under the Engine Cowling (lb) & 145 \\
\# of Cells in Series & 106 \\
\# of Cells in Parallel & 27 \\
\hline \hline
\end{tabular}


The conversion of the Sinus from internal combustion to battery electric involves reusing the fuselage and empennage while redesigning the firewall forward packaging and the internal wing structure. The firewall forward packaging is redesigned to accommodate an electric motor, controller and approximately one third of the battery pack. The internal wing structure is redesigned to accommodate the packaging of the remainder of the battery and the necessary thermal management and safety systems. The outside mold line of the new wing is kept the same as the original wing used on the internal combustion aircraft. To install and access the batteries, cutouts are incorporated into the lower wing skin as shown in Figure 12.1. Air flow used to cool the batteries is provided by forcing air from the wing root along aft side of the spar. The air is then forced through the battery pack and exhausted at the trailing edge of the wing as shown by the blue lines in Figure 12 .. 


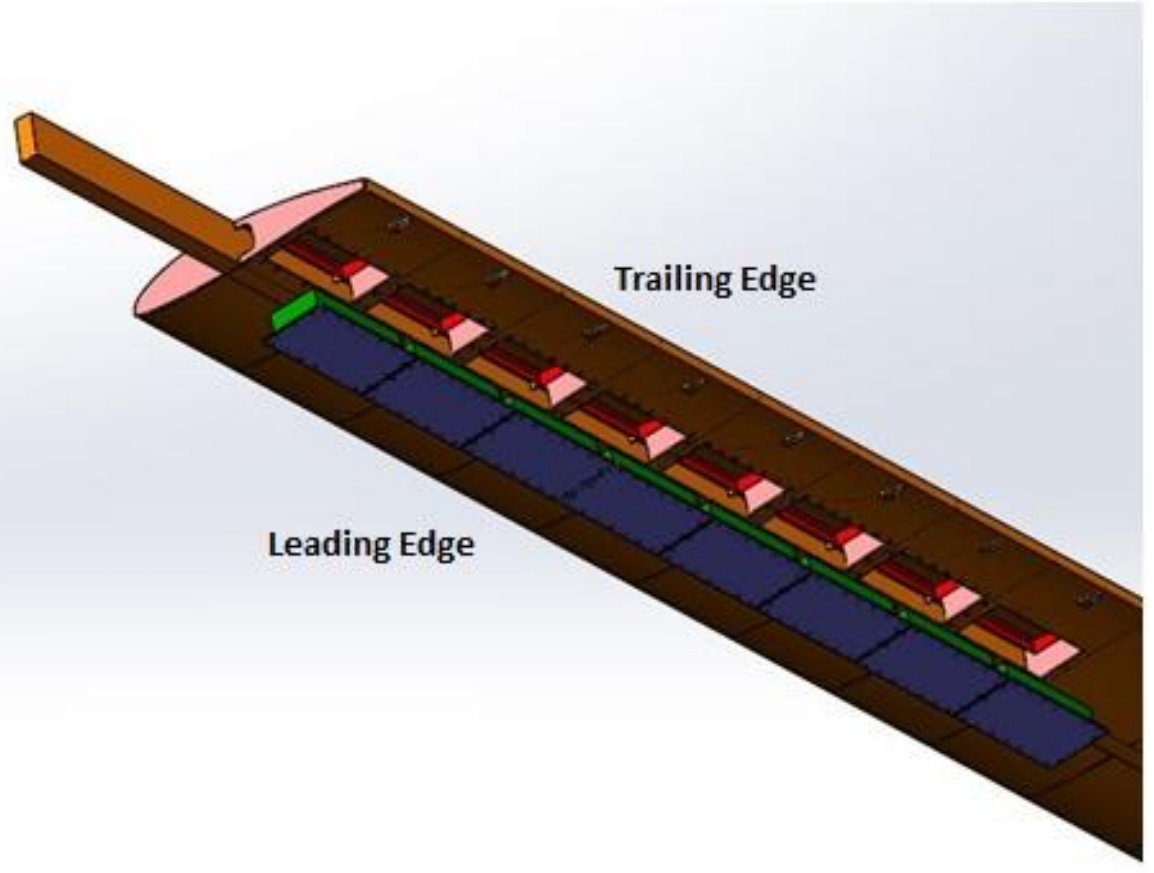

Figure 12.1: Cutouts for battery access

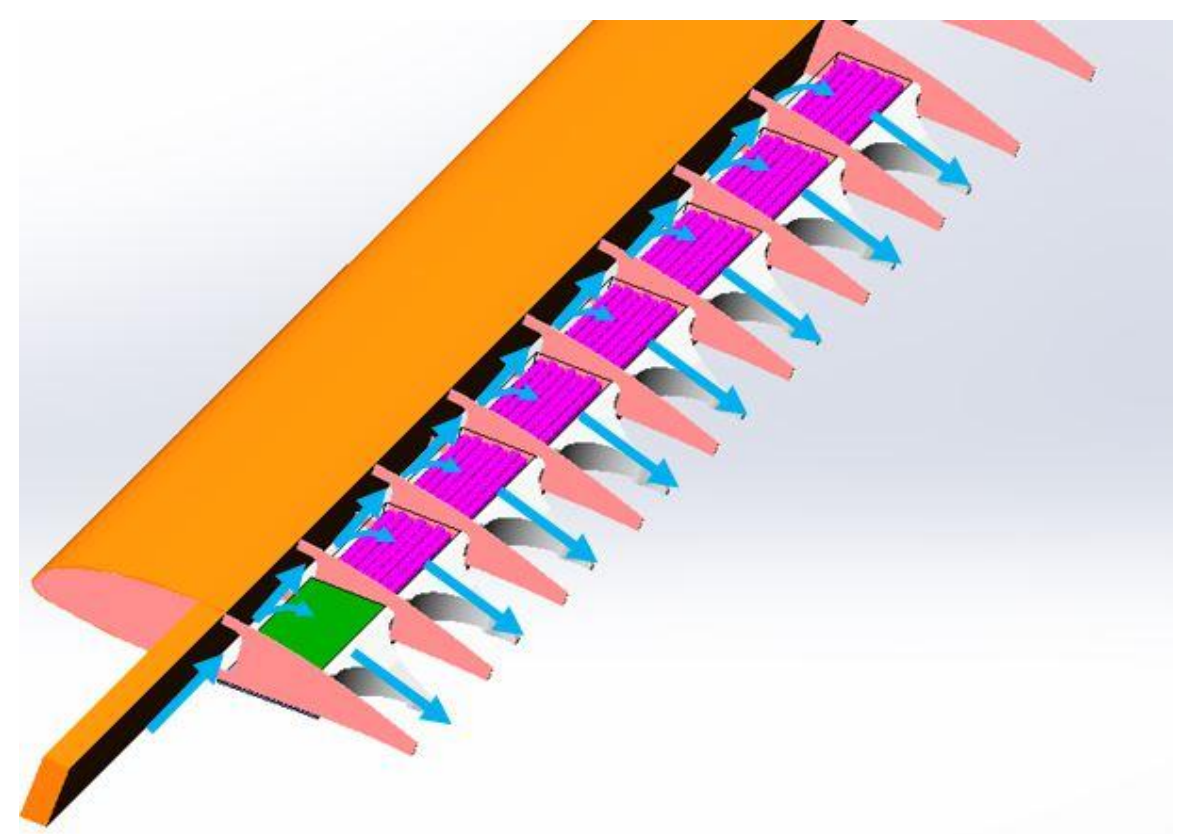

Figure 12.2: Cooling airflow for batteries 
To allow the battery pack to tolerate the failure of a single cell without causing a cascading thermal runaway, provisions are included in the wing vent any hot gasses that might be vented from a cell experiencing thermal runaway. As shown below in Figure 12.1, the gasses are vented out of the top end of a cell and then ducted overboard at the trailing edge of the wing.

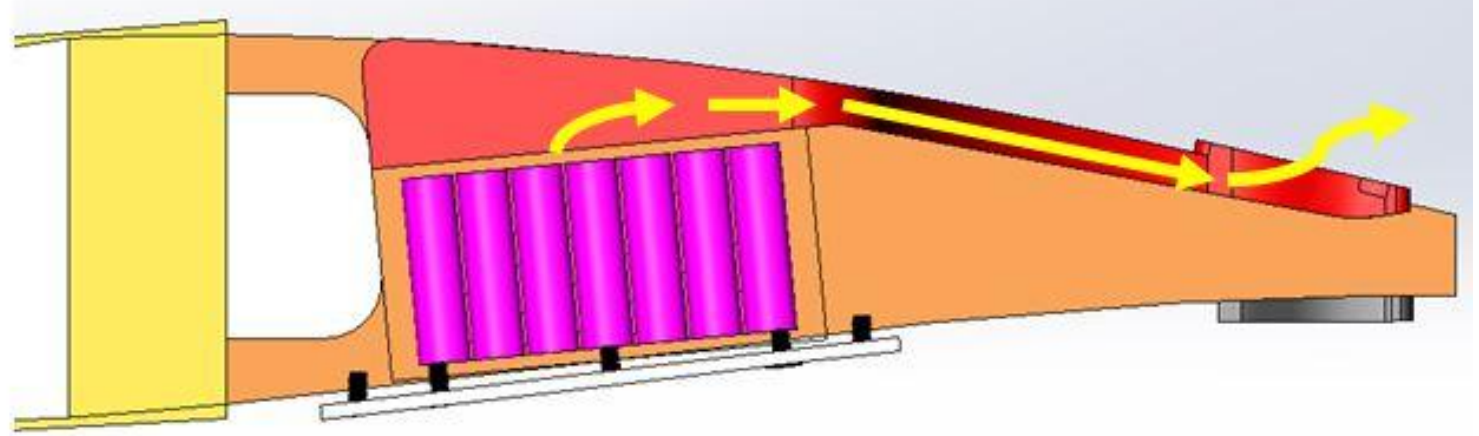

Figure 12.1: Emergency venting system 


\section{CHAPTER 13: $\quad$ Final Conclusions}

A battery powered general aviation aircraft is feasible, but only for a specific category of aircraft. Aircraft valued for their long range, fast cruise speed, or large payload abilities are not suitable candidates for conversion to electric aircraft. The battery electric aircraft will have significantly reduced range, endurance and useful load compared its internal combustion counterparts until a major advancement in battery energy density occurs. This does not mean that electric aircraft are impractical, it just means that they will be machines intended for local flight instead of long distance travel in the same manner that electric cars are used for local trips instead of long road trips. Electric aircraft could be used for any number of types of local flights such as sightseeing or pilot training.

Some types of airframes have been shown to be better suited to electric propulsion than others. The ideal airframe has a combination of high weight carrying abilities for a larger battery pack and low cruise power requirements in order to lengthen endurance. These traits are typically found in touring motor gliders. Packaging effects also must be considered when searching for the ideal airframe for conversion to electric power. The airframe must have the available volume to package the batteries in a location that maintains the overall aircraft's center of gravity in the correct location.

A significant amount of this thesis focused on the technical feasibility of packaging the batteries in the wing structure. This required considering the effect of aeroelastic flutter, battery safety, maintenance and thermal management. It has been shown that it is possible to account for these concerns and package the batteries in the wings. The existing wing structure is adequate, but it can be made lighter due to the shortened load path from the battery weight in the wing to the lifting surface. However, 
the overall aircraft becomes slightly heavier since cutouts must be installed in the wing skin to access the batteries. The wing must be strengthened around these cutouts to transfer the load, which adds significant weight. This weight gain cancels any gains from the more efficient load path, and the net result is that the aircraft is negligibly heavier.

While it has been shown that it is technically feasible to produce a battery electric motor glider with the specifications outlined in the previous chapter, market research is needed to help develop the business case, if any, for an electric aircraft. Just as the required range, speed, payload and price point are vastly different for an electric automobile as compared to a gas automobile, the market requirements for an electric aircraft are likely to be much different from the current market requirements for an internal combustion aircraft. This thesis has helped to increase understanding of what engineering and technology can offer in the form of an electric aircraft. Future efforts are needed to understand what the market truly desires from electric aircraft. The next step in the development of electric aircraft is to determine the best way to mesh what technology can currently offer with what the market demands. 


\section{WORKS CITED}

1. NASA Green Flight Challenge: Conceptual Design Approaches and Technologies to Enable 200 Passenger Miles per Gallon. Wells, Douglas P. s.I. : NASA Langley Research Center; Hampton, Virginia 23681.

2. Rohit, Parimal M. Path Set For Potential Closure Of Santa Monica Airport. Santa Monica Mirror. [Online] March 28, 2014. [Cited: April 14, 2014.] http://www.smmirror.com/articles/News/Path-Set-For-Potential-Closure-Of-SantaMonica-Airport/39842.

3. Avgas Specifications. Experimental Aircraft Association (EAA). [Online] 2014. http://spirit.eaa.org/autofuel/avgas/avgas_specs.asp.

4. Adrian Castro, MD et al. Santa Monica Airport Health Impact Assement (HIA). s.I. : UCLA Department of Pediatrics, 2010.

5. Comparative Aircraft Flight Efficiency (CAFE) Foundation. [Online] http://cafefoundation.org/v2/gfc_2011_results.html.

6. Wikipedia. E-Genius fly-by. Wikipedia. [Online] Wikipedia, August 6, 2011. [Cited: June 19, 2014.] http://commons.wikimedia.org/wiki/File:E-Genius_fly-by.jpg.

7. Pipistrel Taurus G4: on Creation and Evolution of the Winning Aeroplane of NASA Green Flight Challenge 2011. Tomazic, Tine, et al. 57(2011)12, 869-878, s.l. : Journal of Mechanical Engineering.

8. Wood, Janice. Pipistrel Taurus G4 nominated for Design of the Year. General Aviation News. [Online] General Aviation News, January 11, 2012. [Cited: June 19, 2014.] http://generalaviationnews.com/2012/01/11/pipistrel-taurus-g4-nominated-for-designof-the-year/.

9. Pilot Space. Pipistrel Taurus. Pilot Space. [Online] CeskyWebServis.cz. [Cited: June 19, 2014.] http://www.pilotspace.eu/pipistrel-taurus_116.

10. Tennessen, Peter Thomas, Weintraub, Jeffrey C. and Hermann, Weston Arthur: Tesla Motors, Inc. Extruded and Ribbed Thermal Interface for use with a Battery Cooling System. US 20110212356 A1 September 1, 2011. Application.

11. EVHangar. Diamond Aircraft DA36 E-Star 2. EVHangar. [Online] WordPress, April 7, 2014. [Cited: June 19, 2014.] http://www.evhangar.com/aircraft/poc-aircraft/da36-e-star-2/.

12. Technologic Vehicles. EADS E-Fan electric aircraft demonstrator. Youtube. [Online] Youtube, June 17, 2013. [Cited: June 19, 2014.] http://www.youtube.com/watch?v=lavvVN7fSEU. 
13. Kane, Mark. EADS Debuts Electric E-Fan Airplane at 2013 Paris Air Show. Inside EVs. [Online] Inside EVs, June 2013. [Cited: June 19, 2014.] http://insideevs.com/eads-debuts-electrice-fan-airplane-at-2013-paris-air-show-wvideo/.

14. Wikipedia. F-WATT EADS Innovation Works. Wikimedia. [Online] Wikimedia, June 17, 2013. [Cited: June 2014, 2014.] http://commons.wikimedia.org/wiki/File:FWATT_EADS_Innovation_Works-ACS_E-Fan_mock-up_PAS_2013_01.jpg.

15. Electrical Energy Storage and Intercalation Chemistry: Science, New Series. Whittingham, M.S. No. 4244 (Jun. 11, 1976), pp. 1126-1127, s.I. : American Association for the Advancement of Scient, Vol. 192.

16. Panasonic Corporation of America. Lithium Ion. NCR18650A 3.1Ah. 2011.

17. Brooke, Lindsay. Battery guru: Future of 18650 cells unclear beyond Tesla S. SAE International. [Online] SAE International, February 17, 2014. [Cited: June 19, 2014.] http://articles.sae.org/12833/.

18. Panasonic Corporation of America. Overview of Lithium Ion Batteries. Overcharge/Overdischarge/Overcurrent Safety Circuits, Notes and Precautions. 2007.

19. al, Ahmad A. Pesaran et. Designing Safe Lithium-lon Battery Packs Using Thermal Abuse Models. Las Vegas, NV : National Renewable Energy Laboratory, 2008.

20. al, I.J.M. Besselink et. Design of an efficient, low weight battery electric vehicle based on a VW Lupo 3L. The 25th World Battery, Hybrid and Fuel Cell Electric Vehicle Symposium \& Exhibition. Shenzhen, China : EVS-25, 2010.

\section{Texas Instruments.}

22. Kokam. Superior Lithium Polymer Battery. Kokam. [Online] Kokam. [Cited: June 19, 2014.] http://www.kokam.com/new/kokam_en/sub01/sub01_01.html.

23. Automotive Energy Supply Corporation. Cell, Module, and Pack for EV Applications. Automotive Energy Supply Corporation. [Online] Automotive Energy Supply Corporation. [Cited: June 19, 2014.] http://www.eco-aesc-lb.com/en/product/liion_ev/.

24. GSYUASA. Lithium ion cells for aerospace applications LVP series. Tokyo, Japan : GS Yuasa International Ltd.

25. Panasonic. Panasonic Develops High-Capacity Lithium-Ion Battery Cells That Can Power Laptops and Electric Vehicles. Panasonic. [Online] Panasonic, December 29, 2009. [Cited: June 19, 2014.] http://panasonic.co.jp/corp/news/official.data/data.dir/en091225-3/en091225-3.html.

26. Energy, U.S. Department of. fueleconomy.gov. 2014 Nissan Leaf. 2014. 
27. IEEE. 2012 Nissan Leaf. IEEE. [Online] IEEE, 2013. [Cited: June 19, 2014.]

http://electricvehicle.ieee.org/vehicles/2012-nissan-leaf/.

28. U.S. Department of Energy. 2013 Chevrolet Volt. fueleconomy.gov. [Online] 2014. [Cited: June 19, 2014.] http://www.fueleconomy.gov/feg/Find.do?action=sbs\&id=32655.

29. Scott-Thomas, John. Volt Teardown:: The battery pack. Drive For Innovation. [Online] UBM Electronics, April 12, 2012. [Cited: 19 2014, June.] http://driveforinnovation.blogs.tech.ubm.com/volt-teardown-the-battery-pack/.

30. Avgas Specifications. Experimental Aircraft Association (EAA). [Online] 2014. http://spirit.eaa.org/autofuel/avgas/avgas_specs.asp.

31. Chow, Yee. AC Propulsion Partners with BMW to Build 500 Electric Vehicles. s.I. : AC Propulsion, 2008.

32. Gage, Tom. The eBox: A New EV with Li lon Battery and V2G. s.I. : AC Propulsion, Inc.

33. Hermann, Weston Arthur, et al. Integrated battery pressure relief and terminal isolation system. US 20100316894 A1 December 16, 2010. Application.

34. National Transportation Safety Board. Interim Factual Report, Case \#. Washington, DC : Office of Aviation Safety, 2013.

35. Gates, Dominic. Battery smokes on JAL 787; Boeing fix appears to work. Seattle Times. January, 2014, Vol. 15.

36. Dominic Gates. Battery smokes on JAL 787; Boeing fix appears to work. The Seattle Times. [ Online] The Seattle Times, January 14, 2014. [Cited: June 19, 2014.] http://seattletimes.com/html/businesstechnology/2022666851_boeingjalxml.html.

37. Rippel, Wally. Induction Versus DC Brushless Motors. Tesla Motors Blog. [Online] Tesla Motors, January 9, 2007. [Cited: June 19, 2014.] http://www.teslamotors.com/blog/induction-versus-dc-brushless-motors.

38. THtuk. Determing the Specific Heat Capacity of a Battery Pack. Bletchley, England : s.n.

39. Alternative Energies: Electric motors - state of the art. Sigler, Dean. s.I. : Kitplanes, July 2014.

40. d.o.o., Enstroj. Emrax 228 motors/generators. Enstroj. [Online] Enstroj. [Cited: June 19, 2014.] http://www.enstroj.si/Electric-products/emrax-228-motorsgen.html.

41. Unitek. Manual Digital Battery-Motor-Controller Bamocar-D3. s.I. : Unitek.

42. Tritium. WaveScupltor 200 Motor Drive Datasheet. Brisbane, Australia : s.n., 2011. TRI74.015 ver 3. 
43. Piktronik. SAC 50 Motor controller for vehicles and boats. Maribor, Slovenia : s.n.

44. Yuneec International Ltd. Power Systems Tech Specs. [Online] 2013. http://www.yuneec.com/PowerMotor_Tech_spec.html.

45. Roskam, Dr. Jan. Airplane Design Parts I-VII. Lawrence, Kansas : The University of Kansas, 1989.

46. Black, Gary Douglas. Thesis: Aircraft Configuration Study for Experimental 2-Place Aircraft and RPVs. Monterey, California : Naval Postgraduate School, 1990.

47. Pipistrel. Flight manual and Maintenance manual applies to Sinus 503, Sinus 582 in Sinus 912 equipped with Rotax 503, Rotax 582 and Rotax 912 engines REV.0. 2006.

48. National Transportation Safety Board. Interim Factual Report, Case \#. Washington, DC : Office of Aviation Safety, 2013.

49. Jeevarajan, Judith. Performance and Safety Evaluation of High-rate 18650 Lithium IronPhosphate Cells. NASA Battery Workshop. 2009.

50. Office, U.S. Government Printing. Electronic Code of Federal Regulations (e-CFR). Title 14: Aeronautics and Space. 2014.

51. Pipistrel. Pipistrel Price Lists for Ready to Fly Aircraft. [Online] [Cited: June 19, 2014.] http://www.mcp.com.au/sinus/price-list/price-RTF.html.

52. Hodges, Dewey h. Introduction to Structural Dynamics and Aeroelasticity. Cambridge : Cambridge University Press, 2002.

53. Hollman, Martin. Modern Aerodynamic Flutter Analysis. s.l. : Aircraft Designs, Incorporated, 1991. 9781893639096.

54. Bisplinghoff, Raymond L., Ashley, Holt and Halfman, Robert L. Aeroelasticity. Mineola, New York : Dover Publications, Inc., 1955.

55. Scanlan, Robert H. and Rosenbaum, Robert. Introduction to the Study of Aircraft Vibration and Flutter. New York : The Macmillan Company, 1951.

56. Federal Aviation Administration. Means of Compliance with Title 14 CFR, Part 23, \& 23.629, Flutter. s.I. : U.S. Department of Transportation, 2004. AC No:23.629-1B .

57. Black, Sara. Flying High on Composite Wings. High Performance Composites. May, 2008.

58. Rutan Aircraft Factory. Long-EZ Plans. Mojave, CA : Rutan Aircraft Factory, Inc., 1980.

59. Pipistrel. Service and Repair manual applies to Sinus 503, Sinus 582 in Sinus 912. s.l. :

Pipistrel, 2005. 
60. Wikipedia. Aerodynamic Center. [Online] [Cited: June 19, 2014.]

http://en.wikipedia.org/wiki/Aerodynamic_center.

61. Thomas, Fred. Fundamentals of Sailplane Design. Stuttgart : College Park Press, 1979. 09669533-0-7.

62. al, Bhagwan D. Agarwal et. Analysis and Performance of Fiber Composites. Hoboken : John Wiley and Sons, Inc., 2006. 978-0-471-26891-8.

63. Bruhn, E.F. Analysis and Design of Flight Vehicle Structures. 1973. 978-0961523404.

64. al, Michimasa Fujino et. Flutter Characteristics of an Over-the-Wing Engine Mount BusinessJet Configuration. Norfolk : AIAA, 2003. AIAA 2003-1942.

65. THtuk. Determing the Specific Heat Capacity of a Battery Pack. Bletchley, England : s.n.

66. Incropera, Frank P. Introduction to Heat Transfer. s.I. : John Wiley \& Sons, Inc., 2011. 9780470-50196-2.

67. Jeevarajan, Judith. Performance and Safety Evaluation of High-rate 18650 Lithium IronPhosphate Cells. NASA Battery Workshop. 2009.

68. al, Christophe Buckler et. User-friendly composites that take the heat. JEC Composite Magazine. 2009. Vol. December, No53.

69. Wikipedia. Pipistrel Taurus G4 take-off. Wikipedia. [Online] Wikipedia, September 27, 2011. [Cited: June 19, 2014.]

http://commons.wikimedia.org/wiki/File:Pipistrel_Taurus_G4_takeoff_at_2011_Green_Flight_Challenge.jpg.

70. Wood, Janice. Pipistrel Taurus G4 nominated for Design of the Year. General Aviation News. [Online] General Aviation News, January 1, 2012. [Cited: June 19, 2014.] http://generalaviationnews.com/2012/01/11/pipistrel-taurus-g4-nominated-for-designof-the-year/. 